SERVIÇO DE PÓS-GRADUAÇÃO DO ICMC-USP

Data de Depósito: 22.07.2004

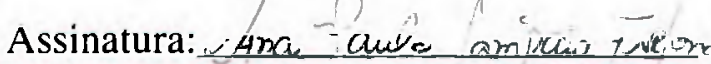

\title{
Uma contribuição para o teste de especificações SDL: aspectos teóricos e empíricos
}

Tatiana Sugeta

Orientador: Prof. Dr. José Carlos Maldonado

Tese apresentada ao Instituto de Ciências Matemáticas e de Computação - ICMC-USP, como parte dos requisitos para obtenção do título de Doutor em Ciências - Ciências de Computação e Matemática Computacional.

USP - São Carlos

Julho de 2004 
A Comissão Julgadora:

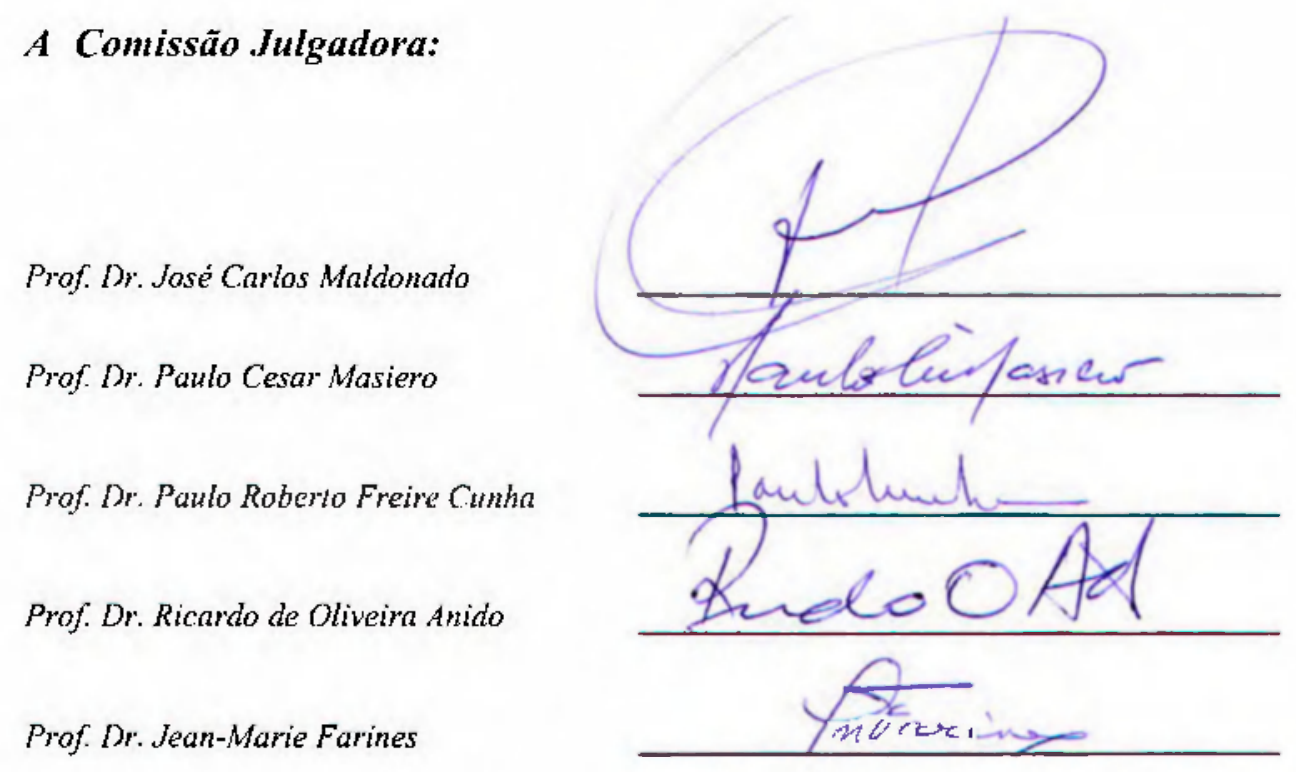


"Study as if you were to live forever; live as if you were die tomorrow."

(Edmund of Abingdon) 
A Deus, pela vida e por tudo que me tem proporcionado.

Ao meu orientador, Prof. Dr. José Carlos Maldonado, pela confiança, incentivo, apoio, amizade e sobretudo, pela oportunidade de trabalhar em seu grupo de pesquisa.

To Prof. Dr. W. Eric Wong who received me at University of Texas at Dallas and contributed a lot to this work; also to the University of Texas at Dallas and Telcordia Technologies.

À minha família e principalmente aos meus pais e irmãs pelo amor, apoio e incentivo constantes e incondicionais, mesmo à distância.

Aos amigos do Labes: Maris, Erika, Ades, Simone, André, Richard, Bira, Ju, Tânia, Thaise, Debora, Sandra, Rosângela, Simone Rocio, Auri, Delamaro, Marco, Elisa, Camila, Cláudio, André Rocha, Otávio, Sandro (KLB), Alê, Fabiano, Valter, Manu, Selma, Rosana, Mateus, Raquel, Edilson, Osnete, Rejane, Gelza e Sandro (cantina) por todos os momentos, de festa e de trabalho, que passarnos juntos. Foi muito bom ter convivido com vocês.

Às meninas de casa: Valeria, Monique e Lu; e aos amigos Ellen, Andrea, Mari, Ana Claudia, Mayb e Carnillo, Marcos, Flavia e Rudinei, Ernesto, Daniel, Araxá e Nilda pela amizade e por todos os anos de convivência.

Aos amigos Erika, Thelma e Ieo, Serginho, Carla Renata, Andréia, Aline e Alessandro que, mesmo à distância, sempre me apoiaram e demonstraram seu carinho e amizade.

Aos brasileiros com quem convivi nos EUA, Paulo, Auri e Elaine, companheiros de casa; Lela e Daniel (e Pedro), Aline e Dário, Vanessa e João, Ana e Gildo, Nadia e Elbson (e Lucas) pela amizade, atenção, apoio e por todos os momentos que passamos juntos. Com certeza foi muito bom tê-los conhecido.

Ao Auri, Delarnaro e Plinio pelas sugestões e auxílio em parte deste trabalho. E ao Adenilso, Erika, Maris e Debora pela revisão do texto.

À Beth, Laura, Ana Paula, Enza, Tati e todo pessoal do ICMC-USP pela atenção e prestatividade sempre demonstradas.

À Telelogic pela licença da ferramenta Telelogic Tau SDL, Suite.

Ao CNPq, CAPES e FAPESP pelo apoio financeiro. 
Resumo xiii

Abstract $\quad$ xv

1 Introdução 1

1.1 Contexto . . . . . . . . . . . . . . . . . . 1

1.2 Motivação . . . . . . . . . . . . . . . . . . . 6

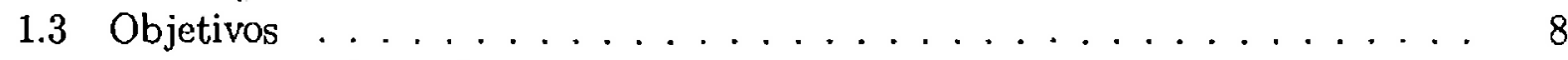

1.4 Organização do Trabalho . . . . . . . . . . . . . . . . . . . 9

2 Revisão Bibliográfica 11

2.1 Considerações Iniciais . . . . . . . . . . . . . . . . . . . . 11

2.2 Terminologia e Conceitos Básicos . . . . . . . . . . . . . . . 12

2.3 Especificação de Software . . . . . . . . . . . . . . . . 13

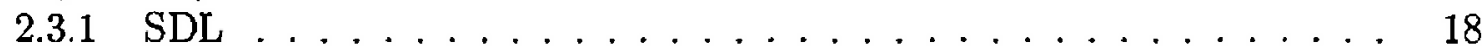

2.4 Atividade de Teste . . . . . . . . . . . . . . . . . . 22

2.4 .1 Técnicas de Teste . . . . . . . . . . . . . . . . 26

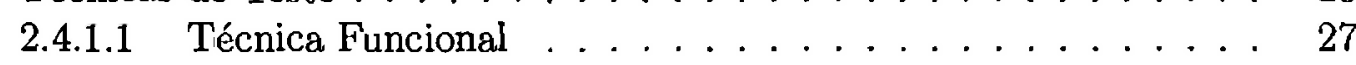

2.4 .1 Técnica Estrutural . . . . . . . . . . . . . . . 28

2.4.1.3 Técnica Baseada em Erros . . . . . . . . . . . . . 35

2.4.1.3.1 Análise de Mutantes . . . . . . . . . . . 36

2.4 .2 Ferramentas de Teste . . . . . . . . . . . . . . . 42

2.4.3 Estudos Teóricos e Empíricos . . . . . . . . . . . . . . . . 44

2.4 .4 Árvore de Alcançabilidade . . . . . . . . . . . . . . . . . . . . 47

2.5 SDL: Aspectos de Teste, Validação e Depuração . . . . . . . . . . . . . . 52

2.6 Considerações Finais . . . . . . . . . . . . . . . . . . . 60

3 Teste Estrutural e Depuração de Especificações SDL 65

3.1 Considerações Iniciais . . . . . . . . . . . . . . . . . . . 65

3.2 Teste Estrutural em Nível de Processo . . . . . . . . . . . . . . . . . . . 66

3.2.1 Grafo de Fluxo para Processos SDL . . . . . . . . . . . . 67

3.2 .2 Critérios de Fluxo de Controle . . . . . . . . . . . . . . . . . 70

3.2 .3 Critérios de Fluxo de Dados . . . . . . . . . . . . . . . 71

3.2.4 Dominadores: Auxiliando a Geração de Casos de Teste . . . . . . . . 72

3.2.5 Uso de Informaçōes de Teste na Atividade de Depuração . . . . . . . 74 
3.3 Teste Estrutural em Nível de Sistema . . . . . . . . . . . . . . . . . . 77

3.3.1 Família de Critérios de Cobertura FCCSDL . . . . . . . . . . 77

3.3.2 Caracterização dos Requisitos de Teste dos Critérios FCCSDL . . . . 80

3.3.2.1 Arvore de Alcançabilidade para SDL . . . . . . . . . . . 80

3.3.3 Análise Teórica dos Critérios FCCSDL: Relação de Inclusão . . . . . 83

3.3.3.1 Relação de Inclusão dos Critérios FCCSDL . . . . . . . . . 83

3.3.4 Estratégia Incremental de Aplicação dos Critérios de Cobertura . . . 88

3.4 Considerações Finais . . . . . . . . . . . . . . . . 89

4 Teste de Mutação para Especificações SDL 91

4.1 Considerações Iniciais . . . . . . . . . . . . . . . . . . . . . . . . . . . 91

4.2 Análise de Mutantes para SDL . . . . . . . . . . . . . . . . . . . . 92

4.2 .1 Operadores de Mutação de Processos . . . . . . . . . . . . . . . . . 94

4.2 .2 Operadores de Mutação de Interface . . . . . . . . . . . . . . 102

4.2.3 Operadores de Mutação de Estrutura . . . . . . . . . . . . . . . . . 106

4.3 Estratégias de Teste para Aplicação da Análise de Mutantes para SDL . . . 108

4.4 Análise Teórica do Teste de Mutação para SDL . . . . . . . . . . . . . . . 109

4.4.1 Complexidade dos Operadores de Mutação de Processos . . . . . . 111

4.4.2 Complexidade dos Operadores de Mutação de Interface . . . . . . . . 114

4.4.3 Complexidade dos Operadores de Mutação de Estrutura . . . . . . . 115

4.5 Considerações Finais . . . . . . . . . . . . . . . . 116

5 Teste e Depuração de Especificações SDL: Aspectos de Automatização 119

5.1 Considerações Iniciais . . . . . . . . . . . . . . . . . . . . . . . . . . 119

5.2 Apoio aos Critérios Estruturais: A Ferramenta $C A T_{S D L} \ldots \ldots \ldots$. . . . . 120

5.2 .1 Aspectos Funcionais e Arquitetura . . . . . . . . . . . . . . . 120

5.2 .2 Aspectos de Implementação . . . . . . . . . . . . . . . . . . . . . . 121

5.2 .3 Principais Aspectos Operacionais . . . . . . . . . . . . . . . . . 123

5.2.3.1 Criação de uma Sessão de Teste . . . . . . . . . . . . . 123

5.2.3.2 Geração de Casos de Teste . . . . . . . . . . . . . . . . . 124

5.2.3.3 Visualização da Cobertura de Teste . . . . . . . . . . . 125

5.2.3.4 Geração de Relatórios de Teste . . . . . . . . . . . . . 126

5.3 Apoio à Depuração: A Ferramenta $S$ mart $D_{S D L} \ldots \ldots \ldots$. . . . . . . . . 129

5.3.1 Aspectos Funcionais e Arquitetura . . . . . . . . . . . . . . . 131

5.3 .2 Aspectos de Implementação . . . . . . . . . . . . . . . . . . . . . 133

5.3.3 Principais Aspectos Operacionais . . . . . . . . . . . . . . . . 133

5.4 Análise de Mutantes: Automatização do Teste de Especificações SDL . . . . 138

5.4 .1 Aspectos Operacionais . . . . . . . . . . . . . . . . . . 138

5.4 .2 Requisitos de Implementação . . . . . . . . . . . . . . . . . . . 139

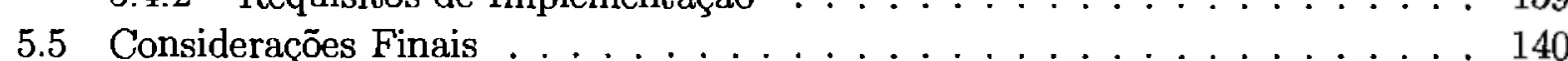

6 Teste de Especificações SDL: Estudo de Caso

6.1 Requisitos de Teste e Geração de Casos de Teste . . . . . . . . . . . . . . . . 143

6.1.1 Critérios de Teste Estruturais apoiados pela $C A T_{S D L} \ldots \ldots \ldots 144$

6.1 .2 Análise de Mutantes . . . . . . . . . . . . . . . . . 145

6.1.3 Critérios de Fluxo de Controle FCCSDL . . . . . . . . . . . . . . 150

6.2 Avaliação dos Critérios de Teste para SDL: Um Estudo de Caso . . . . . . 152

6.2.1 Strength dos Critérios de Teste Estruturais e de Mutação . . . . . . . 153

6.3 Estratégia de Teste para Especificações SDL . . . . . . . . . . . . . 156 
6.4 Considerações Finais $\ldots \ldots \ldots \ldots \ldots \ldots \ldots \ldots \ldots \ldots \ldots$

7 Conclusões 159

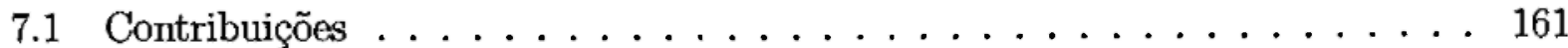

7.2 Diffculdades e Limitações . . . . . . . . . . . . . . . . . 162

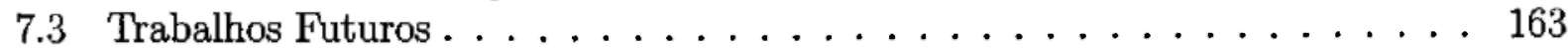

$\begin{array}{ll}\text { Referências Bibliográficas } & 165\end{array}$

A Lista de Abreviações $\quad 185$

$\begin{array}{ll}\text { B Gramática de SDL } & 187\end{array}$ 


\section{Lista de Figuras}

2.1 Exemplo de uma Estrutura de Sistema em SDL (SDL-Forum, 2004) . . . . . 19

2.2 Exemplo de uma Estrutura de Bloco em SDL (SDL-Forum, 2004) . . . . . . 19

2.3 Mecanismo da Fila de Entrada de um Processo (Belina et al., 1991) . . . . . 21

2.4 Exemplo de Grafo de Fluxo de Controle . . . . . . . . . . . . . 35

3.1 Nível de Sistema do Protocolo Bit-Alternante em SDL . . . . . . . . . . . 67

3.2 Processo Sender: Especificação em SDL e Grafo de Fluxo . . . . . . . . . . . . 68

3.3 Arvore de Alcançabilidade para o protocolo Bit-Alternante . . . . . . . . . . 82

3.4 Hierarquia dos Critérios FCCSDL . . . . . . . . . . . . . . . 84

4.1 Mutante Gerado pelo Operador Substituição de Estado Origem . . . . . . 96

4.2 Mutante Gerado pelo Operador Troca Definições dos Fstados . . . . . . . . . 96

4.3 Mutante Gerado pelo Operador Substituição de Estado Destino . . . . . . . . 96

4.4 Mutante Gerado pelo Operador Remoção de Estados . . . . . . . . . . . . 97

4.5 Mutante Gerado pelo Operador Remoção de Transições . . . . . . . . . . . . 97

4.6 Mutante Gerado pelo Operador Substituição de Variável por Variável . . . . 98

4.7 Mutante Gerado pelo Operador Remoção de Tarefas . . . . . . . . . . . . . . 99

4.8 Mutante Gerado pelo Operador Cobertura de Código . . . . . . . . . . . . . 99

4.9 Mutante Gerado pelo Operador Negação de Questão de Decisão . . . . . . . 100

4.10 Mutante Gerado pelo Operador Troca as Respostas do comando de Decisão . 100

4.11 Mutante Gerado pelo Operador Remoção de Resposta do Comando de Decisão 101

4.12 Mutante Gerado pelo Operador Remoşão de Save . . . . . . . . . . . . . 101

4.13 Mutante Gerado pelo Operador Substituição de Operador Relacional . . . . 102

4.14 Mutante Gerado pelo Operador Remoção de Saída . . . . . . . . . . . . . . 103

4.15 Mutante Gerado pelo Operador Substituição de Saída . . . . . . . . . . . . 103

4.16 Mutante Gerado pelo Operador Substituição de Signal Route da Saída . . . 104

4.17 Mutante Gerado pelo Operador Substituição de Variáveis de Interface . . . . 104

4.18 Mutante Gerado pelo Operador Remoção de Entrada . . . . . . . . . . . . 105

4.19 Mutante Gerado pelo Operador Substituição de Entrada . . . . . . . . . . . 106

4.20 Mutante Gerado pelo Operador Inclusão de Sinal na Lista de Sinais . . . . 106

4.21 Mutante Gerado pelo Operador Exclusão de Sinal da Lista de Sinais . . . . . 107

4.22 Mutante Gerado pelo Operador Troca Sinal da Lista de Sinais . . . . . . . . 107

4.23 Mutante Gerado pelo Operador Remoção de Signal routes/Channels . . . . . 107

4.24 Mutante Gerado pelo Operador Remoção de Conexão entre Channels e Signal routes ........................... 108 
4.25 Mutante Gerado pelo Operador Substituição de Channels/Signal routes Conectados . . . . . . . . . . . . . . . . . . . . . . 108

5.1 Arquitetura da Ferramenta $C A T_{S D L} \ldots \ldots \ldots \ldots \ldots \ldots$

5.2 Fluxo de Informações na Ferramenta $C A T_{S D L} \ldots \ldots \ldots \ldots \ldots$

5.3 Telas Iniciais para o processo Sender na $C A T_{S D L}$ com relação ao Critérios Todos-Blocos . . . . . . . . . . . . . . . . . . . . . . . . . 124

5.4 Simulação da Especificação na Telelogic Tau . . . . . . . . . . . . . . . . . 125

5.5 Telas do Processo Sender na $C A T_{S D L}$ com Relação ao Critério Todos-Blocos após a Execução com um Caso de Teste . . . . . . . . . . . . . . . . . . . 126

5.6 Telas para o Processo Sender na $C A T_{S D L}$ com Relação ao Critério Todas-Decisões127

5.7 Relatório de Casos de Teste Gerado pela $C A T_{S D L}$ para um Caso de Teste . . 128

5.8 Relatórios Gerados pela $C A T_{S D L} \ldots \ldots \ldots \ldots \ldots \ldots$

5.9 Relatório de Casos de Teste Após Inclusão de mais um Caso de Teste . . . . 129

5.10 Relatório de Cobertura por Critério de Teste para Dois Casos de Testes . . . 129

5.11 Nível de Sistema do Protocolo INRES em SDL . . . . . . . . . . . . . . . . . 130

5.12 Especificação do Processo Res_Coder . . . . . . . . . . . . . . . . . . 131

5.13 Erro inserido na especificação SDL do Protocolo INRES . . . . . . . . . . . . 132

5.14 Arquitetura da Ferramenta $S \operatorname{Smart} D_{S D L} \ldots \ldots \ldots \ldots \ldots \ldots$

5.15 Tela de Seleção da Heurística do Caso II e Casos de Teste na $S \operatorname{Smart} D_{S D L}$. 134

5.16 Prioridades dos Processos em Relação ao Critério Todos-c-Usos na Smart $D_{S D L}$ : Caso II . . . . . . . . . . . . . . . . . . . . . . . . . . . . . . 134

5.17 Prioridades dos Requisitos do Processo Res_Coder em relação a Todos-c-Usos: Caso II . . . . . . . . . . . . . . . . . . . . . . . . . . . . . 135

5.18 Prioridades dos Processos em Relação ao Critério Todos-Blocos na $S \operatorname{mart} D_{S D L}$ : Caso II . . . . . . . . . . . . . . . . . . . . . . . . . . . . 135

5.19 Prioridades dos Requisitos do Processo Res_Coder em relação a Todos-Blocos: Caso II . . . . . . . . . . . . . . . . . . . . . . . . . . . . . 136

5.20 Tela de Seleção de Heurística do Caso Geral e Casos de Teste na $S \operatorname{mart} D_{S D L} 137$

5.21 Tela de Apresentação de Possíveis Locais em que o Erro se Encontra na $S_{\text {Smart }} D_{S D L}:$ Caso Geral . . . . . . . . . . . . . . . . . . . . 137

5.22 Prioridades dos Requisitos do Processo Res_Coder em relação a Todos-Blocos: Caso Geral . . . . . . . . . . . . . . . . . . . . . . . . . . 137

5.23 Possível Arquitetura da Ferramenta de Apoio à Análise de Mutantes (Vincenzi, 2004) . . . . . . . . . . . . . . . . . . . . . 140

6.1 Relatório de Cobertura do Conjunto de Casos de Teste Adequado ao Critério Todos-Blocos ... . . . . . . . . . . . . . . . . . . . . 145

6.2 Cobertura Obtida Por Processo pelo Conjunto de Teste Adequado à Mutação em Relação a Todos-Usos . . . . . . . . . . . . . . . . . 153

6.3 Relatório de Cobertura Obtida pelo Conjunto de Casos de Teste Adequado à Mutação em Relação aos Critérios Estruturais . . . . . . . . . . . . . . 154 


\section{Lista de Tabelas}

2.1 Comparação de Alguns Métodos de Teste de Especificaçōes SDL . . . . . . . 61

4.1 Conjunto de Operadores de Mutação para SDL . . . . . . . . . . . . . . 93

4.2 Conjunto de Constantes Requeridas . . . . . . . . . . . . . . . . . 95

4.3 Complexidade dos Operadores de Mutação de Processos . . . . . . . . . . 111

4.4 Complexidade dos Operadores de Mutação de Interface . . . . . . . . . . . 114

4.5 Complexidade dos Operadores de Mutação de Estrutura . . . . . . . . . . 116

5.1 Complexidade dos Pacotes que Compõem a Ferramenta $C A T_{S D L} \ldots \ldots \ldots 123$

6.1 Conjunto de Requisitos Derivados dos Critérios Estruturais Apoiados pela $C A T_{S D L}$ para o processo Sender . . . . . . . . . . . . . 144

6.2 Conjuntos de Teste Adequados ao Critérios Estruturais para o protocolo Bit-Alternante . . . . . . . . . . . . . . . . . . . . . . . . . . . 145

6.3 Conjunto de Teste Inicial "Ad Hoc" . . . . . . . . . . . . . . . . . . 146

6.4 Mutantes Gerados para o Protocolo Bit-Alternante . . . . . . . . . . . 147

6.5 Análise dos Mutantes Gerados para o protocolo Bit-Alternante . . . . . . . 150

6.6 Conjunto de Teste Adequado para o protocolo Bit-Alternante . . . . . . . . 150

6.7 Número de Requisitos de Teste para o protocolo Bit-Alternante e Alguns Exemplos de Requisitos . . . . . . . . . . . . . . . . . . . . . 151

6.8 Escore de Mutação Obtido pelos Conjuntos de Teste dos Critérios Estruturais 154 
Atividades sistemáticas e rigorosas no processo de desenvolvimento são fundamentais para a obtenção de produtos de software de qualidade, entre elas a utilização de técnicas formais. Apesar do rigor estabelecido pelo uso dessas técnicas nas fases iniciais de desenvolvimento, a qualidade da especificação pode não ser satisfatória. A condução de atividades de VV\&T - Verificação, Validação e Teste, paralelamente às atividades de desenvolvimento, visa a assegurar a qualidade adequada a cada passo do processo.

Este trabalho tem como objetivo contribuir para o teste de especificações SDL. SDL é uma técnica formal que surgiu da necessidade de se desenvolver uma linguagem padrão de especificação para a área de telecomunicações. Mais recentemente, SDL tem sido utilizada para a descrição de arquiteturas de software. Diversas técnicas têm sido propostas e utilizadas para garantir a qualidade de especificações SDL, como simulação e model checking; no entanto, não propiciam a análise quantitativa da atividade de validação, como por exemplo, a análise de cobertura, um dos aspectos fundamentais reconhecidos por diversos pesquisadores para avaliar a qualidade das atividades de teste e validação.

Neste trabalho foram propostos critérios de teste baseados em fluxo de controle, em fluxo de dados e em mutação, além de estratégias de teste associadas para o teste dos processos de especificações SDL. Também foi definida uma família de critérios de fluxo de controle, FCCSDL, considerando o comportamento de todo o sistema, representado pela Árvore de Alcançabilidade para SDL proposta no escopo deste trabalho. Também foram definidas facilidades para a depuração de especificações SDL, com base nas informações de cobertura de teste. As ferramentas $C A T_{S D L}$ e $S$ mart $D_{S D L}$ foram desenvolvidas para apoiar as atividades de teste e depuração de especificações SDL. Com base no estudo de caso conduzido, foram fornecidas evidências da viabilidade da aplicação dos critérios de teste definidos e estabelecida uma estratégia de teste para guiar a atividade de teste de especificações SDL. 
Systematic and rigorous activities during the development process are fundamental to the quality of the final software product. One of these activities is the use of formal techniques. Although formal techniques can provide rigor in the initial phases of development, the quality of the specification can be unsatisfactory. To guarantee the quality to each development process phase, VV\&T - Verification, Validation and Testing - activities should be conducted.

This work aims at contributing to the testing activity of SDL specifications. SDL is a formal technique proposed to be a standard specification language for the telecommunication area. Recently, SDL has been used to describe software architecture. Many techniques have been proposed to guarantee the quality of SDL specifications, such as simulation and model checking. However, these techniques do not provide a quantitative measure for the validation activity. Many researchers have consider coverage analysis as a fundamental aspect to assess the quality of testing and validation activities.

In this work, testing criteria based on control flow, data flow and mutation were proposed to test SDL processes. Testing strategies associated to these criteria were also established. To test the behavior of the SDL system modelled by a reachability tree, a family of control flow-based criteria were defined. Aiming at aiding the SDL debugging activity, some facilities were defined based on testing coverage information. Two tools were developed to support testing and debugging of SDL specifications, $C A T_{S D L}$ and $S$ mart $D_{S D L}$, respectively. A case study was conducted and its results have shown that to use the testing criteria defined in this work to test SDL specifications is feasible. Based on the results of this case study, an incremental testing strategy was defined to guide the testing of SDL specifications. 
Neste capítulo apresentam-se o contexto em que este trabalho se insere, as motivações para sua realização e também seus objetivos.

\subsection{Contexto}

O rigor e o formalismo constituem uma alternativa para evitar e/ou eliminar erros cometidos ao longo do processo de desenvolvimento de software. Visando a eliminar erros nas fases iniciais de desenvolvimento, com destaque para as fases de análise e especificação de requisitos, que demandam menor custo e retrabalho, atividades sistemáticas e rigorosas têm sido introduzidas. Uma dessas atividades é o uso de técnicas formais para a especificação de sistemas, tais como os sistemas críticos com relação à segurança, sistemas de tempo real, protocolos de comunicação e sistemas embutidos, que são tipos de sistemas reativos (Allworth, 1981; Davis, 1988; Harel, 1987). Esses sistemas necessitam que o processo de desenvolvimento seja realizado com maior rigor, pois a ocorrência de falhas pode colocar em risco vidas humanas ou causar elevados prejuizos materiais.

Em relação à especificação de protocolos de comunicação, uma técnica que tem sido bastante empregada é SDL (Specification and Description Language) (ITU, 1993, 2002). SDL surgiu da necessidade de se desenvolver uma linguagem padrão de especificação para a área de telecomunicações. É uma linguagem aceita pelo ISO e que tem o compromisso e o suporte do órgão francês ITU-T (ITU Telecommunication Standardization Sector). Desde 1976, quando foi publicada sua primeira versão, SDL passa por constantes revisões, sendo 
que várias versões já foram propostas. SDL permite a representação de muitas características dos sistemas, tais como sua estrutura, comportamento, comunicações e encapsulamento de módulos. O comportamento de um sistema especificado em SDL é descrito por processos, que podem ser vistos como Máquinas de Estados Finitos Estendidas Comunicantes (MEFECs). SDL permite a criação dinâmica de instâncias de processos e da comunicação entre esses processos durante a execução, que possibilitam a modelagem de sistemas distribuídos, em que o número de componentes e conexões variam durante a execução; e permite que as especificaçōes possam ser executadas. Essas características fazem com que SDL possa ser empregada em outros contextos que não o de telecomunicação, como por exemplo, para descrever arquiteturas de software (Luckham et al., 1995).

Outros exemplos de técnicas formais utilizadas para a especificação de sistemas são: Esterel (Boussinot e Simone, 1991), CCS (Calculus of Communicating Systems) (Milner, 1980), CSP (Communicating Sequential Processes) (Hoare, 1984), PROMELA (PROcess MEta LAnguage), VDM (Vienna Development Method) (Jones, 1986), Z (Spivey, 1988) e RSL (RAISE ${ }^{1}$ Specification Language) (RAISE, 1992), que é uma derivação de VDM com algumas características adicionais, tais como concorrência e modularidade. A linguagem RSL compõe o método RAISE (RAISE, 1995) de desenvolvimento de software, que é apoiado por um conjunto de ferramentas que levam o mesmo nome.

Um aspecto que deve ser considerado na especificação de sistemas reativos é a modelagem de seu comportamento (Furbach, 1993). Algumas técnicas formais que consideram esse aspecto são baseadas em modelos de máquinas de transição de estados: Máquinas de Estados Finitos (MEFs) (Gill, 1962), Redes de Petri (Peterson, 1981) e Statecharts (Harel, 1987). Para a especificação de protocolos de comunicação, em que devem ser considerado aspectos de controle e de dados, além de SDL, outras técnicas bastante utilizadas são Estelle (ISO/TC97/SC21/WG1/DIS9074, 1987) e Lotos (ISO/IEC, 1989).

Apesar do rigor estabelecido pelo uso de técnicas formais nas fases iniciais de desenvolvimento, as técnicas formais não garantem a qualidade da especificação. A condução de atividades de VV\&T - Verificação, Validação e Teste, paralelamente às atividades de desenvolvimento, visa a assegurar a qualidade a cada passo do processo. Essas atividades constituem a atividade de Garantia de Qualidade de Software e devem ser conduzidas desde as fases iniciais do processo de desenvolvimento.

$\mathrm{Na}$ verificação busca-se garantir que o software está sendo construído de forma correta, visando a assegurar a consistência, completitude e corretitude do software em todas as fases do processo de desenvolvimento. $\mathrm{Na}$ validação procura-se garantir que os requisitos do usuário estão sendo satisfeitos, ou seja, que o software correto está sendo construído. $\mathrm{O}$ teste, com suas limitações inerentes, busca revelar a presença de erros em um produto de software pela sua execução. $O$ teste é uma atividade que visa a aprimorar a produtividade e

\footnotetext{
${ }^{1}$ Rigorous Approach to Industrial Software Engineering.
} 
a fornecer evidências de confiabilidade e qualidade de um produto de software (Maldonado, 1991). No entanto, o teste não é capaz de mostrar a ausência de erros no produto (Myers, 1979).

A atividade de teste deve ser conduzida durante todo o processo de desenvolvimento de software, sendo realizada em quatro etapas: planejamento de testes, projetos de casos de teste, execução e avaliação dos resultados dos testes (Maldonado, 1991; Pressman, 2001). Pode-se dividir a atividade de teste em três fases: Teste de Unidade, Teste de Integração e Teste de Sistema.

Dentre as atividades envolvidas no desenvolvimento de software, o teste tem sido apontado como uma das mais onerosas (Beizer, 1990; Harrold, 2000; Korel, 1990; Myers, 1979; Pressman, 2001). Segundo Pressman (2001), é comum que $40 \%$ do esforço de projeto total seja gasto nesta atividade. Quando se tratam de sistemas críticos com relação à segurança, a atividade de teste pode custar de três a cinco vezes mais que todos os outrọs passos da Engenharia de Software juntos.

Como não é possível utilizar todo o domínio de dados de entrada para avaliar um produto em teste, o objetivo é encontrar casos de teste que tenham alta probabilidade de revelar a maioria dos erros com um mínimo de tempo e esforço, por questões de produtividade (Maldonado, 1997). Para auxiliar a determinação desses casos de teste, são estabelecidos técnicas e critérios de teste que fornecem ao desenvolvedor uma abordagem sistemática $e$ teoricamente fundamentada para a condução e a avaliação da qualidade e da adequação da atividade de teste.

Os critérios de teste podem ser classificados em técnicas que se diferenciam pela fonte de informação utilizada para estabelecer os requisitos de teste (Maldonado, 1997). Essas técnicas são: Técnica Funcional, que utiliza a especificação do software para estabelecer os requisitos de teste; Técnica Estrutural, que utiliza uma implementação particular para estabelecer os requisitos de teste; e Técnica Baseada em Erros, que estabelece os requisitos de teste com base nos erros típicos e comuns cometidos durante o processo de desenvolvimento. Os critérios de teste existentes para o teste de programas são complementares e devem ser aplicados em conjunto para aumentar a qualidade da atividade de teste (Harrold, 2000; Pressman, 2001).

Os critérios de teste podem auxiliar a avaliação da adequação de conjuntos de casos de teste e a geração de conjuntos de casos de teste. A análise da satisfação dos requisitos estabelecidos pelos critérios de teste, também denominada de análise de cobertura ou análise de adequação, permite que a atividade de teste seja quantificada.

Alguns estudos têm mostrado a importância da geração de casos de testes que garantam uma alta cobertura de teste para que um maior número de erros possam ser identificados (Wong et al., 1994b, 1998). Para auxiliar a geração de casos de teste de forma a diminuir o custo de cobertura dos requisitos de teste estruturais, Agrawal (1994) propôs técnicas 
que identificam requisitos que, quando exercitados, exercitam todos ou a maioria dos outros requisitos de teste, em um grafo de programa. Esses requisitos são denominados "dominadores". Assim, casos de teste que exercitem esses requisitos devem ser gerados primeiro, de forma que o número de casos de teste a serem gerados para cobrir todos os requisitos de teste tende a diminuir e, conseqüentemente, diminui-se o custo de aplicação dos critérios de teste estruturais. Nessa mesma linha, outra abordagem utiliza o conceito de arcos primitivos e grafo com redução de herdeiros (Chusho (1987) ${ }^{2}$ apud Maldonado (1991)) no contexto de teste estrutural. Dado um grafo de programa, um arco que é sempre executado quando se executa um outro arco é denominado de arco herdeiro. Arcos herdeiros são considerados não essenciais para a análise de cobertura. Um arco primitivo é todo arco que não é herdeiro de nenhum outro. Assim, um grafo com redução de herdeiros é definido como um grafo de fluxo de controle composto apenas de arcos primitivos. Nessa abordagem, os requisitos de teste de critérios de fluxo de controle são derivados desse modelo de grafo e os casos de teste são gerados para cobrir apenas os arcos primitivos. Maldonado (1991) estende essa abordagem para aplicá-la no contexto de teste de fluxo de dados.

Dada a diversidade de critérios de teste que exploram diferentes características do software, é possível combiná-los de muitas maneiras, considerando, por exemplo, o custo de aplicação e a disponibilidade de recursos para a execução da atividade de teste. Dessa forma, estratégias de teste podem ser definidas de modo a auxiliar a aplicação dos critérios de teste existentes. Harrold (2000) ressalta que uma das principais direções para a área de teste de software é o estabelecimento de estratégias de teste eficazes e de baixo custo. A questão é como uma estratégia de teste pode utilizar os critérios de teste de modo a melhor explorar as vantagens de cada um. Para apoiar essa tarefa, é de fundamental importância a condução de estudos teóricos e empíricos.

Outro aspecto importante para a viabilidade da atividade de teste é a disponibilidade de ferramentas de apoio. As ferramentas propiciam maior qualidade e produtividade para esta atividade, que é propensa a erros e improdutiva, se aplicada manualmente. Além disso, estudos empíricos que visem a avaliar e a comparar os diversos critérios de teste podem ser mais facilmente conduzidos se apoiados por ferramentas.

A depuração, assim como o teste, pode demandar um alto custo durante o desenvolvimento e manutenção de software. Diversas pesquisas têm investigado métodos de depuração de programas, tais como slicing estático (Weiser, 1982, 1984), slicing dinâmico (Agrawal e Horgan, 1990; DeMillo et al., 1997; Korel e Laski, 1988), slicing de execução (Agrawal et al., 1995), dicing (Lyle e Weiser, 1987), backtracking (Agrawal et al., 1996) e o uso de informações de requisitos de teste, obtidas em tempo de execução durante a atividade de teste, combinado com heurísticas (Chaim et al., 2003). DeMillo et al. (1997) combinam o uso de slicing dinâmico e heurísticas para localizar possíveis erros em um programa. Jones

${ }^{2}$ CHUSHO, T. Test data selection and quality estimation based on the concept of essential branches for path testing. IEEE Transactions on Software Engineering, v. 13, n. 5, p. 509-517, 1987 
et al. (2002) propõem uma técnica de visualização para auxiliar a localização de erros por meio de cores, que são atribuídas aos comandos do programa de acordo com os casos de teste que o executaram.

Os aspectos de teste e depuração de programas apresentados são aqueles investigados no contexto de programas desenvolvidos no paradigma procedimental. Os mesmos aspectos também são investigados no desenvolvimento de programas com o paradigma orientado a objetos. Em seu trabalho, Vincenzi (2004) discute os principais aspectos de teste de programas $\mathrm{OO}$.

Questões similares às relacionadas ao teste e depuração de programas podem ser consideradas no contexto de especificações. Para a verificação de especificações de sistemas reativos, várias abordagens de simulação foram propostas (Harel, 1992): simulação interativa, simulação em batch, simulação programada e simulação exaustiva. Outra técnica que também tem sido utilizada é model checking, uma técnica de verificação estática baseada na exploração de estados. Para a aplicação de model checking não é necessário que os modelos estejam totalmente especificados, mas por ser baseada em exploração de estados, apresenta o problema de explosão de estados, aspecto crítico quando se tratam de sistemas complexos (Clarke e Wing, 1996). Além de permitir a verificação de propriedades do software, model checking pode ser aplicada para a avaliação de cobertura do teste (Black et al., 2000b). Nesse caso, um critério de teste deve ser selecionado inicialmente e aplicado na especificação para derivar os requisitos de teste, ou seja, o conjunto de propriedades a serem testadas. Para usar um model checker, estes requisitos são representados como fórmulas em lógica temporal. Para avaliar a cobertura de um conjunto de casos de teste, cada caso de teste é executado e o model checker determina quais requisitos foram satisfeitos pela execução (Ammann e Black, 1999).

Simulação e model checking são duas técnicas muito úteis para a verificação do comportamento da especificação e análise de algumas propriedades, como presença de deadlock, mas não consideram, por si só, o aspecto de cobertura, uma questão relevante abordada em relação às especificações baseadas em MEFs por Petrenko e Bochmann (1996), que salientam a relevância de pesquisas nessa direção, já que com a análise de cobertura a qualidade da atividade de teste pode ser quantificada. Apesar de model checking auxiliar a análise de cobertura, para essa atividade é necessário também ter um critério de teste associado, uma vez que model checking não estabelece requisitos a serem satisfeitos que servem como medida de cobertura.

É importante ressaltar que no contexto de especificações, a atividade de teste pode abranger o teste de especificações e o teste baseado em especificações. No teste de especificações, o produto em teste é a própria especificação, visando a encontrar erros cometidos nessa fase do desenvolvimento e a garantir que a especificação esteja de acordo com os requisitos do usuário. O teste baseado em especificações verifica se a implementação está de acordo com a especificação e é comumente aplicado no teste de protocolos de comunicação, no qual é 
referenciado por teste de conformidade (Bochmann e Petrenko, 1994). Os casos de teste são gerados com base na especificação e são utilizados no teste da implementação relacionada.

\subsection{Motivação}

Petrenko e Bochmann (1996) ressaltam que a qualidade da atividade de teste também deve ser medida em nível de especificação, por meio da análise de cobertura. Considerando esse aspecto, uma diversidade de trabalhos definem critérios de teste e validação de especificações e avaliam os custos/benefícios de sua aplicação. Para as Máquinas de Estados Finitos, os critérios propostos se concentram na geração de casos de teste (Chow, 1978; Fujiwara et al., 1991; Gonenc, 1970; Naito e Tsunoyama, 1981; Sabnani e Dahbura, 1985, 1988). Normalmente, para a aplicação desses critérios é necessário que a máquina satisfaça algumas propriedades, como ser minimal, o que nem sempre ocorre. Como as MEFs não consideram a parte de dados, esses critérios são baseados em fluxo de controle, explorando principalmente erros de transferência e de transições (Bourhfir et al., 1996). Para outras técnicas formais que lidam com a parte de dados, como as Máquinas de Estados Finitos Estendidas (MEFEs), os critérios propostos para o teste de MEFs não são plenamente adequados. Para essas técnicas foram propostos outros critérios, muitos dos quais sendo critérios de teste estabelecidos em nível de programa, tais como os critérios de teste estruturais e os critérios baseados em erros.

Critérios estruturais baseados em fluxo de controle e de dados têm sido explorados no teste de especificações baseadas em MEFEs (Bourhfir et al., 1996; Huang et al., 1995; Martins et al., 2000; Sarikaya e Bochmann, 1986; Wang e Liu, 1993), Statecharts (Bogdanov e Holcombe, 2001; Hong et al., 2000) e Estelle (Sarikaya et al., 1987; Ural e Yang, 1991).

A Análise de Mutantes, um dos critérios baseados em erros, também tem sido explorada no teste e validação de protocolos de comunicação especificados em Estelle e Lotos (Bousquet et al., 2000; Probert e Guo, 1991). A Análise de Mutantes visa a testar a corretitude de um produto de software (programa ou especificação) por meio da geração de mutantes, que são programas (ou especificações) criados com pequenas alterações sintáticas, e da construção de casos de teste capazes de diferenciar o comportamento do programa (ou especificação) original e dos seus mutantes (DeMillo, 1980).

Em consonância com esses trabalhos, o grupo de Engenharia de Software do ICMC-USP/São Carlos tèm investigado técnicas e critérios de teste no teste de especificações de sistemas reativos (Fabbri et al., 1997b; Maldonado et al., 1998a) baseadas em Máquinas de Estados Finitos (Fabbri et al., 1994b), Statecharts (Fabbri et al., 1997a, 1999; Souza et al., 2000c; Sugeta, 1999; Sugeta et al., 1999, 2001), Redes de Petri (Fabbri et al., 1994a, 1995; Simão, 2000; Simão e Maldonado, 2000b), Redes de Petri Coloridas (Simão, 2002; Simão et al., 2003) e Estelle (Souza et al., 2001, 2000a). Esses trabalhos motivam a investigação de 
critérios de teste no teste de especificações baseadas em outras técnicas formais, como é o caso de SDL.

Para a técnica SDL, muitos critérios de teste também têm sido explorados (Bourhfir et al., 2001a,b; Cavalli et al., 1996; Grabowski et al., 1996; Hogrefe, 1996; Kerbrat et al., 1999; Kovács et al., 2003; Touag e Rouger, 1999; Ural et al., 2000), indicando a relevância desta técnica formal na especificação de sistemas. Apesar dessa diversidade, a grande maioria dos critérios propostos para essa técnica são aplicados no teste de conformidade. O objetivo do teste de conformidade é garantir que a implementação esteja de acordo com a especificação. Como os casos de teste são gerados com base na especificação, o comportamento da especificação é também avaliado, porém sem qualquer indício sobre a cobertura de teste da especificação. Técnicas de verificação, como simulação e model checking, apesar de úteis nesse contexto, por si só também não permitem a análise de cobertura de teste. Nesse sentido, este trabalho de doutorado visa à investigação de critérios de teste estruturais e de mutação que complementem a atividade de teste e validação de especificações SDL, permitindo a avaliação da qualidade da atividade de teste nesse contexto.

Bourhfir et al. (2001a) comentam que o custo envolvido na geração de casos de teste é maior que o custo requerido no processo de execução. Os autores ainda citam um comentário de um engenheiro de qualidade de que a automatização da execução do teste ajuda na rapidez da execução dos testes, muitas vezes a um custo mais baixo, mas esse fato não melhora a qualidade do produto, que só acontece com a melhoria da geração dos casos de teste. Para a atividade de teste de especificações SDL e no contexto de outras especificações em geral, existem muitos critérios de teste e ferramentas propostos que auxiliam a geração de casos de teste e o processo de execução da especificação com os casos de teste, mas sem se preocuparem com o custo envolvido na geração dos casos de teste. Considerando esse fato no contexto de especificações SDL, neste trabalho explora-se o conceito de dominadores proposto por Agrawal (1994) para o teste de programas, para auxiliar a geração de casos de teste a partir de critérios estruturais, visando a diminuir o custo envolvido nessa atividade. Essa abordagem foi proposta para auxiliar a geração de casos de teste a partir de critérios de fluxo de controle e de dados comumente utilizados, tais como Todos-Blocos e Todos-Usos.

Chow (1978) demonstra que critérios de fluxo de controle tais como Todos-Blocos e Todas-Transiçōes, apesar de estabelecerem a cobertura de teste mínima desejável em especificaçōes baseadas em transição de estados, como SDL, não são adequados para revelar erros típicos associados a essas especificações, pois não exigem que muitos dos possiveis caminhos do grafo de fluxo sejam percorridos e, conseqüentemente, alguns erros de transferência, de operação e de estados ausentes ou extras não são identificados. Dada a necessidade de se explorarem critérios de teste mais rigorosos, neste trabalho é proposta uma família de critérios de fluxo de controle, composta de critérios que exploram blocos e transições, e critérios que exploram possíveis caminhos de execução, que são critérios considerados mais rigorosos do 
ponto de vista de teste de programas. Essa família de critérios estabelece seus requisitos de teste a partir de um modelo de árvore de alcançabilidade definido para especificações SDL.

Em relação à depuração, ao contrário do que ocorre no caso de programas, são poucos os trabalhos que investigam técnicas para auxiliar essa atividade no contexto de especificações. Para a técnica SDL, na ferramenta Telelogic Tau SDL Suite (Telelogic, 2004a), por exemplo, a simulação da especificação pode ser utilizada para auxiliar o entendimento e a depuração do comportamento da especificação. Harrold (2000) comenta que as informações obtidas durante a atividade de teste podem ser úteis em outras atividades, como a depuração. A ferramenta $\chi$ Slice-SDL ( $\mathrm{Li}$ e Horgan, 2000), é um exemplo da viabilidade dessa abordagem, pois utiliza informações obtidas da cobertura de teste da especificação SDL para indicar possíveis locais em que o erro pode se encontrar. Como essa parece ser uma abordagem promissora, com base nos trabalhos realizados no contexto de programas e no trabalho de $\mathrm{Li}$ e Horgan (2000), neste trabalho foi explorado o uso de informações de cobertura de teste para determinar slices de execução que, combinados em algumas heurísticas, auxiliam a atividade de depuração de especificações SDL.

O desenvolvimento deste trabalho de doutorado contou com a colaboração do Prof. Dr. W. Eric Wong, que também tem interesse na investigação de técnicas e critérios de teste de especificações SDL e tem contribuído em muitas pesquisas realizadas pelo grupo de Engenharia de Software do ICMC-USP/São Carlos. Essa colaboração resultou no doutorado sanduíche realizado entre março/2002 e fevereiro/2003 na University of Texas at Dallas, EUA, em que parte deste trabalho foi realizado. Durante esse período também foi realizada uma visita na Telcordia Tecnologies, New Jersey/EUA, que permitiu o amadurecimento de algumas idéias aplicadas neste trabalho, tais como o uso do conceito de dominadores para auxiliar a geração de casos de teste.

\subsection{Objetivos}

Diante do cenário apresentado nas seçōes anteriores, em linhas gerais, este trabalho consiste em investigar a aplicação de critérios de teste no teste de especificações baseadas em SDL, fornecendo subsídios para o estabelecimento de estratégias de teste neste contexto. Maldonado (1997) caracteriza os conhecimentos e contribuições na área de teste de software em três grupos: estudos teóricos, estudos empíricos e desenvolvimento de ferramentas.

Em relação a estudos teóricos, este trabalho tem como objetivo investigar critérios estruturais de fluxo de controle e de dados e o critério Análise de Mutantes no teste e validação de especificações SDL. Também pretende-se investigar o uso de informações obtidas sobre a cobertura de teste dos casos de teste para auxiliar a depuração de especificações SDL.

Para apoiar a aplicação dos critérios de teste e a condução de estudos empíricos, a existência de ferramentas é fundamental. Dessa forma, outro objetivo deste trabalho é a 
especificação, desenvolvimento e/ou manutenção de ferramentas de apoio aos critérios de teste explorados.

Para avaliar a viabilidade de aplicação dos critérios de teste propostos bem como analisar aspectos como custo e strength desses critérios de teste, pretende-se conduzir alguns estudos de casos. A análise desses aspectos é importante para o estabelecimento de estratégias de teste que auxiliem a condução da atividade de teste.

Assim, este trabalho visa a dar continuidade aos trabalhos desenvolvidos pelo grupo de Engenharia de Software do ICMC-USP/São Carlos, na investigação de técnicas e critérios de teste no teste de especificações de sistemas reativos, enfatizando o teste de especificações baseadas em SDL.

\subsection{Organização do Trabalho}

Neste capítulo foram apresentados o contexto em que o trabalho se insere, as motivações para o desenvolvimento do mesmo e os objetivos pretendidos.

No Capítulo 2 apresenta-se uma visão geral dos conceitos relacionados ao desenvolvimento deste trabalho. A importância da fase de especificação no desenvolvimento de sistemas, como os sistemas reativos, é discutida. Apresentam-se brevemente algumas técnicas formais utilizadas nessa fase e a técnica SDL, utilizada neste trabalho, é descrita em mais detalhes. No que diz respeito à atividade de teste, são apresentados os principais aspectos em relação às técnicas e critérios de teste existentes, às ferramentas de apoio e à condução de estudos teóricos e empíricos, tanto para o teste de programa quanto para o teste de especificações. As pesquisas relacionadas ao teste de especificações baseadas em SDL também são comentadas nesse capítulo.

No Capítulo 3 apresentam-se as contribuições deste trabalho em relação à aplicação de critérios estruturais no teste de especificações SDL. O teste é explorado de duas perspectivas: na primeira, os critérios de teste derivam seus requisitos de teste a partir de grafos de fuxo de controle e de dados, que modelam o comportamento dos processos SDL, e na segunda, os critérios de teste derivam seus requisitos a partir de um modelo de árvore de alcançabilidade. No primeiro caso são explorados critérios de fluxo de controle e de dados para auxiliar a avaliação da cobertura de teste e a geração de casos de teste que promovam maior cobertura, de forma a diminuir o custo de aplicação desses critérios. Na segunda abordagem é definida a FCCSDL - Família de Critérios de Cobertura para SDL-, que exploram o fluxo de controle das especificações SDL. Nesse capítulo também é apresentada uma abordagem que utiliza informações coletadas durante a fase de teste na atividade de depuração de especificações SDL.

No Capítulo 4 , a contribuição deste trabalho no que se refere à definição do critério Análise de Mutantes para o teste de especificações SDL, é apresentada. São apresentados 
um conjunto de operadores de mutação e uma estratégia de teste incremental - ITS-SDL, para auxiliar a aplicação dos operadores definidos. A análise de complexidade, com respeito ao número de mutantes gerados no pior caso, para os operadores de mutação também é apresentada.

No Capitulo 5 apresentam-se duas ferramentas desenvolvidas neste trabalho, $C A T_{S D L} \mathrm{e}$ Smart $D_{S D L}$. A $C A T_{S D L}$ apóia a análise de cobertura de especificações SDL, em relação a cinco critérios estruturais e auxilia a geração de casos de teste. A $\operatorname{Smart} D_{S D L}$ auxilia a atividade de depuração de especificações SDL. Também são apresentados os principais aspectos a serem considerados para o desenvolvimento de uma ferramenta de apoio ao teste de mutação de especificações SDL.

No Capítulo 6 é apresentado um estudo de caso em que os critérios de teste propostos neste trabalho foram aplicados e uma comparação entre os critérios estruturais apoiados pela ferramenta $C A T_{S D L}$ e a Análise de Mutantes foi realizada. Os resultados desse estudo de caso são utilizados para o estabelecimento de uma estratégia de teste incremental para auxiliar a aplicação dos critérios de teste explorados neste trabalho.

As principais contribuições deste trabalho são sumarizadas no Capítulo 7. Também apresentam-se as dificuldades e limitações do trabalho e perspectivas de trabalhos futuros nessa mesma linha de pesquisa.

No Apêndice A encontra-se uma lista de abreviações de alguns termos utilizados neste texto. No Apêndice B são apresentadas uma sintaxe simplificada de SDL e as especificações em SDL de dois protocolos utilizados como exemplos neste trabalho: Bit-Alternante e INRES. 


\subsection{Considerações Iniciais}

Neste trabalho, técnicas e critérios de teste são investigados no contexto de especificações baseadas em SDL, visando a contribuir com a definição de critérios de teste, o desenvolvimento de ferramentas e a condução de estudos de caso para avaliar a aplicação dos critérios de teste propostos nesse contexto. Sendo assim, neste capítulo apresentam-se as principais pesquisas relacionadas a esse tema.

$\mathrm{Na}$ Seção 2.2 são apresentadas algumas definiçōes importantes para o entendimento deste texto. Na Seção 2.3, é discutida a importância da fase de especificação para a qualidade do processo de desenvolvimento de software. Devido ao rigor necessário no desenvolvimento de alguns sistemas, técnicas formais tais como Máquinas de Estados Finitos, Redes de Petri, Statecharts, Estelle e SDL, estão sendo muito utilizadas na fase de especificação. Muitas pesquisas têm investigado SDL, pois essa técnica tem sido bastante empregada para a especificação de protocolos de comunicação e de arquiteturas de software. Na Seção 2.3.1 são apresentadas as principais características da técnica SDL.

$\mathrm{Na}$ Seção 2.4 são introduzidos os principais conceitos relacionados à atividade de teste, organizados de acordo com os três grupos que caracterizam os conhecimentos e contribuições nessa área (Maldonado, 1997): definição de técnicas e critérios de teste, desenvolvimento de ferramentas e estudos teóricos e empíricos. Na Seção 2.4.1 são apresentadas as técnicas e critérios de teste e validação $\mathrm{e}$, majs detalhadamente, as principais características dos critérios baseados em Fluxo de Controle, Fluxo de Dados e da Análise de Mutantes, explorados neste 
trabalho. Na Seção 2.4.2 discute-se a importância do apoio de ferramentas à atividade de teste. Estudos teóricos e empíricos conduzidos na área de teste de software são sucintamente relatados na Seção 2.4.3. O conceito de Árvore de Alcançabilidade, uma técnica utilizada para verificação e análise de especificações, é apresentado na Seção 2.4.4.

Visto que o enfoque principal deste trabalho é o teste de especificações SDL, na Seção 2.5 são apresentados alguns trabalhos relacionados.

\subsection{Terminologia e Conceitos Básicos}

Nesta seção são apresentadas algumas terminologias e conceitos empregados no decorrer deste texto. Alguns conceitos mais específicos serão introduzidos à medida em que forem comentados no texto.

No contexto de teste de software, é importante diferenciar os termos engano (mistake), defeito (fault), erro (error) e falha (failure). O padrão IEEE 610.12-1990 (IEEE, 1990) apresenta as seguintes definições: engano - ação humana que produz um resultado incorreto (por exemplo, uma ação incorreta feita pelo programador); defeito - passo, processo ou definição de dados incorreta (por exemplo, uma instrução ou comando incorreto no programa); erro - diferença entre o valor obtido e o valor esperado, ou seja, qualquer estado intermediário incorreto ou resultado inesperado na execução do programa; e falha - produção de uma saída incorreta em relação à especificação. Neste texto são utilizados os termos erro (causa), que envolve os termos engano, defeito e erro, e falha (consequência).

Alguns critérios de teste derivam seus requisitos de teste de um modelo de grafo de fluxo do programa. Um grafo de fluxo ou grafo de programa é um grafo orientado em que cada nó (ou vértice) representa um bloco indivisível de comandos e cada aresta (ou arco) representa um desvio de um bloco para outro (Myers, 1979). Um bloco de comandos é uma sequência de comandos que sempre são executados de forma consecutiva em um programa. Dessa forma, os desvios de controle só ocorrem para o começo ou a partir do final de um bloco, nunca em seu interior, ou seja, quando o primeiro comando de um bloco é executado, todos os demais também o serão (Rapps e Weyuker, 1985).

Define-se então que $G=(N, E)$ é um Grafo de Programa de um programa $P$ se para cada bloco de comandos de $P$, existe um nó $n \in N$ e para cada possível transferência de controle entre um nó representado por $n_{1}$ e um nó representado por $n_{2}$ existe um arco $\left(n_{1}, n_{2}\right) \in E$. Em um grafo, o nó correspondente ao bloco cujo primeiro comando é o comando inicial do programa é denominado nó inicial e o nó correspondente ao bloco cujo último comando é o comando final do programa é denominado nó final.

O grafo de programa pode ser enriquecido com informações provenientes da análise de fluxo de dados do programa, adicionando-se aos nós e arcos do grafo dados sobre atribuições (definições) de variáveis e sobre usos em computações (uso computacional, ou c-uso, associado 
a um nó do grafo) ou em predicados que influenciam o fluxo de controle do programa (uso predicativo, ou p-uso, associado a um arco do grafo). Esse grafo é denominado grafo def-uso (Rapps e Weyuker, 1985).

A execução de um programa induz a um caminho $C$, ou seja, uma sequência de nós que corresponde aos nós percorridos no grafo de programa durante a execução (Rapps e Weyuker, 1985). Um caminho completo é um caminho $C$ em que o primeiro nó do caminho é o nó inicial e o último nó é o nó final do grafo do programa. Um caminho simples é um caminho $C$ tal que todos os nós que o compõem, exceto possivelmente o primeiro e o último, são distintos. Um caminho livre de laço é um caminho simples $C$ tal que todos os nós são distintos, inclusive o primeiro e o último.

As limitações da área de teste de software estão relacionadas com alguns problemas indecidf́veis (Howden, 1987; Ntafos, 1988; Rapps e Weyuker, 1985), tais como: a equivalência entre programas; dadas duas sequências de comandos (caminhos) de um programa, ou de programas diferentes, se elas computam a mesma função; e, se um caminho é executável ou não, ou seja, se existe um conjunto de dados de entrada que levam à execução desse caminho. Outra limitação fundamental é a correção coincidente, que ocorre quando um programa apresenta, coincidentemente, um resultado correto para um item particular do domínio, ou seja, um particular item de dado é executado, satisfaz um requisito de teste, mas não revela a presença de um erro (Maldonado et al., 1998b).

$\mathrm{Na}$ condução da atividade de teste é importante a existência de um oráculo que auxilie a determinar, para qualquer dado do domínio de entrada de um programa ou especificação, se o comportamento do programa ou especificação com esse dado é o esperado, dentro de limites de tempo e esforços razoáveis. Ou seja, cabe ao oráculo, que pode ser o próprio testador ou algum mecanismo automatizado, decidir se o programa ou especificação se comporta corretamente.

\subsection{Especificação de Software}

O processo de desenvolvimento de software envolve um conjunto de atividades e resultados associados para produzir um produto. Quatro atividades fundamentais são comumente identificadas em todos os processos de desenvolvimento de software (Sommerville, 1995): especificação, desenvolvimento, validação e evolução. Segundo Cha e Hong (1996), das fases envolvidas no desenvolvimento de software, a especificação e análise de requisitos são as mais cruciais na determinação da qualidade do software. Além disso, é consenso comum que a compreensão completa do sistema e de seu comportamento deveria ser realizada tão cedo quanto possível, pois o custo de corrigir erros de especificação descobertos em fases mais adiantadas do ciclo de vida do sistema é mais alto. 
O processo de modelagem envolve a concepção dos elementos importantes para o sistema e o relacionamento entre eles e a sua representação usando linguagens específicas e bem definidas. A disponibilidade de um bom modelo do sistema é importante para toda a equipe de desenvolvimento, pois constitui uma representação tangível das propriedades conceituais e físicas do sistema e serve como um veículo para o especificador e o projetista representarem suas idéias. Um bom modelo deveria apresentar algumas características (Sommerville, 1995):

- completitude: todos os serviços e restrições requeridos pelo usuário devem ser definidos;

- consistência: os requisitos não devem ter definições contraditórias;

- não ter ambigüidade: não deve permitir diferentes interpretações para um mesmo requisito; a definição dos requisitos deve ser clara e precisa;

- ser verificável: deve facilitar a aplicação de técnicas de verificação, como a inspeção.

Se um modelo consistente, sem ambigüidade e executável é construído numa fase inicial, clientes e subcontratantes, por exemplo, podem se familiarizar com o mesmo e aprovar a funcionalidade e o comportamento do sistema antes de se investir na fase de implementação. Ou seja, um modelo pode ser usado como um meio de comunicação entre os envolvidos no desenvolvimento do sistema.

Visando ao aumento da qualidade e à minimização da inserção de erros, métodos podem ser utilizados para apoiar o trabalho do projetista durante todo o processo de desenvolvimento de software. Por sua base matemática, métodos formais têm sido bastante utilizados para melhorar a qualidade do processo de desenvolvimento de software (Hogrefe et al., 2000; Jackson, 1998; Jones, 1996; McMillan, 1991; Parnas, 1998; Reed, 1996; Widmaier, 2000; Wood, 1990; Young, 1991). Quando usados durante o desenvolvimento de software, métodos formais fornecem mecanismos para eliminar muitos dos problemas que são difíceis de resolver quando se usam outros paradigmas de Engenharia de Software. Ambigüidade, não completitude e inconsistência podem ser descobertas e corrigidas mais facilmente, não por meio de uma revisão ad hoc, mas pela aplicação de análise matemática. Quando usados durante o projeto, eles servem como base para a verificação do programa, e permitem que o engenheiro de software descubra e corrija erros que, de outra forma, só seriam descobertos posteriormente. Os métodos de desenvolvimento de software baseados em técnicas gráficas, tais como diagramas de fluxo de dados e diagramas entidade-relacionamento, auxiliam o engenheiro de software a desenvolver especificações, mas faltam a esses métodos: entre outras coisas, precisão nos detalhes da especificação e facilidades para o desenvolvimento do sistema, desde o projeto até a implementação. Segundo Wood (1990), as técnicas de especificação formal superam essas objeções básicas. Elas permitem a especificação, o desenvolvimento e a verificação de sistemas aplicando uma notação matemática rigorosa, além de facilitarem a evolução do sistema desde a especificação, passando pelo projeto, até 
a implementação. Tretmans e Belinfante (1999) destacam que um aspecto importante é que especificações formais são mais facilmente processadas por ferramentas, permitindo uma maior automação no processo de desenvolvimento de software. Além disso, Geurts et al. (1998) relatam um estudo de caso em que se obtiveram benefícios na fase de teste com o uso de métodos formais. Nesse estudo de caso, devido à precisão, consistência e completitude das especificações formais, casos de teste eficientes puderam ser sistematicamente derivados dessas especificações.

Um ponto importante a ressaltar é que os métodos formais fornecem a base para uma especificação rigorosa, precisa e completa, mas não garantem essas qualidades. Assim, erros podem ocorrer facilmente na própria especificação, tornando o teste e a validação atividades muito importantes (Hogrefe et al., 2000).

No processo de desenvolvimento de sistemas reativos, o projeto e a implementação são atividades de extrema importância, mas não podem ser realizadas sem um entendimento claro do comportamento pretendido do sistema. Uma descrição natural e compreensível do aspecto comportamental do sistema é necessária em todos os estágios do ciclo de desenvolvimento do sistema. E, para auxiliar essa tarefa, métodos formais têm sido utilizados (Broy, 1996. 1999; Neumann, 1996). Widmaier (2000) apresenta um experimento realizado em que um sistema de tempo-real (Sistema de Controle de Acesso Pessoal) foi desenvolvido paralelamente por duas equipes que utilizaram metodologias de desenvolvimento distintas. Uma das equipes utilizou o Método Cascata de desenvolvimento, enquanto que a outra utilizou tecnologia baseada em métodos formais. O objetivo do experimento era determinar, por meio de testes estatísticos, se as metodologias eram capazes de alcançar os objetivos de confiabilidade do usuário sob as mesmas restrições de custo e cronograma. Com esse experimento, pode-se verificar quais os aspectos favoráveis e as fraquezas de cada metodologia e quais os motivos que as impossibilitaram de alcançar os objetivos de confiabilidade do cliente. Widmaier afirma que da perspectiva de confiabilidade, a abordagem formal produz melhores resultados, mostrando-se mais vantajosa na fase de requisitos. Baseado no experimento, Widmaier (2000) conclui que uma metodologia de desenvolvimento de software híbrida é a mais adequada para melhorar a confiabilidade, utilizando métodos formais na fase de análise de requisitos e os métodos de desenvolvimento clássicos no gerenciamento do processo e na documentação do sistema.

De acordo com v. Lamsweerde (2000), uma técnica de especificação é formal se é expressa em uma linguagem composta de três componentes:

- sintaxe: que são as regras que determinam a boa formação gramatical de sentenças;

- semântica: que são as regras para interpretar as sentenças de forma precisa e significante de acordo com o domínio considerado;

- teoria de prova: regras para inferir informações úteis da especificação. 
Como o comportamento dos sistemas reativos pode ser caracterizado como dirigido a entradas e saídas, uma característica principal que um formalismo para a definição de um sistema reativo deve ter é que ele deve fornecer meios para a especificação da comunicação entre os subcomponentes do sistema. Segundo Harel e Pnueli (1985), os requisitos necessários para um método descrever o aspecto comportamental de sistemas reativos são:

(i) fornecer descrições que sejam bem-estruturadas, concisas, não-ambíguas, legíveis e fáceis de entender;

(ii) ser somente descritivo, eliminando ou ao menos minimizando, dependências de qualquer aspecto da implementação.

$O$ requisito (i) implica que o método deve ter uma semântica simples mas rigorosa, e o requisito (ii) implica que a estruturação de uma descrição comportamental deve refletir a decomposição natural do problema ao invés da descrição da implementação.

$\mathrm{Na}$ literatura encontram-se alguns trabalhos que comparam diversas técnicas formais. Davis (1988) faz uma comparação entre técnicas formais e informais utilizadas para a especificação dos requisitos comportamentais de sistemas, entre as quais estão Linguagem Natural, Máquinas de Estados Finitos, Staterchats, PDL (Program Design Language), Análise Estruturada/Tempo-Real, SDL e Redes de Petri. Broy (1996) cita como exemplos de técnicas de especificação formal: SDL, Esterel, Statecharts, Lotos, Lustre e Estelle. Furbach (1993) cita como técnicas formais mais importantes: SDL, Statecharts, Redes de Petri, CCS (Calculus of Communicating Systems), CSP (Communicating Sequential Processes) e Esterel, apresentando as idéias básicas dessas técnicas, comparando-as e avaliando as principais características das mesmas.

A seguir, apresentam-se sucintamente algumas das técnicas formais existentes. A técnica SDL é apresentada com mais detalhes na Seção 2.3.1.

- Máquina de Estados Finitos: uma MEF é uma máquina hipotética composta por estados e transições, e que pode estar, em qualquer instante, em somente um de seus estados (Gill, 1962). Em resposta a uma entrada, a máquina gera uma saída e pode ou não mudar de estado. A saída e o novo estado são funções do estado atual e da entrada (Davis, 1988). O modelo de Máquinas de Estados Finitos serviu de base para algumas extensões, tais como Máquinas de Estados Finitos Estendidas (MEFEs), que permitem a descrição de variáveis e expressões; Máquinas de Estados Finitos Comunicantes (MEFCs), que permitem descrever a comunicação entre as MEFs; Máquinas de Estados Finitos Estendidas Comunicantes (MEFECs), que são uma combinação das MEFEs e MEFCs; e Statecharts;

- Statecharts: essa técnica é similar às Máquinas de Estados Finitos convencionais, agregando três aspectos: hierarquia (decomposição), concorrência (ortogonalidade) e 
comunicação (broadcasting) (Harel, 1987; Harel e Naamad, 1996; Harel et al., 1987). A decomposição permite que o sistema seja desenvolvido de forma modularizada. A ortogonalidade corresponde à especificação do tipo AND de decomposição de estado. Estados do tipo AND são estados compostos de subestados paralelos que são ativados simultaneamente. Por outro lado, em estados do tipo OR, somente um subestado pode estar ativo a cada instante, da mesma forma que nas MEFs. A concorrência pode ser modelada nos statecharts por meio de eventos de saída, as ações. Normalmente essas ações afetam o comportamento do próprio statechart nos componentes ortogonais por meio de um mecanismo de broadcasting (reação em cadeia). Assim, a ação é considerada um evento interno que pode, possivelmente, causar o disparo de outras transições em outros componentes. Uma outra característica de Statecharts é a capacidade de "lembrar" estados visitados anteriormente, denominado história. Quando se ativa um estado, o seu subestado que se torna ativo é, normalmente, o subestado default, a não ser que um símbolo de história $(H)$ esteja associado à transição que leva a esse estado. Harel denomina esse caso de "entrada por história". Com isso, ao invés de ativar o subestado default, ativa-se o último subestado visitado anteriormente. A "entrada por história" também pode ser estendida para toda a hierarquia de estados, associando-se à transição o símbolo $H^{*}$, que indica que, se um estado é decomposto em vários níveis, o aspecto de história é válido para todos os níveis da hierarquia;

- Redes de Petri: as Redes de Petri (Peterson, 1977) são representadas como um grafo em que lugares (círculos) e transições (linhas) săo interconectados por arcos direcionados. As funções de entrada definem o mapeamento das transições para uma coleção de lugares, denominados lugares de entrada, e as funções de saída definem o mapeamento das transições para uma coleção de lugares, denominados lugares de saída. A marcação da Rede de Petri corresponde à atribuição de tokens (marcas) aos lugares, permitindo a execução da rede por meio do disparo das transiçōes. Após o disparo de uma transição, os tokens são removidos dos lugares de entrada e são colocados em todos os lugares de saída. As Redes de Petri são adequadas para descrever partes do comportamento pretendido do sistema, nas quais a ambigüidade não pode ser tolerada e a sincronização precisa do processo é importante. Algumas extensões também foram propostas para Redes de Petri, tais como as Redes de Petri Coloridas (CPNs) (Jensen, 1986), que permitem a definição de tipos de dados e a manipulação dos valores desses tipos. Em Redes de Petri ordinárias tais valores não são distinguíveis. No caso das CPNs, os tipos são as chamadas "cores" da rede;

- Estelle: a técnica Estelle (ISO/TC97/SC21/WG1/DIS9074, 1987) é muito utilizada para especificação de sistemas distribuídos, protocolos de comunicação e serviços. A estrutura de um sistema especificado em Estelle é uma hierarquia de módulos que se comunicam por meio de trocas de mensagens. O comportamento de cada módulo é 
descrito por Máquinas de Estados Finitos Estendidas (MEFEs). As MEFEs trocam mensagens por meio de canais de comunicação bidirecionais. Mensagens recebidas são armazenadas em filas do tipo FIFO (First In First Out) e são processadas de acordo com as condições, prioridades e atrasos associados às transições da máquina. As ações das máquinas são especificadas por comandos da linguagem Pascal, tornando essa técnica bastante familiar.

\subsubsection{SDL}

O interesse de um grupo do órgão francês ITU-T ${ }^{1}-I T U$. Telecommunication Standardization Sector - em produzir padrões no campo das telecomunicações motivou o desenvolvimento da linguagem SDL (Specification and Description Language). O objetivo era desenvolver uma linguagem padrão de especificação para a indústria de telecomunicações. A primeira versão da linguagem foi criada em 1976 e, desde então, outras versões foram apresentadas (SDL-88, SDL-92 e SDL-2000), expandindo a linguagem com novas características de modo a tornar SDL a mais completa possível e sempre apoiada por uma semântica formal. Entre 1992 e 1996, devido a uma decisão estratégica, a linguagem se manteve estável e um número limitado de mudanças foram realizadas em sua gramática (publicadas em um Addendum em 1996). Apesar de algumas vezes ser chamada de SDL-96, esta versão continua sendo conhecida como SDL-92. As vantagens de se manter a linguagem estável, porém, começaram a ter menor importância diante da necessidade de integrar o uso de SDL com outras linguagens, como UML. Assim, a versão SDL-92 foi atualizada, as mudanças publicadas em 1996 foram incorporadas e a mais recente versão, SDL-2000, foi publicada. Essa versão continua em constante revisão, sendo que a última versão revisada foi publicada em 2002, sem no entanto alterar seu nome. A descrição apresentada nesta seção é da versão SDL-92, pois esta foi a versão utilizada neste trabalho.

A cooperação entre ISO e ITU-T no desenvolvimento de Técnicas de Descrição Formal possibilitou que SDL possuísse características de Estelle e Lotos: o conceito de Máquinas de Estados Finitos de Estelle e tipos de dados algébricos de Lotos. Essa cooperação também fez de SDL uma linguagem de padrão reconhecido internacionalmente, tendo o compromisso e o suporte do ITU-T e sendo aceita pela ISO. SDL possui construçōes para representar a estrutura, o comportamento, as interfaces, a comunicação, abstraçōes, encapsulamento de módulos e refinamentos do sistema.

O objeto alvo para uma especificação em SDL é chamado sistema. A propriedade que mais interessa de um sistema é o seu comportamento: o que o sistema faz e em que circunstâncias. Tudo o que não faz parte do sistema é denominado de ambiente. A comunicação entre o sistema e o ambiente acontece por meio do envio e recebimento de sinais. Esses sinais são

\footnotetext{
${ }^{1}$ Até 1993 este órgão era conhecido como CCITT (Comité Consultatif International Tétéphonique et Télégraphique), mas em fevereiro/93 este deixou de existir e em seu lugar foi criado o ITU-T.
} 
transferidos pelos canais como qualquer comunicação interna. O comportamento do sistema é definido em um modelo de estímulo/resposta.

Um sistema em SDL é composto de blocos (blocks) conectados uns aos outros e também com o ambiente por meio de canais (channels), como ilustrado na Figura $2.1^{2}$ (SDL-Forum, 2004). É por meio dos canais que os sinais são trocados.

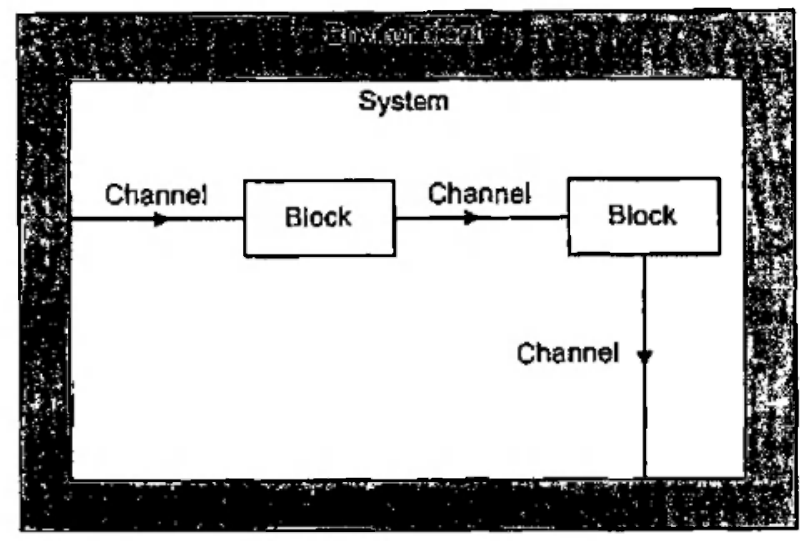

Figura 2.1: Exemplo de uma Estrutura de Sistema em SDL (SDL-Forum, 2004)

Um bloco pode conter outros blocos (sub-blocos) ou um conjunto de processos, como apresentado na Figura 2.2, mas somente nos "blocos-folhas" é que são definidos os processos.

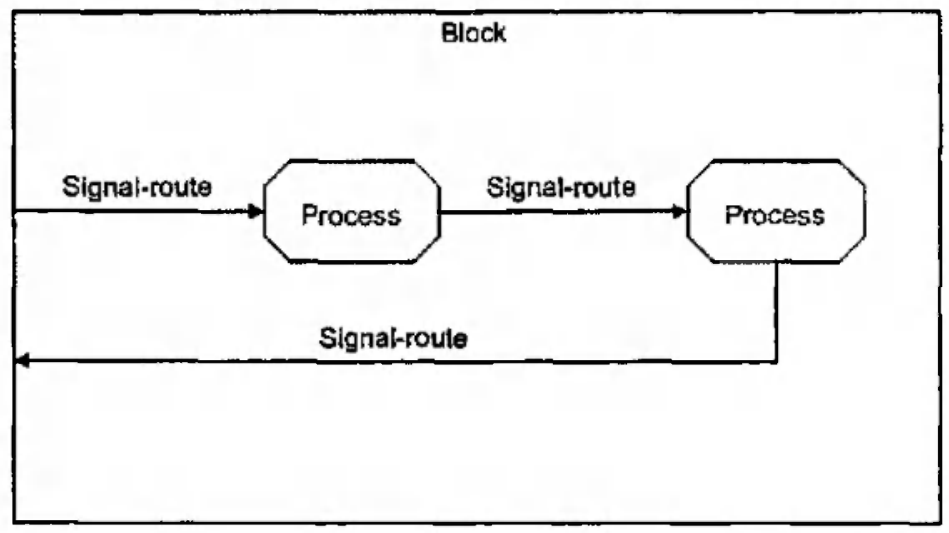

Figura 2.2: Exemplo de uma Estrutura de Bloco em SDL (SDL-Forum, 2004)

O comportamento do sistema é descrito por meio dos processos, que nada mais são do que Máquinas de Estados Finitos Estendidas Comunicantes. Os processos se comunicam entre si por troca de sinais (que podem ter parâmetros para troca de dados) através de signal routes. Em resposta a um sinal, o processo pode enviar outros sinais, atualizar variáveis locais e eventualmente, ficar no mesmo estado ou mudar de estado.

SDL tem duas sintaxes: SDL/GR, que é uma representação gráfica e SDL/PR, que é uma representação textual. Por ser mais intuitiva e mostrar mais claramente os relacionamentos

\footnotetext{
${ }^{2}$ Nas figuras que ilustram a estrutura de uma especificação SDL, os nomes dos componentes foram mantidos em inglês, conforme descritos na sintaxe da linguagem.
} 
do que a forma textual, a forma gráfica é preferida pela maioria das pessoas. Fragmentos na forma textual podem ser embutidos na forma gráfica, em locais onde textos são mais adequados, como por exemplo, na declaração de dados, declaração de sinais e operações. A forma textual se parece um pouco com uma linguagem de programação e tem a vantagem de não requerer ferramentas caras, pois podem ser editadas em qualquer processador de texto (Belina et al., 1991).

Em SDL/GR a descrição de sistema é denominada de diagrama do sistema e contém os elementos: nome do sistema, descrição dos sinais, descrição dos canais, descrição dos tipos de dados e descrição dos blocos. A descrição de um bloco por sua vez, é denominada de diagrama do bloco e contém os seguintes elementos: nome do bloco, descrição dos sinais, descrição dos signal-routes, conexões channel-to-route e descrição dos processos. E a descrição de um processo é denominada de diagrama do processo e contém os seguintes elementos: nome do processo, parâmetros formais, descrição das variáveis, descrição do timer e descrição do procedimento.

Em SDL, o comportamento sempre é considerado no contexto de um sistema, sem importar se é um comportamento simples consistindo de um simples processo ou um comportamento complexo, composto de um grande número de processos organizados em uma hierarquia de blocos. Um processo não é apenas uma parte do comportamento do sistema, ele é um objeto com um comportamento completamente definido que pode ser composto paralelamente com outros objetos para formar uma estrutura de objetos com comportamentos concorrentes. Um processo pode ser visto como uma MEFE que trabalha de forma autônoma, mas concorrentemente aos outros processos.

A comunicação em SDL é assíncrona. Uma fila de sinais do tipo FIFO (First In First Out) é associada a cada processo, guardando os sinais enviados ao processo. Todos os sinais que chegam dos signal routes associados são colocados nessa fila na ordem de chegada (sinais simultâneos são ordenados não-deterministicamente). Mesmo que um processo esteja mudando de estado, ele ainda pode receber mensagens e processá-las imediatamente após terminar sua transição. Os sinais que um processo poderá processar depende de qual estado o processo está. Durante uma transição as variáveis locais podem ser atualizadas.

Cada processo tem um número de identificador de processo único (pid), normalmente usado para endereçar sinais. Os sinais enviados pelos signals routes não sofrem nenhum tipo de atraso, enquanto que os sinais enviados pelos canais sofrem um atraso não-determinístico. Cada processo tem um estado explícito mas pode também conter variáveis locais que podem influenciar as transições de estado. Estados estão em posições estáveis e transições de estados são normalmente disparadas pelo consumo de um sinal da fila de entrada de processos. Se o próximo sinal de entrada não causa a ocorrência de uma transição de estado então ele é simplesmente descartado.

A Figura 2.3 (Belina et al., 1991) ilustra o funcionamento do mecanismo de recebimento de sinais por um processo. Considerando que o processo ilustrado na figura se encontra no 
estado $s 1$ e que a fila de entrada contenha os sinais $a, d, a, b$, nesta ordem, os sinais $a$ e $d$ podem iniciar uma transição. Como o sinal $a$ é o primeiro na fila de entrada, ele é removido da fila, e o processo executa una transição para o estado $s 2$. Agora o sinal $d$ é o primeiro na fila, mas não pode explicitamente estimular o processo no estado $s 2$, então $d$ é consumido e o processo executa uma transição em que o mesmo estado $s 2$ é o próximo estado (transição implícita). O próximo sinal é $a$, que pode iniciar uma transição do estado $s 2$ para algum outro estado (não representado na figura).

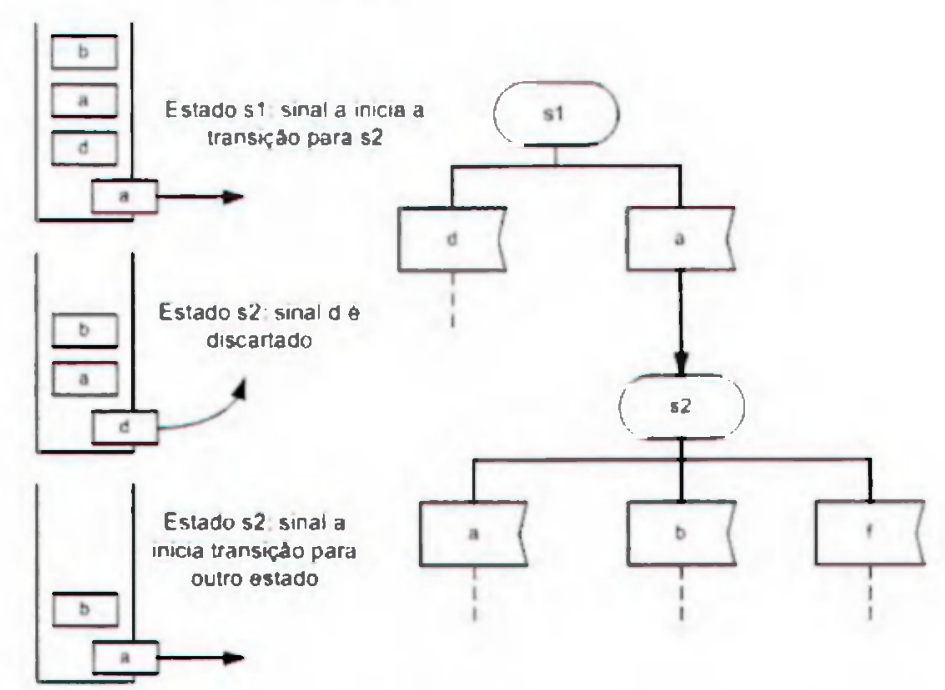

Figura 2.3: Mecanismo da Fila de Entrada de um Processo (Belina et al., 1991)

Freqüentemente porém, não é apropriado consumir os sinais na ordem em que eles chegam em um processo. Nesse caso, é necessário armazenar os sinais que seriam normalmente descartados para que possam ser usados em estados futuros. SDL fornece uma construção para permitir o armazenamento de sinais, denominada save. Uma construção save está associada a um estado, não sendo válida para qualquer outro estado e, se necessário, outro save deve ser especificado explicitamente para outros estados. Os sinais salvos são armazenados na fila até que possam ser consumidos por outro estado do processo.

Outra característica importante é que os processos em SDL têm acesso ao tempo global representado pela expressão now, que pode ser usada para atribuir valores às variáveis e para disparar transições. Além disso, há os temporizadores (timers), que pertencem a um processo e geram um sinal timer, que é colocado na fila de entradas do processo. Se um temporizador é ativado, ele recebe uma certa hora absoluta e supervisiona a hora atual. Quando a hora atual excede a hora recebida, um sinal timer, devidamente identificado, é colocado na fila de entradas do processo. Quando o sinal timer que está na fila é consumido, o temporizador é desativado.

Todas as características de SDL foram projetadas para se adequarem à especificação de sistemas de telecomunicações, incluindo serviços e protocolos, mas SDL tem sido utilizada para outros propósitos tais como projeto, programação de alto-nível e simulação (Turner, 
1993). Mais recentemente, SDL também tem sido utilizada na descrição de arquitetura de software. Alguns estudos de casos mostram as vantagens de utilização de SDL em projetos de empresas como Nokia, Siemens, Nortel e Ericsson (Telelogic, 2002a).

No Apêndice B uma versão simplificada da sintaxe de SDL é apresentada.

\subsection{Atividade de Teste}

O uso de métodos, técnicas e ferramentas nas atividades envolvidas no processo de desenvolvimento de software, não garante que o produto esteja livre da ocorrência de erros. Uma alternativa para garantir um produto de software de qualidade é a condução de atividades de VV\&T - Verificação, Validação e Teste, paralelamente às atividades de desenvolvimento. As atividades de VV\&T fazem parte do conjunto de atividades de apoio que visam a assegurar a qualidade a cada passo do processo, constituindo a atividade de Garantia de Qualidade de Software.

As atividades de VV\&T podem ser de análise estática e de análise dinâmica. A análise estática realiza a verificação de representações intermediárias do software, tais como documentos de requisitos, diagramas de projeto e o código fonte do programa, ou seja, pode ser aplicada em todas as fases do processo de desenvolvimento e não necessita da execução do produto. Como exemplos de técnicas de análise estática têm-se a inspeção de software (revisões cujo objetivo é a detecção de defeitos de um produto de software) e análise e verificação formal. A aplicação das técnicas estáticas não permite a análise do comportamento dinâmico do produto de software, sendo então complementadas pelas técnicas de análise dinâmica, que envolvem a execução do produto (Sommerville, 1995). Exemplos de atividades de análise dinâmica são o teste e a simulação.

Segundo Myers (1979), teste é o processo de executar um programa com a intenção de encontrar um егто, sendo que um teste bem sucedido é aquele que descobre erros ainda não descobertos. O teste porém, não pode mostrar a ausência de erros, pode somente mostrar que os erros estão presentes no software.

A atividade de teste deve ser conduzida ao longo do processo de desenvolvimento de software, sendo realizada em quatro etapas: planejamento de testes, projetos de casos de teste, execução e avaliação dos resultados dos testes (Maldonado, 1991; Pressman, 2001). Em geral, essas atividades concretizam-se em três fases de teste: Teste de Unidade, que tem como objetivo testar a menor unidade do projeto do software, o módulo, procurando identificar erros de lógica e de implementação; Teste de Integração, que visa à identificação de erros na interação entre módulos, sendo uma técnica sistemática para integrar os módulos componentes da estrutura do software; e Teste de Sistema, que visa à identificação de erros funcionais e de características de desempenho que não estejam de acordo com a especificação. Essas fases caracterizam o teste de programas procedimentais; sendo que o teste de unidade 
é intraprocedimental e o teste de integração é interprocedimental. Algumas variações são consideradas para o teste de programas desenvolvidos com base no paradigma Orientado a Objetos, como discutido por Vincenzi (2004), pois há uma divergência em relação à menor unidade a ser testada, se é a classe ou o método. Quando considera-se o método, o teste de unidade é intramétodo e o teste de integração é intermétodo, intraclasse e interclasse. Quando se considera à classe como a menor unidade, o teste de unidade é caracterizado pelo teste intramétodo, intermétodo e intraclasse, e o teste de integração é interclasse.

A atividade de teste tem sido apontada como uma das mais onerosas no desenvolvimento de software (Beizer, 1990; Harrold, 2000; Korel, 1990; Myers, 1979; Pressman, 2001). Pressman (2001) afirma que é comum que uma organização gaste $40 \%$ do esforço de projeto total na atividade de teste. Além disso, ressalta-se que a atividade de teste de sistemas críticos com relação à segurança pode custar de três a cinco vezes mais que todos os outros passos da Engenharia de Software juntos.

Idealmente, todo o domínio de dados de entrada deveria ser utilizado na avaliação de um produto em teste. Isso, porém, é impraticável pelo alto custo e pelo tempo que seriam necessários (Myers, 1979). Assim, é necessário identificar um conjunto finito de dados de entrada que seja eficiente em revelar erros no produto, sem acarretar em um custo muito alto para a atividade de teste.

Para auxiliar a condução, a avaliação da qualidade e da adequação da atividade de teste são estabelecidos técnicas e critérios de teste, que fornecem ao desenvolvedor uma abordagem sistemática e teoricamente fundamentada. Os critérios de teste podem ser classificados em três técnicas: Técnica Funcional, Técnica Estrutural e Técnica Baseada em Erros (Pressman, 2001). Os critérios de teste existentes são complementares e devem ser aplicados em conjunto, aumentando a qualidade da atividade de teste (Harrold, 2000; Pressman, 2001).

Os critérios de teste podem ser utilizados tanto para auxiliar a avaliação da adequação de conjuntos de casos de teste como para auxiliar a geração de conjuntos de casos de teste. Os critérios de teste estabelecem requisitos que devem ser exercitados e, com a análise da satisfação desses requisitos, obtém-se uma maneira de quantificar a atividade de teste. Esta análise da satisfação dos requisitos é denominada análise de cobertura ou análise de adequação.

Goodenough e Gerhart (1975) consideram que um critério de teste é adequado quando sua aplicação bem sucedida resulta em nenhum erro no programa sendo testado. Para garantir a corretitude dos programas, propõem requisitos de confiabilidade e validade para um critério de teste. A confiabilidade se refere à consistência com que os resultados são produzidos, independentemente de seus significados, ou seja, se um programa é testado com sucesso por um conjunto de casos de teste que satisfaz o critério, todos os outros conjuntos de casos de teste que também satisfazem o critério devem testar o programa com sucesso. Um programa é testado com sucesso por um conjunto de casos de teste quando um erro ainda não descoberto é identificado por esse conjunto. Já a validade se refere à habilidade 
de produzir resultados significantes, sem se preocupar com a consistência dos mesmos, ou seja, um critério de teste é válido se, para todo erro em um programa, existe pelo menos um conjunto de casos de teste que satisfaz os requisitos do critério e seja capaz de revelar o erro. A validade somente implica que é possível selecionar dados que revelarão o erro, mas não garante que tais dados serão selecionados. Assim, Goodenough e Gerhart consideram que um programa está correto quando é adequadamente testado por um critério válido e confiável. Esses requisitos porém, são definidos considerando todo o domínio de entrada de um programa, sendo que um critério é válido e confiável se seleciona o domínio todo de entradas do programa (Weyuker e Ostrand, 1980). Porém, não há um critério que satisfaça os dois requisitos e seja aplicável na prática (Howden, 1996). Além disso, segundo Weyuker e Ostrand (1980), não há como saber se um critério é ideal sem o conhecimento prévio dos erros de um programa, ou sem saber ao menos da existência de alguns tipos de erros, fato que em geral não acontece. Outras limitações à aplicação do "teste ideal" de Goodenough e Gerhart são discutidas por Weyuker e Ostrand (1980). Segundo Zhu et al. (1997), as pesquisas na área de teste se concentram em critérios que sejam aplicáveis na prática e não em critérios teoricamente ideais.

Dada a diversidade de critérios de teste existentes, uma questão importante é como utilizá-los de forma a melhor explorar em uma estratégia de teste as vantagens de cada um. Harrold (2000) aponta o estabelecimento de estratégias de teste efetivas e de baixo custo como uma das principais direções para a área de teste de software. E destaca também que, para apoiar essa tarefa, é de fundamental importância a condução de estudos teóricos e empíricos que visam a comparar e avaliar os diversos critérios de teste principalmente em relação a três fatores: custo, strength (dificuldade de satisfação) e eficácia.

Para auxiliar a condução de estudos empíricos e, em geral, para a realização da atividade de teste, é essencial o suporte de ferramentas. O teste é uma atividade que demanda muito esforço e pode se tornar improdutiva se aplicada manualmente.

A condução de atividades de teste e validação em nível de especificação é tão importante quanto em nível de programa. De fato, o conhecimento obtido com a condução dessas atividades em nível de programa tem sido muito empregado no nível de especificação.

As técnicas de VV\&T existentes para o teste de especificações também podem ser classificadas como de análise estática e análise dinâmica. Em relação às especificações formais de sistemas, técnicas estáticas analisam a especificação formal sem executar o modelo descrito pela especificação, enquanto que técnicas de análise dinâmica constroem um modelo executável da especificação formal para validá-la (Hogrefe et al., 2000).

Segundo Harel (1992), a verificação da consistência e completitude de um modelo por meio de análises estáticas não previne a ocorrência de erros lógicos. Sendo assim, é necessária a execução do modelo, cujo pré-requisito se resume na disponibilidade de uma semântica formal que contenha informação suficiente para definir com precisão o estado do sistema a cada passo da execução. Um exemplo de técnica dinâmica é a simulação. Para o teste 
de especificações de sistemas reativos, foram propostas várias formas de simulação (Harel 1992): simulação interativa, que com o apoio de uma ferramenta automatizada, possibilita que o usuário represente o meio ambiente do sistema gerando, passo a passo, eventos que provocam alteração no mesmo; simulação em batch, na qual a simulação é realizada de modo iterativo, com base em um conjunto de eventos pré-determinados; simulação programada que permite analisar o modelo sob condições geradas randomicamente, sendo que pontos podem ser definidos de modo que a ferramenta execute determinadas ações quando ocorrem situações específicas; simulação exaustiva, que teoricamente consiste em executar o modelo gerando-se todos os possiveis eventos externos e todas as alterações nos valores das variáveis. A simulação exaustiva é uma técnica que pode ser impraticável, pois pode ter um número de possibilidades muito grande por produzir todos os possíveis cenários. Uma possível solução é a simulação de partes do sistema.

Uma técnica similar à simulação exaustiva, é a árvore de alcançabilidade, um mecanismo que pode ser construído estática ou dinamicamente e que permite a análise de propriedades da especificação. Essa técnica é bastante utilizada para a análise e simulação de Redes de Petri (Murata, 1984, 1989; Peterson, 1977), sendo também utilizada no contexto de Máquinas de Estados Finitos, Máquinas de Estados Finitos Comunicantes (Peng, 1997; Ozdemir e Ural, 1997), Statecharts (Masiero et al., 1994) e Estelle (Huang e Hsu, 1994; Jirachiefpattana e Lai, 1997; Souza, 2000). Na Seção 2.4 .4 mais detalhes sobre a árvore de alcançabilidade são apresentados.

Outra técnica similar à simulação exaustiva é model checking, pois é baseada na exploração de estados. Model checking porém, é considerada uma técnica estática e também auxilia a verificação de propriedades desejadas por meio da representação do sistema por um modelo, por exemplo um sistema de transição de estados, definido em termos de variáveis, valores iniciais de variáveis, suposições sobre o ambiente e uma descrição das condições sob as quais as variáveis podem mudar seus valores. Expressões em lógica temporal representam os estados e caminhos de execução. Um model checker visita todos os estados alcançáveis e verifica se as expressões em lógica temporal estão sendo satisfeitas em todos os caminhos. Para a aplicação dessa técnica, os modelos não necessitam estar totalmente especificados, porém há o problema de explosão de estados, aspecto crítico quando se trata de sistemas complexos (Clarke e Wing, 1996). Além de permitir a verificação de propriedades do software, model checking pode ser aplicada para a avaliação de cobertura do teste (Black et al., 2000b). Nesse caso, um critério de teste deve ser selecionado inicialmente e aplicado na especificação para derivar os requisitos de teste, ou seja, o conjunto de propriedades a serem testadas. Para usar um model checker, esses requisitos são representados como fórmulas em lógica temporal. Para avaliar a cobertura de um conjunto de casos de teste, cada caso de teste é executado e o model checker determina quais requisitos são satisfeitos pela execução (Ammann e Black, 1999). 
No contexto de especificações, a atividade de teste pode ser conduzida de duas formas: teste baseado em especificações e teste de especificações. O teste baseado em especificações verifica se a implementação está de acordo com a especificação e é comumente aplicado no teste de protocolos de comunicação, no qual é referenciado por teste de conformidade. $\mathrm{O}$ teste de conformidade visa a garantir que a implementação de um protocolo esteja em conformidade com a sua especificação, gerando os casos de teste com base na especificação e usando-os no teste da implementação; dessa forma, procurando garantir que o protocolo esteja compatível com outras implementações do mesmo protocolo (Bochmann e Petrenko, 1994). No teste de especificações, o produto em teste é a própria especificação, visando a encontrar erros cometidos nessa fase do desenvolvimento e a garantir que a especificação esteja de acordo com os requisitos do usuário.

Assim como em nível de programa, em nível de especificação também é importante a avaliação da qualidade da atividade de teste, realizada por meio da análise de cobertura (Petrenko e Bochmann, 1996). Técnicas de verificação, como simulação e model checking, por si só não permitem a análise de cobertura. Nesse sentido, é importante a investigação de critérios de teste que complementem a atividade de teste de especificações e que possam ser utilizados tanto para a geração quanto para a avaliação da adequação de um conjunto de casos de teste.

Vários trabalhos foram conduzidos para avaliar a adequação de técnicas e critérios estabelecidos para o teste de programas no contexto de teste de especificações e no teste de conformidade, evidenciando o esforço de se definirem critérios de teste e validação de especificações e de se avaliarem os custos/benefícios associados, com base em conceitos tradicionalmente utilizados para o teste de programas em nível de unidade. (Black et al., 2000a; Fabbri et al., 1994b, 1995, 1999; Kovács et al., 2003; Petrenko e Bochmann, 1996; Probert e Guo, 1991; Simão et al., 2000, 2003; Souza, 2000; Souza et al., 2000a,b,c; Ural et al., 2000; Ural e Yang, 1991; Wang e Liu, 1993; Yang et al., 1998). Os critérios mais explorados têm sido os da técnica estrutural (baseados em fluxo de dados e de controle) e da técnica baseada em erros, e são utilizados tanto para a avaliação da adequação de um conjunto de casos de teste quanto para a geração de conjuntos de casos de teste.

Nas próximas seções são abordados três aspectos associados à atividade de teste, segundo Maldonado (1997): definição de técnicas e critérios de teste, ferramentas de apoio ao teste e estudos teóricos e empíricos. Esses aspectos são discutidos no contexto de teste de programas e de especificações.

\subsubsection{Técnicas de Teste}

Um dos pontos fundamentais para o sucesso da atividade de teste é a escolha de um conjunto de casos de teste. Os critérios de teste auxiliam a avaliação da qualidade e na adequação da atividade de teste, pois estabelecem requisitos que devem ser exercitados por um conjunto 
de casos de teste. Assim, um conjunto de casos de teste $T$ é adequado em relação a um critério $\mathrm{Cr}$ (descrito como $\mathrm{Cr}$-adequado) se $\mathrm{T}$ satisfaz ou executa todos os requisitos de teste impostos pelo critério $C r$ (Rapps e Weyuker, 1985). Um conjunto de seqüências de teste $T$ é adequado por construção a um critério $C r$ quando os requisitos de teste estabelecidos por $C r$ guiam a geração de $T$, ou seja, $T$ é construído de forma a cobrir cada requisito de $C r$. Dessa forma, critérios de teste podem ser utilizados tanto para auxiliar a geração de conjuntos de casos de teste como para auxiliar a avaliação da adequação de conjuntos de casos de teste.

Os critérios de teste podem ser agrupados em técnicas que se diferenciam pela fonte de informação utilizada para estabelecer os requisitos de teste (Maldonado, 1997). Essas técnicas são: Técnica Funcional, que utiliza a especificação do software para estabelecer os requisitos de teste; Técnica Estrutural, que utiliza uma implementação particular para estabelecer os requisitos de teste; e Técnica Baseada em Erros, que estabelece os requisitos de teste com base nos erros típicos e comuns cometidos durante o processo de desenvolvimento. Os requisitos estabelecidos pelos critérios de teste devem ser exercitados e a análise da satisfação desses requisitos permite a quantificação da atividade de teste. A seguir apresentam-se as três técnicas de teste existentes e alguns dos principais critérios de teste explorados de cada uma delas no teste de programas e de especificações.

\subsubsection{Técnica Funcional}

Essa técnica é conhecida como teste caixa preta, pois trata o software como uma caixa cujo conteúdo é desconhecido e apenas os dados de entrada e as respostas geradas pelo programa podem ser visualizados (Myers, 1979). É importante para essa técnica a qualidade da especificação do sistema, pois verificam-se apenas as funções do sistema, identificadas a partir da especificação, sem considerar detalhes de implementação. Como critérios dessa técnica podem-se citar (Pressman, 2001):

- Particionamento de Equivalência: neste critério o domínio de entrada de um programa é dividido em classes de equivalência, a partir das quais os casos de teste são derivados. O objetivo deste critério é minimizar o número de casos de teste, selecionando apenas um de cada classe, tendo como princípio que todos os elementos de uma classe comportam-se equivalentemente;

- Análise do Valor Limite: este critério requer que os casos de teste sejam associados aos limites das condições de entrada, pois os erros costumam ocorrer com maior freqüência nos limites dos domínios de entrada, o que torna esse critério relevante para o teste funcional. Na verdade, este critério e o critério Particionamento de Equivalência são complementares, uma vez que este último exercita cada classe do domínio de entrada e o primeiro exercita os extremos de cada classe; 
- Grafo de Causa-Efeito: com este critério verifica-se o efeito combinado de dados de entrada. As causas (condições de entrada) e os efeitos (ações) são identificados e combinados em um grafo a partir do qual é montada uma tabela de decisão, de onde são derivados os casos de teste e as saídas;

- Error Guessing: neste critério "adivinham-se" os possíveis erros, com base nas características do software e do domínio de entrada; e os casos de teste são elaborados combase em uma lista dos erros relacionados.

Uma ressalva é que a Técnica Funcional está sujeita às inconsistências que podem ocorrer na especificação, uma vez que esta pode ser feita de forma descritiva e informal, além de que é difícil quantificar a atividade de teste, pois não é possível garantir que partes essenciais ou críticas do programa foram testadas. Apesar disso, o teste funcional é bastante utilizado pois pode ser aplicado em praticamente todas as fases de teste e no teste de programas desenvolvidos no paradigma procedimental e orientado a objetos.

\subsubsection{Técnica Estrutural}

Essa técnica é conhecida como teste caixa branca, pois os requisitos de teste são baseados nos aspectos de implementação (Myers, 1979). Muitos dos critérios estruturais utilizam uma representação de programa conhecida como grafo de fluxo de controle ou grafo de programa (Rapps e Weyuker, 1985), apresentado na Seção 2.2. A partir do grafo de programa são escolhidos os componentes que devem ser executados, caracterizando assim o teste estrutural.

Os critérios dessa técnica usam diferentes tipos de estruturas para determinar quais componentes têm sua execução requerida. Alguns critérios estruturais estabelecem seus requisitos utilizando apenas informaçōes do fluxo de controle da execução do programa, tais como comandos ou desvios. Dentre os mais conhecidos estão os critérios (Zhu et al., 1997):

- Todos-Nós: requer que todos os nós do grafo de programa sejam exercitados pelo menos uma vez pelo conjunto de casos de teste, ou seja, que cada comando do programa seja executado pelo menos uma vez;

- Todos-Arcos: requer que cada aresta do grafo de programa seja exercitada pelo menos uma vez, ou seja, que toda transferência de controle do programa seja executada ao menos uma vez pelo conjunto de casos de teste. É o critério mais utilizado dentre os critérios baseados em fluxo de controle;

- Todos-Caminhos: requer que todos os caminhos possíveis do programa sejam executados ao menos uma vez, ou seja, todas as combinações de transferência de controle devem ser executadas.

Rapps e Weyuker (1985) apontam alguns problemas relacionados aos critérios de fluxo de controle. Mesmo considerando o critério mais forte, Todos-Caminhos, erros do programa 
podem não ser revelados, pois exercitar todos os caminhos não garante que todos os erros sejam identificados. Além disso, o critério Todos-Caminhos é geralmente impraticável, pois pode existir um número infinito de caminhos em programas com repetições. Outros critérios também foram definidos e são mais restritos que o critério Todos-Caminhos (Zhu et al., 1997):

- Todos-Caminhos-Completos: requer que todos os caminhos completos sejam executados no mínimo uma vez pelo conjunto de casos de teste;

- Todos-Caminhos-Simples: requer que todos os caminhos simples sejam executados no mínimo uma vez pelo conjunto de casos de teste;

- Todos-Caminhos-Livres-Laços: requer que todos os caminhos livres de laços sejam executados no mínimo uma vez pelo conjunto de casos de teste.

Zhu et al. (1997) também comentam que a complexidade dos programas pode aumentar devido à presença de comandos de repetição ou laços, que podem causar um número infinito de caminhos a serem testados. Nesse caso, critérios como o proposto por Howden (1975) para limitar o número de caminhos podem ser aplicados:

- Critério loop count-k: requer que todo laço do programa em teste seja executado no máximo $k$ vezes pelo conjunto de casos de teste, sendo $k$ um valor inteiro.

Também há critérios de fluxo de controle que exercitam as condições dos programas (Myers, 1979):

- Critério Todas-Decisões: requer que em todos os comandos de decisão de um programa, suas condiçōes sejam avaliadas com valores verdadeiro e falso.

Outros critérios da técnica estrutural exploram o fluxo de dados de programas. Esses critérios podem ser vistos como uma "ponte" entre o critério Todos-Arcos e o critério Todos-Caminhos, aumentando o rigor em relação ao primeiro, mas não a ponto de não serem praticáveis como o segundo.

Os critérios de fluxo de dados associam ao grafo de programa informações sobre o fluxo de dados do programa, explorando as associações entre pontos do programa em que é atribuído um valor a uma variável (definição da variável) e pontos em que esse valor é utilizado (uso ou referência da variável). Esse novo grafo é denominado grafo def-uso (Rapps e Weyuker, 1985). Uma variável é definida em um nó $n$ quando um valor é atribuído a ela ou em uma operação de leitura. Já o uso de uma variável pode ser de duas formas: uso predicativo (p-uso) ou uso-computacional (c-uso). Um uso predicativo é caracterizado quando o valor da variável é utilizado para decidir um desvio de fluxo de controle, ou seja, o valor da variável é utilizado em um predicado ou condição. Um uso computacional ocorre quando o valor da variável é utilizado para a realização de alguma computação. 
Com base nas associações entre definições e usos de variáveis, os critérios de fluxo de dados determinam os caminhos a serem exercitados. Um caminho é denominado livre de definição em relação a uma variável $x$ quando não há definição de $x$ em nenhum outro nó deste caminho, exceto no primeiro e último nós. Dentre esses critérios, podem-se citar os critérios de Rapps e Weyuker (1985) e de Maldonado (1991). Alguns dos critérios de fluxo de dados definidos por Rapps e Weyuker (1985) são:

- Todas-Defs: requer que toda definição de uma variável seja exercitada ao menos uma vez, ou por um uso computacional ou por um uso predicativo;

- Todos-Usos: requer que todas as associações entre uma definição de uma variável e seus usos, seja predicativo ou computacional, sejam executadas por pelo menos um caminho livre de definição;

- Todos-p-usos: requer que todas as associações entre uma definição de uma variável e seus usos predicativos sejam exercitadas por pelo menos um caminho livre de definição.

Maldonado (1991) define os critérios Potenciais Usos, em que os elementos requeridos são caracterizados independentemente de existir um uso explícito de uma variável referente a uma determinada definição. Dessa forma, se um uso associado a uma definição de variável pode existir (caracterizando um potencial uso), uma potencial associação entre a definição e o potencial uso é identificada e requerida. Para os critérios Potenciais Usos, o grafo Def é definido, sendo uma restrição do grafo def-uso, que associa a cada nó informações sobre as definiçōes que ocorrem nesses nós. Um potencial-du-caminho, em relação à variável $x$ definidà em $n_{1}$, é um caminho livre de definiçãa $\left(n_{1}, \ldots, n_{j}, n_{k}\right)$ com relação a $x$ do nó $n_{1}$ para o nó $n_{k}$ e para o arco $\left(n_{j}, n_{k}\right)$, e o caminho $\left(n_{1}, \ldots, n_{j}\right)$ é um caminho livre de laço.

Alguns critérios Potenciais Usos são definidos:

- Todos-Potenciais-Usos: requer que todas as potenciais associações existentes entre uma definição de uma variável e seus potenciais usos (p-usos ou c-usos) sejam exercitadas por pelo menos um caminho livre de definição da variável;

- Todos-Potenciais-Du-Caminhos: requer que todos os potenciais-du-caminhos que associam todas as definições de variáveis a todos os nós e arcos possíveis de serem alcançados a partir dessa definição, sejam exercitados.

Algumas pesquisas têm estendido os conceitos estabelecidos para o teste estrutural em nível de unidade, para o teste de integração. Podem-se citar, por exemplo, o trabalho de Harrold e Soffa (1991) e de Vilela et al. (1998). Harrold e Soffa (1991) propõem uma técnica para determinar as estruturas de definição-uso interprocedimentais que permite a aplicação dos critérios de fluxo de dados no nível de integração. Já Vilela et al. (1998) propõem estender os critérios Potenciais-Usos para o teste de integração. 
Um problema relacionado ao teste estrutural é a impossibilidade de se determinar automaticamente se um caminho é ou não executável, ou seja, se existe um conjunto de dados de entrada que executam esse caminho (Weyuker, 1979a,b).

No contexto de especificações, observa-se o estabelecimento de critérios de geração de sequiências de teste baseados em Máquinas de Estados Finitos (Chow, 1978; Fujiwara et al., 1991; Gonenc, 1970; Sabnani e Dahbura, 1985, 1988). Os métodos utilizados exploram principalmente erros de transferência e de transições (Bourhfir et al., 1996), enfatizando o aspecto de controle. No entanto, para aplicar esses métodos é necessário que a máquina satisfaça algumas propriedades, o que nem sempre acontece:

- minimalidade: quando não há nenhum par de estados equivalentes. Dois estados $s_{i}$ e $s_{j}$ são equivalentes se produzem saídas idênticas quando exercitados por qualquer seqüência de entrada; caso contrário são considerados estados distinguíveis. $s_{i}$ e $s_{j}$ podem ou não pertencer à mesma máquina;

- especificação completa: para cada estado existe uma transição para cada símbolo de entrada;

- determinismo: para cada estado e para cada símbolo de entrada, existe uma única transição definida;

- conectividade forte: para todo par de estados $\left(s_{i}, s_{j}\right)$ existe uma sequiência de símbolos de entrada tal que essa seqüência leva a máquina do estado $s_{i}$ para o estado $s_{j}$.

Esses métodos são: Transition Tour (TT) (Naito e Tsunoyama, 1981), Distinguishing Sequence (DS) (Gonenc, 1970), Characterizing Set (W) (Chow, 1978; Sidhu e Leung, 1989), Unique Input/Output Sequence (UIO) (Sabnani e Dahbura, 1985, 1988) e Partial W:Method (Wp) (Fujiwara et al., 1991). Como a parte de dados não é considerada pelas MEFs, muitas vezes é mais adequada a utilização de Máquinas de Estados Finitos Estendidas. Os métodos propostos para MEFs porém, não são adequados para as MEFEs, pois a parte de dados também precisa ser testada. Outros métodos foram então propostos para a geração de casos de teste a partir de especificações baseadas em MEFEs, usando técnicas de fluxo de dados (Bourhfir et al., 1996; Huang et al., 1995; Martins et al., 2000; Sarikaya e Bochmann, 1986; Ural e Yang, 1991).

Martins et al. (2000) apresentam uma estratégia para desenvolver entradas de teste para especificações baseadas em MEFEs, que combinando diferentes métodos de teste, como teste de transição, teste baseado em sintaxe e teste de equivalência, possibilita a geração de casos de teste que cobrem tanto a parte de controle quanto a parte de dados de uma especificação de protocolo de comunicação. A aplicação da estratégia proposta é apoiada pela ferramenta ConData. Bourhfir et al. (1996) apresentam uma revisão de métodos de geração de teste existentes para MEFs e MEFEs. É importante ressaltar que esses métodos são utilizados no contexto de teste de conformidade de protocolos de comunicação, testando portanto a implementação e não a especificação. 
Os métodos de geração de seqüências de teste existentes para MEFs e MEFEs porém, não exploram muitas das características intrínsecas de outras técnicas de especificação, como Statecharts, Estelle e SDL. Essas técnicas têm seu comportamento baseado em extensões de MEFs, mas agregam outras características que os métodos tradicionais de teste para MEFs e MEFEs não são capazes de explorar. Apenas seus componentes básicos podem ser testados com relação a tais métodos, de forma que outros métodos devem ser utilizados para melhor testar as características particulares de cada técnica de especificação.

Alguns métodos foram propostos para a geração de casos de teste de especificações Statecharts (Bogdanov e Holcombe, 2001; Hong et al., 2000; Souza et al., 2000c). Bogdanov e Holcombe (2001) apresentam um método de teste para sistemas de controle aéreo especificados em Statecharts. Este método se concentra em testar cada transição, verificando se o estado do sistema alcançado pela transição é o mesmo que foi especificado. Para a geração de casos de teste, a especificação deve ser minimal e a implementação deve ter um número de estados limitados. Já Hong et al. (2000) propuseram um método para geração de sequências de teste, em que o statechart é transformado em um grafo de fluxo, modelando dessa forma o fluxo de dados e de controle no statechart. Este método na verdade transforma o statechart em uma MEFE e a partir desta é gerado um grafo de fluxo. Ao grafo de fluxo são aplicadas as técnicas de seleção de seqüências de teste baseadas no fluxo de dados.

Souza et al. (2000c) propuseram a família de critérios de cobertura FCCS - Família de Critérios de Cobertura para Statecharts, que fornece medidas de cobertura de teste por meio da verificação da satisfação dos requisitos do sistema pela especificação, além de permitir a avaliação das seqüências de teste geradas por simulação, contribuindo para melhorar a qualidade da atividade de teste de especificações Statecharts. A aplicação desses critérios é feita usando-se a árvore de alcançabilidade definida para Statecharts (Masiero et al., 1994). A árvore de alcançabilidade mostra os possíveis estados e caminhos - sequências de configurações - que o sistema pode ter.

Algumas observações podem ser feitas sobre os trabalhos de Hong et al. (2000) e Souza et al. (2000c). Ambos utilizam uma representação de statecharts para gerar casos de teste. No caso de Hong et al. (2000), o statechart é transformado em uma MEFE, que não representa as estruturas hierárquicas e de concorrência entre os estados e o mecanismo de broadcasting, características da técnica Statecharts. Os autores salientam que a vantagem de transformar o statechart em uma MEFE é que os critérios de teste existentes para MEFEs podem ser aplicados, ou seja, também podem ser explorados critérios de fluxo de dados. A idéia é usar as configurações do statechart como os estados da MEFE e as possíveis execuções do statechart como as transições da MEFE. Dependendo do statechart porém, essa transformação pode resultar numa MEFE complexa, pois essa transformação é exponencial, como os autores mesmo afirmam, apesar de os valores das variáveis não serem expandidos. Souza et al. (2000c) utilizam a árvore de alcançabilidade para representar o statechart, e que, similarmente, é baseada nas configurações e nas possiveis execuções do statechart. A 
árvore de alcançabilidade é construída utilizando-se algumas técnicas de redução para evitar o problema de explosão de estados. A árvore de alcançabilidade porém, não representa o mecanismo de broadcasting e as variáveis da especificação, de forma que não é possível avaliar o fluxo de dados na especificação. Outro ponto a ser observado é que no trabalho de Hong et al. (2000), os casos de teste gerados pelos critérios são aplicados no teste de conformidade, enquanto que os casos de teste gerados pelos critérios de fluxo de controle de Souza et al. $(2000 \mathrm{c})$, são aplicados no teste de especificação, podendo também ser empregados no teste de conformidade.

Para a técnica Estelle, Souza (2000) faz uma revisão de alguns métodos para geração de sequiências de teste baseados em fluxo de dados e de controle. Um desses trabalhos é o de Ural e Yang (1991), que definem o critério input-output dataftow chain (IO-df-chain), um critério de fluxo de dados que requer que todas as associações entre cada saída e as entradas que a influenciam sejam exercitadas. Esse critério, assim como outros, necessitam que a especificação Estelle seja transformada em um modelo intermediário, uma forma equivalente de representação denominada de forma normal e, a partir dessa forma normal, são gerados os grafos de fluxo de dados e de controle. De acordo com Souza (2000), as técnicas de geração de sequiências de teste, em geral, restringem algumas características de Estelle, principalmente as relacionadas ao paralelismo dos componentes e às cláusulas das transições.

Com base na FCCS proposta para Statecharts, Souza et al. (2000c) propôs a família de critérios FCCE - Família de Critérios de Cobertura para Estelle -, que possuem algumas vantagens em relação aos métodos de geração de sequências de teste existentes, tais como: não fazem restrições quanto às características de Estelle; podem ser aplicados diretamente na especificação Estelle, não necessitando que o modelo esteja na forma normal, e; fornecem uma medida quantitativa da cobertura de teste da especificação obtida por um conjunto de seqüências de teste.

A FCCE também explora aspectos de fluxo de controle no teste de especificações Estelle, permitindo a validação de aspectos de comunicação entre os módulos, aspectos dinâmicos e possíveis intercalações entre as transições disparadas, de acordo com o tipo de sincronismo do sistema especificado em Estelle. Os requisitos de teste que exploram esses aspectos sāo gerados a partir da definição de um modelo de árvore de alcançabilidade para Estelle, com base em sua semântica e considerando-se algumas técnicas de redução para evitar o problema de explosão de estados. Similarmente às famílias FCCS e FCCE, Simão et al. (2003) propuseram uma família de critérios de cobertura para Redes de Petri Coloridas, a CPNCCF - Coloured Petri Nets Coverage Criteria Family, que deriva seus requisitos a partir de um grafo de ocorrência. Um grafo de ocorrência representa o comportamento de uma Rede de Petri Colorida, modelando os possíveis caminhos (seqüências de marcações) que podem ocorrer em uma Rede de Petri Colorida.

Souza et al. e Simão et al. consideraram os trabalhos de Taylor et al. (1992) e Chung et al. (1996), que propuseram a aplicação de critérios estruturais para progra- 
mas concorrentes. Os critérios definidos por Taylor et al. (1992) têm como base os conceitos de estados concorrentes e grafo de concorrência, que modela o comportamento do programa em execução e as possíveis sincronizações existentes. Cinco critérios foram propostos por Taylor et al. (1992): all-concurrency-paths, all-proper-cc-histories, all-edges-between-cc-states, all-cc-states e all-possible-rendezvous. No trabalho de Chung et al. (1996) foram definidos quatro critérios de teste para programas concorrentes escritos em Ada: all-entry-call, all-possible-entry-acceptance, all-entry-call-permutation e all-entry-call-dependency-permutation. Esses critérios exploram os aspectos de comunicação e sincronização entre as tarefas no programa que acontecem por meio do mecanismo de rendezvous ${ }^{3}$.

Para reduzir o custo de cobertura de teste, Agrawal (1994) propõe uma técnica para encontrar subconjuntos de nós ou arcos de um grafo de programa que, quando exercitados por um conjunto de teste, garantem que todos os outros nós ou arcos do grafo de programa sejam também exercitados. Essa técnica é suscintamente apresentada a seguir.

\section{Dominadores em um Grafo de Programa}

Em sua abordagem, Agrawal (1994) define o conceito de superbloco em um grafo de programa. Um superbloco consiste de um ou mais blocos com a propriedade de que, quando um bloco é executado por uma entrada, todos os outros blocos no superbloco devem ser exercitados pela mesma entrada. Uma relação de "dominadores" entre os superblocos é utilizada para identificar um subconjunto de superblocos cuja cobertura implica a cobertura de todos os superblocos e, por consequência, de todos os blocos do grafo. Analogamente, pode ser identificado um superconjunto de arcos. Essa abordagem visa a reduzir o número de casos de teste para obter a cobertura desejada.

Para estabelecer um superbloco são utilizadas duas relações entre blocos, "pré-domina" e "pós-domina". Um nó $n_{1}$ pré-domina um nó $n_{3}$ em um grafo, se todo caminho que parte do nó de entrada do grafo para o nó $n_{3}$, contém $n_{1}$. Um nó $n_{2}$ pós-domina um nó $n_{3} \mathrm{em}$ um grafo, se todo caīninho que parte do nó $n_{3}$ para o nó de saída do grafo, contém $n_{2}$. Se $n_{1}$ pré-domina um nó $n_{3}$ e $n_{3}$ é coberto por um caso de teste, então $n_{1}$ também deve ser coberto pelo mesmo caso de teste. O mesmo é válido se $n_{2}$ pós-domina $n_{3}$ e $n_{3}$ é coberto por um caso de teste, então $n_{2}$ também deve ser coberto pelo mesmo caso de teste. A partir dessas definições, pode-se dizer que um nó $n$ domina um nó $m$ em um grafo de programa, se todo caminho que parte do nó de entrada do grafo para o nó de saída, passando por $m$, passa também por $n$. Ou seja, $n$ domina $m$ se e somente se $n$ pré- ou pós-domina $m$.

Para ilustrar como o conceito de dominadores é aplicado, observa-se o grafo da Figura 2.4. Para alcançar o bloco 15 nesse grafo, é necessário passar pelos blocos 1, 2, 4,7 e 12. Portanto,

\footnotetext{
${ }^{3}$ Quando a troca de mensagem entre dois processos é feita por uma sincronização de ambos, seguida pela troca de informaçōes.
} 
o bloco 15 é dominado por tais blocos e, dessa forma, se uma execução passa pelo bloco 15 , essa mesma execução passa pelos blocos 1, 2, 4, 7 e 12, de forma a cobrir esses requisitos, se ainda não tinham sido cobertos.

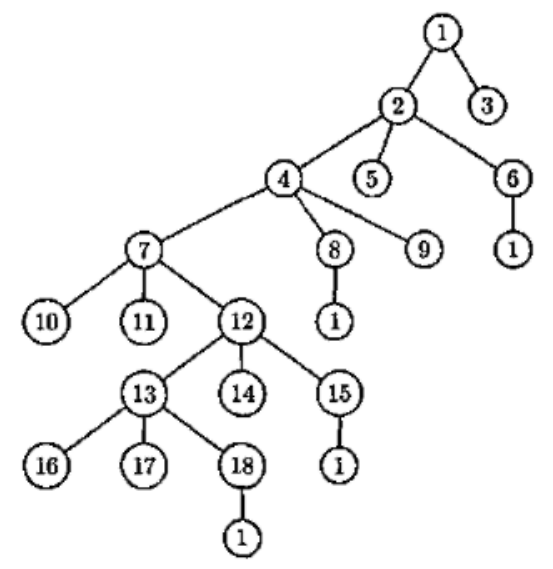

Figura 2.4: Exemplo de Grafo de Fluxo de Controle

Agrawal (1994) também propõe a atribuição de pesos aos blocos para auxiliar a geração de casos de teste. O peso de um bloco é definido pelo número de blocos que o dominam, mais ele mesmo. Assim, cobrir primeiro um bloco com maior peso implica um número máximo de blocos a serem cobertos. Após a cobertura desses blocos, os mesmos são marcados como cobertos e o peso dos blocos ainda não cobertos são recalculados e o bloco com maior peso deve ser selecionado para ser coberto. Esse processo continua até que a cobertura desejável seja obtida.

Considerando que nenhum bloco da Figura 2.4 tenha sido coberto, o peso do bloco 15 é 6, pois uma execução que passa por esse bloco, passa por outros 5 blocos (além dele mesmo). Resultados de experimentos conduzidos por Agrawal (1994) utilizando informaçōes sobre os dominadores, indicam que, na média, casos de teste gerados para cobrir $29 \%$ dos blocos e $32 \%$ dos arcos obtiveram cobertura de $100 \%$ dos blocos e arcos, respectivamente.

\subsubsection{Técnica Baseada em Erros}

Nessa técnica utilizam-se informações sobre os erros mais freqüentes no processo de desenvolvimento de software e sobre tipos específicos de erros que se desejam localizar. Exemplos de critérios dessa técnica são Análise de Mutantes e Semeadura de Erros. O critério Análise de Mutantes, pela relevância no contexto deste trabalho, é apresentado com mais detalhes na Seção 2.4.1.3.1. O critério Semeadura de Erros é descrito a seguir: 
- Semeadura de Erros: neste critério, erros são inseridos artificialmente no programa e durante o teste, dentre os erros encontrados, verificam-se quais são erros naturais e quais são artificiais. A razão dos erros artificiais pelos naturais indica, teoricamente, o número de erros naturais ainda existentes no programa. Alguns pontos podem ser questionados em relação a esse critério. Estatisticamente, o tamanho do programa é um deles. Conseqüentemente, o tamanho da razão calculada é outro fator a ser questionado (Budd, 1981). Além disso, para aplicar esse critério considera-se que os erros sejam distribuídos uniformemente no programa, o que não acontece na prática. Pressman (2001) afirma que uma região que possui um erro tem grande probabilidade de possuir outros erros. Um outro ponto é que alguns erros artificiais podem interagir com os naturais, fazendo com que os naturais sejam omitidos pelos semeados.

\subsection{Análise de Mutantes}

A Análise de Mutantes surgiu na década de 70 na Yale University e Georgia Institute of Technology (DeMillo et al., 1978) e visa a testar a corretitude de um programa por meio da geração de programas mutantes, que são programas criados com pequenas alterações sintáticas, e da construção de casos de teste capazes de diferenciar o comportamento do programa original e dos seus mutantes (DeMillo, 1980). As alterações sintáticas feitas no programa para gerar os mutantes são realizadas com base em um conjunto de operadores de mutação, sendo que cada operador pode ter associado um tipo ou classe de erros que se pretende revelar no programa.

Se o conjunto $M$ de mutantes modelasse todos os erros possíveis em um programa $P$, um conjunto $T$ de casos de teste adequado a $M$ poderia ser utilizado para provar que o programa não possui erros e, conseqüentemente, provar que $P$ está correto. No entanto, o conjunto de mutantes seria infinito e a adequação de $T$ não poderia ser avaliada. Portanto, para tornar factível a tarefa de avaliação da adequação, $M$ deve ser finito, escolhendo-se apenas alguns tipos de erros. A escolha de quais erros modelar é um dos passos mais importantes para a eficácia da aplicação da Análise de Mutantes. Os mutantes devem ser projetados de forma a encontrarem o maior número de erros com o menor custo de aplicação, ou seja, com o menor número de mutantes gerados. Duas hipóteses são utilizadas para escolher o conjunto de erros modelados: Hipótese do Programador Competente (Competent Programmer Hypothesis) e Hipótese do Efeito de Acoplamento (Coupling Effect) (DeMillo et al., 1978).

A primeira hipótese afirma que um programa produzido por um programador competente, ou está correto ou próximo do correto. Dessa forma, o conjunto de erros que devem ser modelados pode ser reduzido apenas aos erros tipicamente cometidos. A segunda hipótese considera que dados de teste que são capazes de distinguir os mutantes que diferem do programa correto apenas em erros simples, são tão sensíveis que também distinguem, de forma implícita, os mutantes com erros mais complexos. Um erro é simples quando apenas 
uma alteração sintática é suficiente para criar uma versão correta do programa. Um erro é complexo quando necessita de várias alteraçōes (um erro complexo pode ser considerado como uma composição de erros simples). Com base nessas duas hipóteses, os erros modelados podem ser restringidos a erros simples. Para modelar os erros, são criados os operadores de mutação. Um operador de mutação é uma função que, a partir de um programa $P$, gera um conjunto de programas semelhantes a $P$, mas que possuem o erro modelado. Como o mesmo tipo de erro pode ocorrer em diferentes posiçōes do programa, um operador gera um conjunto de programas mutantes, sendo um mutante para cada ponto onde a alteração pode ser aplicada.

Dado um caso de teste, ele revelará um erro se o resultado obtido com a execução do programa original for incorreto. Se não revelar um erro no programa original, o caso de teste é utilizado para executar o conjunto de mutantes. Se um mutante apresenta um resultado incorreto (diferente do programa original), então diz-se que ele foi morto pelo caso de teste, ou que o caso de teste matou o mutante. Uma vez que o programa mutante está morto, pode-se concluir que o programa original não possui o erro modelado por esse mutante. Se um caso de teste não matar um mutante, duas situações podem estar ocorrendo: ou o mutante é equivalente ao programa original (e nenhum caso de teste poderá matá-lo) ou o caso de teste não foi adequado para revelar o erro no mutante. A determinação dos mutantes equivalentes é obtida com a intervenção do testador, que decide se o mutante é equivalente, ou então a decisão é tomada, quando possível, por heurísticas em um processo automatizado. Se o caso de teste não foi adequado para revelar o erro, um novo caso de teste deve ser criado para matar o mutante em questão. Um conjunto $T$ de casos de teste é dito adequado a um programa $P$ e a um conjunto $M$ de mutantes se, para cada mutante $m \in M$, não equivalente a $P$, existir um caso de teste $t \in T$ tal que $t$ mata $m$ com relação a $P$.

A Análise de Mutantes fornece uma medida do nível de confiança na adequação dos casos de teste analisados (DeMillo, 1980). É possível avaliar, depois da execução dos mutantes, a adequação dos casos de teste pelo cálculo do escore de mutação, que relaciona o número de mutantes gerados com o número de mutantes mortos, fornecendo dessa maneira maior confiabilidade na atividade de teste e, conseqüentemente, maior qualidade do programa testado. Considerando $P$ o programa sendo testado e $T$ o conjunto de casos de teste, o escore de mutação $m s(P, T)$ é definido como:

$$
m s(P, T)=\frac{D M(P, T)}{M(P)-E M(P)}
$$

sendo,

$D M(P, T)$ : número de mutantes mortos pelos casos de teste em $T$

$M(P)$ : número total de mutantes gerados

$E M(P)$ : número de mutantes gerados equivalentes a $P$ 
Quatro etapas caracterizam a Análise de Mutantes:

1. Execução do programa original com base em um conjunto de casos de teste: nessa etapa, o programa original é executado utilizando-se um conjunto de casos de teste e verifica-se se o programa produz os resultados esperados para esse conjunto. Caso um erro seja revelado, o programa deve ser corrigido e a atividade de teste é retomada posteriormente;

2. Geração de mutantes: nesse passo, a vizinhança de programas mutantes é construída com base no conjunto de operadores de mutação. Essa vizinhança deve ser finita de modo que a atividade de teste seja praticável. Assim, a escolha e determinação do conjunto de operadores de mutação é fundamental, sendo o ponto chave deste critério. O sucesso da aplicação do critério depende da determinação dessa vizinhança, que deve ser abrangente o suficiente para que possa revelar o maior número de erros possível e ter uma cardinalidade pequena para que o problema de gerar e verificar o comportamento dos mutantes seja tratável;

3. Execução dos mutantes: nesse passo, todos os mutantes gerados devem ser executados com o mesmo conjunto de casos de teste utilizados na primeira etapa. Se um mutante apresenta um resultado diferente do programa original, considera-se este mutante morto. Se o mutante apresenta resultados idênticos aos do programa sendo testado, ele continua vivo. Nesse caso ou o conjunto de casos de teste não contém casos capazes de distinguir o mutante e o programa testado e novos casos de teste devem ser adicionados para matar o mutante, ou ambos executam as mesmas funções, sendo portanto, equivalentes;

4. Análise dos mutantes: nesse passo, o testador deve decidir sobre a continuidade ou não da atividade de teste por meio da avaliação do escore de mutação. Se julgar que a atividade de teste pode ser finalizada, o conjunto de casos de teste é considerado um bom conjunto para o programa em questão. Se for necessário continuar o teste, os mutantes que permaneceram vivos devem ser analisados para que se determine sua equivalência ou não. Se forem equivalentes, esses mutantes são descartados, pois nenhum caso de teste será capaz de distingui-los. Porém, se o mutante não for equivalente, então é possível criar um caso de teste capaz de matá-lo. Melhora-se, dessa forma, o conjunto de casos de teste inicial e repetem-se os passos 1, 3 e 4 até que se obtenha um bom conjunto de casos de teste, isto é, que o escore de mutação esteja o mais próximo possível de 1 , indicando que o programa sendo testado não contém a maioria dos erros retratados nos mutantes gerados.

Com o objetivo de explorar a Análise de Mutantes no contexto de teste de integração, Delamaro (1997) definiu o critério Mutação de Interface para explorar erros de interface relacionados às conexöes entre as unidades de programas escritos em C (Delamaro e Maldonado, 
1999; Delamaro et al., 2001a,b). Com esse critério, modelam-se os erros simples de integração que podem ocorrer na passagem de dados, no uso de variáveis globais ou no comando return do módulo chamado. Como os operadores de Mutação de Interface estão relacionados a uma conexão entre duas unidades, o critério é aplicado ponto-a-ponto, testando cada conexão existente entre as unidades. Vincenzi et al. (2001) conduziram alguns estudos que indicam o aspecto complementar dos critérios Análise de Mutantes e Mutação de Interface, de modo que se forem aplicados em conjunto podem aumentar a qualidade da atividade de teste. Para auxiliar a aplicação desses critérios, os autores propõem uma estratégia de teste incremental. A Análise de Mutantes tem sido também explorada em outros contextos, como no teste de programas orientados a objetos. Vincenzi (2004) discute as várias abordagens exploradas.

O critério Análise de Mutantes também tem sido utilizado em nível de especificação (Ammann e Black, 1999; Ammann et al., 1998; Black et al., 2000a; Bousquet et al., 2000; Fabbri et al., 1994b, 1995, 1999; Kovács et al., 2003; Maldonado et al., 1998a; Probert e Guo, 1991; Simão, 2000; Souza et al., 2000a,b).

Probert e Guo (1991) propõem a técnica de teste de especificações Estelle E-MPT (Estelle-directed Mutation-based Protocol Testing). Com essa técnica, na verdade, validam-se as Máquinas de Estados Finitos Estendidas definidas pela especificação. Os mutantes são gerados a partir da especificação e, por meio de um compilador para Estelle, a especificação original e as especificações mutantes são traduzidas em programas na linguagem C. Como o compilador não gera códigos completos, os programas gerados devem ser completados manualmente. A análise dos mutantes é feita executando-se os casos de teste com as implementações (da especificação original e das especificações mutantes) e comparando-se os resultados obtidos. Assim, no trabalho de Probert e Guo (1991) valida-se somente o comportamento de cada módulo da especificação.

Ammann et al. utilizam a Análise de Mutantes e a técnica model checking para produzir automaticamente casos de teste a partir de especificaçoóos baseadas em Máquinas de Estados Finitos (Ammann et al., 1998) e para medir a cobertura de teste (Ammann e Black, 1999). No primeiro caso, cada transição da máquina de estado é representada como uma cláusula em lógica temporal. Para gerar os testes, os operadores de mutação são aplicados a todas essas cláusulas, resultando em um conjunto de cláusulas mutantes. O model checker compara a especificação original com os mutantes. Com base nas cláusulas inconsistentes, o model checker produz, se possível, os casos de teste. No segundo caso, para medir a cobertura de um conjunto de teste, cada caso de teste é transformado em uma MEF que representa a seqüência de execução daquele caso de teste. Cada MEF é comparada pelo model checker ao conjunto de mutantes produzidos. A métrica de cobertura de adequação à mutação utilizada é o número de mutantes mortos dividido pelo número total de mutantes gerados. Black et al. (2000b) refinaram o conjunto de operadores definidos por Ammann et al. (1998) e propuseram novos operadores para serem aplicados neste contexto. 
No experimento de Bousquet et al. (2000), o critério tem sido aplicado no teste de conformidade de um protocolo de conferência entre usuários, verificando se a implementação do sistema está de acordo com sua especificação, sendo que nesse experimento, a especificação do protocolo foi feita na linguagem formal Lotos.

O grupo de Engenharia de Software do ICMC-USP/São Carlos também tem investigado a Análise de Mutantes no teste de especificações, explorando o teste de aspectos comportamentais de sistemas reativos (Fabbri et al., 1997b; Maldonado et al., 1994, 1998a), considerando-se as técnicas: Máquinas de Estados Finitos (Fabbri et al., 1994b), Statecharts (Fabbri et al., 1997a, 1999) e Redes de Petri (Fabbri et al., 1994a, 1995; Simão, 2000). Neste caso, a especificação sendo testada é a base para a geração de mutantes. Os mutantes são gerados pela aplicação de operadores de mutação definidos de forma a modelar os erros típicos relacionados à técnica de especificação utilizada. Em seguida, a simulação de cada mutante e a comparação dos resultados obtidos com os da especificação em teste contribuem para a análise da adequação do teste e, conseqüentemente, da corretitude da especificação.

Nessa mesma linha de trabalho, Souza et al. (2000a,b) investigaram a aplicação da Análise de Mutantes no teste de especificações Estelle, diferenciando-se do trabalho de Probert e Guo (1991) por apresentar um conjunto de operadores de mutação mais abrangente, que exploram erros que podem ser cometidos na hierarquia dos módulos da especificação Estelle, na comunicação entre os módulos e nos aspectos estruturais da especificação. Dessa forma três classes de operadores de mutação foram definidas: Mutação nos Módulos, Mutação de Interface e Mutação na Estrutura. Para explorar os aspectos de interface, Souza et al. $(2000 \mathrm{a}, \mathrm{b})$ se inspiraram no trabalho de trabalho de Delamaro, que definiu o critério Mutação de Interface para o teste de integração (Delamaro, 1997; Delamaro e Maldonado, 1999).

No escopo de um trabalho de doutorado do grupo também tem sido investigada a aplicação da Análise de Mutantes no teste de especificações baseadas em Redes de Petri Coloridas (Simão, 2002).

As principais diferenças entre os trabalhos desenvolvidos no ICMC-USP/São Carlos e os demais trabalhos, em relação à aplicação da Análise de Mutantes em nível de especificação, são:

- no trabalho de Bousquet et al. (2000), os casos de teste são gerados em nível de especificação, mas são aplicados no teste da implementação; portanto, o critério é aplicado no teste de conformidade e não há informação sobre a análise de cobertura da especificação;

- no trabalho de Probert e Guo (1991), testa-se somente o aspecto comportamental de cada módulo da especificação. Além disso, a especificação e seus mutantes são transformados em programas C, para posterior análise dos mutantes. Durante essa transformação, em que há interferência humana para completar os códigos, novos erros podem ser introduzidos, comprometendo a aplicação do teste de mutação; 
- no trabalhos de Ammann et al. (1998) e Black et al. (2000a), as especificações também são transformadas em cláusulas em lógica temporal e a mutação é aplicada a essas cláusulas e não diretamente na especificação em MEF;

- nos trabalhos do grupo de Engenharia de Software do ICMC-USP/São Carlos, o critério Análise de Mutantes é aplicado no teste de especificações propriamente dito, ou seja, os casos de teste são derivados da especificação e aplicados no teste da mesma, fornecendo informações sobre a cobertura de teste da especificação. Certamente, esses casos de teste poderiam também ser posteriormente aplicados no teste da implementação.

Uma ressalva quanto à aplicabilidade do critério Análise de Mutantes é em relação ao número de mutantes gerados. Mesmo em programas pequenos esse número pode ser proibitivo, uma vez que todos os mutantes devem ser compilados e executados e os que permanecerem vivos devem ser analisados pelo testador para que se decida sobre sua equivalência. Decidir sobre a equivalência dos mutantes e, no caso dos que não são, gerar casos de teste que sejam capazes de matá-los, são tarefas onerosas e que necessitam da intervenção do testador. Para diminuir os custos dessas atividades, várias alternativas foram propostas para o teste de programas:

- mutação seletiva aleatória (Randomly Selected Mutation) (Acree et al., 1979): examina uma pequena porcentagem de mutantes, selecionados aleatoriamente, de cada operador de mutação, ignorando os demais;

- mutação restrita (Constrained Mutation) (Mathur, 1991; Wong et al., 1994a): seleciona intuitivamente, com base na experiência do testador, alguns operadores de mutação para a geração dos mutantes, considerando os erros que se desejam revelar;

- mutação seletiva (Selective Mutation) (Offutt et al., 1993): não se aplicam os operadores de mutação que geram um grande número de mutantes, pois, segundo Offutt et al. (1993), esses operadores de mutação não contribuem para aumentar a eficácia do conjunto de casos de teste.

Outra abordagem é a definição de um conjunto essencial de operadores de mutação (Barbosa et al., 2001; Offutt et al., 19̄96a; Vincenzi et al., 1999). Para a definição desse conjunto essencial são coletadas estatísticas sobre cada operador de mutação, a partir dos resultados de experimentos empíricos. Utilizando essas informações coletadas, foram definidos conjuntos essenciais de operadores de mutação para a linguagem Fortran (Offutt et al., 1996a) e para a linguagem C, em nível de unidade (Barbosa et al., 2001) e de integração (Vincenzi et al., 1999).

Algumas pesquisas também investigaram a diminuição do custo de aplicação da Análise de Mutantes pela automatização do processo de geração de casos de teste e determinação 
dos mutantes equivalentes (DeMillo e Offutt, 1991; Offutt e Pan, 1997), pois dessa forma o número de mutantes a serem analisados pelo testador é menor. DeMillo e Offutt (1991) propuseram a técnica Teste Baseado em Restrição (Constraint Based Testing - CBT) que gera casos de teste para matar os mutantes usando restrições algébricas. Para utilizar a técnica CB'T, foi implementado o sistema Godzila (DeMillo e Offutt, 1993), que gera os dados de teste para matar os mutantes gerados pela ferramenta Mothra. Seguindo essa mesma linha, mas em nível de especificação, Simão e Maldonado (2000a) investigam a diminuição do custo de aplicação desse critério para Redes de Petri, com a automatização do processo de geração de casos de teste e determinação dos mutantes equivalentes. Os autores propõem um algoritmo para geração de sequiências de teste baseado em mutação para validar Redes de Petri e que, em alguns casos, identifica mutantes equivalentes. A aplicação do algoritmo em um estudo de caso reduziu o número de mutantes que devem ser analisados manualmente, pois matou mais de $83 \%$ dos mutantes gerados no pior caso e $93 \%$ na média. Além de terem sido identificados $74 \%$ dos mutantes equivalentes gerados (Simão e Maldonado, 2000a).

\subsubsection{Ferramentas de Teste}

O apoio de ferramentas propicia maior qualidade e produtividade para a atividade de teste, pois esta atividade é propensa a erros e improdutiva, se aplicada manualmente. Além disso, estudos empíricos que visem a avaliar e a comparar os diversos critérios de teste podem ser mais facilmente conduzidos se apoiados por ferramentas. Ainda, segundo Barbosa (2004), ferramentas de teste têm um papel importante no processo de ensino e treinamento de conceitos, técnicas e critérios de teste, contribuindo para a formação e capacitação de pessoal na área de teste. Geurts et al. (1998) também ressaltam a importância do desenvolvimento de ferramentas de teste de métodos formais e, em especial, ferramentas para derivação automática de teste de especificações formais.

Diante desse cenário, podem-se observar diversos esforços da comunidade científica nessa direção (Agrawal et al., 1998; Chaim, 1991; Chaim et al., 1998; Delamaro, 1997; Delamaro e Maldonado, 1996; Delamaro et al., 2000; DeMillo et al., 1988; Fonseca, 1993; Frankl e Weyuker, 1985; Horgan e Mathur, 1992; Korel e Laski, 1985; Leitão Jr., 1992; Luts, 1990; Vincenzi et al., 2003; Yano et al., 2003). Por parte da indústria, pode-se observar o esforço alocado pela Telcordia Technologies (EUA), em cooperação com o SERC/Purdue University (EUA), para o desenvolvimento do pacote $\chi$ Suds (Software Understanding System), para a visualização, teste, análise e depuração de software. Este pacote é composto por sete ferramentas: $\chi$ ATAC, $\chi$ Regress, $\chi$ Vue, $\chi$ Slice, $\chi$ Prof, $\chi$ Find e $\chi$ Diff. Dentre elas, destacam-se a ferramenta $\chi$ ATAC, que apóia a aplicação de critérios baseados em fluxo de controle e de dados no teste de programas $\mathrm{C}$, e a ferramenta $\chi$ Regress, que reduz o custo do teste de regressão (Agrawal et al., 1998; Horgan e Mathur, 1992). 
Frankl e Weyuker (1985) desenvolveram a ferramenta ASSET (A System to Select and Evaluate Tests) para apoiar a aplicação dos critérios baseados em fluxo de dados no teste de programas Pascal. Os critérios apoiados pela ferramenta são os propostos por Rapps e Weyuker $(1982,1985)$.

Como exemplo de ferramenta que apóia a aplicação da Análise de Mutantes no teste de programas pode-se citar a ferramenta Mothra (DeMillo et al., 1988), desenvolvida na Purdue University e Georgia Institute of Technology. Esta ferramenta apóia o teste de programas escritos na linguagem Fortran.

O grupo de Engenharia de Software do ICMC-USP/São Carlos tem desenvolvido uma família de ferramentas de apoio ao critério Análise de Mutantes para o teste de programas e de especificações (Maldonado et al., 2000b). Para programas escritos na linguagern $C$, têm-se as ferramentas Proteum (Delamaro, 1993; Delamaro e Maldonado, 1996), que apóia o teste de unidade, e RROTEMMIM (Delamaro et al., 2001a), que apóia o critério Mutação de Interface para o teste de integração. As ferramentas Proteum e FROTZMM/MM foram integradas no ambiente PROTZM/IM2.0 (Delamaro et al., 2000), que permite a aplicação do teste de mutação tanto em nível de unidade como de integração. Para o teste de programas SML (Standard Meta Language), tem-se a ferramenta Proteum/SML (Yano et al., 2003). Vincenzi (2004) apresenta a descrição da ferramenta Proteum/OO, para apoiar o teste de programas Java. Essa ferramenta encontra-se em desenvolvimento. Para o teste de especificações, têm-se as ferramentas: Proteum-RS/FSM, para especificações baseadas em MEFs (Fabbri et al., 1994b); Proteum-RS/ST, para especificaçōes baseadas em Statecharts(Fabbri et al., 1999; Sugeta et al., 2001); Proteum-RS/PN, para especificações baseadas em Redes de Petri (Simão et al., 2000) e Proteum/CPN, para apoiar o teste de especificações em Redes de Petri Coloridas. Essas ferramentas apóiam as principais atividades envolvidas na aplicação da Análise de Mutantes no teste de especificações. Uma ferramenta para apoiar o teste de especificações Estelle também foi especificada no trabalho de Souza (2000).

Para o desenvolvimento da Proteum/SML foi considerada uma abordagem que busca reutilizar módulos comuns em ferramentas de apoio ao teste de mutação. Dessa forma, tem-se um conjunto de módulos independentes, que são módulos que atendem às funcionalidades comuns a todas as ferramentas de apoio ao teste de mutação, independente da linguagem/especificação alvo, e um conjunto de módulos dependentes, que são responsáveis pelas funcionalidades inerentes a cada linguagem/especificaçāo alvo do teste de mutação. Sendo assim, os módulos independentes da ferramenta Proteum/CPN foram identificados e reutilizados no desenvolvimento da Proteum/SML. Com essa abordagem de desenvolvimento, procura-se facilitar a implementação de ferramentas de apoio ao teste de mutação, uma vez que apenas os módulos dependentes devem ser implementados para cada linguagem/especificação alvo. 
Outra característica das ferramentas Proteum/CPN e Proteum/SML é que são utilizadas via web, permitindo, entre outras coisas, que as sessões de teste possam ser realizadas por grupos de testadores fisicamente separados.

Além da Análise de Mutantes, outros critérios também foram apoiados por ferramentas desenvolvidas em trabalhos conduzidos no escopo deste grupo. A ferramenta PokeTool (Potential Uses Criteria Tool for Program Testing) (Chaim, 1991; Chaim et al., 1998), desenvolvida na FEEC/UNICAMP em colaboração com o ICMC-USP/São Carlos, apóia a aplicação dos critérios Potenciais-Usos (Maldonado, 1991) e também outros critérios estruturais como Todos-Nós e Todos-Arcos para o teste de programas C (Chaim, 1991; Chaim et al., 1998), Fortran (Fonseca, 1993) e Cobol (Leitão Jr., 1992). Para apoiar o teste estrutural de programas e componentes Java, foi desenvolvida a ferramenta JaBUTi (Java Bytecode Understanding and Testing) (Vincenzi et al., 2003). Para o teste de MEFs, foi desenvolvida a ferramenta MGASet (Candolo et al., 2001; Nakazato, 1995), que apóia a verificação de propriedades e a geração de seqüências de teste com os métodos DS, UIO, W e Wp.

A ferramenta Spin (Holzmann, 1997), desenvolvida pelo grupo de métodos formais e verificação da Bell Labs, suporta a verificação formal de sistemas distribuídos. Essa ferramenta utiliza a linguagem de alto nível PROMELA para especificar as descrições de sistemas. Spin verifica a consistência lógica de uma especificação e tem sido usada em projetos de sistemas tais como protocolos de comunicação de dados, sistemas operacionais, sistemas de switching e algoritmos concorrentes. Outro exemplo é a ferramenta UPPAAL (Pettersson e Larsen, 2000), que é um ambiente integrado de ferramentas para modelagem, simulação e verificação de sistemas de tempo real, desenvolvida pelo Department of Computing Systems da Uppsala University em conjunto com Basic Research in Computer Science da Aalborg University. Essa ferramenta consiste de três partes principais: uma linguagem de descrição, um simulador e um model checker. A linguagem de descrição é uma linguagem de modelagem/projeto que descreve o comportamento do sistema como redes de autômatos estendidos com relógio e variáveis de dados. O simulador é uma ferramenta de validação que permite a análise de possíveis execuções dinâmicas de um sistema durante fases iniciais de projeto e fornece um modo econômico de deteç̧ão de falhas. O model checker analisa o comportamento do sistema de modo exaustivo, verificando propriedades de alcançabilidade e invariantes pela exploração do estado-espaço do sistema, ou seja, realiza a análise de alcançabilidade em termos de estados simbólicos representados por restriçōes.

\subsubsection{Estudos Teóricos e Empíricos}

Diante da diversidade de critérios estabelecidos para o teste de programas e da dificuldade de escolher qual (ou quais) é mais adequado, a importância do estabelecimento de estratégias de teste eficazes e de baixo custo é ressaltada. Harrold (2000) destaca que essa tarefa constitui uma das principais direções para a área de teste de software, sendo fundamental a condução 
de estudos teóricos e empíricos para apoiar essa tarefa. Lai (1999) também aponta que a condução de estudos empíricos que ofereçam informações comparativas sobre os diversos critérios de teste é um dos aspectos importantes para a transferência do conhecimento obtido na academia para a indústria.

Nos estudos teóricos, têm-se avaliado os critérios de teste em termos de complexidade e da relação de inclusão entre eles (Rapps e Weyuker, 1982, 1985). A complexidade é definida como o número máximo de casos de teste requeridos, para qualquer programa, no pior caso. A relação de inclusão estabelece uma ordem parcial hierárquica entre os critérios. Um critério $C r_{1}$ inclui um critério $C r_{2}$ se, para qualquer programa $P$, todo conjunto de casos de teste $T_{1}$ adequados a $C r_{1}$, isto é, que satisfazem os requisitos de $C r_{1}$, também for adequado a $C r_{2}$. Um critério $C r_{1}$ inclui estritamente um critério $C r_{2}$ (denotado por $C r_{1} \Rightarrow C r_{2}$ ) se $C r_{1}$ inclui $C r_{2}$, mas $C r_{2}$ não inclui $C r_{1}$. Dois critérios $C r_{1}$ e $C r_{2}$ são incomparáveis se $C r_{1}$ não incluir $\mathrm{Cr}_{2}$ e nem $\mathrm{Cr}_{2}$ incluir $C r_{1}$. Com a condução de estudos teóricos e empíricos, pode-se comparar e analisar os critérios de teste considerando principalmente o custo, que é o esforço necessário para aplicar o critério ${ }^{4}$; a eficácia, que é a capacidade do critério em revelar um maior número de erros em relação ao outro; e o strength, que é a probabilidade de satisfazer um critério tendo satisfeito outro (Mathur e Wong, 1994). Dessa forma, com os resultados desses estudos, busca-se fornecer subsídios para que os critérios de teste possam ser aplicados na prática.

Alguns trabalhos têm investigado a relação de inclusão entre os critérios de fluxo de controle, de dados e baseados em mutação (Clarke et al., 1989; Delamaro, 1997; Frankl e Weyuker, 1988; Maldonado, 1991; Rapps e Weyuker, 1985; Vincenzi et al., 2001) e estabelecem uma hierarquia entre esses critérios. Observa-se, por exemplo, que o critério Todos-Arcos inclui estritamente o critério Todos-Nós, ou seja, um conjunto de teste adequado ao critério Todos-Arcos também é adequado a Todos-Nós porém, um conjunto de teste adequado a Todos-Nós não é necessariamente adequado a Todos-Arcos. O critério Todos-Usos inclui estritamente os critérios Todas-Defs e Todos-Arcos. Já os critérios Todas-Defs e Todos-Arcos são incomparáveis, ou seja, um conjunto de teste que satỉsfaz Todas-Defs não satisfaz Todos-Arcos e vice-e-versa. Em relação aos critérios Potenciais-Usos, Maldonado (1991) observou que nenhum critério de teste os inclui. Critérios estruturais e de mutação são, em geral, incomparáveis, devendo ser aplicados em conjunto, tanto em nível de unidade como de integração.

A relação de inclusão tem sido utilizada para comparar os critérios quanto ao custo e strength, mas não há um consenso quanto à sua utilização em relação à eficácia em revelar erros. Alguns pesquisadores (Frankl e Weyuker, 1993a; Hamlet e Taylor, 1990; Ntafos, 1988; Weyuker e Jeng, 1991) afirmam que a hierarquia estabelecida pela relação de inclusão não

\footnotetext{
${ }^{4}$ Normalmente o custo de aplicação de um critério de teste é medido pelo número de casos de teste necessários para satisfazê-lo, mas outras medidas podem ser utilizadas, taís como: para a Análise de Mutantes, o tempo gasto para executar os mutantes gerados ou para identificar mutantes equivalentes; para critérios estruturais, o tempo para identificar caminhos e associaçōes não executáveis.
} 
fornece uma medida quantitativa em termos de eficácia, ou seja, pode acontecer de um critério $C r_{1}$ incluir um critério $C r_{2}$ e os casos de teste gerados por $C r_{1}$ não revelarem erros encontrados por casos de teste gerados por $\mathrm{Cr}_{2}$. Frankl e Weyuker (1993a) propuseram novas relações que, se satisfeitas pelos critérios de teste, podem garantir a habilidade do critérios em revelar a presença de erros. Essas relações são: restringe, cobre, particiona, cobre propriamente e particiona propriamente. Três medidas probabilísticas são utilizadas por essas relações, $M_{1}, M_{2}$ e $M_{3}$. No entanto, Frankl e Weyuker (1993a) observam que é difícil aplicar essas relações em uma avaliação teórica de critérios de teste mais elaborados, de forma que outros experimentos deveriam ser conduzidos para que esses resultados possam ser representativos na prática. (Frankl e Weyuker, 1993b)

Zhu (1996) identifica dois cenários de teste: prior testing scenario, em que o testador utiliza seu conhecimento sobre um critério de teste para gerar um conjunto de teste adequado, e posterior testing scenario, em que o critério de teste é apenas usado para medir a adequação do teste e para decidir quando parar a geração de testes. Segundo Zhu (1996), para o primeiro cenário nenhuma afirmativa pode ser feita sobre a eficácia dos critérios de teste com base na relação de inclusão, mas o autor demonstra que, no segundo cenário, para todos os critérios de teste $A$ e $B$ tal que $A$ inclui $B$, então $A$ será melhor sucedido em encontrar erros do que o critério B. Nesse estudo, Zhu (1996) mediu a habilidade em detectar erros dos critérios de teste utilizando a probabilidade de detectar erros e o número esperado de erros. Outro resultado da pesquisa de Zhu (1996) é que no posterior testing scenario, a relação de inclusão também implica um número maior de casos de teste.

Frankl et al. (1998) apresentam um estudo empírico em que a eficácia dos critérios Todas-Decisões e Todos-Usos foi avaliada, juntamente com conjuntos de teste gerados randomicamente. Os resultados desse estudo indicam que os conjuntos de teste que satisfazem os requisitos dos critérios de teste se mostraram mais capazes em detectar erros do que os conjuntos de teste gerados randomicamente.

O custo de aplicação dos critérios de teste, em termos de número de casos de teste gerados, também foi empiricamente analisado (Budd et al., 1980; Delamaro, 1997; Maldonado, 1991; Vincenzi et al., 2001; Weyuker, 1990). Em geral, o custo de aplicação dos critérios de teste se mostrou mais baixo do que indicavam os estudos teóricos.

Como o custo de aplicação do teste de mutação é, em geral, alto, alguns estudos empíricos avaliam a relação custo/eficácia das abordagens alternativas, como Mutação Aleatória e Restrita (Maldonado et al., 2000a; Mathur e Wong, 1993; Souza, 1996; Wong et al., 1994a, 1997). Os resultados desses estudos indicam que ambas as abordagens apresentam uma eficácia satisfatória, a um custo de aplicação menor. Estudos também foram realizados para determinar conjuntos essenciais de operadores de mutação para programas Fortran (Offutt et al., 1996a) e C (Barbosa et al., 2001; Wong et al., 1997). A aplicação desses conjuntos mostrou que o custo pode ser significativamente reduzido em relação à aplicação do conjunto completo de operadores de mutação, mantendo a mesma eficácia. 
Alguns estudos empíricos também foram conduzidos para investigar a relação de custo, eficácia e strength entre critérios de fluxo de dados e a Análise de Mutantes (Mathur e Wong, 1994; Offutt et al., 1996b; Souza, 1996; Wong et al., 1994c). Do ponto de vista teórico, estes critérios são incomparáveis, mas segundo os resultados, a Análise de Mutantes é praticamente equivalente ao critério Todos-Potenciais-Usos quando se considera a relação de inclusão, não possuindo muitas diferenças entre si; e os conjuntos de teste adequados à Análise de Mutantes estão mais próximos de serem adequados ao critério Todos-Usos do que o contrário. $\mathrm{O}$ custo da Análise de Mutantes é mais alto, considerando-se o número de casos de teste, mas sua eficácia também é maior em revelar erros.

Em suma, os estudos empíricos que têm sido conduzidos no contexto de teste de programas apontam que o aspecto complementar dos critérios de teste estruturais e de mutação deve ser investigado de forma a estabelecer estratégias de teste de baixo custo e que melhor explorem as características de cada um.

Apesar da importância da conduçāo de estudos empíricos, pouco tem sido realizado no contexto de teste em nível de especificações (Bochmann e Petrenko, 1994; Souza, 2000). Um dos possíveis motivos é que a maior parte dos critérios utilizados no teste de especificações são aqueles já estabelecidos no teste de programas e nesse caso, vários estudos comparativos já foram realizados. Apesar disso, é importante que estudos empíricos sejam também realizados em nível de especificação para comprovar que os mesmos resultados se mantêm válidos.

\subsection{4 Árvore de Alcançabilidade}

A análise de alcançabilidade é uma técnica muito utilizada para verificação e análise de propriedades de modelos baseados em Redes de Petri (Murata, 1984), Máquinas de Estados Finitos, Máquinas de Estados Finitos Comunicantes (Peng, 1997; Özdemir e Ural, 1997) e Statecharts (Masiero et al., 1994). A árvore de alcançabilidade também tem sido utilizada como um método para a verificação da corretitude de protocolos de comunicação especificados com base em máquinas de transição de estado, como Estelle (Huang e Hsu, 1994; Jirachiefpattana e Lai, 1997; Souza, 2000).

Com a árvore de alcançabilidade modela-se o comportamento do sistema, sendo formada pelo conjunto de possíveis estados do sistema, também chamados de configurações do sistema. A raiz da árvore consiste do conjunto de estados iniciais do sistema (configuração inicial). Transições possíveis de serem disparadas são representadas pelos arcos e, a partir da configuração inicial, novas configurações são alcançadas. No contexto de protocolos de comunicação, uma configuração em uma árvore de alcançabilidade é denominada de estado global, que consiste do estado de cada processo e do conteúdo de cada canal de comunicação. Assim, a raiz da árvore é o estado global inicial e o conjunto de configurações é o conjunto de todos os estados globais alcançáveis a partir do estado global inicial. O conjunto de arcos é o conjunto de entradas, saídas ou tarefas. 
Com o auxílio da árvore de alcançabilidade pode-se verificar algumas propriedades dinâmicas do modelo (Masiero et al., 1994):

- sequência de eventos válidos: uma sequência de eventos é válida se cada evento da seqüência pode causar o disparo de uma transição, fazendo com que o sistema mude de configuraçãa;

- alcançabilidade: uma configuração de estados $C_{k}$ é alcançável a partir de uma outra configuração de estados $C_{i}$ se existe pelo menos uma sequência de eventos válida $\left\{s_{\mathrm{I}}, s_{2}, \ldots, s_{n}\right\}$ e um conjunto de configurações de estados intermediárias $\left\{C_{i}, C_{i+1}, \ldots, C_{i+n}\right\}$ tal que $C_{k}$ seja alcançada percorrendo-se $\left\{s_{1}, s_{2}, \ldots, s_{n}\right\}$, a partir de $C_{i}$;

- reiniciabilidade: um modelo é reinicializável quando, para cada configuração de estados $C_{i}$ alcançada a partir da configuração inicial $C_{0}$, há uma sequência de eventos que levam à configuração inicial $C_{0}$;

- existência de deadlock: um modelo tem deadlock se sua execução pode alcançar uma configuração de estados em que o sistema não evolui, pois nenhuma transição pode ser disparada;

- uso de transições: uma transição é utilizada se aparece em pelo menos um caminho de execução do modelo, ou seja, aparece no mínimo em um caminho da árvore de alcançabilidade.

Apesar de ser facilmente automatizada, a análise de alcançabilidade tem o problema de explosão de estados, que compromete a sua aplicabilidade. Esse problema ocorre quando o número de estados que podem ser analisados torna-se muito grande, podendo ser infinito para alguns sistemas complexos. Mesmo para sistemas pequenos o número de estados possíveis pode ser grande, tornando o custo de sua aplicação muito alto. Para tentar resolver, ou ao menos diminuir esse problema, muitas técnicas de redução de estados têm sido propostas.

Lin et al. (1987) propuseram uma estratégia denominada PROVAT (PROtocol VAlidation Testing) que, baseada nas técnicas de busca heurística, identifica quais estados globais deverão ser expandidos, quais transições serão disparadas e quais estados globais serão descartados, auxiliando a redução do tamanho da árvore de alcançabilidade gerada para o teste de protocolos de comunicação.

Outra técnica de redução para análise de alcançabilidade de protocolos especificados por MEFEs é apresentada em (Chu e Liu (1989) ${ }^{5}$ apud Souza (2000)). Uma análise de fluxo

${ }^{5} \mathrm{CHU}$, P. M.; LIU, M. T. Global state graph reduction techniques for protocol validation in the EFSM model. In: Proceedings of the IEEE Phoenix Conference on Computers and Communications, p. 371-377, 1989 
de dados nas MEFEs deve ser realizada para obter informações sobre as variáveis mortas. O conceito de variável morta é definido como: considere que $x$ é uma variável da MEFE $M$ e $s$ é um estado de $M$. A variável $x$ está morta em $s$ se, a partir de $s, x$ não é usada (ou referenciada) em nenhum dos possíveis caminhos de $M$, ou o próximo acesso a $x$ é uma definição. Caso contrário, $x$ é considerada uma variável viva. O comportamento de $M$ a partir do estado $s$ não depende do valor de $x$ que está morta em $s$. Isso ocorre porque as variáveis vivas não serão influenciadas ou trocadas pela variável morta. Desse modo, dois estados globais são considerados equivalentes quando seus elementos são idênticos exceto, possivelmente, para os valores das variáveis mortas. Isso significa que o comportamento futuro desses estados globais é o mesmo e somente um deles necessita ser considerado durante a análise de alcançabilidade.

A técnica de redução apresentada em (Jeron e Jard $(1993)^{6}$ apud Souza (2000)) foi proposta para sistemas que utilizam filas, como por exemplo, sistemas especificados em Estelle, SDL e em MEFECs. Durante a construção da árvore de alcançabilidade são identificadas sequências de transições que podem ser infinitamente repetidas e que, conseqüentemente, aumentam o tamanho da fila do canal de comunicação, resultando em uma árvore de alcançabilidade infinita. Com essa técnica, essas seqüências de transições são detectadas pela determinação de uma relação (denominada relação binária), entre os dois estados globais que estão no início e no final da sequência de transições. Informalmente, essa relação binária identifica dois estados globais $S_{1}$ e $S_{2}$ entre uma sequência de transições, sendo que todos os elementos de $S_{1}$ e $S_{2}$ são idênticos, a menos do conteúdo das filas, e o conteúdo da fila de $S_{2}$ é um prefixo ordenado do conteúdo da fila de $S_{1}$. Essa seqüência de transições é identificada e marcada de forma que a árvore não seja mais explorada a partir dela.

Özdemir e Ural (1997) propõem a análise de alcançabilidade simultânea para diminuir o problema de explosão de estados em MEFCs. Na análise de alcançabilidade seqüencial, o espaço de um estado global é examinado pela execução de uma única transição por vez. Quando algumas transições podem executar simultaneamente a partir de um estado global, considera-se todas as possíveis combinações dessas transições. Assim, se há $k$ transições nessas condições, haverá $k$ ! combinações das mesmas. Com a técnica proposta por Özdemir e Ural (1997), examina-se apenas parte do espaço dos estados globais pela geração dos estados globais que são alcançáveis pela execução simultânea de transições que são executáveis em um estado global e assim, previne-se a geração de um grande número de estados globais intermediários.

Barnard (1998) apresenta quatro técnicas de redução do tamanho da árvore de alcançabilidade que podem ser aplicadas durante sua construção:

- nós duplicados: consiste da identificação de nós duplicados na árvore, que é um nó representando uma configuração que já existe nos níveis mais altos da árvore. Não se

\footnotetext{
${ }^{6}$ JeRON, T.; JARD, C. Testing for unboundedness of FIFO channels. Theoretical Computer Science, v. 113 , n. 1 , p. $93-117,1993$
} 
considera qualquer comportamento depois de um nó duplicado. O mesmo se aplica às configurações que retornam para si mesma, que são consideradas como nós duplicados;

- boundedness: é utilizada para restringir o número infinito de valores que algumas variáveis (variáveis inteiras, por exemplo) podem ter, e que, conseqüentemente, leva a um número infinito de configurações do sistema. Isso pode ser muito útil pois as configurações contêm, além dos estados dos componentes individuais do sistema, os valores das variáveis que pertencem a esses estados. O número infinito de valores da variável pode ser restringido a um único valor $\omega$, que representa todos os possíveis valores da variável, reduzindo o infinito número de estados para um só estado. Isso é muito útil para sistemas que possuem o mesmo comportamento, independente dos valores das variáveis, mas pode prejudicar a análise de sistemas que dependem dos valores dessas variáveis;

- stubborn sets: um stubborn set é um conjunto de transições habilitadas que são independentes umas das outras. Essas transições podem ser disparadas em qualquer ordem antes de ser obtida a próxima configuração. Não se consideram todas as possíveis combinações dessas transições, mas apenas uma é considerada, a stubborn set;

- conjunto de componentes: uma configuração é composta de um estado de cada componente do sistema, mas nem sempre é necessário considerar todos os componentes. Essa técnica restringe o número de componentes durante a construção da árvore de alcançabilidade, podendo reduzir o número de configurações e assim o tamanho da árvore de alcançabilidade.

Para a construção da árvore de alcançabilidade para Statecharts (Masiero et al., 1994), foram consideradas as técnicas de redução nós duplicados e stubborn sets. Com a técnica nós duplicados, quando uma configuração já existente na árvore é inserida, considera-se apenas uma ligação para a primeira ocorrência dessa configuração, sem gerar configuraçōes sucessoras. A técnica stubborn sets trata transições independentes que são disparadas no mesmo passo considerando-se somente uma das possíveis ordem entre elas.

A árvore de alcançabilidade proposta por Souza (2000) para a técnica Estelle é construída considerando-se as técnicas de redução nós duplicados, stubborn sets e conjunto de componentes. Segundo Souza (2000), a construção da árvore considerando a técnica conjunto de componentes é muito útil em especificações de protocolos de comunicação compostos de várias camadas pois, em geral, as camadas do protocolo são especificadas separadamente, descrevendo as interações entre elas. Dessa forma, uma configuração $C_{i}$ da árvore de alcançabilidade para Estelle representa um possível estado do(s) componente(s) selecionado(s), e tem as seguintes informações: estado $E\left(C_{i}\right) \mathrm{da}(\mathrm{s}) \mathrm{MEFE}(\mathrm{s}) \mathrm{do}(\mathrm{s})$ componente(s) e conteúdo das filas $C,\left(C_{i}\right)$ dos pontos de interação do(s) componente(s). O conteúdo de $C\left(C_{i}\right)$ é expresso pelas primitivas de comunicação recebidas. 
Como o comportamento de um sistema especificado em SDL é constituído pela combinação do comportamento de uma coleção de processos, que se comportam como MEFECs, os modelos de árvore de alcançabilidade propostos na literatura para SDL são baseados nos conceitos de MEFECs (Bourhfir et al., 2001b; Huang e Hsu, 1994).

No modelo de MEFEC de Huang e Hsu (1994), um estado global é representado como uma matriz $n \times n$, em que $n$ é o número de MEFEs. Cada elemento da diagonal da matriz registra o estado da MEFE correspondente e os valores das variáveis de contexto declarados na máquina; e cada elemento não pertencente à diagonal da matriz representa a sequência de mensagens pendentes presentes na fila correspondente, por exemplo, na posição $M_{i j}$ estão as mensagens da fila do canal de comunicação entre as máquinas $i$ e $j$.

Huang e Hsu (1994) propõem um método de verificaçāo incremental de protocolos, que permite a verificação dos protocolos a partir do ponto em que houve modificações, ou seja, esse método é útil quando modificações são realizadas na especificação. Esse método utiliza a técnica de redução proposta por Chu e Liu (1989) que, como apresentado anteriormente, analisa as variáveis vivas e mortas, tratando os estados globais que tem os mesmos valores para as variáveis vivas e diferentes valores para as variáveis mortas como o mesmo estado.

Bourhfir et al. (2001b) representam um sistema comunicante por uma $2 k$-tupla $\left(C_{1}, C_{2}, \ldots, C_{k}, F_{1}, F_{2}, \ldots, F_{k}\right)$, em que $C_{i}$ são as MEFEs e $F_{i}$ é uma fila FIFO para cada MEFE. Supondo que um protocolo $\Pi$ consista de $k$ MEFECs $C_{1}, C_{2}, \ldots, C_{k}$, seu estado global é uma $2 k$-tupla $\left\langle s^{(1)}, s^{(2)}, \ldots, s^{(k)}, m_{i}, m_{2}, \ldots, m_{k}\right\rangle$, em que $s^{(j)}$ é um estado de $C_{j}$ e $m_{j}, j-1 \ldots k$, são conjuntos de mensagens contidas em $F_{1}, F_{2}, \ldots, F_{k}$, respectivamente. As MEFECs trocam mensagens por meio de canais FIFO.

O método de geração de casos de teste proposto por Bourhfir et al. (2001b) para um sistema composto de MEFECs, como é o caso de SDL, analisa cada MEFEC que compõe o sistema, evitando o problema de explosão de estados. Bourhfir et al. (2001a) afirmam que testar o modelo global de um sistema comunicante pode ser muito custoso, ou então impossível por causa do problema de explosão de estado. Mas por outro lado, testar cada máquina isoladamente não é suficiente por não considerar sua interação com o contexto. Bourhfir et al. (2001b), apresentam a geração de casos de teste baseada na árvore de alcançabilidade para um sistema comunicante composto de 3 MEFECs pequenas e afirmam que para sistemas comunicantes maiores, o teste pode ser impraticável, tornando o teste de cada MEFEC a única solução para grandes sistemas.

Özdemir e Ural (1997) estabelecem que um protocolo $\Pi$ consiste de um conjunto $P=$ $\left\{P_{i} / i=1,2, \ldots, n\right\}$ de processos que se comunicam por meio de canais representados por filas FIFO. Um estado global $G_{k}$ do protocolo $\Pi$ é definido como $\left(\left\langle s_{i}^{k}\right\rangle_{i=1,2, \ldots, n},\left\langle c_{i j}^{k}\right\rangle_{i, j=1,2, \ldots, n}\right.$ e $\left.i \neq j\right\rangle$, tal que $s_{i}^{k}$ é o estado de $P_{z}$ e $c_{i j}^{t}$ são mensagens contidas nos canais $C_{i j}$ que ligam os processos em $G_{k}$. Se o conteúdo de $C_{i j}$ é vazio em $G_{k}$, ele é representado por $\varepsilon$, ou seja, $c_{i j}^{\text {le }}=\varepsilon$. $G_{0}$ denota o estado global inicial de $\Pi$, em que cada processo está em seu estado inicial e todos os canais estão vazios, ou seja, $G_{0}=\left(\left\langle o_{i}\right\rangle_{t=1,2, \ldots, n},\left\langle c_{i j}^{0}\right\rangle_{i, j=1,2, \ldots, n \text { e } \imath \neq j}\right)$ e $c_{i j}^{n}=\varepsilon$. 
De modo geral, as definiçōes de estados globais apresentadas são bastante similares, apesar do fato de Özdemir e Ural (1997) não considerarem a presença de variáveis nas especificações de protocolos de comunicação.

\subsection{SDL: Aspectos de Teste, Validação e Depuração}

Diferentes métodos e critérios de teste têm sido investigados no contexto de especificações SDL (Bourhfir et al., 2001a,b; Cavalli et al., 1996; Grabowski et al., 1996; Hogrefe, 1996; Kerbrat et al., 1999; Kovács et al., 2003; Touag e Rouger, 1999; Ural et al., 2000). No entanto, o que pode ser observado é que o aspecto de cobertura de teste da especificação propriamente dita, apontado como relevante nesse contexto por Petrenko e Bochmann (1996), não é explorado. Os trabalhos encontrados na literatura se concentram no teste de conformidade, que, como ressaltado anteriormente, tem como propósito assegurar que a implementação do sistema esteja conforme a especificação. Nesses trabalhos, os critérios de teste são aplicados na especificação SDL para gerar conjuntos de teste que são utilizados no teste da implementação associada. Quando os casos de teste são gerados, o comportamento da especificação SDL é avaliado, mas não se tem informações sobre a cobertura dos requisitos da especificação.

Em geral, a especificação SDL é verificada por meio de simulação, análise de alcançabilidade e model checking, técnicas que não permitem a quantificação da atividade de teste. Essa é a principal diferença entre esses trabalhos e a pesquisa apresentada nesta tese, que, entre outras coisas, investiga critérios de teste no teste de especificações SDL, auxiliando a quantificação desta atividade e, dessa forma, permitindo a avaliação da qualidade da mesma.

Cavalli et al. (1996) apresentam uma visão geral dos métodos de teste de conformidade para sistemas SDL, classificando-os em dois grupos: os que pretendem automatizar totalmente a geração de teste de especificações de sistemas SDL e aqueles que fornecem métodos de geração de teste interativo, ou seja, que necessitam da intervenção humana.

Os métodos de geração de teste automatizados podem derivar os testes diretamente da especificação SDL ou transformam a especificação SDL em um modelo escrito em outro formalismo, a partir do qual os testes são gerados. Os métodos de geração de teste interativos, como o próprio nome diz, permitem a geração de casos de teste de modo interativo e podem ser de dois tipos: orientados pela especificação SDL do protocolo ou orientados pela especificação SDL juntamente com os propósitos do teste. Como exemplos de métodos orientados pela especificação, Cavalli et al. (1996) citam o método TVEDA e o método DFC (Data Flow Control), para controle de fluxo de dados. O método TVEDA gera casos de teste a partir de MEFEs, que podem ser abstraídas de especificações SDL ou Estelle, e para uma MEFE apenas, que corresponde a um processo da especificação SDL. Sua estratégia é gerar um caso de teste para cada transição. A ferramenta TVEDA apóia a aplicação 
desse método. O método DFC possibilita a derivação seletiva de casos de teste de uma especificação SDL. A derivação é baseada na análise das relações de entrada-saída (I/O) da especificação para expor os efeitos de cada interação de entrada nas interações de saída. Os efeitos são identificados por meio da análise das variáveis na especificação. O método consiste de quatro passos, em que os primeiros três passos se preocupam com a análise da relação de entrada-saída, que é facilitada pelo rastreamento do fluxo de controle e de dados na especificação. O quarto passo lida com a seleção de sequiências de teste que capturam o relacionamento de entrada-saída identificado.

Um propósito de teste pode ser visto como parte de um requisito de conformidade, sendo uma descrição precisa do que deve ser testado para satisfazer esse requisito de conformidade. O objetivo dos métodos orientados ao propósito do teste, é fornecer uma saída em TTCN (Tree and Tabular Combined Notation), que é uma notação padrão para descrever conjuntos de teste de teste de conformidade de padrões ISO, quando são fornecidos como entrada uma especificação SDL e os propósitos de teste. Os propósitos de teste são representados em MSC (Message Sequence Charts), uma notação própria para esta tarefa. Exemplos são os métodos SaMsTaG (SDL And Msc baSed Test cAse Generation) e STED (Specification-Directed TTCN Editor). O método SaMsTaG (Grabowski (1994) ${ }^{7}$ apud Bourhfir et al. (2001a)) permite gerar casos de teste na notação TTCN baseados em especificações SDL e propósitos de teste em MSCs. A ferramenta SaMsTaG automatiza a aplicação do método. Para cada propósito de teste descrito em MSC, é gerado um caso de teste. O método STED é similar ao SaMsTaG.

Ainda de acordo com Cavalli et al. (1996), todos esses métodos possuem suas vantagens e limitaçōes. Em relação aos métodos automatizados, a máquina de estados finitos obtida das especificações SDL representa os dados e as estruturas de controle da especificação, modelando assim, o sistema SDL completo. As sequências de teste obtidas pela aplicação desses métodos são finitas e permitem obter uma cobertura de teste completa, obedecendo algumas suposições, em relação às falhas de saída e transferências, que garantem que qualquer desvio da implementação em relação à especificação será encontrado. A principal limitação desses métodos é devido ao tamanho da máquina de estados finitos obtida.

Em relação aos métodos de geração de teste interativos, eles têm dificuldade em incluir dados nos testes, pois são limitados somente à análise estática da especificação. Mesmo no caso em que são capazes de calcular a entrada e a saída de um caso de teste, isto é feito manualmente, de modo interativo. Uma outra conseqüência da análise estática é que isso torna impossível modelar o sistema SDL inteiro (Cavalli et al., 1996).

Hogrefe (1996) também discute várias técnicas de verificaçã̃o e validação de especifcações SDL, tais como análise de alcançabilidade e simulação. As técnicas discutidas são utilizadas para verificar a especificação em relação a algumas propriedades e para avaliar o

\footnotetext{
${ }^{7}$ GRABOWSKI, J. SDL and MSC based teste case generation: an overall view of the SaMsTaG method. Relatório Técnico IAM-94-005, Institute for Informatics, University of Bern, Suíça, 1994
} 
comportamento da especificação, mas não fazem nenhuma análise da cobertura do teste da especificação.

Grabowski et al. (1996) apresentam uma abordagem que auxilia a geração de casos de teste com base na exploração de estado-espaço das especificações SDL. Nessa abordagem são aplicadas algumas técnicas de redução da complexidade da árvore que modela o comportamento das especificações SDL.

Ural et al. (2000) investigam dois critérios de fluxo de dados, Todos-Usos e $1 O$-df-chains, que explora a relação entre o uso de uma variável e a definição de uma outra variável. Ambos critérios derivam seus requisitos de um modelo de grafo de fluxo de dados e são utilizados para a geração de casos de teste para o teste de conformidade.

Uma metodologia automatizada para geração de casos de teste a partir de sistemas especificados em SDL é proposta por Bourhfir et al. (2001b). Essa metodologia consiste de extrair as MEFEs que correspondem aos processos do sistema em SDL e ao mesmo tempo criar arquivos contendo declarações em SDL de interações (sinais) e canais, e gerar automaticamente casos de teste executáveis. A metodologia é apoiada pelas ferramentas FEX, que extrai as MEFEs da especificação SDL e gera arquivos que podem ser utilizados para completar os casos de teste, e CEFTG (Communicating Extended Finite State Machine Test Generator), que gera automaticamente os casos de teste executáveis. A CEFTG foi baseada em outra ferramenta, EFTG (Extended Finite State Machine Test Generator), que apóia a geração automática de casos de teste para sistemas baseados em MEFEs. A saída gerada pela ferramenta FEX é transformada em um formato aceito pela CEFTG. Na verdade, a CEFTG gera os casos de teste para sistemas modelados por uma MEFE usando a ferramenta EFTG, de forma que os casos de teste são gerados para cada MEFEC de uma especificação SDL, sem considerar as interações existentes entre as máquinas. Posteriormente, a CEFTG gera os casos de teste para o sistema como um todo.

Os casos de teste gerados pelo método proposto por Bourhfir et al. (2001b) cobrem aspectos de fluxo de dados e de controle. O critério de fluxo de controle utilizado é o UIO (Unique Input/Output Sequence) e o critério de fluxo de dados é o Todos-du-caminhos (Rapps e Weyuker, 1985), onde todos os caminhos na especificação contendo uma definição de uma variável e seu uso são gerados. Porém, em um experimento realizado com um sistema real em SDL em que uma das MEFEC era composta por 11 estados e 24 transições, a ferramenta CEFTG não pode gerar os casos de teste para essa MEFEC, pois o custo de aplicação do critério Todos-du-caminhos foi alto. Assim, Bourhfir et al. (2001b) consideram que um critério mais fraco, como Todos-Usos deveria ser utilizado para gerar casos de teste para sistemas grandes.

Bourhfir et al. (2001a) apresentam e discutem alguns métodos existentes para a geração de casos de teste para o teste de conformidade de protocolos de comunicação especificados em SDL. Como o comportamento de uma especificação SDL é expresso por MEFEs e MEFECs, os métodos apresentados são aqueles propostos para geração de casos de teste de 
especificações em MEFEs e em MEFECs. Para as MEFEs, Bourhfir et al. (2001a) discutem sobre os diversos critérios de teste de fluxo de controle e de dados. Os critérios de fluxo de dados apresentados por Bourhfir et al. (2001a) são basicamente adaptados dos empregados no teste de programas, ou seja, são definidos critérios como Todos-Nós, Todos-Arcos, entre outros. Três problemas são identificados:

- muito pouco esforço tem sido feito para resolver o problema da executabilidade, ou seja, não se tem verificado se os predicados associados com as diferentes transições de um caminho são satisfeitos. A maioria dos métodos existentes gera as sequências de teste que satisfazem determinado critério primeiro e depois verificam se as sequências geradas são executáveis;

- a presença de loops na especificação e nos casos de teste. O problema é determinar o número de vezes que um loop deve estar presente em um caso de teste;

- o tipo de cobertura alcançada pelos casos de teste gerados. Durante o teste, todos os possíveis valores de entrada forneceriam a mais completa ilustração do comportamento do programa, mas o domínio de entrada é geralmente muito grande para o teste exaustivo ser praticável. Assim, o procedimento normalmente empregado é selecionar um subconjunto relativamente pequeno e que seja representativo em relação ao domínio de entrada completo. O problema é encontrar esse conjunto ideal de dados de teste que, em geral, é uma tarefa impossível.

Para as MEFECs, Bourhfir et al. (2001a) afirmam que testar o modelo global de um sistema comunicante pode ser muito custoso, ou entâo impossível por causa do problema de explosão de estado. Mas por outro lado, testar cada máquina isoladamente não é suficiente por não considerar sua interação com o contexto.

Kovács et al. (2003) investigam a aplicação da Análise de Mutantes no teste de conformidade de protocolos de comunicação especificados em SDL. Nesse caso, o critério auxilia a geração e seleção de casos de teste para testar programas implementados com base na especificação SDL do protocolo. O conjunto de operadores de mutação proposto por Kovács et al. (2003) é composto por 6 tipos de operadores para SDL que exploram modificações nos estados, entradas, saídas, ações e predicados, e ainda remoção do comando save. Para gerar casos de teste, foi proposto um algoritmo que tem como entrada uma especificação SDL e o resultado é um conjunto de casos de teste adequado à Análise de Mutantes para testar implementações relacionadas. Para auxiliar a seleção de casos de teste, uma ferramenta foi implementada e tem como entradas uma especificaçào SDL e um conjunto de testes. O conjunto de teste inicial é analisado e somente aqueles casos de teste que identificam os mutantes são selecionados.

Um ponto importante é o custo de aplicação dos critérios de teste, que pode ser medido pelo número de requisitos de teste ou de casos de teste gerados para satisfazer esses requisitos. 
Em geral, os trabalhos propõem como os requisitos de teste devem ser derivados, de acordo com o que cada critério de teste pretende explorar na especificação, mas não apresentam indícios de como gerar casos de teste de forma a satisfazer esses requisitos a um custo mais baixo. Segundo Bourhfir et al. (2001a), o custo envolvido na geração de casos de teste é maior que o custo requerido no processo de execução. Os autores ainda comentam que não basta automatizar a execução do teste para melhorar a qualidade do produto, é preciso melhorar a geração dos casos de teste. Considerando esse fato, neste trabalho explora-se o conceito de dominadores (Agrawal, 1994) para auxiliar a geração de casos de teste para o teste de especificações SDL. Os casos de teste gerados são adequados aos critérios estruturais já estabelecidos nesse contexto, visando a diminuir o custo envolvido nessa atividade. Essa abordagem é apresentada no Capítulo 3 .

Harrold (2000) comenta que as informações obtidas durante a atividade de teste podem ser úteis em outras atividades, como a depuração de programas. A atividade de depuração, assim como o teste, pode acarretar um alto custo no desenvolvimento e manutenção de software. Em relação à depuração, na literatura são raros os trabalhos que investigam técnicas que auxiliem essa atividade no contexto de especificações SDL. Na ferramenta Telelogic Tau, por exemplo, a simulação da especificação é utilizada para auxiliar a depuração do comportamento da especificação SDL. A ferramenta $\chi$ Slice-SDL (Li e Horgan, 2000) auxilia a depuração de especificações SDL, utilizando uma heurística que combina informações de casos de teste que identificaram o erro e de casos de teste que não o identificaram. Nessa mesma linha de pesquisa, neste trabalho de doutorado são propostas facilidades para a atividade de depuração com base em informações obtidas durante o teste de especificações SDL com relação aos critérios estruturais. Uma vez que essa abordagem é derivada de técnicas exploradas na depuração de programas, a seguir apresentam-se algumas dessas técnicas.

Quando um programa se comporta diferentemente do esperado, uma forma comum de depurá-lo quando não se tem uma ferramenta de apoio, é inserir comentários que mostrem os valores das variáveis nos comandos e declarações suspeitas de conter o erro. Para essa técnica porém, é necessário um bom conhecimento da execuçäo do programa sendo depurado em relação às entradas que causam o mau comportamento para que comentários sejam inseridos somente nos locais apropriados. Caso contrário, se a complexidade do programa for grande e sem o conhecimento de como ele executa com um valor de entrada, esta pode ser uma tarefa custosa, principalmente em termos de tempo.

Uma outra técnica que tem sido aplicada na depuração de programas é slicing. O conceito de slicing de programa foi proposto por Weiser $(1982,1984)$, que definiu um slice (estático) para uma variável, em um determinado comando, como o conjunto de comandos executáveis que poderiam influenciar o valor dessa variável no comando. O slicing pode ser usado para reduzir o domínio de busca, pois se em uma execução com um caso de teste o programa não se comporta como esperado por causa do valor incorreto de uma variável em um comando, 
o erro poderia estar no slice relacionado a esse par variável-comando. Assim, o domínio de busca é reduzido para esse slice. O problema dessa técnica é que ainda podem haver muitos comandos a serem analisados.

Uma extensão a essa técnica foi proposta por Lyle e Weiser (1987). A idéia é construir um dice de programa, como um conjunto diferença entre dois grupos de slices estáticos, reduzindo ainda mais o domínio de busca por possíveis locais do erro. O primeiro grupo contém slices associados aos pares variáveis-comandos em que as variáveis têm valores incorretos e o outro grupo contém slices associados aos mesmos pares variáveis-comandos do grupo anterior, mas as variáveis têm valores corretos. O objetivo é reduzir o domínio de busca a um dice que contenha todos os comandos dos slices do primeiro grupo e não contenha os comandos dos slices do segundo grupo. O tamanho de um dice depende dos pares variáveis-comandos selecionados. Para apoiar essa abordagem foi desenvolvida a ferramenta Focus, que se baseia em slicing estático de programas e em informaçōes sobre quais casos de teste evidenciam o erro. A análise estática porém, não permite saber alguns valores definidos em tempo de execução e alguns dices gerados podem conter comandos que não deveriam estar presentes. Para excluir esses comandos de um dice é necessário usar slicing dinâmico (Agrawal e Horgan, 1990; Korel e Laski, 1988), que pode identificar os comandos que realmente influenciam o valor de uma determinada variável.

Um slice dinâmico pode ser considerado como um refinamento de um slice estático correspondente. Korel e Laski (1988) propõem sua utilização na depuração de programas e afirma que a principal vantagem do slicing dinâmico é que o tamanho do slice pode ser significantemente reduzido pela exclusão daqueles comandos do programa que não produzem efeito nas variáveis de interesse. Um protótipo, denominado PELAS, foi desenvolvido para apoiar a proposta de Korel e Laski (1988). Nessa mesma linha, Agrawal e Horgan (1990) também exploraram a utilização do conceito de slice dinâmico na depuração de programas. Segundo os autores, um slice dinâmico é útil por isolar apenas aqueles comandos que realmente influenciaram, para uma determinada entrada em um certo local, um valor particular de uma variável suspeita. Nessa abordagem são utilizados grafos de dependência de programa e uma extensão de um algoritmo de slicing estático para construir slices dinâmicos de programa. A diferença entre essas duas definições de slice dinâmico é que, sob certas cìrcunstâncias, a proposta de Korel e Laski (1988) pode produzir desnecessariamente grandes slices dinâmicos. Por exemplo, suponha que um mesmo comando ocorra mais de uma vez numa mesma execução, mas somente uma dessas execuções (por exemplo, a segunda) realmente afetou o valor de uma variável de interesse. No caso da abordagem de Korel e Laski (1988), todas as ocorrências daquele comando serão incluídas no slice dinâmico, enquanto que na abordagem de Agrawal e Horgan (1990) somente a segunda ocorrência daquele comando é incluída.

DeMillo et al. (1997) apresentam uma técnica que também usa slices dinâmicos, derivados da execução do programa, considerando resultados de casos de teste bem e mal sucedidos para localizar erros. Heurísticas são aplicadas, de forma a obter várias combinações de 
intersecções e uniões dos slices dinâmicos entre os casos de teste. Os autores demonstram que o uso de heurísticas pode auxiliar a localização de erros no programa.

Uma outra proposta é a utilização de slicing de execução, com base no teste de fluxo de dados para localizar erros em programas C, como proposto por Agrawal et al. (1995). Dados um programa e um caso de teste, um slice de execução é o conjunto de todos os comandos executados pelo caso de teste, enquanto que o correspondente slice dinâmico, em relação às variáveis de saída, inclui somente aqueles comando que foram executados e que influenciaram a saída do programa em teste. Considerando o fato de que nem todos os comandos executados influenciam as variáveis de saída, um slice de execução pode ser visto como um superconjunto do slice dinâmico correspondente. Agrawal et al. (1995) utilizam heurísticas baseadas nos slices para auxiliar a abordagem proposta, de forma a combinar informações de casos de teste bem sucedidos e mal sucedidos.

Também pode-se usar backtracking de execução para auxiliar a depuração de programas. A desvantagem dessa técnica é que pode ser requerido um grande espaço para armazenamento do histórico da execução e dos estados do programa. Uma solução proposta por Agrawal et al. (1996) é utilizar um backtracking estruturado, que não armazena todo o histórico de execução. Para apoiar essa técnica foi implementada a ferramenta SPYDER'. Essa abordagem é baseada em slicing dinâmico, que contém todos os comandos que realmente influenciaram o valor de uma variável em um ponto do programa para uma determinada execução, e backtracking, que é usado para recuperar o estado do programa em um ponto sem ter que executar o programa novamente desde o começo.

Jones et al. (2002) descrevem uma técnica de visualização para auxiliar a localização de erros que destaca os comandos de um programa em diferentes cores. A cor de cada comando depende da porcentagem relativa de casos de teste bem sucedidos e mal sucedidos ${ }^{8}$ que o executaram. Se o comando é executado por mais casos de teste bem sucedidos do que mal sucedidos, sua cor é esverdeada, caso contrário, sua cor é avermelhada. Para avaliar a efetividade dessa técnica alguns estudos empíricos foram realizados e os resultados mostram que a técnica funciona bem para alguns erros, mas para identificar erros nos códigos de inicialização e no caminho principal do programa que são executados pela maioria dos casos de teste, nenhum dos comandos com erro foi colorido em vermelho.

Chaim et al. (2003) propõem uma estratégia - DRT (Debugging strategy based on Requirements of Testing) - baseada na investigação de indícios fornecidos em tempo de execução pelos requisitos de teste de fluxo de dados. A motivação para essa proposta é que, apesar de falharem na localização do erro, esses requisitos de teste ainda podem fornecer alguma informação útil para localizá-lo. São utilizadas heurísticas que auxiliam a identificação de

\footnotetext{
${ }^{8}$ Ao contrário da atividade de teste em que um caso de teste bem sucedido é aquele que revela um erro na depuração, um caso de teste é bem sucedido se o programa se comporta corretamente quando executado pelo caso de teste.
} 
um conjunto de requisitos inicial, candidatos a revelar o erro e mecanismos para identificar os requisitos de teste que revelam o erro, aplicados até que este seja encontrado.

\section{Ferramentas de Apoio}

Há uma diversidade de ferramentas que apóiam o teste e validação com base na técnica SDL, indicando sua grande utilização, principalmente no contexto de protocolos de comunicação. As ferramentas são basicamente de três tipos: ferramentas de simulação, ferramentas de análise/verificação baseadas na exploração de estado-espaço e ferramentas de geração de casos de teste. As ferramentas que se enquadram nos dois primeiros tipos visam a verificação da própria especificação SDL e aquelas de geração de casos de teste apóiam o teste de conformidade.

As ferramentas de simulação possibilitam que as especificações SDL sejam executadas, permitindo a investigação interativa do comportamento. Sinais podem ser enviados ao sistema e a resposta do sistema pode ser verificada. Normalmente é possível forçar o sistema a entrar em um estado pré-definido (mudando valores das variáveis ou criando instâncias do processo, por exemplo) e continuar a simulação a partir deste estado.

As ferramentas de análise/verificação que exploram estado-espaço permitem a verificação de certas propriedades específicas de uma especificação SDL. Essas propriedades podem ser, por exemplo, a falta de deadlock ou outros erros gerais, ou podem ser propriedades específicas definidas pelo projetista da especificação SDL. Para sistemas pequenos é possivel verificar a falta de propriedades indesejáveis, mas em geral, isso não é possível por causa dos problemas de explosão de estados. Apesar disso, esse tipo de análise automática tem sido útil mesmo para sistemas grandes e complexos. Essas ferramentas executam um teste mais extensivo se comparado com as ferramentas de simulação. Ferramentas que exploram estado-espaço são usadas para complementar as ferramentas de simulação, principalmente para detectar erros de projeto envolvendo comportamentos não usuais do sistema.

Em Turner (1993), é ilustrado um método que emprega ferramentas de simulação e que exploram estado-espaço. Nesse método, a ferramenta de simulação é usada para validar as capacidades do sistema SDL, isto é, verificar se a especificação se comporta como o esperado, e a ferramenta de exploração de estado-espaço é usada para encontrar problemas causados por comportamentos inesperados, tais como algumas combinações indevidas de sinais e timeouts.

Li e Wong (2002) propõem uma abordagem para geração automática de casos de teste com base em critérios estruturais a partir de especificações SDL. Para apoiar esta abordagem foi implementada a ferramenta TestGen.

A ferramenta TESDL (Bromstrup e Hogrefe (1989) ${ }^{9}$ apud Bourhfir et al. (2001b)) é um protótipo para geração de casos de teste automática a partir de especificações SDL.

\footnotetext{
${ }^{9}$ Bromstrup, L.; HogrefE, D. TESDL: Experience with generating test cases from SDL specifications. In: Proceedings of Fourth SDL Forum, p. 267-279, 1989
} 
A ferramenta deriva o comportamento global de um protocolo por meio de uma árvore, denominada de ACT (Asynchronous Communication Tree), que é baseada em um conjunto de modelos SDL. Os modelos SDL no entanto, têm algumas restriçōes, tais como: não podem apresentar dois processos recebendo o mesmo tipo de sinal, e apenas pode existir um processo por bloco. Os nós da árvore ACT representam o estado global, que contém infarmação sobre os estados de todos os processos na especificação. A entrada para a ferramenta TESDL é uma especificação SDL textual em SDL/PR, e sua saída são os casos de teste na notação TTCN.

A ferramenta Telelogic Tau SDL Suite (anteriormente denominada SDT), que pertence ao pacote comercial Telelogic Tau (Telelogic, 2004a), provê um ambiente de projeto de sistemas de tempo-real, na linguagem SDL. Essa ferramenta apóia o projeto do sistema, validação por meio de simulação, verificação por meio de análise de alcançabilidade e geração de testes. Os casos de teste gerados pela ferramenta são escritos na notação TTCN.

Outro conjunto de ferramentas comerciais é ObjectGeode (Telelogic, 2004b), que auxilia a análise, projeto e validação por meio da simulação e geração de código de aplicações distribuídas e de tempo-real. O projeto do sistema na ferramenta é realizado com SDL e é possível gerar casos de teste do modelo SDL. Para guiar a geração de testes, usam-se os propósitos de teste em MSC (objetivos de teste funcionais).

A Tabela 2.1 apresenta um sumário comparativo de alguns dos métodos de teste propostos para a técnica SDL. Foram considerados a técnica formal apoiada, o tipo de teste realizado, o apoio ferramental ao método e se há alguma restrição na especificação SDL para a aplicação do método.

Todos esses métodos apresentados na Tabela 2.1 foram propostos para o teste de conformidade, de forma a auxiliarem a geração de casos de teste com base em especificações SDL. Sendo assim, a cobertura de teste da especificação SDL não é analisada.

\subsection{Considerações Finais}

O propósito deste capítulo foi abordar os principais conceitos relacionados ao contexto em que este trabalho se insere. Visto que a qualidade deve estar presente no produto desde as fase iniciais do processo de desenvolvimento, foi evidenciado o uso de técnicas formais na fase de especificação. Dentre essas técnicas, SDL tem sido bastante empregada, principalmente na especificação de protocolos de comunicação e de arquitetura de software.

Apesar do rigor proporcionado com o uso de técnicas formais na fase de especificações, a presença de erros não é evitada. Para auxiliar a garantia da qualidade, a atividade de teste deve ser conduzida desde as fases iniciais do processo de desenvolvimento de software, pois quanto mais cedo os erros são encontrados, menor é o custo para eliminá-los. 
Tabela 2.1: Comparação de Alguns Métodos de Teste de Especificações SDL

\begin{tabular}{|l|c|l|c|c|}
\hline \multicolumn{1}{|c|}{$\begin{array}{c}\text { Método de } \\
\text { Teste }\end{array}$} & $\begin{array}{c}\text { Técnica } \\
\text { Formal }\end{array}$ & \multicolumn{1}{|c|}{$\begin{array}{c}\text { Tipo de } \\
\text { Teste }\end{array}$} & Ferramenta & Restrição \\
\hline \hline TVEDA & $\begin{array}{c}\text { SDL } \\
\text { Estelle }\end{array}$ & FD & TVeda & $\checkmark$ \\
\hline DFC & SDL & FD (UIO) e FD & FEX e & \\
\hline Bourhfir et al. (2001b) & SDL & $\begin{array}{l}\text { FC (Todos-du-Caminhos) } \\
\text { SDL }\end{array}$ & CEFTG & \\
\hline Li e Wong (2002) & SDL & FC e FD & TestGen & $\checkmark$ \\
\hline $\begin{array}{l}\text { Bromstrup e Hogrefe } \\
\text { (1989) }\end{array}$ & SDL & $\begin{array}{l}\text { Análise de Alcançabi- } \\
\text { lidade }\end{array}$ & TESDL & $\checkmark$ \\
\hline Kovács et al. (2003) & SDL & Mutação & & \\
\hline Ural et al. (2000) & SDL & $\begin{array}{l}\text { FD (Todos-Usos e } \\
\text { IO-df-chains) }\end{array}$ & & \\
\hline SaMsTaG & SDL & $\begin{array}{l}\text { Orientado ao Propó- } \\
\text { sito de Teste (MSC) }\end{array}$ & SaMsTaG & \\
\hline STED & SDL & $\begin{array}{l}\text { Orientado ao Propó- } \\
\text { sito de Teste (MSC) }\end{array}$ & STED & \\
\hline Telelogic Tau & SDL & $\begin{array}{l}\text { Simulação e Análise } \\
\text { de Alcançabilidade }\end{array}$ & Tau SDL Suite & \\
\hline ObjectGeode & SDL & $\begin{array}{l}\text { Simulação e Orientado } \\
\text { ao Propósito de Teste } \\
\text { (MSC) }\end{array}$ & ObjectGeode & \\
\hline & & \multicolumn{3}{|c|}{ Legenda:FC-Fluxo de Controle } \\
\hline
\end{tabular}

FD-Fluxo de 'Dados

Os principais aspectos envolvidos no teste foram introduzidos neste capítulo. Como pode ser observado, na literatura há uma diversidade de trabalhos que exploram a atividade de teste de programas. Quando explorado na fase de especificação, duas abordagens de teste podem ser investigadas, o teste baseado em especificação e o teste de especificações. $O$ teste baseado em especificações tem como objetivo avaliar a qualidade da implementação, com relação a casos de teste gerados a partir da especificação associada. Nesse caso, o comportamento da especificação pode ser avaliado durante a geração dos casos de teste, mas não há evidências de cobertura de teste da especificação, um aspecto importante apontado por Petrenko e Bochmann (1996) para indicar a qualidade da atividade de teste. O aspecto de cobertura de teste da especificação é explorado quando se conduz o teste de especificações, pois os casos de teste são gerados para cobrir os requisitos de teste derivados pelos critérios de teste para a especificação, e a cobertura de teste pode ser analisada, quantificando a atividade de teste nesse contexto.

O teste baseado em especificações tem sido bastante explorado no contexto de protocolos de comunicação, em que é conhecido como teste de conformidade. Como comentado anteriormente, a técnica SDL é bastante utilizada para especificar protocolos de comunicação, 
sendo que a maioria dos critérios de teste propostos exploram o teste visando ao teste de conformidade. Evidencia-se, dessa maneira, a necessidade de se investigarem critérios de teste para o teste da própria especificação, complementando as outras técnicas exploradas, como simulação e model checking.

O grupo de Engenharia de Software do ICMC-USP/São Carlos tem investigado critérios estruturais e baseados em mutação no teste de especificações. Esses trabalhos motivam a investigação de critérios de teste no teste de especificações baseadas em outras técnicas formais, como é o caso de SDL, para fornecer evidências da qualidade do teste da especificação.

Um ponto importante na atividade de teste é o custo de aplicação dos critérios de teste, que pode ser medido pelo número de requisitos de teste ou de casos de teste gerados para satisfazer esses requisitos. Em geral, os trabalhos propõem como os requisitos de teste devem ser derivados, de acordo com o que cada critério de teste pretende explorar na especificação, mas não dão indícios de como gerar casos de teste de forma a satisfazer esses requisitos a um custo mais baixo. Isso ocorre em todos os métodos apresentados na Tabela 2.1. Segundo Bourhfir et al. (2001a), o custo envolvido na geração de casos de teste é maior que o custo requerido no processo de execução. Os autores ainda comentam que não basta automatizar a execução do teste para melhorar a qualidade do produto. Para isso, é preciso melhorar a geração dos casos de teste. Considerando esse fato, neste trabalho explora-se o conceito de dominadores (Agrawal, 1994) para auxiliar a geração de casos de teste para o teste de especificações SDL. Os casos de teste gerados são adequados à critérios estruturais já estabelecidos nesse contexto, tais como Todos-Blocos e Todos-Usos, visando a diminuir o custo envolvido nessa atividade. Essa abordagem é apresentada no Capítulo 3.

Segundo Chow (1978), critérios de fluxo de controle como Todos-Blocos e Todas-Transições, apesar de garantirem a cobertura mínima desejável de especificaçōes baseadas em transição de estados, como é o caso de SDL, não são adequados para revelar erros típicos associados a essas especificaçōes, pois não identificam erros de transferência, de operação e de estados ausentes ou extras. Evidencia-se assim a necessidade de aplicação de critérios mais rigorosos nesse contexto. Neste trabalho uma família de critérios de fluxo de controle é proposta. Essa família, denominada FCCSDL (Família de Critérios de Cobertura para SDL), é composta de critérios que exploram os blocos e transiçōes, menos rigorosos, e critérios considerados mais fortes, do ponto de vista de teste de programas. Os critérios FCCSDL derivam seus requisitos da árvore de alcançabilidade que modela o comportamento da especificação SDL

Pode-se observar a carência de estudos teóricos e empíricos que investiguem os critérios de teste utilizados mo teste de especificações. Estudos teóricos e empíricos são importantes para a análise de adequação e análise comparativa de critérios de teste pois, usando métodos e ferramentas, ajudam a demonstrar a importância dos critérios de teste na prática. Também se destacou que o apoio de ferramentas é indispensável para a realização da atividade de teste de forma produtiva e para auxiliar a condução de estudos empíricos. 
Em relação à atividade de depuração, ficou evidente a necessidade de se investigarem técnicas que auxiliem essa atividade no contexto de especificações SDL ( $\mathrm{Li}$ e Horgan, 2000). A depuração é bastante investigada no contexto de programas, mas para especificações são poucos os trabalhos relacionados.

Visando a contribuir no escopo de teste e depuração de especificações, neste trabalho investigam-se critérios baseados em fluxo de controle e de dados, a Análise de Mutantes e a família FCCSDL no teste de especificações SDL. Também foram propostas facilidades para a atividade de depuração com base em informações obtidas durante o teste de especificações SDL com relação aos critérios estruturais. No próximo capítulo os critérios estruturais investigados para o teste de especificações SDL são apresentados. Também é introduzida a proposta para auxiliar a depuração de especificações SDL. 


\section{Teste Estrutural e Depuração de Especificações SDL}

\subsection{Considerações Iniciais}

A análise da cobertura é um aspecto relevante para a quantificação da atividade de teste. A cobertura de teste pode ser medida pelo número de requisitos estabelecidos por um critério de teste que foram cobertos por um conjunto de teste. Em se tratando de especificações SDL porém, esse aspecto é pouco explorado na liter atura, como visto no Capítulo 2. Evidencia-se, portanto, a necessidade de se explorarem critérios de teste no teste de especificações SDL.

Neste capítulo, critérios estruturais são investigados no teste de especificaçōes SDL a partir de duas perspectivas de derivação dos requisitos de teste: uma que utiliza informações do fluxo de controle e de dados dos processos SDL modeladas em grafos de fluxo de controle e de $\operatorname{dados}^{1}$ (GFs) definidos para cada processo SDL; e a outra que estabelece seus requisitos de teste a partir de um modelo de árvore de alcançabilidade definido para especificações SDL, buscando exercitar o comportamento de toda a especificação.

Cinco critérios de teste estabelecem seus requisitos a partir de grafos de fluxo: Todos-Blocos, Todas-Decisões, Todos-c-Usos, Todos-p-Usos e Todos-Usos. Para auxiliar a geração de casos de teste, é proposta a aplicação do conceito de dominadores proposto por Agrawal (1994) combinado aos requisitos de teste estabelecidos por esses critérios. Dessa

\footnotetext{
${ }^{1}$ No restante do texto esse grafo é denominado simplesmente de grafo de fluxo.
} 
forma, são fornecidas informações ao testador para diminuir o custo de aplicação desses critérios.

Com a evidência da necessidade de aplicação de critérios mais rigorosos no teste de especificações baseadas em transição de estados, como é o caso de SDL, uma família de critérios de fluxo de controle, FCCSDL, é definida. Essa família é composta de critérios menos rigorosos, que exploram os blocos e transições, e critérios considerados mais fortes do ponto de vista de teste de programas. Esses critérios estabelecem seus requisitos de teste a partir da árvore de alcançabilidade que modela o comportamento das especificações SDL.

Neste capítulo também apresenta-se uma proposta para auxiliar a atividade de depuração que utiliza informações coletadas durante o teste de especificações SDL, com base nas execuções dos casos de teste.

\subsection{Teste Estrutural em Nível de Processo}

Nessa proposta dois critérios de fluxo de controle (Todos-Blocos e Todas-Decisões) e três critérios de fluxo de dados (Todos-Usos, Todos-p-Usos e Todos-c-Usos) sāo utilizados para auxiliar a análise de cobertura de teste nos processos SDL e a geração de casos de teste. Para cada processo definido na especificação SDL, um grafo de fluxo (GF) é construído e, a partir desse grafo, os requisitos de teste de cada critério são derivados.

A ferramenta $C A T_{S D L}$ foi implementada para apoiar a aplicação desses critérios de fluxo de controle e de dados no teste de especificações SDL e será apresentada na Seção 5.2 do Capítulo 5.

Para ilustrar a aplicação dos critérios estruturais utiliza-se a especificação do protocolo Bit-Alternante. Esse protocolo, utilizado também como exemplo em outros capítulos, é introduzido a seguir.

\section{Protocolo Bit-Alternante}

O protocolo Bit-Alternante é uma representação mais simples do "protocolo de janela deslizante", com uma janela de tamanho 1 (Tanenbaum, 1996). Esse protocolo fornece comunicação confiável em um serviço de rede não confiável, usando uma seqüência de 1-bit (que alterna entre 0 e 1) em cada mensagem ou acknowledgement para determinar quando as mensagens devem ser retransmitidas. A Figura 3.1 ilustra o protocolo em SDL no nível de sistema, com três blocos SDL: sender_block, medium e receiver_block. O bloco medium contém dois processos, Medium1 e Medium2. Esses dois processos são como canais de comunicą̧ão entre os processos Sender e Receiver, pertencentes aos blocos sender.block, e receiver_block, respectivamente. A comunicação com o ambiente ocorre por meio de dois canais, sender_higher_interface e receiver_higher_interface. A especificação textual completa desse protocolo é apresentada no Apêndice B. 


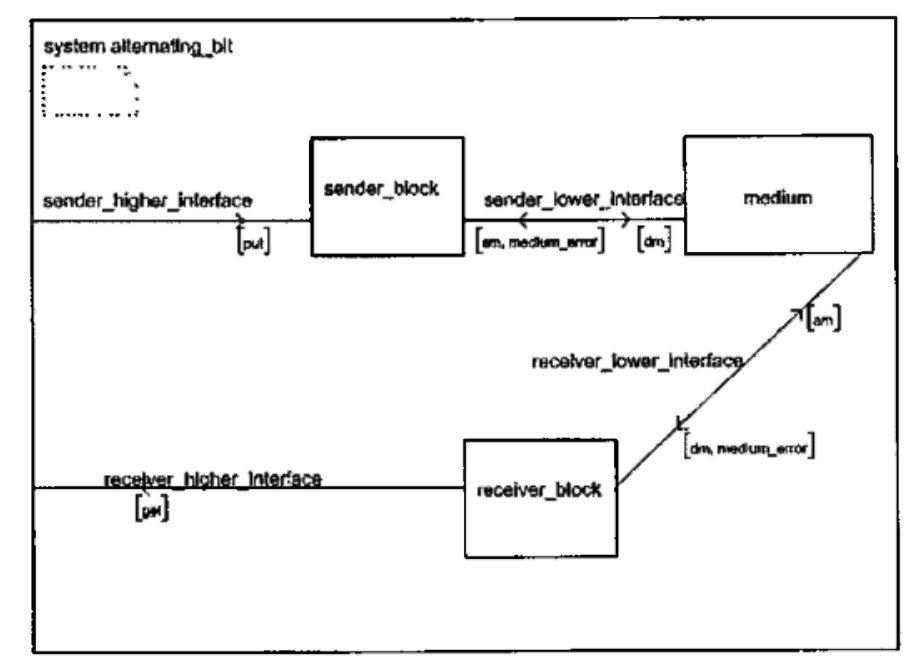

Figura 3.1: Nível de Sistema do Protocolo Bit-Alternante em SDL

A Figura 3.2 ilustra as especificaçōes textual (Figura 3.2(a)) e gráfica (Figura 3.2(b)) do processo Sender. O processo Sender recebe a mensagem a ser enviada e tenta enviá-la ao processo Receiver, adicionando um bit (0 ou 1) à mensagem. Após o envio, o Sender fica aguardando uma mensagem de reconhecimento (acknowledgement) enviado pelo Receiver, caso este tenha recebido a mensagem corretamente, ou então pode receber uma mensagem do Receiver avisando do recebimento da mensagem incorreta. Se receber a mensagem de reconhecimento ( acknowledgement), o Sender alterna o valor do bit atual e aguarda a chegada da próxima mensagem a ser enviada. Caso contrário, a mensagem é enviada novamente ao Receiver e o Sender fica aguardando o recebimento de uma mensagem enviada pelo Receiver.

\subsubsection{Grafo de Fluxo para Processos SDL}

O grafo de programa auxilia a aplicação dos critérios estruturais no teste de programas (Rapps e Weyuker, 1985). Similarmente, para auxiliar a aplicação desses critérios no teste de especificações SDL, um modelo de grafo de fluxo (GF) foi estabelecido: $G F=(N, E)$, em que $N$ é o conjunto de blocos e $E$ é o conjunto de arcos. Um GF é definido para cada processo em uma especificação SDL. Os conceitos de blocos (ou nós) e arcos de um GF para cada processo SDL são definidos:

- Blocos: um bloco $b_{i}$ representa um conjunto de comandos que são executados sequencialmente durante a simulação da especificação SDL, de forma que, se o primeiro comando é executado, todos os demais comandos também o serão ${ }^{2}$. É importante diferenciar um bloco nesse contexto e um bloco da estrutura da especificação SDL, apresentado no Capítulo 2. No restante do texto, quando o termo bloco for utilizado será no contexto de um GF, a menos que o contrário seja especificado.

- Arcos: um arco descreve o fluxo de controle entre os blocos.

\footnotetext{
${ }^{2}$ Neste caso, assume-se que o hardware envolvido não falha durante a execução de um bloco.
} 


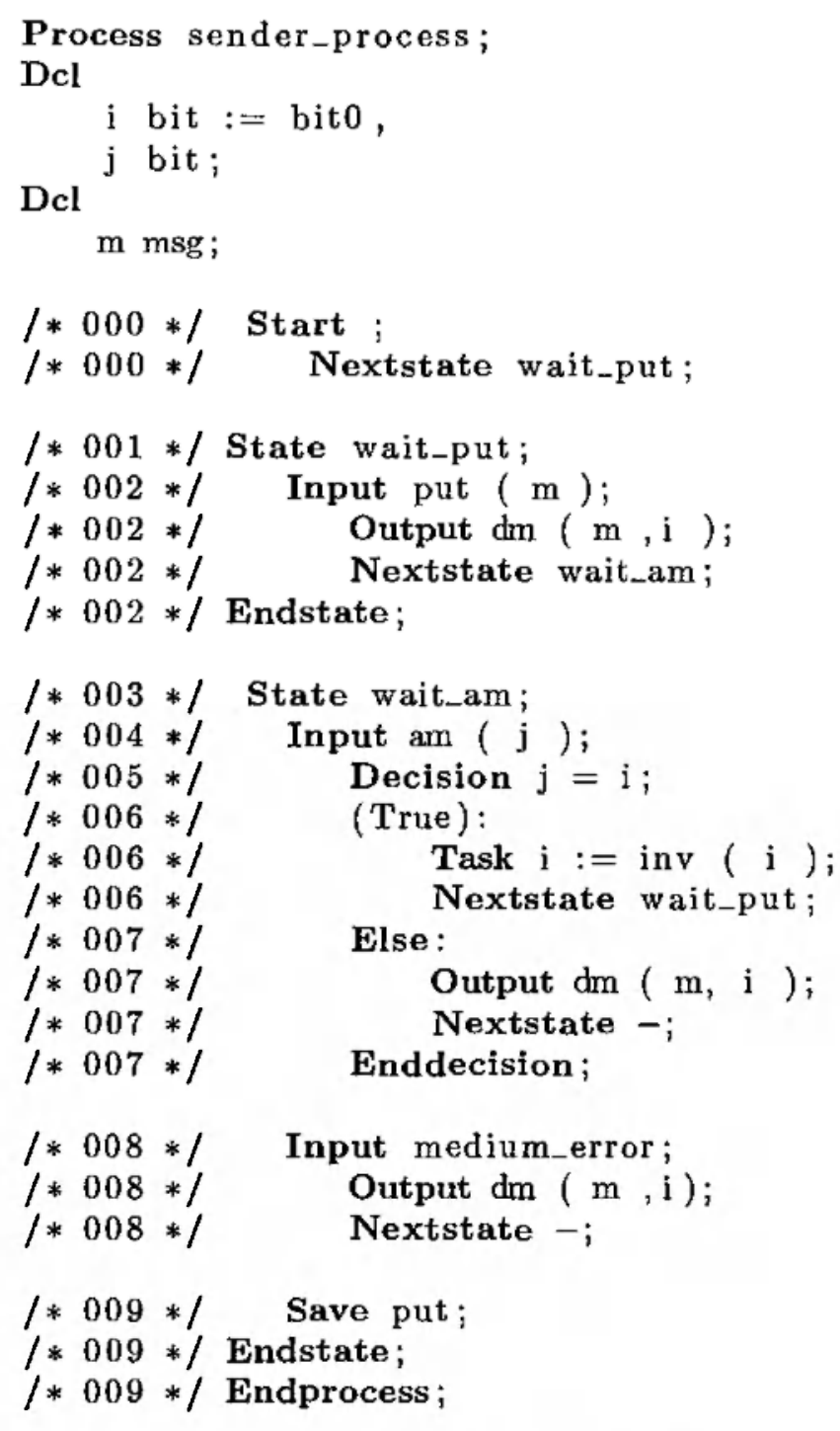

(a) Representação Textual em SDL

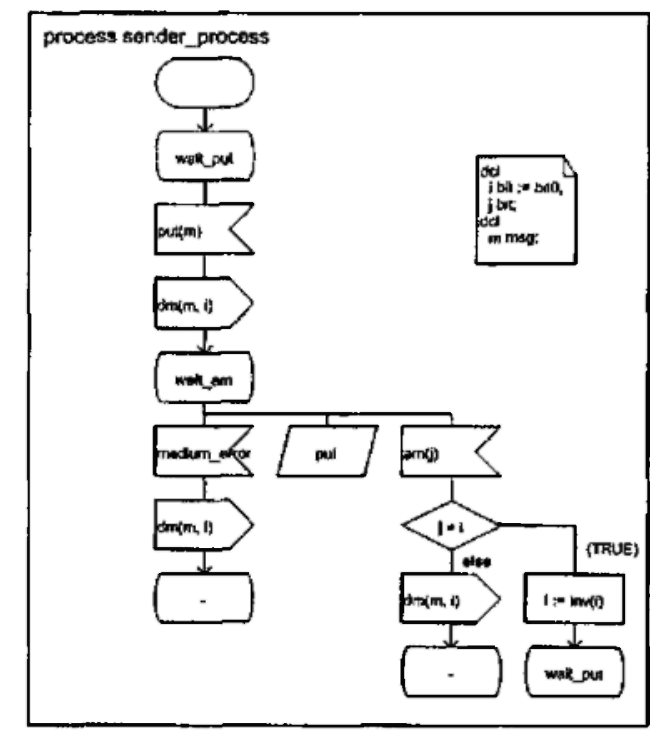

(b) Representação Gráfica em SDL

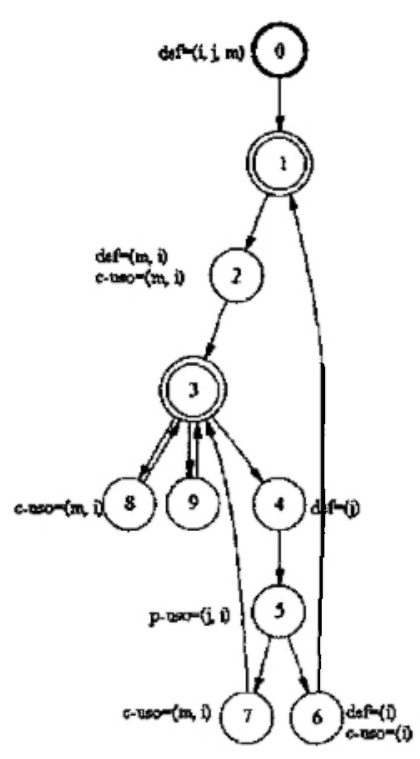

(c) Grafo de Fluxo

Figura 3.2: Processo Sender: Especificação em SDL e Grafo de Fluxo

Para decidir quando um novo bloco do GF deve ser criado, além das informações do fluxo de controle, algumas particularidades de SDL também foram consideradas. Dado que um GF é construído para cada processo SDL, blocos desse GF sempre são gerados quando se tem:

- estados: um bloco é criado exclusivamente para cada estado do processo SDL, pois transições, em geral, partem desse bloco e outras retornam a ele. Assim, o fluxo de controle durante a simulação da especificação pode ser mantido; 
- entradas (comando input): as entradas sempre são definidas posteriormente a um estado e como os estados pertencem a um bloco exclusivo, novos blocos devem ser criados para as possiveis entradas;

- decisões (comando decision): a partir dos blocos com comando de decisão partem os blocos com as possíveis opções;

- declaração de labels: os labels são utilizados para marcar um ponto da especificação a partir do qual um comando join continuará sua execução. Assim, para manter o fluxo corretamente, é necessário que os comandos localizados a partir de um label sejam colocados em um novo bloco;

- comando save: esse comando é um caso especial, pois o fluxo, após sua execução, retorna ao estado ao qual está ligado. Esse fato porém, não é explicitamente declarado na especificação SDL.

Sendo assim, a sequência de comandos em um bloco do GF é quebrada pelo próprio fluxo de controle da especificação ou sempre que ocorrer um desses casos.

A Figura 3.2(c) ilustra o grafo de fluxo do processo Sender. O número à esquerda de cada comando da especificação textual (Figura 3.2(a)) é referente ao bloco do GF ao qual o comando pertence. No GF, os círculos duplos correspondem aos blocos representando estados do processo. Observa-se que a parte inicial da especificação, que contém declarações das variáveis, não é representada no grafo. No GF do processo Sender pode-se perceber como é o fluxo de controle quando há um comando save. Observando-se a especificação textual em SDL apresentada na Figura 3.2(a), tem-se que o bloco 9 contém o comando save e após o mesmo, não há nenhuma declaração explícita sobre o fluxo da execução. Sabe-se no entanto, que a execução retorna para o estado ao qual o comando está ligado, no caso, o estado wait_am. No GF ilustrado na Figura 3.2(c), observa-se que o bloco 9 tem um arco que retorna ao bloco 3 , que corresponde ao estado wait_am.

Assim como o grafo de programa pode ter informações adicionadas sobre o fluxo de dados do programa, o grafo de fluxo para especificações SDL também pode ter adicionado aos blocos informações sobre atribuições (definições) de variáveis e sobre usos em computações (uso computacional ou c-uso) e adicionado aos arcos informações sobre usos em predicados que influenciam o fluxo de controle do processo SDL (uso predicativo ou p-uso). Um modelo de fluxo de dados para especificações SDL foi definido e segue as seguintes suposições para identificar definições e usos de variáveis:

1. variáveis podem ser definidas em blocos que contêm tarefas (comando task) em que algum valor é atriburdo à variável, e em blocos que contêm entradas (comando input);

2. pode haver um c-uso de uma variável nas tarefas, em que seu valor é utilizado em alguma computação, ou então nas saídas (comındo output); 
3. pode haver um p-uso de uma variável nas decisões (comando decision), quando seu valor é utilizado em um predicado;

4. no caso de variáveis estruturadas, qualquer ação (definição ou uso) executada em um de seus elementos é considerada uma ação executada na variável. Por exemplo, seja uma variável estruturada var declarada como tendo os elementos $e_{1}, e_{2}$ e $e_{3}$ do tipo inteiro. Uma definição var! $e_{2}:=0$ é considerada uma definiçāo de var.

Para cada bloco $b \in N$ de um GF de um processo SDL, dois conjuntos são identificados: def $(b)$, que é o conjunto de variáveis definidas em $b$ e c-uso $(b)$, que é o conjunto de variáveis com c-uso em $b$. Para cada arco $\left(b_{i}, b_{j}\right)$, é identificado o conjunto p-uso $\left(b_{i}, b_{j}\right)$ de variáveis com p-uso nesse arco.

Seja uma variável $x \in \operatorname{def}\left(b_{i}\right)$, dois conjuntos podem ser definidos a partir dos conjuntos c-uso e p-uso: $\operatorname{dcu}\left(x, b_{i}\right)$, que é o conjunto de blocos $b_{j}$ tal que $x \in \mathrm{c}$-uso $\left(b_{j}\right)$ e existe um caminho livre de definição em relação a $x$ do bloco $b_{i}$ para o bloco $b_{j}$; e dpu $\left(x, b_{i}\right)$, que é o conjunto de $\operatorname{arcos}\left(b_{j}, b_{k}\right)$ tal que $x \in \mathrm{p}$-uso $\left(b_{j}, b_{k}\right)$ e existe um caminho livre de definição em relação a $x$ do bloco $b_{i}$ para o arco $\left(b_{j}, b_{k}\right)$. Uma associação definição-c-uso é uma tripla $\left\{\left(b_{i}, b_{j}, x\right) \mid x \in \operatorname{def}\left(b_{i}\right) \wedge b_{j} \in \operatorname{dcu}\left(x, b_{i}\right)\right\}$. Uma associação definição-p-uso é uma tripla $\left\{\left(b_{i},\left(b_{j}, b_{k}\right), x\right) \mid x \in \operatorname{def}\left(b_{i}\right) \wedge\left(b_{j}, b_{k}\right) \in \operatorname{dpu}\left(x, b_{i}\right)\right\}$.

Em SDL, o fluxo de dados em um processo pode ser visto como os relacionamentos entre sinais de entrada, variáveis e sinais de saída. Por exemplo, na especificação do processo Sender da Figura 3.2(c), há um c-uso com relação à variável $m$, definida no bloco 2 (input put $(m)$ ) e usada no bloco 8 (output $d m(m, i)$ ). Um exemplo de p-uso ocorre com a variável $j$, definida no bloco 4 (input am $(j))$ e usada no arco $(5,6)($ decision $j=i$ ).

No caso de SDL, a definição do modelo de fluxo de dados é mais simples do que para uma linguagem de programação como $\mathrm{C}$ ou Java, em que variáveis agregadas, como os vetores, podem existir e é preciso decidir como lidar com elas.

\subsubsection{Critérios de Fluxo de Controle}

Considerando os critérios de fluxo de controle existentes para o teste de programas, dois critérios säo explorados no contexto de teste de especificações SDL, Todos-Blocos e Todas-Decisões, definidos a seguir:

- Todos-Blocos: requer que todos os blocos $b_{i}$ existentes no GF de cada processo SDL sejam executados.

- Todas-Decisões: requer que todas as decisões existentes nos blocos do GF sejam executadas. Em SDL, considera-se que as decisōes são relacionadas aos dados e às alternativas existentes nas especificaçöes ( $\mathrm{Li}$ e Wong, 2002), e podem ser causadas por 
transições de estados provocadas por entradas distintas ou por comandos de decisão. Por exemplo, na Figura 3.2(c), o processo Sender, a partir do estado wait_am (bloco 3), tem três ramificações correspondendo às entradas (1) am(j), (2) medium_error e (3) put, para três possíveis situações: (1) uma mensagem de reconhecimento (acknowledgement) com o bit $j$ é recebida; ou (2) uma mensagem medium error é recebida, indicando que houve um problema no envio de uma mensagem pelo Receiver; ou (3) uma nova mensagem a ser enviada, que vai para a fila de espera do processo, é recebida. No caso de receber uma mensagem de reconhecimento, há uma segunda ramificação causada por um comando de decisão. Nessa situação é decidido se o bit recebido tem o mesmo valor do bit esperado ou não. Assim, para o processo Sender há cinco requisitos de teste (decisões) a serem executados, com base no critério Todas-Decisões.

\subsubsection{Critérios de Fluxo de Dados}

Para explorar o fluxo de dados nas especificações SDL, são utilizados os critérios Todos-p-Usos, Todos-c-Usos e Todos-Usos, definidos a seguir:

- Todos-p-Usos: um conjunto de teste satisfaz os requisitos de teste desse critério se, para todo bloco $b$ e toda variável $x \in \operatorname{def}(b)$, exercitar um caminho livre de definição em relação a $x$ do bloco $b$ para todos os elementos de dpu $(x, b)$.

- Todos-c-Usos: requer que, para todo bloco $b$ e todo $x \in \operatorname{def}(b)$, um caminho livre de definição em relação a $x$ do bloco $b$ para todos os elementos de dcu $(x, b)$ seja exercitado.

- Todos-Usos: o conjunto de teste deve exercitar, para todo bloco $b$ e toda variável $x \in \operatorname{def}(b)$, um caminho livre de definição em relação a $x$ do bloco $b$ para todos os blocos de $\operatorname{dcu}(x, b)$ e todos $\operatorname{arcos} \operatorname{de} \operatorname{dpu}(x, b)$, ou seja, os requisitos de teste do critério Todos-Usos é a união dos conjuntos de requisitos dos critérios Todos-c-Usos e Todos-p-Usos.

Resumindo essas definições, o critério Todos-p-Usos requer que todas associações definição-p-uso $\left\{\left(b_{i},\left(b_{j}, b_{k}\right), x\right) \mid x \in \operatorname{def}\left(b_{i}\right) \wedge\left(b_{j}, b_{k}\right) \in \operatorname{dpu}\left(x, b_{i}\right)\right\}$ sejam exercitadas ao menos uma vez pelo conjunto de casos de teste; enquanto que o critério Todos-c-Usos requer que todas associações definição-c-uso $\left\{\left(b_{i}, b_{j}, x\right) \mid x \in \operatorname{def}\left(b_{i}\right) \wedge b_{j} \in \operatorname{dcu}\left(x, b_{i}\right)\right\}$ sejam exercitadas ao menos uma vez pelo conjunto de casos de teste. E por fim, o conjunto de teste deve exercitar todas associações definição-uso $\left\{\left(b_{i},\left(b_{j}, b_{k}\right), x\right) \mid x \in \operatorname{def}\left(b_{i}\right) \wedge\left(b_{j}, b_{k}\right) \in\right.$ $\left.\operatorname{dpu}\left(x, b_{i}\right)\right\}$ e $\left\{\left(b_{i}, b_{j}, x\right) \mid x \in \operatorname{def}\left(b_{i}\right) \wedge b_{j} \in \operatorname{dcu}\left(x, b_{i}\right)\right\}$, requeridas pelo critério Todos-Usos, para satisfazê-lo.

Ressalta-se que associações em que uma variável é definida e utilizada no mesmo bloco, ou seja, associações $\left\{\left(b_{i}, b_{i}, x\right) \mid x \in \operatorname{def}\left(b_{i}\right) \wedge b_{i} \in \operatorname{dcu}\left(x, b_{i}\right)\right\}$, não são consideradas como 
requisitos de teste dos critérios de fluxo de dados, pois sua cobertura é garantida pela execução de $b_{i}$.

Os critérios de fluxo de dados são baseados em associações def-uso (associações definição-c-uso ou definição-p-uso) executáveis (feasible), ou seja, existe pelo menos uma sequêencia de teste que exercita cada associação. Porém, a executabilidade (feasibility) é um problema indecidível. Embora algumas técnicas de análise possam ser aplicadas para identificar algumas associaçōes def-uso não-executáveis (infeasible) (Vergílio et al., 1992), na prática é muito difícil identificá-las e eliminá-las. Bourhfir et al. (2001a) apresentam uma discussão sobre o problema de executabilidade no contexto de SDL. No caso de SDL, pode ser que algumas associações def-uso sejam não executáveis, mas o problema da executabilidade não é tratado no contexto deste trabalho. Com isso, a cobertura obtida pode ser um pouco diferente daquela que seria obtida caso as associações def-uso não executáveis fossem eliminadas. No entanto, como a sintaxe de SDL é mais simples do que a sintaxe de linguagens de programação, tais como $\mathrm{C}$, espera-se que o número de associações não-executáveis seja pequeno e, nesse caso, o impacto dessas associações na cobertura de teste deve ser menor do que no caso de programas $\mathrm{C}$.

\subsubsection{Dominadores: Auxiliando a Geração de Casos de Teste}

Para auxiliar a geração de casos de teste para o teste de especificações SDL, o conceito de análise de dominadores proposto por Agrawal (1994) e apresentado na Seção 2.4.1.2 do Capítulo 2, é utilizado. Por exemplo, considerando o critério Todos-Blocos, diz-se que um bloco $A$ domina um bloco $B$ se a cobertura do bloco $B$ implica a cobertura do bloco $A$ ou seja, sempre que o bloco $B$ é executado, essa execução passa necessariamente pelo bloco $A$. A idéia é atribuir pesos aos requisitos de teste derivados do GF, de forma que o peso de um requisito é calculado com base no número de requisitos de teste que o dominam e, se possível, gerar casos de teste para cobrir primeiro os requisitos com major peso para que uma maior cobertura possa ser obtida a cada execução.

Essa abordagem de aplicação de teste estrutural no teste de especificações SDL, que auxilia a geração de casos de teste, foi implementada na ferramenta $C A T_{S D L}$, a ser apresentada posteriormente no Capítulo 5. Pretende-se com isso fornecer informações para a geração de casos de teste que sejam capazes de cobrir mais requisitos de teste dos critérios estruturais a cada execução, de forma que esses casos de teste devem ter prioridade de geração.

Para atribuir pesos aos requisitos de teste é utilizada uma abordagem conservativa, ou seja, consideram-se apenas os requisitos de teste que realmente serão cobertos pela execução desse requisito. Algumas vezes, uma execução que passa por um requisito pode passar por mais requisitos do que o valor atribuído ao seu peso. Por exemplo, retomando o grafo da Figura 2.4 do Capítulo 2 (apresentada a seguir), o bloco 15 tem peso 6 , ou seja, quando executado, esse bloco garante que outros 5 blocos também o serão. Mas uma possível 
execução que passa pelo bloco 15 executa os blocos $1,2,4,8,1,2,4,7$ e 12 , passando por 6 blocos ao invés de 5 .

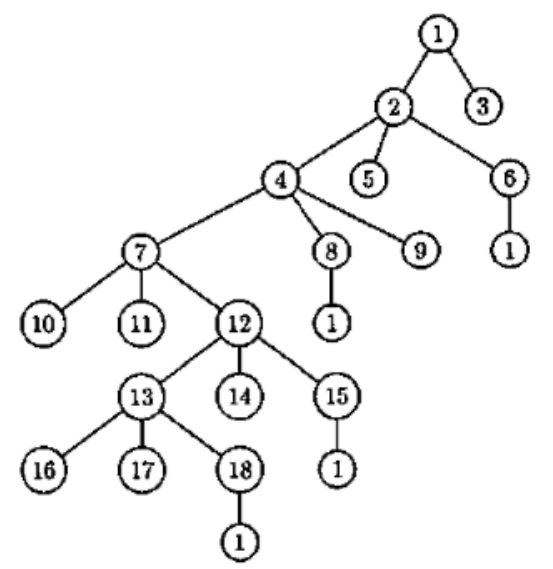

O bloco 5 do mesmo grafo tem peso 3 , pois é dominado pelos blocos 1 e 2. Comparando-se, por exemplo, o peso desse bloco com o do bloco 15 , o bloco 15 deveria ter prioridade de execução sobre o bloco 5, uma vez que seu peso é maior. Dessa forma, se a cobertura de blocos (critério Todos-Blocos) estiver sendo analisada e a cobertura do bloco 15 tem prioridade sobre a cobertura do bloco 5, garante-se a cobertura de pelo menos 6 blocos. Conseqüentemente, uma maior cobertura é obtida em uma única execução.

Conforme a especificação é executada, o peso dos requisitos de teste ainda não cobertos pode mudar. Por exemplo, após a execução de um caso de teste $c_{1}$, que cobre o bloco 15 , a execução de um outro caso de teste $c_{2}$, que cobre o bloco 5 , aumenta a cobertura em somente um bloco, pois a execução de $c t_{1}$ passa pelos blocos 1,2,4,7 e 12 e a execução de $c t_{2}$ passa pelos blocos 1,2 , já cobertos pelo primeiro caso de teste, e 5 , único bloco ainda não coberto anteriormente. Ou seja, o bloco 5 , após a execução do caso de teste $c t_{1}$ passa a ter peso 1 , pois os blocos que o dominam foram cobertos рог $c t_{1}$.

Após cada execução com um caso de teste, o peso de cada requisito ainda não coberto pelos casos de teste é recalculado, e a prioridade dos testes a serem executados para cobrir tais requisitos deve ser revista. O objetivo é repetir esse procedimento até que todos os requisitos tenham sido cobertos ou até que o testador decida parar a atividade de teste e, nesse caso, embora a cobertura alcançada possa não ser de $100 \%$, ainda assim espera-se que a cobertura obtida seja a mais alta possível, com o menor número de casos de teste.

No caso do critério Todas-Decisões, como os requisitos de teste são os arcos associados aos blocos em que há decisão, o valor do peso desses blocos é o maior peso dos seus arcos, ou seja, se de um bloco de decisão partem dois arcos, um com peso 2 e outro com peso 4 , o 
seu peso será 4. O peso de um bloco de decisão será zero quando todos os seus arcos forem cobertos. Assim, o peso de um arco indica o número mínimo de arcos associados aos blocos de decisão que podem ser cobertos se esse arco for executado.

Para o critério Todos-c-Usos, apenas as associações definição-c-usos $\left(b_{i}, b_{j}, x\right)$, têm seu peso considerado. $O$ peso do bloco $b_{i}$, em que a variável $x$ é definida, depende do valor dos pesos dos blocos $b_{j}$, em que há um c-uso de $x$, recebendo o valor do maior peso. $O$ peso de um bloco $b_{j}$ indica o número mínimo de associações definição-c-usos que podem ser cobertas se a associação $\left(b_{i}, b_{j}, x\right)$ for coberta. Por exemplo, se uma variável é definida em um bloco $b$ e tem três c-usos associados, com pesos 2,3 e 5 , o peso do bloco $b$, em relação a essa variável, é 5 . O mesmo raciocínio é válido para os critérios Todos-p-Usos e Todos-Usos.

Um ponto importante a ser ressaltado é que no cálculo dos pesos dos requisitos de teste, aspectos como complexidade de partes da especificação não são considerados. Assim, se é de conhecimento do testador que há alguma parte da especificação que seja mais crítica e mereça maior atenção, pode-se ou deve-se dar prioridade de cobertura para essa parte e quando essa for satisfatória, as informações dos pesos dos demais requisitos podem ser então consideradas.

\subsubsection{Uso de Informações de Teste na Atividade de Depuração}

Ainda com o intuito de avaliar a aplicação do conhecimento adquirido em nível de programa para o nível de especificação, investigou-se a aplicação de técnicas de depuração de programas na depuração de especificações. Mais especificamente, foi avaliada a aplicação de heurísticas baseadas em slices de execução propostas para a depuração de programas C (Agrawal et al., 1995) na depuração de especificações SDL (Wong et al., 2003, 2004).

Dentre as três formas de geração de slices, estático, dinâmico e de execução, já apresentadas na Seção 2.5 do Capítulo 2, optou-se pelos slices de execução pelo fato de que um slice estático tenta encontrar comandos que poderiam possivelmente ter influência nas variáveis de interesse, independente das entradas, sem se importar em buscar aqueles comandos que realmente influenciaram aquelas variáveis para uma entrada específica. Ou seja, o slice estático não utiliza informação dos valores de entrada que revelam o erro. Este fato contraria a idéia de que, na depuração, o programador analisa o comportamento do programa tendo conhecimento de um caso de teste que revela o erro. Em relação ao slice dinâmico, o problema é que selecioná-lo pode ser custoso em termos de tempo e espaço de armazenamento. Já um slice de execução de um caso de teste, pode ser um conjunto de requisitos de teste (determinados pelo critério de teste sendo aplicado) que foram executados pelo caso de teste, ou seja, slices de execução podem ser definidos com o auxílio de informaçōes provenientes da atividade de teste.

Assim, nessa proposta aplicam-se os critérios estruturais apresentados nas Seções 3.2.2 e 3.2.3, para obter informações de cobertura que auxiliem a depuração de forma a determinar 
os slices de execução de cada caso de teste. Para apoiar essa proposta foi desenvolvida a ferramenta $S \operatorname{mart} D_{S D L}$, que será apresentada na Seção 5.3 do Capítulo 5.

Para utilizar as informações dos slices de execução na depuração de especificações SDL, foi proposta uma estratégia que auxilia a localização de erros. Nessa estratégia considera-se que a especificação pode ser executada com alguns casos de teste sem que erros sejam descobertos. Diz-se que esses casos de teste foram bem sucedidos. No caso de um caso de teste expor um comportamento não esperado da especificação, supõe-se que o erro esteja no slice de execução desse caso de teste. Esse caso de teste é dito mal sucedido. A estratégia então propõe que para a localização do erro seja dada prioridade aos comandos pertencentes ao slice de execução de casos de teste mal sucedidos. Algumas observações devem ser consideradas:

- Quanto mais casos de teste bem sucedidos executarem uma parte da especificação, menos provável que essa parte contenha algum erro;

- Quanto mais casos de teste forem mal sucedidos, em relação a um mesmo erro, durante a execução de uma determinada parte da especificação, maior é a probabilidade dessa parte conter o erro.

Resumindo, a probabilidade de uma parte da especificação conter um erro específico é inversamente proporcional ao número de casos de teste bem sucedidos que a executaram, mas é proporcional ao número de casos de teste mal sucedidos que a executaram, com respeito ao mesmo erro.

O critério de teste selecionado determina como os slices de execução são representados, ou seja, os slices podem ser representados por blocos, decisões, c-usos ou p-usos, dependendo se a cobertura estiver sendo avaliada em relaçāo aos critérios Todos-Blocos, Todas-Decisões, Todos-c-Usos, Todos-p-Usos ou Todos-Usos.

Pode-se buscar um erro em duas situações: logo que um caso de teste provoca um comportamento anormal da especificação ou esperar até que mais casos de teste provoquem o mesmo comportamento inesperado da especificação. Na primeira situação, tem-se um caso de teste mal sucedido e possivelmente alguns casos de teste bem sucedidos para fornecerem informações para a atividade de depuração. No segundo caso, há mais de um caso de teste mal sucedido para fornecer informações. Foram propostas heurísticas que atribuem prioridades aos slices em três diferentes situações:

1. Caso I: um caso de teste mal sucedido e um caso de teste bem sucedido. Nessa situação, o ideal é começar a procurar o erro em partes da especificação que estejam no slice de execução do caso de teste mal sucedido e não estejam no slice de execuçāo do caso de teste bem sucedido. Assim, a prioridade maior, 2, é dada às partes da especificação executadas apenas pelo caso de teste mal sucedido. Partes da especificação executadas por ambos casos de teste recebem prioridade 1 e partes não executadas pelo caso de 
teste mal sucedido têm prioridade 0. A busca pelo erro deveria ser iniciada pelas partes com prioridade 2, seguida pelas partes da especificação com prioridade 1 e por fim, pelas partes com prioridade 0 ;

2. Caso II: um caso de teste mal sucedido e dois casos de teste bem sucedidos. Nesse caso, a heurística propõe a identificação de partes executadas apenas pelo caso de teste que provocou um comportamento inesperado da especificação, atribuindo a elas prioridade 3. Partes executadas pelo caso de teste mal sucedido e apenas por um dos casos de teste bem sucedido recebem prioridade 2, enquanto que as partes executadas pelos três casos de teste recebem prioridade 1. Partes não executadas pelo caso de teste mal sucedido têm prioridade 0. A busca pelo erro deve começar pelas partes da especificação com prioridade 3 , seguida pelas de prioridade 2,1 e 0 , respectivamente;

3. Caso Geral: um conjunto de casos de teste mal sucedidos e um conjunto de casos de teste bem sucedidos. Nessa situação, a heurística propõe a definição de dois grupos de slices de execução, grupo I com os casos de teste bem sucedidos, e grupo II, com casos de teste mal sucedidos, e permite identificar os slices executados por todos os casos de teste mal sucedidos e apenas por esses, determinando o conjunto união dos slices executados pelos casos de teste bem sucedidos (grupo I) e subtraindo esse conjunto do conjunto interseç̧ão dos slices executados pelos casos de teste mal sucedidos (grupo II). Assim, três passos devem ser realizados: (a) identificação de slices executados por todos os casos de teste do grupo II, ou seja, é calculada a interseç̧ão dos slices executados por todos os casos de teste mal sucedidos $\left(\cap_{\text {grupo II }}\right)$; (b) identificação de slices executados pelos casos de teste do grupo I, ou seja, é calculada a união de todos os slices executados pelos casos de teste bem sucedidos $\left(\cup_{\text {grupo I }}\right)$; e, (c) identificação dos slices executados por todos os casos de teste mal sucedidos e apenas por esses, ou seja, é realizada a subtração do conjunto de slices identificados no passo (b) do conjunto de slices identificados no passo (a) ( $\cap_{\text {grupo }}$ II $\left.-\cup_{\text {grupo } I}\right)$. Esses slices são indicados como os possíveis locais que contêm o erro.

No caso da terceira situação, em que há muitos casos de teste mal e bem sucedidos, há um grande número de prioridades que poderiam ser atribuídas às partes da especificação, o que possibilita a definição de inúmeras heurísticas. A solução proposta permite que as informações dos casos de teste sejam utilizadas de forma flexível, possibilitando diversas combinações dos casos de teste. Por exemplo, suponha a existência de cinco casos de teste mal sucedidos e quatro casos de teste bem sucedidos. Pode-se desejar examinar todos os casos de teste, e com a utilização da terceira heurística, visualiza-se apenas as partes da especificação executadas pelos cinco casos de teste mal sucedidos. Ou então, pode-se desejar saber quais slices foram executados por três casos de teste mal sucedidos e não executados por dois casos de teste bem sucedidos, examinando-se informações apenas desses cinco casos de teste. 
Observa-se que quando se tem a situação abordada pelo Caso I, com um caso de teste mal sucedido e um caso de teste bem sucedido, examinada pelo Caso Geral, os slices indicados por esse último são os apontados pelo Caso I com prioridade 2. Os slices de prioridades 1 e 0 não são apontados pelo Caso Geral. O mesmo ocorre quando um caso de teste mal sucedido e dois casos de teste bem sucedidos são examinados pelo Caso Geral. Essa heurística indica apenas os slices que têm prioridade 3 quando examinados pelo Caso II. Os slices de prioridades 2, 1 e 0 não são apontados. Assim, é interessante também a existência das heurísticas dos Casos I e II, que apresentam as informações dos slices com diferentes prioridades.

\subsection{Teste Estrutural em Nível de Sistema}

Nessa seção apresentam-se critérios de teste baseados em fluxo de controle que derivam seus requisitos a partir da árvore de alcançabilidade, que modela o comportamento da especificação SDL. Na mesma linha de trabalhos anteriores em que foram definidos critérios de fluxo de controle para o teste de especificações Statecharts - FCCS (Família de Critérios de Cobertura para Statecharts) (Souza et al., 2000c), Estelle - FCCE (Família de Critérios de Cobertura para Estelle) (Souza et al., 2001) e Redes de Petri Coloridas - CPNCCF (Coloured Petri Nets Coverage Criteria Family) (Simão et al., 2003), uma família de critérios denominada FCCSDL - Família de Critérios de Cobertura para SDL, é estabelecida para o teste de especificações SDL.

O modelo de árvore de alcançabilidade definido para SDL é apresentado na Seção 3.3.2.1. Os critérios FCCSDL são definidos na seção a seguir.

\subsubsection{Família de Critérios de Cobertura FCCSDL}

Para a aplicação dos critérios FCCSDL é importante a definição do conceito de configuração, que é um conjunto de estados ativos em um dado passo da execução da especificação. Para construir o espaço de possíveis configurações de uma especificação, supõe-se que, a cada passo, os sinais associados à configuração atual são válidos e disparam a transição associada. A partir de um espaço de possíveis configurações, outros conceitos são definidos, com base em conceitos já apresentados no Capítulo 2. Esses conceitos são retomados:

- caminho: é uma seqüência finita de configurações $\left(C_{1}, C_{i}, C_{j}, \ldots, C_{m}, C_{k}\right), k \geq 1$, tal que a primeira configuração é $C_{1}$, e existe uma transição de $C_{i}$ para $C_{j}, \forall C_{i}, C_{j} \mid 1 \leq$ $i<k \wedge j=i+1$

- caminho simples: é um caminho $P$ tal que todas as configurações que compõem esse caminho, exceto possivelmente a primeira e a última, sāo distintas;

- caminho livre de laço: é um caminho simples $P$ tal que todas as configurações são distintas. 
A FCCSDL é composta de oito critérios de cobertura que exploram aspectos de fluxo de controle das especificações SDL. Esses critérios são descritos a seguir:

1. Critério Todas-Configurações: requer que todas as configurações sejam percorridas no mínimo uma vez pelo conjunto de seqüências de teste;

2. Critério Todas-Transições: requer que todas as transições sejam executadas no mínimo uma vez pelo conjunto de sequiências de teste;

3. Critério Todos-Caminhos: requer que todos os caminhos sejam percorridos no mínimo uma vez pelo conjunto de sequências de teste;

4. Critério Todos-Caminhos- $k$ - $C_{1}$-Configuração: requer que todos os caminhos contendo no máximo $k$ repetições da primeira configuração $C_{1}$ da árvore de alcançabilidade sejam percorridos no mínimo uma vez pelo conjunto de sequências de teste. Considera-se a configuração $C_{1}$ e não a configuração $C_{0}$ como a configuração inicial porque $C_{0}$ representa os estados dos processos antes de serem inicializados, o que normalmente acontece apenas uma única vez durante uma execução da especificação SDL. A exceção acontece apenas quando um processo é criado e finalizado dinamicamente por um outro processo;

5. Critério Todos-Caminhos- $k$-Configurações: requer que todos os caminhos contendo no máximo $k$ repetições de cada configuração sejam percorridos no mínimo uma vez pelo conjunto de seqüências de teste;

6. Critério Todos-Caminhos-com-um-Laço: requer que todos os caminhos contendo no máximo 2 repetições de uma (somente uma) configuração $C_{i}$ sejam percorridos no mínimo uma vez pelo conjunto de sequiências de teste;

7. Critério Todos-Caminhos-Simples: requer que todos os caminhos simples sejam percorridos no mínimo uma vez pelo conjunto de seqüências de teste;

8. Critério Todos-Caminhos-livre-Laço: requer que todos os caminhos livres de laços sejam percorridos no mínimo uma vez pelo conjunto de seqüências de teste.

Os critérios Todas-Configurações e Todas-Transições são similares aos critérios Todos-Nós e Todos-Arcos, respectivamente, muito utilizados no teste de programas. Esses dois critérios estabelecem requisitos que determinam à cobertura mínima desejável em sistemas baseados em transições, como é o caso de SDL, cujo comportamento é descrito por meio de MEFECs, que é executar todas as configurações de estados e todas as transições. Esses critérios porém, não são apropriados para revelar erros típicos de especificações baseadas em Máquinas de Estados Finitos, tais como erros de transferência, erros de operação e erros de estados extras ou ausentes (Chow, 1978). Esse aspecto já havia sido observado por Souza (2000) para 
as técnicas Statecharts e Estelle. Assim, dada a necessidade da definição de critérios mais rigorosos, propôs-se outro critério, também derivado do teste de programas, Todos-Caminhos. Esse critério porém, do ponto de vista do teste estrutural, corresponde ao teste exaustivo, que muitas vezes é impraticável dada a possibilidade de existirem infinitos caminhos.

Para preencher a lacuna entre os critérios Todas-Configurações e Todas-Transições, por um lado, menos rigorosos e custosos, e por outro lado, o critério Todos-Caminhos, rigoroso porém normalmente inviável, foram propostos os critérios Todos-Caminhos- $k$ - $C_{1}$-Configuração, Todos-Caminhos- $k$-Configurações, Todos-Caminhos-com-um-Laço, Todos-Caminhos-Simples e Todos-Caminhos-livre-Laço. Esses critérios são menos custosos que o critério Todos-Caminhos, mas impõem maior rigor que os critérios Todas-Configurações e Todas-Transições.

Duas ressalvas sobre a aplicação do critério Todos-Caminhos- $k-C_{1}$-Configuração devem ser feitas. A primeira é que só é possível aplicá-lo efetivamente no teste de especificações que são reinicializáveis. Uma especificação é reinicializável quando, para cada configuração $C_{i}$ alcançada a partir de $C_{1}$, existe uma sequência de eventos que retorna a $C_{1}$, sendo $C_{1}$ a primeira configuração de estado após todos os processos terem sido inicializados. Entretanto, não é possível determinar se uma especificação é reinicializável sem percorrer a árvore de alcançabilidade até encontrar um caminho em que $C_{1}$ é alcançado a partir de uma configuração $C_{i}$. Para Statecharts, Boaventura (1992) desenvolveu um algoritmo para analisar se um statechart é reinicializável. Souza (2000) considera que esse algoritmo pode ser estendido para ser aplicado no contexto de especificações Estelle, o que, similarmente, também poderia ser feito para SDL, auxiliando a verificação da aplicabilidade desse critério de teste. A segunda ressalva é que, em alguns casos, esse critério pode gerar um número infinito de requisitos de teste, pois apenas o número de repetições da configuração $C_{1}$ limitado, de forma que as outras configurações podem ser repetidas inúmeras vezes.

Os critérios FCCSDL podem ser utilizados como critérios de adequação e como métodos de seleção de seqüências de teste, pois fornecem mecanismos que permitem a análise de cobertura de teste da especificação SDL e que guiam a geração de seqüências de teste adequadas, por construção, a esses critérios. Um conjunto de seqüências de teste $T$ é adequado em relaçã̉o a um critério $C r$ (descrito como $C r$-adequado) se $T$ satisfaz ou executa todos os requisitos de teste impostos por $C r$ (Rapps e Weyuker, 1985). Um conjunto de sequêencias de teste $T$ é adequado, por construção, a um critério $C r$ quando os requisitos de teste estabelecidos por $C r$ guiam a geração de $T$, ou seja, $T$ é construído de forma a cobrir cada requisito de $C r$.

É importante também ressaltar que, apesar de ter sido proposta para o teste de especificações SDL, os critérios FCCSDL podem também ser aplicados no teste de conformidade. Ou seja, podem-se utilizar os requisitos estabelecidos por esses critérios para guiar a geração de um conjunto de sequiências de teste adequado para ser aplicado no teste de uma implementação relacionada. 


\subsubsection{Caracterização dos Requisitos de Teste dos Critérios FCCSDL}

Os critérios FCCSDL derivam seus requisitos da árvore de alcançabilidade para especificações SDL. Nesta seção, apresentam-se o modelo de árvore de alcançabilidade utilizado e a proposta de como os requisitos de teste para os critérios da família FCCSDL podem ser derivados a partir desse modelo.

\subsubsection{1 Árvore de Alcançabilidade para SDL}

Como comentado anteriormente, a árvore de alcançabilidade permite modelar o comportamento dinâmico do sistema (ou especificação) por meio da descrição dos possiveis estados alcançados quando ocorre um evento ou sinal. O maior problema dessa técnica é que pode haver um número muito grande de possíveis estados, o que compromete seu custo de aplicação. Para tentar solucionar ou diminuir esse problema, algumas técnicas de redução foram propostas, como apresentado no Capítulo 2.

No Capítulo 2 também foram apresentados alguns modelos de árvore de alcançabilidade propostos para técnicas baseadas em transição de estados, como as MEFECs, Estelle e Statecharts, e também para protocolos de comunicação. Para a árvore de alcançabilidade proposta neste trabalho, foram utilizadas algumas características dos modelos propostos em trabalhos anteriores que mais se adequavam à SDL, assim como algumas técnicas de redução, conforme apropriado para as especificações SDL.

No modelo de árvore de alcançabilidade proposto para SDL, a árvore é construída, a princípio, para todo o sistema e duas técnicas de redução são aplicadas para evitar o problema de explosão de estados: nós duplicados e stubborn sets (Barnard, 1998). Aplicando-se a técnica de nós duplicados, quando uma configuração que já está presente na árvore for inserida, uma ligação para sua primeira ocorrência é considerada. Com a técnica stubborn sets, quando transições independentes, ou seja, de processos diferentes, podem ser disparadas no mesmo passo, considera-se apenas uma das possibilidades de ordem entre elas.

Uma outra possibilidade é utilizar, a exemplo de Souza (2000), a técnica de redução conjunto de componentes, que seleciona previamente alguns componentes do sistema modelado para a construção da árvore de alcançabilidade. Dessa forma, para especificações SDL mais complexas, pode-se analisar apenas alguns processos e obter uma árvore de alcançabilidade de tamanho menor, mas que considera as interações entre alguns processos da especificação. Bourhfir et al. (2001b) propuseram um método de geração de casos de teste para sistemas compostos por MEFECs, como é o caso de SDL, que analisa cada MEFEC que compõe o sistema separadamente, evitando o problema de expiosão de estados. Porém, Bourhfir et al. (2001a) afirmam que testar cada máquina isoladamente não é suficiente por não considerar sua interação com o contexto, mas que testar um sistema comunicante como um todo pode ser muito custoso, ou então impossível por causa do problema de explosão de estado. 
Os trabalhos que exploram a árvore de alcançabilidade para sistemas especificados em SDL denominam de estado global o conjunto de estados que representam o comportamento do sistema em cada nó da árvore. Neste trabalho, esse conjunto de estados é denominado de configuração, mantendo a terminologia adotada nas árvores de alcançabilidade definidas para Statecharts e Estelle, por Masiero et al. (1994) e Souza (2000), respectivamente.

Para um sistema SDL composto de $n$ processos $P_{i}, i=1,2, \ldots, n$, define-se uma configuração $C_{k}=\left(\left\langle s_{\imath}^{k}\right\rangle_{i=1,2, \ldots, n},\left\langle F_{i}^{k}\right\rangle_{i=1,2, \ldots, n},\left\langle B_{i}^{k}\right\rangle_{i<=n}\right)$, em que $\left\langle s_{i}^{k}\right\rangle$ é o estado atual do processo $P_{i},\left\langle F_{i}^{k}\right\rangle$ é uma fila com as entradas que chegam em $P_{i}$ e $\left\langle B_{i}^{k}\right\rangle$ é uma fila para armazenar as entradas que foram salvas pelo comando save para cada processo $P_{i}$ em que este comando existir. Se o conteúdo de $F_{i}$ é vazio em $C_{k}$, ele é representado por $\emptyset$, ou seja, $F_{i}^{k}=\emptyset$. O mesmo pode ser considerado para as filas que armazenam os sinais que devem ser salvos. $C_{1}$ denota a configuração inicial, em que cada processo está em seu primeiro estado $\left\langle o_{i}\right\rangle_{i=1,2, \ldots, n}$, após sua inicialização, e todas as filas estão vazias, ou seja, $C_{1}=\left(\left\langle o_{i}\right\rangle_{i=1,2, \ldots, n},\left\langle F_{i}^{1}\right\rangle_{i=1,2, \ldots, n},\left\langle B_{i}^{1}\right\rangle_{i<=n}\right)$ e $F_{i}^{1}=\emptyset$ e $B_{i}^{1}=\emptyset$.

Como a técnica SDL permite que algumas entradas sejam "salvas" em um estado para serem consumidas em outro do mesmo processo, essa característica também foi considerada na definição de uma configuração da árvore de alcançabilidade, caso seja pertinente à especificação SDL sendo modelada. Os sinais que devem ser salvos são considerados em outra fila, como um terceiro componente na configuração da árvore, para que não haja o risco de confundi-los com os outros sinais, de forma a não descartá-los indevidamente, como acontece com os outros sinais armazenados em $F_{i}$ quando não podem ser consumidos no estado atual do processo. É importante ressaltar que, para simplificar, considera-se que um sinal pode estar salvo apenas uma vèz na fila $B_{i}$, ou seja, uma véz salvo, mesmo que um caminho na árvore passe por um comando save em que este sinal deveria ser salvo novamente, o sinal não será salvo e essa configuração não terá sucessoras. Se o sinal salvo na fila $B_{i}$ for consumido, ele poderá ser novamente salvo, caso o caminho que passe pelo save desse sinal seja executado. Isso é válido quando apenas um sinal deve ser salvo. Quando vários sinais devem ser salvos em um mesmo estado, cada um deles pode estar salvo apenas uma única vez na fila $B_{i}$. Dessa forma, uma fila $B_{i}$ tem tamanho finito, ou seja, seu tamanho é no máximo $z$, para um processo que pode receber $z$ sinais diferentes como entrada.

A árvore de alcançabilidade que modela o comportamento do protocolo Bit-Alternante é ilustrada na Figura 3.3. As configurações dessa árvore são definidas como: $C_{i}=$ ( [(sender, fila $\left.\left._{\text {sender }}, f_{\text {Save }}\right)\right],\left[\left(\right.\right.$ medium1, fila $\left.a_{\text {medium } 1}\right),\left(\right.$ medium2, fila $\left.\left.a_{\text {medium } 2}\right)\right]$, [(receiver, fila $\left.\left.a_{\text {receiver }}\right)\right]$ ). A seguir apresentam-se todas as configurações que compõem essa árvore:

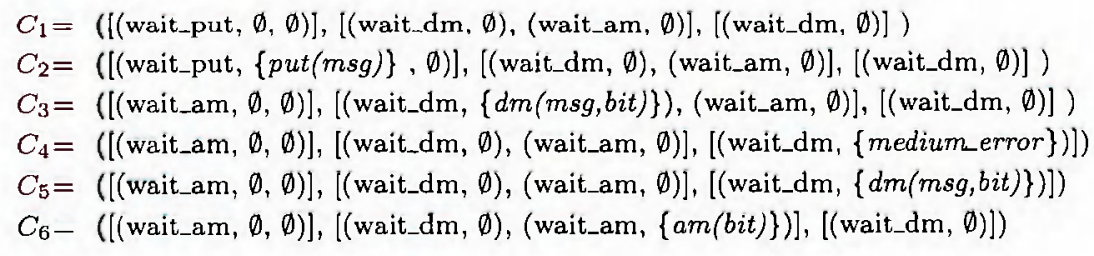


$C_{7}=(\lfloor($ wait_am, \{medium_error $\}, \emptyset)],[($ wait_dm, $\emptyset)$, (wait_am, $\left.\emptyset)\right],[($ wait_dm, $\left.\emptyset)]\right)$

$C_{8}=$ ([(wait_am, $\{a m($ bit $\left.\left.)\}, \emptyset\right)\right],[($ wait_dm, $)$ ), (wait_am, $\left.)\right],[($ wait_dm, $\left.\emptyset)]\right)$

$C_{9}=$ ([(wait_an, $\{$ put $\left.\left.(m s g)\}, \emptyset\right)\right],[($ wait_dm, $\{d m(m s g, b i t)\})$, (wait_am, Ø)], [(wait_dm, Ø)])

$C_{10}=([($ wait_am, $\{$ put $(m s g)\}, \emptyset)],[($ wait_dm, $\emptyset),($ wait_am, $\emptyset)],[($ wait_dm, $\{$ medium_error $\})])$

$C_{11}=([($ wait_am, $\{$ put $(m s g)\}, \emptyset)],[($ wait_dm, $\emptyset)$, (wait_am, $\emptyset)],[($ wait_dm, $\left.\{d m(m s g, b i t)\})]\right)$

$C_{12}=$ ([(wait_am, \{put(msg)\}, $\left.\left.\emptyset\right)\right],[($ wait_dm, $\emptyset)$, (wait_am, \{am(bit)\})], [(wait_dm, $\left.\left.\emptyset)\right]\right)$

$C_{13}=$ ([(wait_am, \{put(msg), medium_error $\left.\left.\}, \emptyset\right)\right],[($ wait_dm, $\emptyset),($ wait_am, $\emptyset)],[($ wait_dm, $\left.)]\right)$

$C_{14}=([($ wait_asn, \{medium_error $\},\{$ put $($ msg $)\})],[($ wait_dm, $\emptyset),($ wait_am, $\emptyset)],[($ wait_dm, $\emptyset])$

$C_{15}=$ ([(wait_am, \{meditumerror, put (msg)\}, $\left.\left.\emptyset\right)\right]$, [(wait_dm, $\left.\emptyset\right)$, (wait_am, $\left.\left.\emptyset\right)\right],[($ wait_dm, $\left.\emptyset)]\right)$

$C_{16}=([($ wait_am, $\{$ put $(m s g)$, am(bit) $\}, \emptyset)],[($ wait_dm, $\emptyset)$, (wait_am, $\emptyset)],[($ wait_dm, $\left.\emptyset)]\right)$

$C_{17}=$ ([(wait_am, $\{a m($ bit $)\},\{$ put $($ msg $\left.\left.)\}\right)\right],[($ wait_dm, $\emptyset),($ wait_am, $\emptyset)],[($ wait_dm, $\left.\emptyset)]\right)$

$C_{18}=([($ wait_am, $\{a m($ bit $), p u t(m s g)\}, \emptyset)],[($ wait_dm, $\emptyset),($ wait_am, $\emptyset)],[($ wait_dm, $\emptyset)])$

$C_{19}=$ ([(wait_am, $\emptyset,\{$ put $\left.\left.(m s g)\}\right)\right],[($ wait_dm, $\emptyset)$, (wait_am, \{am(bit $\left.\left.\left.)\right\}\right)\right]$, [(wait_dm, $\left.\left.\emptyset\right)\right]$ )

$C_{20}=([($ wait_am, $\emptyset,\{$ put $(m s g)\})],[($ wait_dm, $\emptyset)$, (wait_am, $\emptyset)],[($ wait_dm, $\left.\{d m(m s g, b i t)\})]\right)$

$C_{21}=([($ wait_am, $\emptyset,\{$ put $(m s g)\})],[($ wait_dm, $\emptyset)$, (wait_am, $\emptyset)],[($ wait_dm, \{mediurn_error $\left.\left.\})\right]\right)$

$C_{22}=([($ wait_am, $\emptyset,\{$ put $(m s g)\})],[($ wait_dm, $\{d m(m s g, b i t)\}),($ wait_am, $\emptyset)],[($ wait_dm, $\bullet)])$

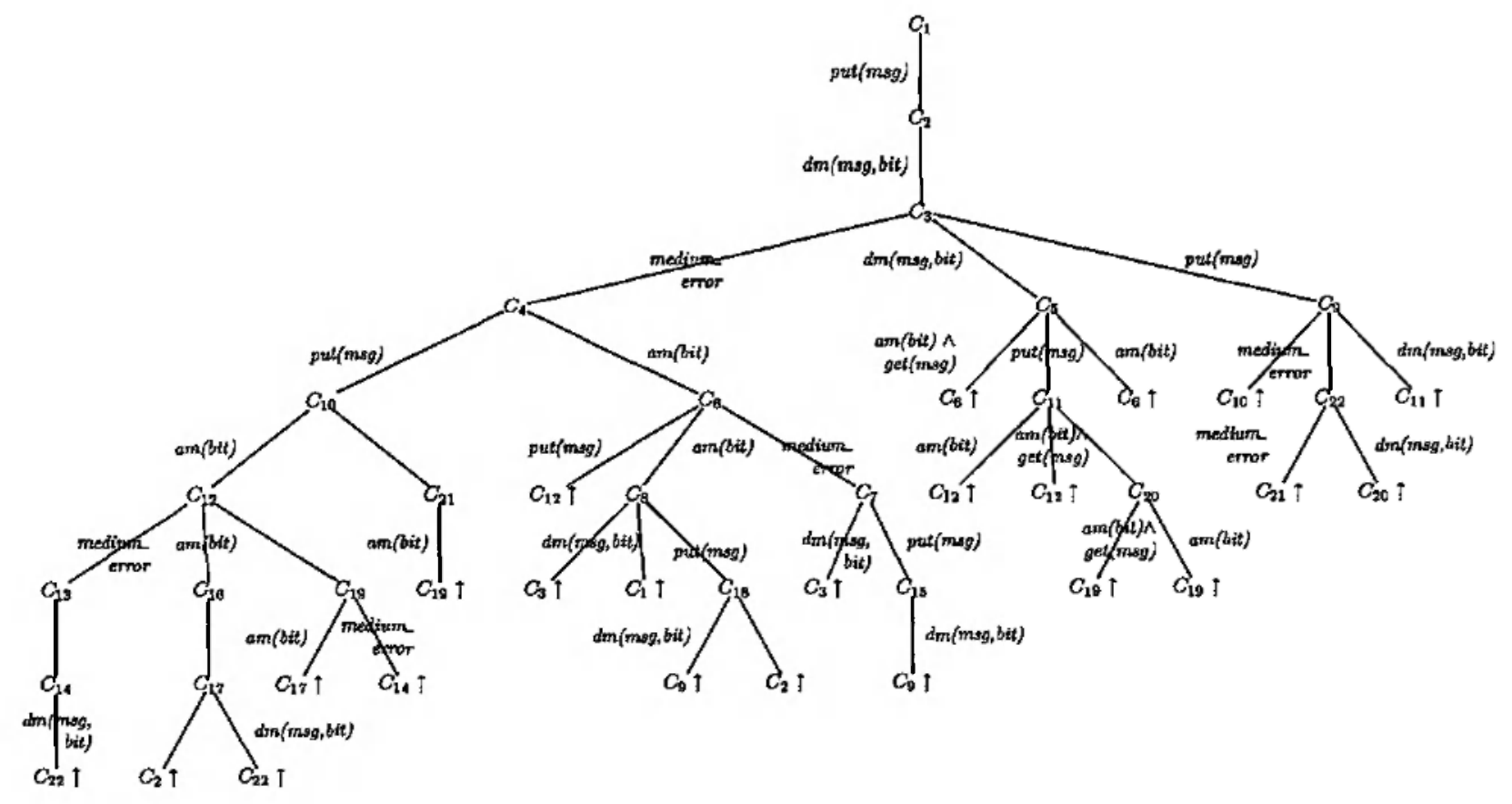

Figura 3.3: Árvore de Alcançabilidade para o protocolo Bit-Alternante

Para obter os requisitos de teste dos critérios FCCSDL, a árvore de alcançabilidade é percorrida em profundidade até que todos os requisitos sejam derivados, seguindo a definição de cada critério. Esses requisitos podem ser usados para guiar a geração de sequiências de teste ou para auxiliar a avaliação da adequaçāo de um conjunto de teste em relação a um 
dos critérios de teste. Quando utilizados no primeiro caso, as sequências de teste podem ser utilizadas, por exemplo, na simulação da especificação SDL. Essas sequências de teste podem ser vistas como um conjunto inicial para a simulação e novas sequências podem ser adicionadas durante a simulação. Uma outra aplicação é no teste de conformidade. Já para avaliar a adequação de um conjunto de testes, pode-se analisar a satisfação desses requisitos por um conjunto de teste gerado por outros critérios de teste ou mesmo por simulação. O cálculo da cobertura para cada critério ou para todos critérios FCCSDL pode ser feito segundo a expressão:

$$
\text { Cobertura } a_{F C C S D L}=\frac{\text { Número de Requisitos de Teste Cobertos }}{\text { Número de Requisztos Gerados }}
$$

Na Seção 6.1.3 do Capítulo 6 apresentam-se os requisitos de teste gerados pelos critérios FCCSDL para a especificação SDL do protocolo Bit-Alternante.

\subsubsection{Análise Teórica dos Critérios FCCSDL: Relação de Inclusão}

Como comentado no capítulo anterior, os critérios de teste podem ser comparados segundo três aspectos: custo, eficácia e strength. Do ponto de vista teórico, o strength pode ser analisado pela relação de inclusão (Rapps e Weyuker, 1985). Segundo Zhu (1996), a relação de inclusão entre os critérios é talvez o aspecto mais conhecido dos critérios de teste. Zhu (1996) também demonstrou que, sob certas circunstâncias, essa relação pode fornecer informações para comparar a eficácia entre os critérios. Assim como esses aspectos são importantes para os critérios de teste propostos para o teste de programas, considerá-los também no teste de especificações pode contribuir para a definição de estratégias de teste.

A relação de inclusão entre os critérios FCCSDL foi estabelecida, conforme apresentado na próxima seção.

\subsubsection{Relação de Inclusão dos Critérios FCCSDL}

A relação de inclusão estabelece uma hierarquia entre os critérios de teste, de forma que um critério $C r_{1}$ inclui um critério $C r_{2}$ se, para qualquer conjunto de teste que satisfaça $C r_{1}$, então esse conjunto de teste também satisfaz $C r_{2}$, para qualquer programa/especificação. Diz-se que $C r_{1}$ inclui estritamente $C r_{2}$ (denotado por $C r_{1} \Rightarrow C r_{2}$ ), se $C r_{1}$ inclui $C r_{2}$, mas $C r_{2}$ não inclui $C r_{1} . C r_{1}$ e $C r_{2}$ são incomparáveis se $C r_{1}$ não inclui $C r_{2}$ e $C r_{2}$ não inclui $C r_{1}$ (Rapps e Weyuker, 1985). Analisando a relação de inclusão entre os critérios FCCSDL, têm-se que as seguintes relações são válidas:

(i) Todos-Caminhos $\Rightarrow$ Todos-Caminhos- $k$ - $C_{1}$-Configuração

(ii) Todos-Caminhos- $k$ - $C_{1}$-Configuração $\Rightarrow$ Todos-Caminhos- $k$-Configurações

(iii) Todos-Caminhos- $k$-Configurações $\Rightarrow$ Todos-Caminhos-com-um-Laço 
(iv) Todos-Caminhos-com-um-Laço $\Rightarrow$ Todos-Caminhos-Simples

(v) Todos-Caminhos-Simples $\Rightarrow$ Todos-Caminhos-livre-Laço

(vi) Todos-Caminhos-livre-Laço $\Rightarrow$ Todas-Configurações

(vii) Todos-Caminhos-com-um-Laço $\Rightarrow$ Todas-Transições

(viii) Todas-Transições $\Rightarrow$ Todas-Configurações

(ix) Todos-Caminhos-Simples e Todas-Transições são incomparáveis

(x) Todos-Caminhos-livre-Laço e Todas-Transições são incomparáveis

Com base nessas relações, uma hierarquia entre os critérios da família FCCSDL pode ser definida, como ilustra a Figura 3.4.

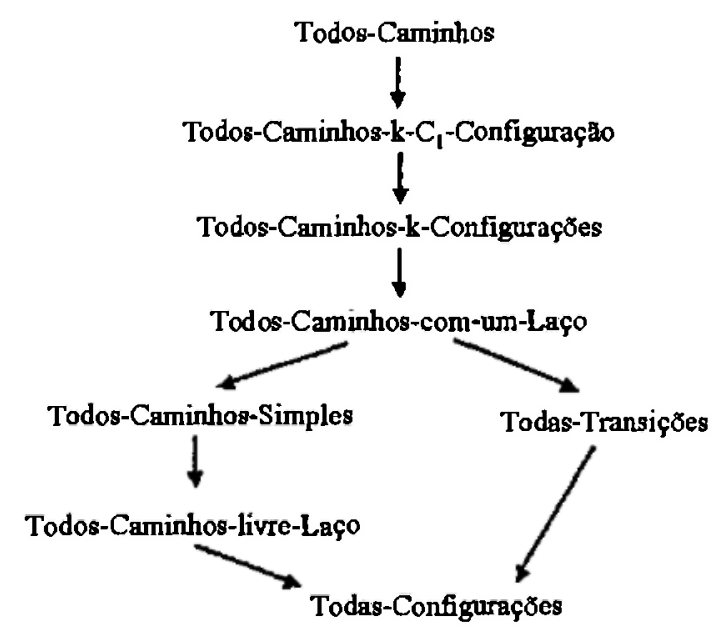

Figura 3.4: Hierarquia dos Critérios FCCSDL

A seguir, apresentam-se as provas dessas relações. Visto que a relação de inclusāo é transitiva, basta provar que:

(i) Todos-Caminhos $\Rightarrow$ Todos-Caminhos- $k$ - $C_{\mathrm{I}}$-Configuração

Essa relação só é válida em especificações SDL que são reinicializáveis. Sejam $P_{1}$ um conjunto de caminhos adequados ao critério Todos-Caminhos e $P_{2}$ um conjunto de caminhos adequados ao critério Todos-Caminhos- $k$ - $C_{1}$-Configuração. Assim, $P_{1}$ contém todos os possíveis caminhos, inclusive caminhos de comprimento infinito, de forma que, para todo caminho $p_{2} \in P_{2}$, existe pelo menos um caminho $p_{1} \in P_{1}$ que inclui $p_{2}$. Assim, pode-se concluir que $P_{1}$ também é Todos-Caminhos- $k$ - $C_{1}$-Configuração-adequado, isto é, o critério Todos-Caminhos inclui o critério Todos-Caminhos- $k-C_{1}$-Configuração. Por outro lado, $P_{2}$ não é Todos-Caminhos-adequado pois, por exemplo, um caminho contido em $P_{1}$ que tenha $k_{1}$ repetições da configuração $C_{1}, k_{1}>k$, não está incluído em $P_{2}$. Portanto, 
o critério Todos-Caminhos inclui estritamente o critério Todos-Caminhos- $k$ - $C_{1}$-Configuração.

(ii) Todos-Caminhos- $k$ - $C_{1}$-Configuração $\Rightarrow$ Todos-Caminhos- $k$-Configurações, para caminhos reinicializáveis

Sejam $\quad P_{1} \quad$ e $\quad P_{2}$ adequados aos critérios Todos-Caminhos- $k$-Configurações e Todos-Caminhos- $k$ - $C_{1}$-Configuração, respectivamente. $\quad P_{2}$ satisfaz o critério Todos-Caminhos- $k$-Configurações uma vez que pode incluir caminhos contendo repetições de cada configuração $C_{i}, C_{i} \neq C_{1}$, pois no conjunto de requisitos do critério Todos-Caminhos- $k$ - $C_{1}$-Configuração só não pode haver caminhos com mais de $k$ repetições de $C_{1}$, não importando as repetições das demais configurações. Por outro lado, $P_{1}$ pode não satisfazer o critério Todos-Caminhos- $k$ - $C_{1}$-Configuração pois, para isso, seria necessário que $P_{1}$ incluísse caminhos em que configurações $C_{i}, C_{i} \neq C_{1}$, são repetidas $k_{i}$ vezes, $k_{i}>k$. Dessa forma, o critério Todos-Caminhos- $k$ - $C_{1}$-Configuração inclui estritamente o critério Todos-Caminhos- $k$-Configurações.

(iii) Todos-Caminhos- $k$-Configurações $\Rightarrow$ Todos-Caminhos-com-um-Laço

Sejam $P_{1}$ e $P_{2}$ dois conjuntos de caminhos adequados aos critérios Todos-Caminhos- $k$-Configurações e Todos-Caminhos-com-um-Laço, respectivamente. Todo caminho $p_{1} \in P_{1}$ contém uma seqüencia de configurações em que todas as configurações podem aparecer repetidas no máximo $k$ vezes. Todo caminho $p_{2} \in P_{2}$ contém uma seqüência de configurações em que apenas uma configuração $\left(C_{i}\right)$ aparece repetida uma vez no caminho, caracterizando um laço. Assim, para todo $p_{2}$, existe pelo menos um caminho $p_{1} \in P_{1}$ tal que $p_{1}$ inclui $p_{2}$. Assim, todo $P_{1}$ adequado ao critério Todos-Caminhos- $k$-Configurações é também Todos-Caminhos-com-um-Laço-adequado. Por outro lado, como $P_{2}$ pode incluir somente caminhos com um laço, $P_{2}$ pode não satisfazer o critério Todos-Caminhos- $k$-Configurações. Isso pode ser comprovado quando se considera um caminho de $P_{1}$ com $k$ repetições de, no mínimo, duas configurações diferentes $C_{j}$ e $C_{k}$, que não está incluído em $P_{2}$. Portanto, o critério Todos-Caminhos-com-um-Laço não inclui o critério Todos-Caminhos- $k$-Configurações, pois existe pelo menos um conjunto $P_{1}$ que é Todos-Caminhos- $k$-Configurações-adequado e que não é adequado a Todos-Caminhos-com-um-Laço, Dessa forma, o critério Todos-Caminhos- $k$-Configurações inclui estritamente o critério Todos-Caminhos-com-um-Laço.

(iv) Todos-Caminhos-com-um-Laço $\Rightarrow$ Todos-Caminhos-Simples

Sejam $P_{1}$ e $P_{2}$ dois conjuntos Todos-Caminhos-com-um-Laço-adequado e Todos-Caminhos-Simples-adequado, respectivamente. Todo caminho $p_{1} \in P_{1}$ contém sequências de configurações em que apenas uma única configuração se repete, e todo caminho $p_{2} \in P_{2}$ contém uma seqüência de configurações $\left\{C_{1}, C_{j}, \ldots, C_{k}, C_{l}\right\}$, 
em que o intervalo $\left\{C_{j}, \ldots, C_{k}\right\}$ contém apenas configurações distintas e, no caso da configuração $C_{l}, l$ pode ser igual a 1 . Assim, para todo $p_{2} \in P_{2}$ existe pelo menos um caminho $p_{1} \in P_{1}$ tal que $p_{1}$ inclui $p_{2}$, de modo que todo $P_{1}$ adequado a Todos-Caminhos-com-um-Laço é Todos-Caminhos-Simples-adequado. Por outro lado, $P_{2}$ pode não satisfazer o critério Todos-Caminhos-com-um-Laço, pois, por exemplo, um caminho de $P_{1}$ que contenha uma repetição de uma configuração $C_{n}$, sendo $C_{n} \neq C_{1}$, não pode ser incluído em $P_{2}$. Portanto, existe pelo menos um conjunto $P_{2}$ Todos-Caminhos-Simples-adequado que não é Todos-Caminhos-com-um-Laço-adequado. Dessa forma, o critério Todos-Caminhos-com-um-Laço inclui estritamente o critério Todos-Caminhos-Simples.

(v) Todos-Caminhos-Simples $\Rightarrow$ Todos-Caminhos-livre-Laço

Sejam $\quad P_{1} \quad$ e $\quad P_{2}$ adequados aos critérios Todos-Caminhos-Simples e Todos-Caminhos-livre-Laço, respectivamente. Todo caminho $p_{2} \in P_{2}$ contém uma seqüência de configurações $\left\{C_{1}, C_{i}, \ldots, C_{n}\right\}$, todas distintas. Para todo $p_{2}$, existe pelo menos um caminho $p_{1} \in P_{1}$, tal que $p_{1}$ inclui $p_{2}$. Dessa forma, todo $P_{1}$ adequado a Todos-Caminhos-Simples é também adequado ao critério Todos-Caminhos-livre-Laço. Por outro lado, $P_{2}$ não satisfaz o critério Todos-Caminhos-Simples quando, por exemplo, considera-se um caminho $p_{1} \in P_{1}$ tal que $p_{1}=\left\{C_{1}, C_{j}, \ldots, C_{1}\right\}$, pois este caminho pode não estar incluído em $P_{2}$. Assim, o critério Todos-Caminhos-Simples inclui estritamente o critério Todos-Caminhos-livre-Laço.

(vi) Todos-Caminhos-livre-Laço $\Rightarrow$ Todas-Configuraçōes

Seja $P_{1}$ Todos-Caminhos-livre-Laço-adequado. Para toda configuração $C_{j}$, existe um caminho $p_{j}=\left\{C_{i}, \ldots, C_{j}\right\}$, tal que $C_{j}$ está incluída em $p_{j}$ e esse caminho é livre de laço. Dessa forma, $p_{j}$ está incluído em $P_{1}$ e $P_{1}$ é também adequado ao critério Todas-Configurações. Seja $P_{2}$ Todas-Configurações-adequado, ou seja, $P_{2}$ contém caminhos que passam por todas as configurações, mas não necessariamente contém todos os caminhos livres de laço. Assim, conclui-se que o critério Todos-Caminhos-livre-Laço inclui estritamente o critério Todas-Configurações.

(vii) Todos-Caminhos-com-um-Laço $\Rightarrow$ Todas-Transições

Seja $P_{1}$ Todos-Caminhos-com-um-Laço-adequado. Suponha que $P_{1}$ não seja adequado ao critério Todas-Transições. Dessa forma, há pelo menos um arco $\left(C_{i}, C_{j}\right)$, tal que não existe um caminho $p_{i} \in P_{1}$ em que $\left(C_{i}, C_{j}\right)$ está incluído. Entretanto, para todo arco, em particular para o arco $\left(C_{i}, C_{j}\right)$, existe um caminho $m_{i}$ livre de laço de $C_{0}$ a $C_{i}$. Para $m=m_{i} \wedge C_{j}, m$ contém o arco $\left(C_{i}, C_{j}\right)$ e está incluído em $P_{1}$. Portanto, $P_{1}$ é adequado ao critério Todas-Transições. Por outro lado, um conjunto $P_{2}$ Todas-Transições-adequado 
pode não ser Todos-Caminhos-com-um-Laço-adequado. Isto porque o conjunto $P_{2}$ não contém necessariamente todos os possíveis caminhos com um laço, pois para ser Todas-Transições-adequado, basta que todas as transições sejam exercitadas ao menos uma vez. Assim sendo, conclui-se que o critério Todos-Caminhos-com-um-Laço inclui estritamente o critério Todas-Transições.

(viii) Todas-Transiçōes $\Rightarrow$ Todas-Configuraçōes

Seja $P_{1}$ Todas-Transições-adequado e não Todas-Configurações-adequado. Dessa forma, existe pelo menos uma configuração $C_{i}$ que não está incluída no conjunto de caminhos $p_{1} \in P_{1}$. Com isso, todo arco $\left(C_{i}, C_{j}\right)$ e $\left(C_{k}, C_{i}\right)$ não estão presentes em $P_{1}$, e $P_{1}$ não é Todas-Transiçôes-adequado, contradizendo a hipótese inicial. Portanto, todo caminho $P_{1}$ é Todas-Configurações-adequado. Porém, um conjunto $P_{2}$ que é Todas-Configurações-adequado pode não ser Todas-Transiçōes-adequado. Para provar isso, basta considerar uma configuração $C_{j}$ sendo destino de dois $\operatorname{arcos}\left(C_{i}, C_{j}\right)$ e $\left(C_{k}, C_{j}\right)$. Para que a configuração $C_{j}$ seja incluída em um conjunto de caminhos $P_{2}$ que satisfaz o critério Todas-Configuraçōes, basta que um dos arcos seja exercitado e, portanto, o outro arco não necessariamente é exercitado. Se isso acontecer, $P_{2}$ não é adequado a Todas-Transições. Assim sendo, conclui-se que o critério Todas-Transições inclui estritamente o critério Todas-Configuraçōes.

(ix) Todos-Caminhos-Simples e Todas-Transições são incomparáveis.

Sejam $P_{1}$ Todos-Caminhos-Simples-adequado e $P_{2}$ Todas-Transiçōes-adequado. $P_{1}$ pode não satisfazer o critério Todas-Transiçōes porque seria necessário que $P_{1}$ incluísse caminhos $\left\{C_{0}, \ldots, C_{j}, C_{j}, \ldots, C_{m}\right\}$, o que significa incluir transições $\left(C_{j}, C_{j}\right)$. Por outro lado, $P_{2}$ pode não satisfazer o critério Todos-Caminhos-Simples pois, considerando um conjunto adequado ao critério Todas-Transições, o conjunto não necessariamente contém todos os possíveis caminhos simples. Assim sendo, conclui-se que o critério Todas-Transições e o critério Todos-Caminhos-Simples são incomparáveis.

(x) Todos-Caminhos-livre-Laço e Todas-Transiçōes são incomparáveis.

Sejam $P_{1}$ Todos-Caminhos-livre-Laço-adequado e $P_{2}$ Todas-Transiçōes-adequado. Se considerarmos que todo caminho $p \in P_{1}$ inicia pela configuração $C_{1}$ os $\operatorname{arcos}\left(C_{i}, C_{1}\right)$ năo são incluídos em $P_{1}$, pois para isso seria necessário que a configuração $C_{1}$ estivesse repetida em $P_{1}$, o que não acontece nos caminhos adequados ao critério Todos-Caminhos-livre-Laço. Portanto, $P_{1}$ pode não satisfazer o critério Todas-Transições. Por outro lado, $P_{2}$ pode não satisfazer o critério Todos-Caminhos-livre-Laço, pois um conjunto adequado ao critério Todas-Transições não necessariamente contém todos os possíveis caminhos livre de laço. Assim sendo, os critérios Todas-Transiçōes e Todos-Caminhos-livre-Laço são incomparáveis. 


\subsubsection{Estratégia Incremental de Aplicação dos Critérios de Cobertura}

A relação de inclusão determina uma hierarquia entre os critérios e pode ser utilizada como base para o estabelecimento de estratégias de teste incremental, de forma a aplicar primeiramente critérios com custo mais baixo e, conforme haja disponibilidade de recursos, outros critérios mais rigorosos podem ser aplicados. Com base nas informações da hierarquia dos critérios FCCSDL, uma possivel estratégia de teste pode ser:

1. Aplicar o critério Todas-Configurações e determinar um conjunto de seqüências de teste adequadas;

2. Aplicar o critério Todas-Transições e determinar um conjunto de sequêencias de teste adequadas;

3. Aplicar o critério Todos-Caminhos-livre-Laço e determinar um conjunto de sequências de teste adequadas;

4. Aplicar o critério Todos-Caminhos-Simples e determinar um conjunto de sequêencias de teste adequadas;

5. Aplicar o critério Todos-Caminhos-com-um-Laço e determinar um conjunto de sequências de teste adequadas;

6. Aplicar o critério Todos-Caminhos-k-Configur ações e determinar um conjuntō de sequências de teste adequadas;

7. Aplicar o critério Todos-Caminhos-k- $C_{1}^{\prime}$-Configuração e determinar um conjunto de seqüências de teste adequadas;

8. Aplicar o critério Todos-Caminhos e determinar um conjunto de seqüências de teste adequadas.

Essa estratégia de teste pode ser aplicada de acordo com a disponibilidade de tempo, considerando-se também o custo de aplicação de cada critério. Ressalta-se que, em geral, a aplicação do critério Todos-Caminhos é inviável, pois pode gerar um conjunto infinito de requisitos de teste. $\mathrm{O}$ mesmo pode acontecer para o critério Todos-Caminhos-k- $C_{1}$-Configuração.

Outro ponto que pode ser considerado ao aplicar essa estratégia de teste é analisar, durante a construção da árvore de alcançabilidade, se todos os processos da especificação SDL serão considerados ou não. Dessa forma, pode-se aplicar a técnica de redução conjunto de componentes na construção da árvore de alcançabilidade e testar apenas alguns processos SDL, seguindo a estratégia de teste proposta. 


\subsection{Considerações Finais}

Neste capítulo, critérios estruturais foram propostos para o teste de especificações SDL considerando duas perspectivas, uma que explora o comportamento dos processos SDL, representado por grafos de fluxo, e outra que explora o comportamento de toda a especificação SDL, representado pela árvore de alcançabilidade. Especificaçōes SDL podem ser vistas como programas escritos em uma linguagem de descrição e isso facilita o emprego de critérios de teste propostos para o teste de programas.

Cinco critérios são utilizados para o teste de processos SDL, dois baseados em fluxo de controle (Todos-Blocos e Todas-Decisões) e três baseados em fluxo de dados (Todos-c-Usos, Todos-p-Usos e Todos-Usos). Os requisitos de teste desses critérios são derivados de grafos de fluxo de controle e de dados construídos para cada processo SDL. Além de auxiliar a análise de cobertura, propõe-se o uso de informações que guiem a geração de casos de teste que proporcionem maior cobertura de teste a cada execução. Essas informações são geradas com base no conceito de dominadores e possibilitam a atribuição de pesos aos requisitos de teste, indicando quais requisitos de teste deveriam ser cobertos antes dos outros para obter uma maior cobertura a cada execução. Essa proposta foi implementada na ferramenta $C A T_{S D L}$, que será apresentada no Capítulo 5.

Para auxiliar a depuração de especificaçōes SDL foi proposta uma abordagem baseada em slices de execução utilizada para a depuração de programas. Essa abordagem atribui prioridades às partes da especificação, com base em sua probabilidade de conter erros. $\mathrm{O}$ objetivo é reduzir o espaço de busca pelo erro durante a depuração, de forma que partes com maior prioridade deveriam ser examinadas antes de outras partes com menor prioridade. Comparado com técnicas que utilizam slices estáticos ou dinâmicos, utilizar slices de execução é uma melhor opção por permitir, sem muita dificuldade, que se reutilizem informações coletadas durante a atividade de teste. Essas informaçōes são relacionadas aos caminhos de execução de cada caso de teste. Para apoiar a utilização dessa abordagem, foi desenvolvida a ferramenta $S m a r t D_{S D L}$, que também será apresentada no Capítulo 5 .

Buscando aplicar critérios estruturais de fluxo de controle mais rigorosos de modo a explorar o aspecto comportamental das especificações SDL, foram propostos os critérios FCCSDL, que derivam seus requisitos de teste a partir de um modelo de árvore de alcançabilidade. A relação de inclusão foi estabelecida para esses critérios e, com base nessa relação, uma estratégia de teste foi proposta. Essa estratégia propõe inicialmente a aplicação de critérios mais fracos e menos custosos para depois serem aplicados critérios mais rigorosos e custosos.

Os critérios FCCSDL para SDL são similares aos critérios FCCE definidos para Estelle (Souza et al., 2001). Conseqüientemente, a relação de inclusão e a estratégia de teste para a aplicação dos critérios definidas para ambas as técnicas também são similares. Não foi necessária a definição de novos critérios para SDL pois os principais aspectos relacionados ao comportamento de especificações SDL que podem ser explorados pelos critérios de 
operadores no teste de especificações SDL, uma estratégia de teste incremental, denominada ITS-SDL (Incremental Testing Strategy), foi proposta. A especificação SDL do protocolo Bit-Alternante, apresentada no Capítulo 3, foi utilizada para ilustrar os conceitos definidos neste capítulo.

A análise da complexidade dos operadores de mutação definidos também foi realizada e é apresentada neste capítulo.

No contexto de especificações baseadas em SDL, Kovács et al. (2003) investigaram a aplicação da Análise de Mutantes no teste de conformidade de protocolos de comunicação. Nesse caso, o critério auxilia a geração e seleção de casos de teste para testar programas implementados com base na especificação SDL do protocolo. Ressalta-se que no trabalho de Kovács et al. (2003), a atividade de teste não é realizada na especificação SDL em si, diferentemente da forma como o critério Análise de Mutantes é explorado neste trabalho, em que a cobertura de teste da especificação é analisada. Além disso, o conjunto de operadores definido por Kovács et al. (2003) é mais restrito do que o definido neste trabalho.

\subsection{Análise de Mutantes para SDL}

O critério Análise de Mutantes foi proposto para o teste de programas com base em duas hipóteses básicas: hipótese do programador competente e hipótese do efeito de acoplamento (DeMillo et al., 1978). Fabbri (1996), ao propor a aplicação desse critério para o teste de especificações, adaptou as duas hipóteses e definiu: hipótese do projetista competente uma especificação construída por um projetista competente está correta ou está próxima do correto; e hipótese do efeito de acoplamento - erros complexos são acoplados a erros simples de forma que casos de teste capazes de detectar erros simples são capazes de detectar a maioria dos erros.

Como já ressaltado, o sucesso da Análise de Mutantes depende muito da definição dos operadores de mutação. Da mesma forma como trabalhos anteriores do grupo de Engenharia de Software do ICMC-USP/Săo Carlos em que conjuntos de operadores de mutação foram definidos para Máquinas de Estados Finitos (Fabbri et al., 1994b), Redes de Petri (Fabbri et al., 1994a, 1995; Simão, 2000), Statecharts (Fabbri et al., 1999) e Estelle (Souza et al., 2000a), o conjunto de operadores de mutação para SDL foi estabelecido com base nas classes de erros de seqüenciamento para Máquinas de Estados Finitos definidas por Chow (1978), no conjunto de operadores de mutação para expressões booleanas definido por Weyuker et al. (1994) e no conjunto de operadores de mutação para a linguagem $\mathrm{C}$ definido por Agrawal (1989) e Delamaro e Maldonado (1996), para o teste de unidade, e por Delamaro et al. (2001a) para o teste de integração. O conjunto de operadores de mutação para SDL também explora algumas características intrínsecas da técnica, como os comandos save e task. 
para gerar o mutante $Z$, para o teste de especificação, essas três condições que devem ser satisfeitas pelo conjunto de testes $T$ para distinguir $Z$ de $S$ são definidas:

1. Alcançabilidade: $s_{m}$ deve ser executado;

2. Necessidade: o estado do processo que contém $s_{m}$ em $Z$, logo após alguma execução de $s_{m}$, deve ser diferente do estado do mesmo processo da especificação $S$, após a execução de $s$

3. Suficiência: os estados do processo em que houve a mutação devem se manter diferentes até o final da execução de $S$ ou $Z \operatorname{com} T$, para que os estados finais alcançados sejam diferentes e o mutante possa ser distinguido.

Uma seqüência de teste para a técnica SDL é constituída pela seqüência de sinais trocados durante a execução da especificação SDL. Por exemplo, uma possível seqüência de teste para o protocolo Bit-Alternante é $t s=\langle p u t(m), d m(m, 0), d m(m, 0), \operatorname{get}(m) \wedge a m(0), a m(0)\rangle$, que corresponde aos seguintes passos: o processo Sender deseja enviar uma mensagem para o processo Receiver (sinal $p u t(m)$ ), então a mensagem $(m)$ é empacotada e enviada para Medium1 $(d m(m, 0))$ com um bit identificador $(0)$. Medium1 envia a mensagem para o Receiver. A mensagem chega ao Receiver, que verifica que é a mensagem esperada e então armazena a mensagem $(g e t(m)$ ) e envia a mensagem de reconhecimento (acknowledgement) para o Sender (sinal am(0)), por meio de Medium2. Medium2 recebe essa mensagem e a envia para o Sender $(a m(0))$. A mensagem de reconhecimento é recebida pelo Sender, que a reconhece como a mensagem esperada.

Nas seções a seguir são descritas as três classes de operadores, e a definição informal dos operadores de mutação de cada classe é apresentada. Para cada operador de mutação, um mutante gerado pela sua aplicação na especificação textual do protocolo Bit-Alternante é apresentado. Observa-se que alguns operadores definem mutações em estruturas que não estão presentes na especificação desse protocolo e, portanto, não geram mutantes.

\subsubsection{Operadores de Mutação de Processos}

Os operadores de mutação desta classe modelam erros relacionados ao comportamento dos processos, que é similar ao comportamento das Máquinas de Estados Finitos Estendidas Comunicantes (MEFECs). Como o aspecto de comunicação entre os processos SDL é abordado pelos operadores de mutação de interface, nesta classe de operadores considera-se que os processos SDL comportam-se apenas como MEFEs. Dessa forma, para definir esta classe de operadores foram exploradas características particulares de SDL. Dois trabalhos anteriores também foram revistos: o conjunto de operadores de mutação para MEFEs definido por Fabbri (1996) e o conjunto de operadores de mutação para módulos de especificações Estelle, que se comportam como MEFEs, definido por Souza et al. (2000b). Os operadores de mutação definidos por Fabbri (1996) e Souza et al. (2000b) para MEFEs, têm como base os 
operadores de mutação definidos por Agrawal (1989) para a linguagem C, por Weyuker et al. (1994) para a validação de expressões booleanas e por Chow (1978) para a classificação de erros de seqüenciamento para MEFs.

De maneira geral, o conjunto de operadores de mutação para processos SDL modelam:

- erros de transições e de estados;

- erros em expressões, operadores matemáticos, variáveis e constantes; e,

- erros nos controladores temporais (set e reset).

A seguir são apresentadas as descrições dos operadores de mutação de processos. É importante observar que, como todo processo SDL possui o estado START como estado inicial, não se considerou o operador de mutação Substituição de Estado Inicial, presente ao conjunto de operadores de mutação definidos para outras linguagens como Statecharts e Estelle.

Para a realização de mutação sobre as variáveis são apresentados na Tabela 4.2 os conjuntos de constantes requeridas, em que MAX IN.T e MAX_REAL representam os valores máximos para variáveis inteiras e reais, respectivamente.

Tabela 4.2: Conjunto de Constantes Requeridas

\begin{tabular}{|l|l|}
\hline Tipo de Variável & Constantes Requeridas \\
\hline \hline Inteiro & $-1,1,0$, MAX INT \\
\hline Real & $-1.0,1.0,0.0,-0.0$, MAX REAL \\
\hline
\end{tabular}

\section{Substituição de Estado Origem}

Esse operador realiza a mutação nos estados origem das transições. Assim, o estado origem de uma transição é trocado pelos demais estados definidos no mesmo processo, um de cada vez. Um mutante que pode ser gerado por este operador é ilustrado na Figura 4.1.

Restrição: o estado origem $S_{i}$ de uma transição t só pode ser trocado pelo estado $S_{j}$ se o conjunto de entradas de t não existe no conjunto de entradas das transições de $S_{j}$, evitando, dessa forma, que seja inserido não-determinismo na especificação mutante.

\section{Troca Definições dos Estados}

Esse operador realiza a mutação dos estados, atribuindo a definição de um estado para outro estado e vice-e-versa. Dessa forma, todas as transições que eram de um estado passam a ser de outro, em cada mutante. A Figura 4.2 ilustra um dos possíveis mutantes gerados pela aplicação deste operador na especificação do protocolo Bit-Alternante. 


\begin{tabular}{|c|c|}
\hline Especificaçāo Original & Especificaçāo Mutante \\
\hline $\begin{array}{l}\text { STATE wait_put; } \\
\text { INPUT put ( } \mathrm{m}) ; \\
\text { OUTPUT dm ( } \mathrm{m}, \mathrm{i}) ; \\
\text { NEXTSTATE wait_am; } \\
\text { ENDSTATE; }\end{array}$ & $\begin{array}{l}\text { STATE wait_put; } \\
\rightarrow\end{array}$ \\
\hline $\begin{array}{l}\text { STATE wait_am; } \\
\text { INPUT am }(\mathrm{j}) ; \\
\ldots \\
\ldots\end{array}$ & $\begin{array}{l}\text { STATE wait_am; } \\
\text { INPUT put }(\mathbf{m}) ; \\
\text { OUTPUT dm }(\mathbf{m}, \mathbf{i}) ; \\
\text { NEXTSTATE wait_am; }\end{array}$ \\
\hline$\ldots$ & $\begin{array}{l}\text { INPUT am }(\mathrm{j}) \text {; } \\
\ldots\end{array}$ \\
\hline
\end{tabular}

Figura 4.1: Mutante Gerado pelo Operador Substituição de Estado Origem

\begin{tabular}{|l|l|}
\hline Especificação Original & Especificação Mutante \\
\hline \hline STATE wait_put; & $\rightarrow$ STATE WAIT_AM; \\
INPUT put $(m) ;$ & INPUT put $(m) ;$ \\
OUTPUT dm $(m, i) ;$ & OUTPUT dm $(m, i) ;$ \\
NEXTSTATE wait_am; & NEXTSTATE wait_am; \\
ENDSTATE; & ENDSTATE; $;$ \\
STATE wait_am; & $\rightarrow$ STATE WAIT_PUT; \\
INPUT am $(j) ;$ & INPUT am $(j) ;$ \\
$\ldots$ & $\ldots$ \\
\hline
\end{tabular}

Figura 4.2: Mutante Gerado pelo Operador Troca Definições dos Estados

\section{Substituição de Estado Destino}

Esse operador substitui o estado destino de cada transição do processo (indicado pelo comando nextstate) pelos outros estados definidos no processo. No caso do estado destino ser diferente de "-", que indica que a transição não resulta em troca de estado, permanecendo no mesmo estado, ele pode ser substituido por "-". Na Figura 4.3 um mutante gerado por este operador é ilustrado.

\begin{tabular}{|l|l|}
\hline Especificação Original & \multicolumn{1}{|c|}{ Especificação Mutante } \\
\hline \hline STATE wait_am; & STATE wait_am; \\
INPUT am $(\mathrm{j}) ;$ & INPUT am $(\mathrm{j}) ;$ \\
DECISION $\mathrm{j}=\mathrm{i} ;$ & DECISION $\mathrm{j}=\mathrm{i} ;$ \\
( TRUE $):$ & ( TRUE $):$ \\
TASK $\mathrm{i}:=\operatorname{inv}(\mathrm{i}) ;$ & TASK $\mathrm{i}:=\operatorname{inv}(\mathrm{i}) ;$ \\
NEXTSTATE wait put; & $\rightarrow$ NEXTSTATE WATT_AM; \\
ELSE: & ELSE; \\
$\ldots$ & $\ldots$ \\
\hline
\end{tabular}

Figura 4.3: Mutante Gerado pelo Operador Substituição de Estado Destino

\section{Remoçāo de Estados}

Esse operador exclui cada um dos estados do processo. Na verdade, o estado a ser removido é unido a outro estado, desde que haja uma transição conectando-os. Um mutante que pode ser gerado por este operador é apresentado na Figura 4.4. 
Restrição: é aplicado para processos contendo mais de 2 estados e o estado origem $S_{i}$ de uma transição $\mathrm{t}$ só pode ser trocado pelo estado $S_{j}$ se $\mathrm{t}$ não existe no conjunto de transições disparadas a partir de $S_{j}$, evitando, dessa forma, que seja inserido não-determinismo na especificação mutante.

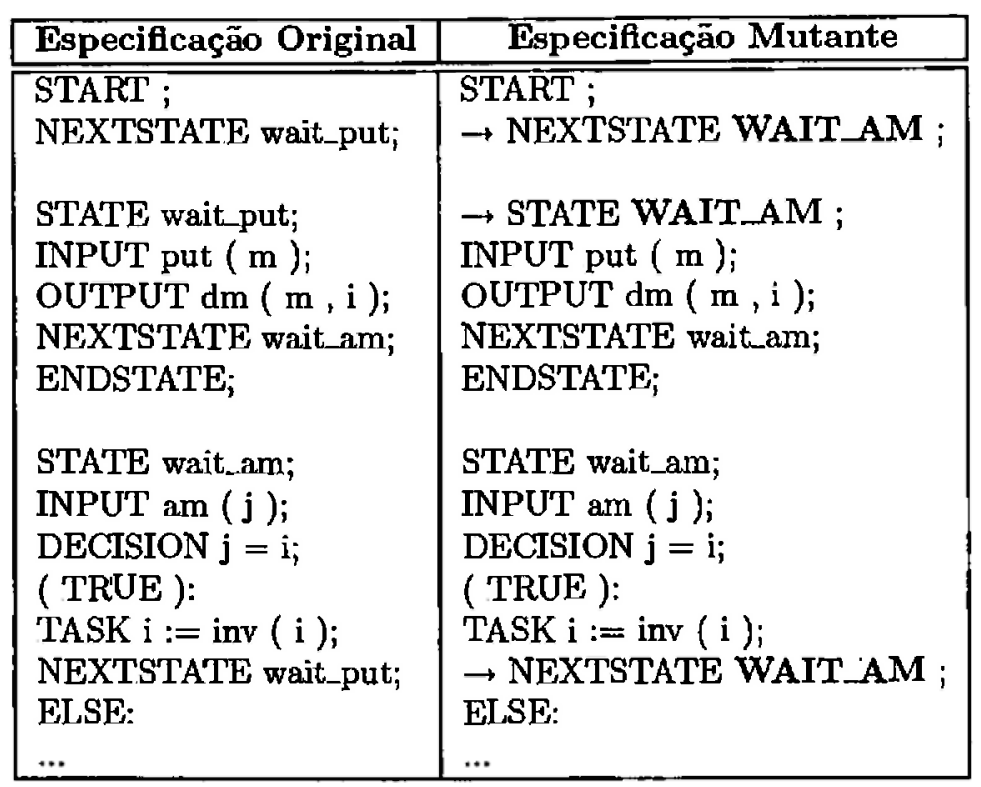

Figura 4.4: Mutante Gerado pelo Operador Remoção de Estados

\section{Remoção de Transições}

Esse operador exclui as transiçōes dos estados do processo, uma por vez, como no mutante apresentado na Figura 4.5.

\begin{tabular}{|l|l|}
\hline Especificação Original & Especificação Mutante \\
\hline \hline START ; & STA'RT ; \\
NEXTSTATE wait_put; & NEXTSTATE wait_put; \\
& \\
STATE wait_put; & STATE wait_put; \\
INPUT put ( $\mathrm{m}$ ); & $\rightarrow$ \\
OUTPUT dm ( $\mathrm{m}, \mathrm{i}$ ); & \\
NEXTSTATE wait_am; & \\
ENDSTATE; & ENDSTATE; \\
$\ldots$ & $\ldots$ \\
\hline
\end{tabular}

Figura 4.5: Mutante Gerado pelo Operador Remoção de Transições

\section{Remoção de Condição das Transições}

Esse operador exclui a cláusula provided declarada nas enabling condition e nos continuous signal das transições.

\section{Negação de Condição das Transições}

Esse operador é aplicado na cláusula provided declarada nas enabling condition e nos continuous signal das transiçōes. O operador de negação lógica (not) é inserido na condição da cláusula provided. 


\section{Substituição de Atribuição Booleana}

Esse operador troca cada atribuição de variáveis booleanas. Se for true passa a ser false, e vice-versa.

9. Substituição de Variável por Variável

Esse operador substitui cada ocorrência de uma variável nas transições e na inicialização pelas demais variáveis, de tipos compatíveis, declaradas pelo processo. Um exemplo de aplicação deste operador é apresentado na Figura 4.6.

\begin{tabular}{|l|l|}
\hline Especificação Original & Especificação Mutante \\
\hline \hline STATE wait_am; & STATE wait_am; \\
INPUT am $(\mathrm{j}) ;$ & INPUT am $(\mathrm{j}) ;$ \\
DECISION $\mathrm{j}=\mathrm{i} ;$ & $\rightarrow$ DECISION $\mathbf{I}=\mathrm{i} ;$ \\
( TRUE $):$ & ( TRUE $):$ \\
TASK $\mathrm{i}:=$ inv ( $\mathrm{i}) ;$ & TASKK $\mathrm{i}:=$ inv $(\mathrm{i}) ;$ \\
NEXTSTATE wait_put; & NEXTSTATE wait_put; \\
$\ldots$ & $\ldots$ \\
\hline
\end{tabular}

Figura 4.6: Mutante Gerado pelo Operador Substituiçāo de Variável por Variável

\section{Substituição de Variável por Constante}

Esse operador substitui cada ocorrência de uma variável nas transições e na inicialização por constantes requeridas (Tabela 4.2) e por constantes de tipos compatíveis, declaradas pelo processo.

11. Incremento/Decremento de Variáveis/Constantes

Esse operador é aplicado nas variáveis e constantes de tipo escalar, incrementando $(+1)$ e decrementando $(-1)$ cada uso de uma variável ou constante nas transiçōes e na inicialização.

12. Inclusão de Operador Unário nas Variáveis

Esse operador inclui o operador de negação aritmética (símbolo -) em cada ocorrência de uma variável ou constante do tipo escalar nas transições e na inicialização.

13. Substituição de Tarefas das Transições

Esse operador de mutação modifica a tarefa (task) realizada em uma transição, substituindo-a por tarefas diferentes a serem realizadas em outras transiçōes do mesmo processo.

14. Remoção de Tarefas

Esse operador exclui as tarefas que deveriam ser realizadas nas transições, uma de cada vez, como ilustrado na Figura 4.7.

15. Cobertura de Código

Esse operador de mutação é do tipo instrumentado e procura selecionar casos de teste que forneçam coberturas mínimas, relacionadas ao fluxo de controle dos comandos definidos em uma transição. O objetivo desse operador é garantir que todas as 


\begin{tabular}{|l|l|}
\hline Especificação Original & Especificação Mutante \\
\hline \hline STATE wait_am; & STATE wait_am; \\
INPUT am $(\mathrm{j}) ;$ & INPUT am $(\mathrm{j}) ;$ \\
DECISION $\mathrm{j}=\mathrm{i} ;$ & DECISION $\mathrm{j}=\mathrm{i} ;$ \\
( TRUE $) ;$ & ( TRUE ): \\
TASK $\mathrm{i}:=$ inv $(\mathrm{i}) ;$ & $\rightarrow$ \\
NEXTSTATE wait_put; & NEXTSTATE wait_put; \\
ELSE: & ELSE: \\
$\ldots$ & $\ldots$ \\
ENDDECISION $;$ & ENDDECISION; \\
$\ldots$ & $\ldots$ \\
\hline
\end{tabular}

Figura 4.7: Mutante Gerado pelo Operador Remoção de Tarefas

transições de cada estado e todas as alternativas de um comando decision sejam executadas, inserindo uma função chamada Trap-On-Execution para cada entrada de urn estado e para cada alternativa de uma decisão. Quando essa função é executada, o mutante é distinguido. A Figura 4.8 ilustra um mutante gerado por este operador.

\begin{tabular}{|l|l|}
\hline Especificação Original & \multicolumn{1}{|c|}{ Especificação Mutante } \\
\hline \hline STATE wait_put; & STATE wait_put; \\
INPUT put ( m ); & INPUT put ( m ); \\
& - Trap-On-Execution(); \\
OUTPUT dm ( m, i ); & OUTPUT dm ( m, i ); \\
NEXTSTATE wait_am; & NEXTSTATE wait_am; \\
ENDSTATE; & ENDSTATE; \\
\hline
\end{tabular}

Figura 4.8: Mutante Gerado pelo Operador Cobertura de Código

\section{Negação da Questão de Decisão}

Esse operador é aplicado na questão do comando de Decisão (Decision), podendo ser utilizado quando a questão requer um valor booleano e quando a questão verifica o valor de um escalar. No primeiro caso, insere-se o operador de negação lógica (not) na questão. No segundo caso, inclui-se o operador de negação aritmética (-) na questão. Observa-se que os mutantes gerados por este último caso são idênticos aos gerados pelo operador Inclusão de Operador Unário nas Variáveis. Mesmo assim, o operador Negação da Questão de Decisão gera esses mutantes, pois uma estratégia de teste pode aplicar este operador e não aplicar o operador Inclusão de Operador Unário nas Variáveis e, neste caso, garante-se a geração de mutantes com esta alteração sintática. Um exemplo de aplicação deste operador é apresentado na Figura 4.9.

\section{Troca as Respostas do comando de Decisão}

Esse operador troca as respostas definidas para urn comando de decisão, de forma que cada resposta nos inutantes segue um caminho diferente do definido pela especificação original. No caso de haver apenas duas respostas, os mutantes gerados por este operador, apesar de sintaticamente diferentes, semanticamente são idênticos aos gerados pelo operador Negação da Questão de Decisão. No caso de haver mais de 


\begin{tabular}{|l|l|}
\hline Especificação Original & \multicolumn{1}{|c|}{ Especificação Mutante } \\
\hline \hline STATE wait_am; & STATE wait_am; \\
INPUT am $(\mathrm{j}) ;$ & INPUT am $(\mathrm{j}) ;$ \\
DECISION $\mathrm{j}=\mathrm{i} ;$ & $\rightarrow$ DECISION NOT $(\mathrm{j}=\mathbf{i}) ;$ \\
( TRUE $):$ & (TRUE $):$ \\
TASK $\mathrm{i}:=$ inv $(\mathrm{i}) ;$ & TASK $\mathrm{i}:=$ inv $(\mathrm{i}) ;$ \\
NEXTSTATE wait_put; & NEXTSTATE wait_put; \\
ELSE: & ELSE: \\
OUTPUT dm $(\mathrm{m}, \mathrm{i}) ;$ & OUTPUT dm $(\mathrm{m}, \mathrm{i}) ;$ \\
NEXTSTATE $; ;$ & NEXTSTATE -; \\
ENDDECISION; & ENDDECISION; \\
$\ldots$ & $\ldots$ \\
\hline
\end{tabular}

Figura 4.9: Mutante Gerado pelo Operador Negação de Questão de Decisão

duas respostas, elas são trocadas duas a duas, para cada mutante gerado. Um exemplo de mutante gerado por este operador é apresentado na Figura 4.10.

\begin{tabular}{|c|c|}
\hline Especificação Original & Especificaçāo Mutante \\
\hline STATE wait_am; & STATE wait_am; \\
\hline $\operatorname{INPUT}$ am $(\mathrm{j})$ & $\operatorname{INPUT}$ am $(\mathrm{j})$; \\
\hline DECISION $\mathrm{j}=\mathrm{i}$ & DECISION $\mathrm{j}=\mathrm{i}$; \\
\hline ( TRUE ): & $\rightarrow$ ELSE: \\
\hline TASK $\mathrm{i}:=\operatorname{inv}(\mathrm{i})$ & TASK $\mathrm{i}:=\operatorname{inv}(\mathrm{i})$ \\
\hline NEXTSTATE wait_put; & NEXTSTATE wait_put; \\
\hline OUTPUT $\operatorname{dm}(m, i)$ & OUTPUT $\operatorname{dm}(\mathrm{m}, \mathrm{i})$ \\
\hline NEXTSTATE -; & NEXTSTATE -; \\
\hline ENDDECISION; & ENDDECISION; \\
\hline & \\
\hline
\end{tabular}

Figura 4.10: Mutante Gerado pelo Operador Troca as Respostas do comando de Decisão

\section{Remoção de Resposta do comando de Decisão}

Esse operador exclui cada uma das respostas definidas para um comando de decisão. São removidos apenas os comandos relacionados, com exceção do comando nextstate, que define o próximo estado a ser alcançado, que deve permanecer. A Figura 4.11 apresenta um mutante gerado por este operador.

19. Remoção de Parada de Processo (Stop)

Esse operador exclui o comando Stop, que finaliza a execução de um processo, substituindo-o pelo comando nextstate -

20. Remoção de Save

Esse operador exclui a oper ação Save definida em um estado. Um exemplo de aplicação deste operador é apresentado na Figura 4.12.

21. Remoção de sinais a serem salvos por Save

Esse operador se aplica quando há uma lista de sinais a serem salvos. Nesse caso, o operador remove um sinal de cada vez da lista de sinais. No caso de haver um único sinal a ser salvo, o mutante gerado é similar ao gerado pelo operador Remoção de Save. 


\begin{tabular}{|l|l|}
\hline Especificação Original & Especificaçāo Mutante \\
\hline \hline STATE wait_am; & STATE wait_am; \\
INPUT am $(\mathrm{j}) ;$ & INPUT am $(\mathrm{j}) ;$ \\
DECISION $\mathrm{j}=\mathrm{i} ;$ & DECISION $\mathrm{j}=\mathrm{i} ;$ \\
( TRUE $):$ & ( TRUE ): \\
TASK $\mathrm{i}:=$ inv $(\mathrm{i}) ;$ & $\rightarrow$ \\
NEXTSTATE wait_put; & NEXTSTATE wait_put; \\
ELSE: & ELSE: \\
OUTPUT dm ( $\mathrm{m}, \mathrm{i}) ;$ & OUTPUT dm $(\mathrm{m}, \mathrm{i}) ;$ \\
NEXTSTATE -; & NEXTSTATE -; \\
ENDDECISION; & ENDDECISION; \\
$\ldots$ & $\ldots$ \\
\hline
\end{tabular}

Figura 4.11: Mutante Gerado pelo Operador Remoção de Resposta do Comando de Decisão

\begin{tabular}{|l|l|}
\hline Especificação Original & Especificação Mutante \\
\hline \hline STATE wait_am; & STATE wait_am; \\
$\ldots$ & $\ldots$ \\
INPUT t; & INPUT t; \\
OUTPUT dm $(\mathrm{m}, \mathrm{i}) ;$ & OUTPUT dm $(\mathrm{m}, \mathrm{i}) ;$ \\
NEXTSTATE -; & NEXTSTATE $-;$ \\
SAVE ( put $) ;$ & $\rightarrow$ \\
ENDSTATE; & ENDSTATE; \\
$\ldots$ & $\ldots$ \\
\hline
\end{tabular}

Figura 4.12: Mutante Gerado pelo Operador Remoção de Save

22. Substituição de sinais salvos por Save

Esse operador modifica os sinais a serem salvos pelo comando Save, substituindo-os, um de cada vez, pelos outros sinais de entrada declarados no mesmo processo, mas não pertencentes à lista de entradas do mesmo estado.

23. Remoção de Set Timer

Esse operador exclui a operação de Set para um timer.

\section{Remoção de Reset Timer}

Esse operador exclui a operação de Reset para um timer.

25. Remoção de Create process

Esse operador exclui a operação de criação de um processo.

26. Substituição de Operador Aritmético

Esse operador de mutação substitui um operador aritmético $(+,-, *, /)$ utilizado nos comandos Tasks, Decision e Output pelos demais operadores aritméticos.

27. Substituição de JOIN/LABEL

Esse operador de mutação substitui os pontos declarados em um comando Join, pelos pontos definidos por outros Join, no mesmo processo.

Restrição: Esse operador é aplicado apenas quando há mais de um Join definido no processo. 
28. Substituição de Operador Relacional

Esse operador de mutação substitui um operador relacional $(=, \backslash=,>,<, \leq, \geq)$ utilizado no comando Decision, pelos demais operadores relacionais, um de cada vez. É substituída também cada ocorrência de um operador lógico (and,or) por outro operador lógico desse conjunto. Na Figura 4.13 é apresentado um mutante gerado por este operador.

\begin{tabular}{|c|c|}
\hline Especificaçăo Original & Especificação Mutante \\
\hline $\begin{array}{l}\text { STATE wait_am; } \\
\text { STE }\end{array}$ & STATE wait_am; \\
\hline INPUT am $(j)$; & $\operatorname{INPUT}$ am $(\mathrm{j}) ;$ \\
\hline DECISION $\mathrm{j}=\mathrm{i}$; & $\rightarrow$ DECISION $\mathrm{j}<>\mathrm{i}$ \\
\hline ( TRUE ): & ( TRUE ): \\
\hline TASK $\mathrm{i}:=\operatorname{inv}(\mathrm{i})$; & $\operatorname{TASK} \mathrm{i}:=\operatorname{inv}(\mathrm{i})$ \\
\hline $\begin{array}{l}\text { NEXTSTATE wait_put; } \\
\text { ELSE: }\end{array}$ & $\begin{array}{l}\text { NEXTSTATE wait_put; } \\
\text { ELSE: }\end{array}$ \\
\hline OUTPUT $d m(m, i)$ & OUTPUT $d m(m, i) ;$ \\
\hline NEXTSTATE -; & NEXTSTATE -; \\
\hline $\begin{array}{l}\text { ENDDECISION; } \\
\ldots\end{array}$ & $\begin{array}{l}\text { ENDDECISION; } \\
\ldots\end{array}$ \\
\hline
\end{tabular}

Figura 4.13: Mutante Gerado pelo Operador Substituição de Operador Relacional

\subsubsection{Operadores de Mutação de Interface}

Este grupo de operadores de mutação foi definido, assim como no trabalho de Souza et al. (2000a), com base no trabalho de Delamaro (1997), que definiu o critério Mutação de Interface para testar as interações entre as unidades que compõem um programa. Com o objetivo de explorar a comunicação entre os processos de um sistema especificado em SDL, os operadores de mutação de interface foram divididos em dois grupos, o primeiro (Grupo I) explora o ponto em que há uma chamada a um processo (comando Output) e o segundo grupo (grupo II) explora o processo chamado, modificando os comandos que realizam computações com os dados recebidos.

Delamaro (1997) definiu o conceito de variáveis de interface, que é o conjunto de variáveis passadas como parâmetros à função chamada e de variáveis globais usadas na função chamada. No contexto de mutação de interface de SDL esse conceito também foi considerado, sendo que para SDL, as variáveis de interface são as variáveis enviadas como parâmetro quando o comando Output é utilizado. O mesmo conceito foi utilizado por Souza et al. (2000a) no contexto de Estelle, considerando que o conjunto de variáveis de interface é formado pelos parâmetros das primitivas de comunicação enviados para um módulo e também pelas variáveis exportadas pelos módulos filhos. Também no trabalho de Ghosh e Mathur (2001), as variáveis de interface foram investigadas no contexto de teste de sistemas baseados em componentes.

A seguir, apresentam-se as descrições dos operadores de mutação de Interface, divididos em Grupo I e Grupo II. 
Grupo I: Operadores que exploram o ponto de chamada em um processo

\section{Remoção de Saída}

Esse operador de mutação exclui cada um dos eventos de saída (comando Output) definidos nas transições dos estados, como ilustra um dos mutantes gerados, apresentado na Figura 4.14.

\begin{tabular}{|l|l|}
\hline Especificação Original & Especificação Mutante \\
\hline \hline STATE wait_put; & STATE wait_put; \\
INPUT put ( m ); & INPUT put ( m ); \\
OUTPUT dm ( m , i ); & $\rightarrow$ \\
NEXTSTATE wait_am; & NEXTSTATE wait_am; \\
ENDSTATE; & ENDSTATE; \\
\hline
\end{tabular}

Figura 4.14: Mutante Gerado pelo Operador Remoção de Saída

\section{Substituição de Saída}

Esse operador de mutação substitui cada saída definida no comando Output pelas saídas definidas nas demais transições do mesmo processo. A Figura 4.15 ilustra um dos mutantes gerados por este operador.

\begin{tabular}{|l|l|}
\hline \multicolumn{1}{|c|}{ Especificação Original } & \multicolumn{1}{c|}{ Especificaçã̄o Mutante } \\
\hline \hline STATE wait_am; & STATE wait_am; \\
INPUT am ( i ); & INPUT am (i ); \\
DECISION 'Transmission error?'; & DECISION 'Transmission error?'; \\
('yes' ): & ('yes' ): \\
OUTPUT medium_error ; & $\rightarrow$ OUTPUT AM(I) ; \\
('no' ): & ('no' ): \\
OUTPUT am ( i ) VIA' medium_to_sender; & OUTPUT am (i ) VIA' medium_to_sender; \\
ENDDECISION; & ENDDECISION; \\
NEXTSTATE -; & NEXTSTATE -; \\
ENDSTATE; & ENDSTATE; \\
\hline
\end{tabular}

Figura 4.15: Mutante Gerado pelo Operador Substituição de Saída

\section{Substituição de Destino da Saída}

Esse operador de mutação substitui o estado destino, quando explicitamente declarado pelo comando $T O$, da saída definida no comando Output, pelos demais estados presentes no mesmo processo.

\section{Substituição de Signal Route da Saída}

Esse operador de mutação substitui o signal route explicitamente declarado (pelo comando VIA) para a saída definida no comando Output, pelos demais signal routes declarados no mesmo bloco da estrutura SDL. Na Figura 4.16, apresenta-se um mutante gerado pela aplicação deste operador de mutação. 


\begin{tabular}{|l|l|}
\hline \multicolumn{1}{|c|}{ Especificação Original } & \multicolumn{1}{|c|}{ Especificação Mutante } \\
\hline \hline STATE wait_dm; & STATE wait_dm; \\
INPUT dm ( $m, i$ ); & INPUT dm ( m , i ); \\
DECISION 'Transmission error?'; & DECISION 'Transmission error?'; \\
('yes' ): & ('yes' ): \\
OUTPUT medium_error; & OUTPUT medium_error; \\
('no' ): & ('no' ): \\
OUTPUT dm ( m , i ) & OUTPUT dm ( m , i ) \\
VIA medium to_receiver; & - VIA RECEIVER_TO_MEDIUM; \\
ENDDECISION; & ENDDECISION; \\
$\ldots$ & $\ldots$ \\
\hline
\end{tabular}

Figura 4.16: Mutante Gerado pelo Operador Substituição de Signal Route da Saída

\section{Substituição de Parâmetros}

Esse operador substitui cada parâmetro do comando Output por uma variável, constante requerida (Tabela 4.2) ou constante de tipo compatível, declarada no mesmo processo.

\section{Incremento/Decremento de Parâmetros}

Esse operador incrementa e decrementa cada um dos parâmetros do comando Output de tipo escalar, adicionando e subtraindo o valor 1 a cada parâmetro.

\section{Troca na Ordem dos Parâmetros}

Esse operador troca os parâmetros, dois a dois, de tipos compatíveis, que aparecem no comando Output.

\section{Inclusão de Operador Unário nos Parâmetros}

Esse operador inclui o operador de negação aritmética (símbolo -) em cada parâmetro de tipo escalar do comando Output.

Grupo II: Operadores que exploram pontos do processo chamado

\section{Substituição de Variáveis de Interface}

Esse operador substitui cada uso de uma variável de interface (nas transições) por constantes requeridas (Tabela 4.2), por variáveis e por constantes, de tipos compatíveis, declaradas no processo. Um mutante gerado por este operador é apresentado na Figura 4.17.

\begin{tabular}{|l|l|}
\hline Especìficação Original & \multicolumn{1}{|c|}{ Especificacăo Mutante } \\
\hline \hline STATE wait_put; & STATE wait_put; \\
INPUT put $(\mathrm{m}) ;$ & INPUT put $(\mathrm{m}) ;$ \\
OUTPUT dm $(\mathbf{m}, \mathrm{i}) ;$ & $\rightarrow$ OUTPUT dm $(\mathbf{m}, \mathbf{J}) ;$ \\
NEXTSTATE wait_am; & NEXTSTATE wait_am; \\
ENDSTATE; & ENDSTATE; \\
\hline
\end{tabular}

Figura 4.17: Mutante Gerado pelo Operador Substituição de Variáveis de Interface 


\section{Substituição de Variáveis de Não Interface}

Esse operador substitui as variáveis que não são de interface, mas que aparecem em expressões que contêm pelo menos uma variável de interface e que, dessa forma, afetam o valor da variável de interface, por variáveis, constantes requeridas (Tabela 4.2) e constantes do mesmo tipo declaradas no processo.

\section{Incremento/Decremento de Variáveis}

Esse operador incrementa e decrementa de 1 , cada uso de variáveis de interface e não interface de tipo escalar, que aparecem em expressões contendo pelo menos uma variável de interface.

\section{Inclusão de Operador Unário nas Variáveis}

Esse operador inclui o operador de negação aritmética (símbolo -) em cada uso de variável de interface de tipo escalar no processo SDL. É aplicado também nas variáveis de não interface de tipo escalar que aparecem em expressões contendo pelo menos uma variável de interface.

\section{Substituição de Atribuição Booleana}

Esse operador troca cada ocorrência de uma atribuição verdadeira (true) em variáveis de interface booleanas por atribuições falsas (false), e vice-versa.

\section{Remoção de Entrada}

Esse operador exclui os eventos de entrada (sinais) associados a cada transição, um de cada vez. Caso haja apenas uma possível entrada a partir de um estado, a transição passa a ser disparada por um continuous signal Neste caso, a entrada é substituída pela expressão "Provided $(1>0)$ ", sempre verdadeira. A. Figura 4.18 ilustra um mutante gerado pelo operador

\begin{tabular}{|l|l|}
\hline Especificação Original & Especificação Mutante \\
\hline \hline STATE wait_put; & STATE wait_put; \\
INPUT put ( $\mathrm{m}) ;$ & $\rightarrow$ PROVIDED 1 >0; \\
OUTPUT dm ( m , i ); & OUTPUT dm ( m , i ); \\
NEXTSTATE wait_am; & NEXTSTATE wait_am; \\
ENDSTATE; & ENDSTATE; \\
\hline
\end{tabular}

Figura 4.18: Mutante Gerado pelo Operador Remoção de Entrada

\section{Substituição de Entrada}

Esse operador substitui cada evento de entrada (sinal) das transições disparadas a partir de um estado, pelos eventos de entrada (sinais) de transições de outros estados, desde que o evento de entrada ainda não exista em nenhuma outra transição do mesmo estado, evitando-se a inserção de não-determinismo na especificação mutante. Na Figura 4.19 é ilustrado um mutante gerado por este operador de mutação. 


\begin{tabular}{|l|l|}
\hline Especificaçāo Original & Especificaçāo Mutante \\
\hline \hline STATE wait_put; & STATE wait_put; \\
INPUT put $(\mathrm{m}) ;$ & INPUT AM $(\mathrm{J}) ;$ \\
OUTPUT dm $(\mathrm{m}, \mathrm{i}) ;$ & OUTPUT dm $(\mathrm{m}, \mathrm{i}) ;$ \\
NEXTSTATE wait_am; & NEXTSTATE wait_am; \\
ENDSTATE; & ENDSTATE; \\
\hline
\end{tabular}

Figura 4.19: Mutante Gerado pelo Operador Substituiçāo de Entrada

\subsubsection{Operadores de Mutação de Estrutura}

Esses operadores de mutação modelam erros que podem ocorrer na estrutura ou na arquitetura da especificação SDL, que representa a composição hierárquica dos componentes (ou blocos e processos) do software, as interações entre esses componentes e os dados trocados pelos mesmos. O fluxo de dados é expresso pelos sinais de entrada e saída e pelas variáveis locais dos processos. Observa-se que os aspectos de interface estão relacionados aos aspectos da arquitetura, de modo que os erros de interface são associados aos erros explorados pela mutação de estrutura. Desse modo, quando se desejar validar os aspectos da estrutura ou arquitetura de especificações SDL as duas classes de mutação (de Interface e de Estrutura) devern ser consideradas.

Os erros modelados por esses operadores de mutação são relacionados às conexões entre signal routes e channels e entre channels em uma especificação SDL:

- erros na definição dos channels e signal routes;

- erros na definição das conexões entre signal routes e channels e entre channels;

- erros na lista de sinais trocados.

Quando o termo "canal" for utilizado, ele engloba tanto os channels quanto os signal routes.

\section{Inclusão de Sinal na Lista de Sinais}

Esse operador inclui na lista de sinais de um canal, um sinal presente na lista de sinais de um outro canal presente no mesmo bloco, desde que o mesmo já não esteja presente na lista de sinais. Um exemplo de mutante gerado por este operador é apresentado na Figura 4.20.

\begin{tabular}{|l|l|}
\hline \multicolumn{1}{|c|}{ Especificaçāo Original } & \multicolumn{1}{c|}{ Especificaçāo Mutante } \\
\hline \hline SIGNALROUTE sender_Jower_interface & SIGNALLROUTE sender_Jower_interface \\
FROM ENV TO sender_process & $\rightarrow$ FROM ENV TO sender_process \\
WITH am, medium_error; & WITH am, medium_error, DM ; \\
FROM sender_process TO ENV WITH dm; & FROM sender_process TO ENV WITH dm; \\
\hline
\end{tabular}

Figura 4.20: Mutante Gerado pelo Operador Inclusão de Sinal na Lista de Sinais 


\section{Exclusão de Sinal da Lista de Sinais}

Esse operador exclui os sinais presentes na lista de sinais a serem transmitidos entre dois blocos ou dois processos. A Figura 4.21 apresenta um mutante gerado por este operador de mutação.

Restrição: este operador só é aplicável no caso de haver dois ou mais sinais a serem transmitidos em um canal.

\begin{tabular}{|l|l|}
\hline \multicolumn{1}{|c|}{ Especificaçāo Original } & \multicolumn{1}{c|}{ Especificaçāo Mutante } \\
\hline \hline SIGNALROUTE sender_lower_interface & SIGNALROUTE sender_lower_interface \\
FROM ENV TO sender_process & $\rightarrow$ FROM ENV TO sender_process \\
WITH am, medium_error; & WITH medium_error; \\
FROM sender_process TO ENV WITH dm; & FROM sender_process TO ENV WITH dm; \\
\hline
\end{tabular}

Figura 4.21: Mutante Gerado pelo Operador Exclusão de Sinal da Lista de Sinais

\section{Troca de Sinal da Lista de Sinais}

Esse operador troca os sinais presentes nas listas de sinais a serem transmitidos por dois canais, dois a dois, por sinais diferentes, que ainda não existam na lista de sinais. Na Figura 4.22 é ilustrado um mutante gerado por este operador.

\begin{tabular}{|l|l|}
\hline \multicolumn{1}{|c|}{ Especificaçāo Original } & \multicolumn{1}{c|}{ Especificação Mutante } \\
\hline \hline SIGNALROUTE sender_lower_interface & SIGNALROUTE sender_lower_interface \\
FROM ENV TO sender_process & $\rightarrow$ FROM ENV TO sender_process \\
WITH am , medium_error; & WITH DM , medium_error; \\
FROM sender_process TO ENV WITH dm; & $\rightarrow$ FROM sender_process TO ENV WITH AM; \\
\hline
\end{tabular}

Figura 4.22: Mutante Gerado pelo Operador Troca Sinal da Lista de Sinais

\section{Remoção de Signal routes/Channels}

Esse operador de mutação exclui cada um dos canajs que ligam os processos e blocos definidos no sistema. Na Figura 4.23 é ilustrado um mutante gerado por este operador.

\begin{tabular}{|l|l|}
\hline \multicolumn{1}{|c|}{ Especificaçāo Original } & \multicolumn{1}{c|}{ Especificaçāo Mutante } \\
\hline \hline SIGNALROUTE sender_lower_interface & SIGNALROUTE sender_lower_interface \\
FROM ENV TO sender_process & $\rightarrow$ \\
WITH am, medium_error; & \\
FROM sender_process TO ENV WITH dm; & FROM sender_process TO ENV WITH dm; \\
\hline
\end{tabular}

Figura 4.23: Mutante Gerado pelo Operador Remoção de Signal routes/Channels

\section{Remoção de Conexão entre Channels e Signal routes}

Esse operador de mutação exclui cada uma das conexões que ligam os canais de um bloco SDL no sistema. Um mutante gerado por este operador é ilustrado na Figura 4.24. 


\begin{tabular}{|c|l|}
\hline Especificação Original & Especificação Mutante \\
\hline \hline CONNECT sender_Jower_interface AND sender_lower_interface; & $\rightarrow$ \\
\hline
\end{tabular}

Figura 4.24: Mutante Gerado pelo Operador Remoção de Conexão entre Channels e Signal routes

\section{Substituição de Channels / Signal routes conectados}

Esse operador substitui os canais presentes em uma conexão, um de cada vez, por canais de outras conexões pertencentes ao mesmo bloco. Apenas channels / signal routes diferentes são trocados de modo a não gerar mutantes equivalentes. Como exemplo de mutante apresenta-se na Figura 4.25um dos mutantes gerados por este operador.

\begin{tabular}{|c|c|}
\hline Especificação Original & Especiflcação Mutante \\
\hline $\begin{array}{l}\text { CONNECT sender_lower_interface } \\
\text { AND sender_lower_interface; }\end{array}$ & $\begin{array}{l}\text { CONNECT SENDER_HIGHER.INTERTACE } \\
\text { AND sender_lower_interface; }\end{array}$ \\
\hline
\end{tabular}

Figura 4.25: Mutante Gerado pelo Operador Substituição de Channels/Signal routes Conectados

\subsection{Estratégias de Teste para Aplicação da Análise de Mu- tantes para SDL}

Para guiar a aplicação do conjunto de operadores de mutação definidos para SDL, de forma a melhor explorar as diferentes características abordadas, foi proposta uma Estratégia de Teste Incremental, ITS-SDL (Incremental Testing Strategy). Os passos da estratégia ITS-SDL são:

1. para validar o comportamento dos processos da especificação SDL, para cada processo

(a) aplicar os Operadores de Mutação de Processos e determinar um conjunto de teste adequado;

2. para validar as interações entre os processos, para cada processo

(a) aplicar os Operadores de Mutação de Interface e determinar um conjunto de teste adequado;

3. para validar a estrutura da especificação SDL

(a) para cada definição de signal route e de channel

- aplicar os Operadores de Mutação de Estrutura (operadores 1 a 4) e selecionar um conjunto de teste adequado; 
(b) para cada conexão entre um channel e um signal route

- aplicar os Operadores de Mutação de Estrutura (operadores 5 e 6) e selecionar um conjunto de teste adequado.

Pode-se aplicar essa estratégia top-down ou bottom-up, priorizando-se um ou outro aspecto que se deseja explorar na atividade de teste de uma especificação SDL: comportamento dos processos, comunicação entre processos e estrutura da especificação. Além disso, pode-se selecionar somente um subconjunto de operadores de mutação em cada passo da estratégia. No caso de identificação de algum erro durante a aplicação da estratégia, a especificação deve ser corrigida e a estratégia aplicada novamente.

$\mathrm{O}$ alto custo de aplicação da Análise de Mutantes causado pelo número de mutantes gerados que devem ser executados e analisados, muitas vezes pode comprometer sua utilização. Para o teste de programas, existem algumas abordagens de mutação alternativa que permitem a seleção de um subconjunto de operadores de mutação: mutação seletiva aleatória (Acree et al., 1979), mutação restrita (Mathur, 1991; Wong et al., 1994a) e mutação seletiva (Offutt et al., 1993). Para o teste de especificações, Fabbri (1996) propôs a utilização de duas dessas alternativas, mutação aleatória e mutação restrita. Essas abordagens podem ser utilizadas para a aplicação da Análise de Mutantes para SDL e podem ser aplicadas em combinação com a estratégia de teste incremental ITS-SDL.

Outra abordagem é a definição de um conjunto essencial de operadores de mutação, a exemplo dos trabalhos de Offutt et al. (1996a), Vincenzi et al. (1999) e Barbosa et al. (2001). Para a definição desse conjunto essencial são coletadas estatísticas sobre cada operador de mutação, a partir dos resultados de experimentos empíricos. Essa abordagem pode ser utilizada no contexto de especificações SDL, definindo, a partir do conjunto de operadores inicial, um conjunto de operadores essenciais para SDL.

Uma outra alternativa proposta para diminuir o custo computacional da Análise de Mutantes para o teste de especificações em Redes de Petri é a geração automática de sequêencias de teste (Simão e Maldonado, 2000a). Essa proposta em alguns casos também identifica mutantes equivalentes. A aplicação dessa abordagem no contexto de SDL também deveria ser investigada.

\subsection{Análise Teórica do Teste de Mutação para SDL}

Estudos teóricos podem analisar a complexidade dos critérios de teste considerando o número máximo de casos de teste requeridos no pior caso ou o número de requisitos de teste requeridos no pior caso. Segundo Budd (1981), em se tratando da Análise de Mutantes no teste de programas, o número de mutantes gerados é influenciado pelo número de variáveis vezes o número de referências às variáveis. Considerando o critério Mutação de Interface, sua 
complexidade foi analisada por Delamaro (1997), considerando o número de requisitos de teste requeridos no pior caso. Nesse caso, o número de mutantes gerados é determinado também pelo número de parâmetros das funções do programa. Souza (2000) também analisou a complexidade da Análise de Mutantes no teste de especificações Estelle, e, tendo como base a análise teórica realizada por Delamaro (1997), identificou o número de mutantes gerados no pior caso, pelo conjunto de operadores de mutação definido para Estelle.

Nessa mesma linha de pesquisa, apresenta-se a análise de complexidade realizada para os operadores de mutação definidos para SDL. São utilizados os seguintes conjuntos de elementos:

- P é o conjunto de processos da especificação;

- $\mathrm{S}(p)$ é o conjunto de estados do processo $p$;

- $\mathrm{I}(p)$ é o conjunto de possíveis entradas do processo $p$;

- $\mathrm{C}(p)$ é conjunto de constantes utilizadas no processo $p+$ constantes requeridas;

- $\mathrm{v}(p)$ é conjunto de variáveis declaradas no processo $p$;

- $\mathrm{V}(p)$ é conjunto de variáveis declaradas nos níveis de blocos e de sistema na hierarquia da especificação SDL;

- $\mathrm{PO}(p)$ é conjunto de parâmetros que cada comando Output pode ter;

- num op é o número máximo de operadores relacionais associados às condições das transições existentes no processo $p$;

- var é o número máximo de ocorrências de variáveis que não são de interface e de constantes no processo $p$;

- intervar é o número máximo de ocorrências de variáveis de interface (variáveis enviadas pelo processo por meio do comando Output);

- max elem é o número máximo de arcos de alternativas em um processo, que podem ser originadas por comandos de decisão ou por diferentes entradas a partir de um estado do processo SDL

- max tarefa é o número máximo de tarefas, distintas ou nāo, existentes em um processo $p$;

- max_saida é o número máximo de saídas (comando Output) existentes em uma transição.

Para a análise da complexidade, é necessário considerar que o comportamento dos processos SDL é determinístico, ou seja, em cada estado existe somente uma transição definida para cada entrada. Dessa forma, o número máximo de transições em um processo $p$ é calculado em função de $\mathrm{S}(p)$ e de $\mathrm{I}(p)$, considerando também uma transição espontânea (sem evento de entrada) para cada estado de $\mathrm{S}(p)$. Portanto, tem-se que o número máximo $T$ de transições é: $T=|\mathrm{S}(p)|^{*}|\mathrm{I}(p)|+|\mathrm{S}(p)|$.

A análise foi realizada individualmente para cada operador de mutação, ou seja, foi calculado o número máximo de mutantes que podem ser gerados pela aplicação de cada 
operador de mutação no pior caso. Para uma melhor apresentação dos resultados, os operadores são apresentados separados por classes de mutação.

\subsubsection{Complexidade dos Operadores de Mutação de Processos}

A Tabela 4.3 apresenta a complexidade de cada operador de mutação de processos. Nos próximos parágrafos, a complexidade de cada operador é comentada.

Tabela 4.3: Complexidade dos Operadores de Mutação de Processos

\begin{tabular}{|c|c|}
\hline Operador de Mutaçáo de Processos & Complexidade \\
\hline 1. Substituiçāo de Estado Origem & $\left.\bar{I}(p)\right|^{*}(|\mathrm{~S}(p)|-1)$ \\
\hline 2. Troca Definiçāo de Estado & $|\mathrm{S}(\mathrm{p})|^{*}(|\mathrm{~S}(\mathrm{p})|-1)$ \\
\hline 3. Substituição de Estado Destino & $|I(p)|^{*}(|\mathbf{S}(p)|-1)$ \\
\hline 4. Remoção de Estado & $|S(p)| *(|S(p)|-1)$ \\
\hline 5. Remoção de Transição & $\mathrm{T}$ \\
\hline 6. Remoção de Condiçāo & $|\mathrm{S}(\mathrm{p})|^{*}|\mathrm{I}(p)|$ \\
\hline 7. Negaçāo de Condição & $|S(p)|^{*}|I(p)|$ \\
\hline 8. Substituiçấo de Atribuiçāo Booleana & var \\
\hline 9. Substituiçâo de Variável por Variável & $\operatorname{var}^{*}(|v(p)+V(p)|-1)$ \\
\hline 10. Substituição de Variável por Constante & $\operatorname{var}^{*}(|\mathrm{C}(p)|-1)$ \\
\hline 11. Incremento/Decremento de Variáveis/Constantes & $\operatorname{var} * \frac{1}{2}$ \\
\hline 12. Inclusão de Operador Unário nas Variáveis & var \\
\hline 13. Substituiçāo de Tarefa & max_tarefa $*($ max_tarefa -1$)$ \\
\hline 14. Remoção de Tarefa & max_tarefa \\
\hline 15. Cobertura de Código & max_elem \\
\hline 16. Negação de Questão de Decisão & $\frac{\max =\frac{A l a m}{2}}{2}$ \\
\hline 17. Troca de Resposta de Decisão & maxcelem ${ }^{*}($ max_elem - 1$)$ \\
\hline 18. Remoção de Resposta de Decisẽo & max_elem \\
\hline 19. Remoção de Parada de Prooesso (Stop) & $\mathbf{T}$ \\
\hline 20. Remoção de Save & $|\mathrm{S}(\mathrm{p})|$ \\
\hline 21. Remoção de Sinal a ser Salvo & $|S(p)| *|I(p)-1|$ \\
\hline 22. Substituiçāo de Sinal a ser Salvo & $|S(p)| *|1(p)-2|$ \\
\hline 23. Remoçäo de Set Timer & $T$ \\
\hline 24. Remoção de Reset Timer & $T$ \\
\hline 25. Remoção de Criação Create de Processo & $T$ \\
\hline 26. Substituiçāo de Operador Aritmético & $\max -\operatorname{tarefa} * 3$ \\
\hline 27. Substituiçầo de Join/Label & $\bar{T}$ \\
\hline 28. Substituiçẫo de Operador Relacional & num_op *5 \\
\hline
\end{tabular}

1. Substituição de estado origem: o número de mutantes gerados é determinado pelo número de estados e entradas do processo $p$. Assim, o número de mutantes gerados, no pior caso, é igual ao número de entradas multiplicado pelo número de estados menos um, que corresponde ao estado origem original

2. Troca Definiçāo de Estado: cada estado pode ser trocado por todo o conjunto de estados, dois a dois.

3. Substituição de estado destino: o número de mutantes gerados é influenciado pelo número de estados e entradas do processo $p$, de modo que o número de mutantes gerados, no pior caso, é igual ao número de entradas multiplicado pelo número de estados menos um, correspondendo ao estado destino original. 
4. Remoção de estados: cada estado $s_{\mathfrak{i}}$ será retirado e substituído por outro do conjunto $\mathrm{S}(p)$ que esteja conectado a $s_{i}$. Assim sendo, o número de mutantes gerados, no pior caso, é igual ao número de estados, multiplicado pelo número de estados menos um.

5. Remoção de Transição: o número de mutantes gerados é igual ao número de transições do processo $p$.

6. Remoção de Condição: o número de mutantes gerados é igual ao número de transições (não espontâneas) pois, no pior caso, todas as transiçōes possuem condições.

7. Negaçāo de Condição: considera-se que, no pior caso, todas as transições (não espontâneas) possuem condições. Portanto, o número de mutantes gerados é igual ao múmero de transições.

8. Substituição de Atribuição Booleana: considera-se que todas as ocorrências de var são variáveis booleanas, de forma que o número de mutantes gerados por este operador, no pior caso, é igual ao número de var.

9. Substituição de Variável por Variável: considera-se que todas as ocorrências de var serão trocadas por todos os elementos dos conjuntos $v(p)$ e $V(p)$.

10. Substituição de Variável por Constante: no pior caso, supõe-se que todas as ocorrências de var serão trocadas por todos os elementos do conjunto $\mathrm{C}(\mathrm{m})$.

11. Incremento/Decremento de Variáveis/Constantes: no pior caso, supōe-se que todas as ocorrências de var serão incrementadas e decrementadas.

12. Inclusão de Operador Unário nas Variáveis: considera-se que, no pior caso, pode-se incluir o operador unário "-" em todas as ocorrências de var.

13. Substituição de Tarefa: no pior caso, toda tarefa definida em um processo é distinta, de forma que todas as max_tarefa podem ser substituídas por todas as outras tarefas diferentes dela mesma.

14. Remoção de Tarefa: o número de mutantes gerados é o número de tarefas existentes no processo.

15. Cobertura de Código: no pior caso, considera-se que esse operador será aplicado em todos max elem.

16. Negação de Questão de Decisão: no pior caso, considera-se que max_elem representa apenas alternativas de questões de decisão e que cada decisão tem apenas duas alternativas. 
17. Troca de Resposta de Decisão: no pior caso, considera-se que o processo contém apenas um comando de decisão e que max.elem representa as alternativas desta decisão. Então a troca ocorrerá entre cada alternativa e todas as demais.

18. Remoção de Resposta de Decisão: no pior caso, considera-se que max elem representa apenas alternativas de questões de decisão, portanto, o número de mutantes gerados é max elem.

19. Remoção de Parada de Processo (Stop): supõe-se que, no pior caso, cada transição tem um comando de parada.

20. Remoção de Save: supõe-se que, no pior caso, haja um comando save associado a cada estado do processo $p$.

21. Remoção de Sinal a ser Salvo: considera-se que, no pior caso, todas as possíveis entradas podem ser salvas, com exceção de uma, em cada estado de um processo $p$.

22. Substituição de Sinal a ser Salvo: considera-se que, no pior caso, todo estado tem uma entrada e um sinal a ser salvo e este pode ser trocado por todas as outras entradas diferentes da entrada e dele mesmo.

23. Remoção de Set Timer: supõe-se que, no pior caso, toda transição tem um Set Timer, então o número de mutantes gerados é o número de transições.

24. Remoção de Reset Timer: supõe-se que, no pior caso, toda transição tem um Reset Timer, então o número de mutantes gerados é o número de transições.

25. Remoção de Criação Create de Processo: supõe-se que, no pior caso, toda transição tem um Create, então o número de mutantes gerados é o número de transições.

26. Substituição de Operador Aritmético: considera-se que, no pior caso, cada tarefa tenha um operador aritmético a ser substituído pelos demais.

27. Substituição de Join/Label: no pior caso considera-se que há um Join/Label em cada transição, então o número de mutantes é o número de transições.

28. Substituição de Operador Relacional: o número de mutantes gerados, no pior caso, é o número de operadores relacionais num op, multiplicado pelos demais operadores relacionais.

Como pode ser observado, a complexidade dos operadores de mutação de processos está relacionada ao número de estados, entradas, transições, variáveis, operadores relacionais das condições, tarefas e decisões nas transições presentes na especificação SDL. Alguns operadores têm complexidade quadrática em relação ao número de estados $(\mathrm{S}(p))$ e complexidade linear em relação aos outros elementos. 


\subsubsection{Complexidade dos Operadores de Mutação de Interface}

A complexidade dos operadores de Mutação de Interface é apresentada na Tabela 4.4. Considera-se que há uma comunicação entre dois processos por meio de um comando de saída Output, presente no processo que "chama", e um comando de entrada Input, presente no processo "chamado".

Tabela 4.4: Complexidade dos Operadores de Mutação de Interface

\begin{tabular}{|c|c|}
\hline Operador de Mutação de Interface & Complexidade \\
\hline 1. Remoçāo de Saída & $\mathrm{T}^{*}$ max saida \\
\hline 2. Substituiçāo de Saída & $\left(T^{*}\right.$ max-saida $) *(T *($ max_saida -1$))$ \\
\hline 3. Subatituiçāo de Destino de Saída & $\left(T^{*} \max\right.$ saida $) *\left(|S(p)|^{*}(|\mathrm{P}|-1)\right)$ \\
\hline 4. Substituição de Signal Route de Saída & $\frac{|P| \cdot(|P|-1)}{2}$ \\
\hline 5. Substituição de Parâmetros & $\max _{2} \operatorname{sajda}^{*}|\mathrm{PO}(p)|^{*}(|\mathrm{v}(p)|+|\mathrm{V}(p)|)$ \\
\hline 6. Incremento/Decremento de $\bar{P}$ arâmetros & $|\mathrm{PO}(p)|^{*} 2$ \\
\hline 7. 'Troca a Ordem dos Parâmetros & $P Q(p) \mid *(\mid P O(p))-1)$ \\
\hline 8. Inclusão de Operadores Unários nos Parâmetros & $|\overline{P O}(p)|^{*}$ max $_{\text {_saida }}$ \\
\hline 9. Substituição de Variáveis de Interface & intervar * $(|v(p)+V(p)+C(p)|)$ \\
\hline 10. Substituiçāo de Variável de Não-Interface & $\operatorname{var}^{*}(|\mathrm{v}(p)+V(p)+C(p)|-1)$ \\
\hline 11. Incremento/Decremento de Variável & $($ var $t$ - intervar $) * 2$ \\
\hline 12. Inclusāo de Operadores Unários nas Variávejs & var + intervar \\
\hline 13. Substituição de Atribuiçāo Booleana & max_tarefa \\
\hline 14. Remoção de Entrada & $|\mathrm{S}(p)|^{*}|\mathrm{I}(p)|$ \\
\hline 15. Substituiçāo de Entrada & $|I(p)|^{*}(|I(p)|-1)$ \\
\hline
\end{tabular}

A seguir apresentam-se alguns comentários sobre a complexidade de cada operador de interface.

1. Remoção de Saída: o número de mutantes gerados é o número de saídas (comandos Output) existentes no processo.

2. Substituição de Saída: supõe-se, no pior caso, que todas as saídas são distintas e, portanto, uma saída pode ser substituída por todas as demais saídas.

3. Substituição de Destino de Saída: supõe-se, no pior caso, que o destino de uma saída pode ser trocado por todos os estados de outros processos.

4. Substituição de Signal Route de Saída: supõe-se, no pior caso, que haja um signal route ligando todos os processos, dois a dois.

5. Substituição de Parâmetros: supõe-se que, no pior caso, cada parâmetro de um comando de saída pode ser substituído por todas as variáveis e constantes existentes.

6. Incremento/Decremento de Parâmetros: no pior caso, cada parâmetro é incrementado e decrementado, de forma que o número de mutantes é o número de parâmetros multiplicado por 2 .

7. Troca a Ordem dos Parâmetros: supõe-se que, no pior caso, todos os parâmetros podem ser trocados por todos os outros. 
8. Inclusão de Operadores Unários nos Parâmetros: o número de mutantes gerados, no pior caso, é o número de parâmetros existentes.

9. Substituição de Variáveis de Interface: considera-se que, no pior caso, todas as variáveis em intervar podem ser substituídas pelas variáveis dos conjuntos $\mathrm{v}(p), \mathrm{V}(p)$ e $\mathrm{C}(p)$.

10. Substituição de Variável de Não-Interface: supõe-se que é possível trocar todas variáveis em var por todas as variáveis dos conjuntos $\mathrm{v}(p), \mathrm{V}(p)$ e $\mathrm{C}(p)$.

11. Incremento/Decremento de Variável: no pior caso, considera-se que todas que as variáveis em var e de intervar podem ser incrementadas e decrementas.

12. Inclusão de Operadores Unários nas Variáveis: supõe-se que, no pior caso, todas as variáveis em var e intervar, podem receber o operador unário.

13. Substituição de Atribuição Booleana: considera-se que, no pior caso, há uma atribuição booleana para as variáveis de interface em toda tarefa definida nas transições, de forma que o número de mutantes gerados é o número de tarefas existentes.

14. Remoção de Entrada: considera-se que, no pior caso, todo estado tenha transições que são habilitadas por todas as possíveis entradas.

15. Substituição de Entrada: supõe-se, no pior caso, que cada estado tenha apenas uma entrada e esta pode ser substituída por todas as demais entradas.

Analisando a Tabela 4.4, pode-se observar que, para alguns operadores de mutação, a complexidade é quadrática em relação ao número de transições, variáveis, entradas e saídas presentes na especificação SDL. Para os demais elementos, como tarefas e estados, a complexidade é linear.

\subsubsection{Complexidade dos Operadores de Mutação de Estrutura}

Para determinar a complexidade dos operadores de mutação de estrutura, consideram-se três variáveis: max_sr, que é o número máximo de signal routes que podem existir em uma especificação SDL; $\max c h$, que é o número máximo de channels que podem existir em uma especificação; e max_con, que é o número máximo de conexões existentes entre os canais. A Tabela 4.5 apresenta as complexidades dos operadores de mutação de estrutura.

Na sequiência, apresentam-se alguns comentários sobre a análise da complexidade de cada operador de mutação de estrutura.

1. Inclusão de Sinal da Lista de Sinais: considera-se que, no pior caso, a lista de sinais tem apenas um sinal e este pode ser substituído por todos os demais. 
Tabela 4.5: Complexidade dos Operadores de Mutação de Estrutura

\begin{tabular}{|c|c|}
\hline Operador de Mutaçāo de Estrutura & Complexidade \\
\hline 1. Inclusão de Sinal da Lista de Sinais & $\mid \overline{|I(p)|^{*}(||(p) \mid-1)}$ \\
\hline 2. Remoção de Sinal da Lista de Sinais & $\mid I(p) !$ \\
\hline 3. Troca de Sinais da Lista de Sinais & {$[(p)[-(1, p)]-1)$} \\
\hline 4. Romoçāo de Signal routes/Channels & max_sr + max_ch \\
\hline 5. Remoçāo de Conexão entre Channels e Signal routes & $\max$ con \\
\hline 6. Substituiçầo de Channels/Signal routes Conectados & $\left(\max \operatorname{con}^{*}(\max -\operatorname{sr}-1)\right)+\left(\left(\max \operatorname{con}^{*}(\max -c h-1)\right)\right.$ \\
\hline
\end{tabular}

2. Remoção de Sinal da Lista de Sinais: o número de mutantes gerados é o número de possiveis sinais (que são as entradas do conjunto $\mathrm{I}(p)$ ).

3. Troca de Sinais da Lista de Sinais: considera-se que, no pior caso, cada sinal esteja presente em uma lista de sinais diferente, de forma que todos os sinais podem ser trocados, dois a dois.

4. Remoção de Signal routes/Channels: o número de mutantes gerados é o número de signal routes e de channels existentes na especificação SDL.

5. Remoção de Conexão entre Channels e 'Signal routes: o número de mutantes gerados corresponde ao número de conexões existentes, $\max c o n$.

6. Substituição de Channels/Signal routes Conectados: supõe-se que, no pior caso, cada conexão pode ter trocado seu signal route por todos os demais signal routes e seu channel por todos os demais channels.

Observa-se que a complexidade dos operadores de mutação de estrutura está relacionada ao número de entradas, signal routes, channels e ao número de conexões existentes entre eles. Para um dos operadores, a complexidade é quadrática em relaçāo ao número de entradas, sendo linear para os demais operadores de mutação dessa classe.

\subsection{Considerações Finais}

Neste capítulo foi introduzida uma proposta para aplicação do critério Análise de Mutantes no teste de especificações SDL. Trabalhos anteriores apresentaram indícios da viabilidade da aplicação desse critério no teste de especificações, como uma forma complementar a outros critérios de teste.

A Análise de Mutantes pode ser utilizada para auxiliar a geração de conjuntos de teste e a avaliação da adequação de um conjunto de teste. Um conjunto de operadores de mutação foi definido e para auxiliar a aplicação desse conjunto de operadores, uma estratégia de teste incremental também foi definida, a ITS-SDL.

Os operadores de mutação para SDL foram divididos em três classes que exploram o comportamento dos processos, a comunicação entre processos e a estrutura da especificação 
SDL. Essa subdivisão é similar à estabelecida por Souza et al. (2000b) para Estelle, mas apenas alguns operadores de mutação são similares. Apesar de Estelle e SDL serem técnicas baseadas em transição de estados, algumas características são intrínsecas a cada técnica e para explorar possíveis erros nas especificaçōes foram definidos operadores específicos a cada uma dessas características. Por exemplo, é o caso dos operadores de mutação para SDL relacionados às tarefas e ao comando save.

O custo de aplicação da Análise de Mutantes pode ser um obstáculo, em virtude do número de mutantes que podem ser gerados. Assim, uma análise da complexidade dos operadores de mutação, em relação ao número de mutantes que podem ser gerados no pior caso, também foi realizada. Nessa análise, pode-se perceber que alguns operadores têm complexidade quadrática em relação a algum elemento da especificação, como por exemplo, o número de variáveis. Na maioria dos casos porém, a complexidade é linear em relação a algum elemento presente na especificação SDL.

A exemplo de outros trabalhos que propuseram alternativas menos custosas em relação à Análise de Mutantes, é importante investigar por exemplo, um conjunto de operadores essenciais que podem ser aplicados no teste de especificações SDL, com um custo menor, sem perder a eficácia em revelar erros.

A aplicação de critérios como a Análise de Mutantes porém, pode ser improdutiva e propensa a erros sem o auxílio de ferramentas de apoio. No próximo capítulo, os principais aspectos a serem considerados no desenvolvimento de uma ferramenta para apoiar o teste de especificaçães SDL, com base no teste de mutação, serão apresentados. 


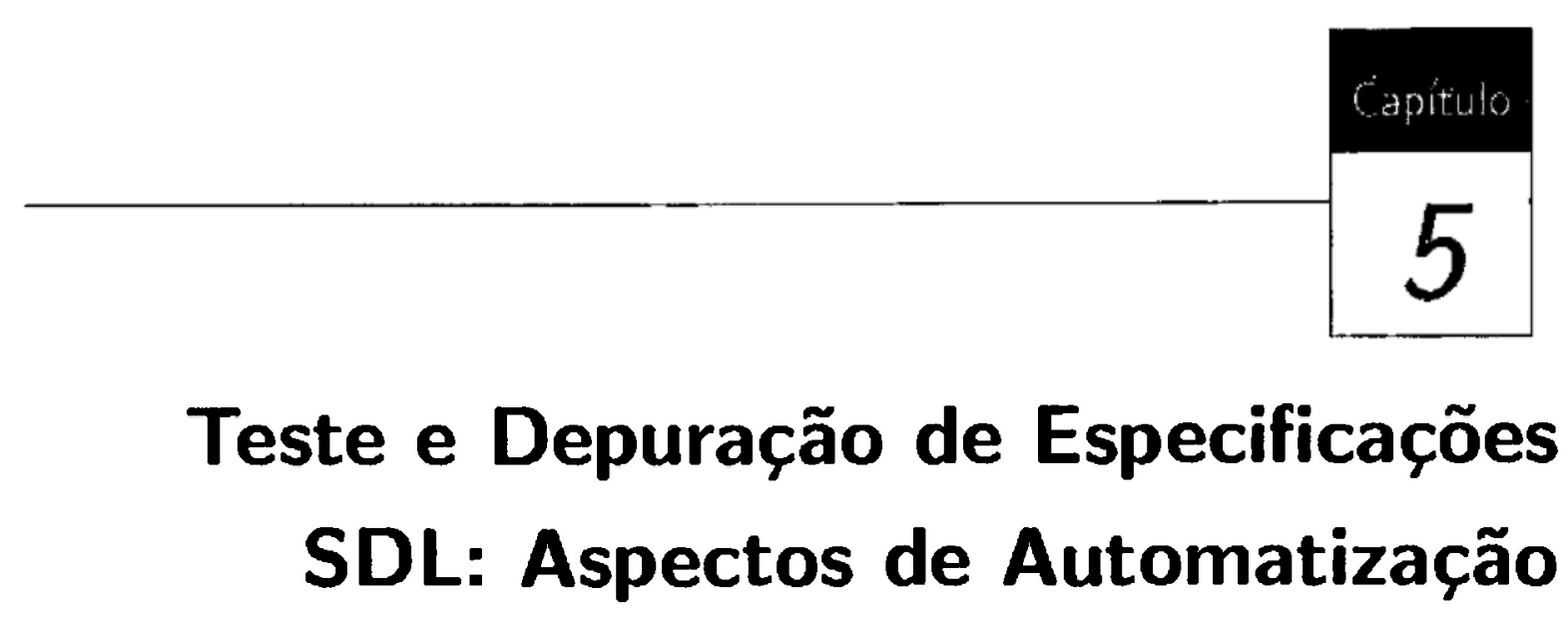

\subsection{Considerações Iniciais}

Para auxiliar a atividade de teste, o apoio de ferramentas é crucial, pois elas possibilitam que a realização dessa atividade seja mais produtiva e menos propensa a erros. Neste capítulo é apresentada a ferramenta $C A T_{S D L}$ (Coverage Analysis Tool), que apóia o teste estrutural dos processos SDL. Essa ferramenta permite a análise da cobertura de teste com relação a cinco critérios de teste e fornece informações, com base no conceito de dominadores, para a geração de casos de teste que aumentem mais eficientemente a cobertura de teste a cada execuçāo.

Também apresenta-se a ferramenta $S$ mart $D_{S D L}$ (Smart Debugging Tool), que auxilia a atividade de depuração de especificaçōes SDL. A $S$ mart $D_{S D L}$ fornece informações sobre a localizaçăo de erros nas especificaçōes SDL com base nas informaçōes de cobertura de teste obtidas durante o teste realizado com a $C A T_{S D L}$. Com essas informaçōes, a $S$ mart $D_{S D L}$ identifica os slices de execução dos casos de teste e com a aplicação de heurísticas, aponta possiveis locais do erro na especificação SDL. Ambas ferramentas implementam as abordagens de teste e depuração propostas na Seção 3.2 do Capítulo 3 .

Uma ferramenta para auxiliar a aplicação do teste de mutação no teste de especificações SDL, como apresentado no Capítulo 4, também é proposta com base nos trabalhos anteriores do grupo de Engenharia de Software do ICMC--USP/São Carlos, em que ferramentas de 
apoio a esse critério, para o teste de programas e de outras técnicas de especificaçāo, foram desenvolvidas.

\subsection{Apoio aos Critérios Estruturais: A Ferramenta $C A T_{S D L}$}

No Capítulo 3 foi proposta a aplicacão de teste estrutural no teste de especificaçōes SDL, em que a cobertura de teste dos processos SDL é medida em relaçāo a cinco critérios de teste: Todos-Blocos, Todas-Decisões, Todos-c-Usos, Todos-p-Usos e Todos-Usos. Os dois primeiros sāo critérios de fluxo de controle e os outros três são critérios de fluxo de dados. Além da análise de cobertura de teste, propõe-se a utilizaçāo do conceito de dominadores para fornecer informaçōes sobre quais requisitos deveriam ser satisfeitos primeiro para melhorar de forma mais eficiente a cobertura de teste a cada execuçāo. Para apoiar essa proposta, a ferramenta $C A T_{S D L}$ foi desenvolvida. A seguir apresentam-se os requisitos funcionais, a arquitetura e os aspectos de implementação e operacionais da $C A T_{S D L}$.

\subsubsection{Aspectos Funcionais e Arquitetura}

As três principais atividades que a ferramenta deve realizar são: instrumentação da especificação SDL, coleta de informações de cobertura de teste durante a simulação da especificação SDL. e determinação da cobertura de teste da especificação em relação aos cinco critérios de teste apoiados.

A Figura 5.1 ilustra a arquitetura da $C A T_{S D L}$. Módulos são responsáveis pelas tarefas a serem realizadas pela ferramenta, tais como as análises sintática e estática e derivaçāo dos requisitos dos critérios de teste. Das atividades realizadas pelos módulos podem resultar dados que devem ser informados aos usuários, como é o caso dos grafos de fluxo e relatórios de cobertura (apresentados em Interface na Figura 5.1) ou dados utilizados pelos próprios módulos ou para simulação, como é o caso dos requisitos de teste e da especificação SDL instrumentada (apresentados em Dados na Figura 5.1). Para a simulação, é necessário o auxílio de uma outra ferramenta, uma vez que a $C A T_{S D L}$ nāo tem um módulo simulador.

A especificaçāo SDL deve ser instrumentada para que, durante sua execuçāo com os casos de teste (simulação), os requisitos cobertos possam ser identificados. Antes da instrumentação da especificação, um grafo de fluxo deve ser constrúdo para cada processo SDL, de forma a permitir a derivaçāo dos requisitos de teste de cada critério de teste. A partir dos GFs, os requisitos de teste de cada critério de teste devem ser derivados.

A ferramenta também deve calcular e informar ao usuário os pesos de cada requisito de teste para auxiliar a geração dos casos de teste. As informações sobre os requisitos cobertos durante a execução da especificaçāo devem ser coletadas e processadas. Assim, a ferramenta deve medir o quanto uma especificação SDL foi testada por um conjunto de casos de teste e identificar áreas da especificação que requerem mais testes. 


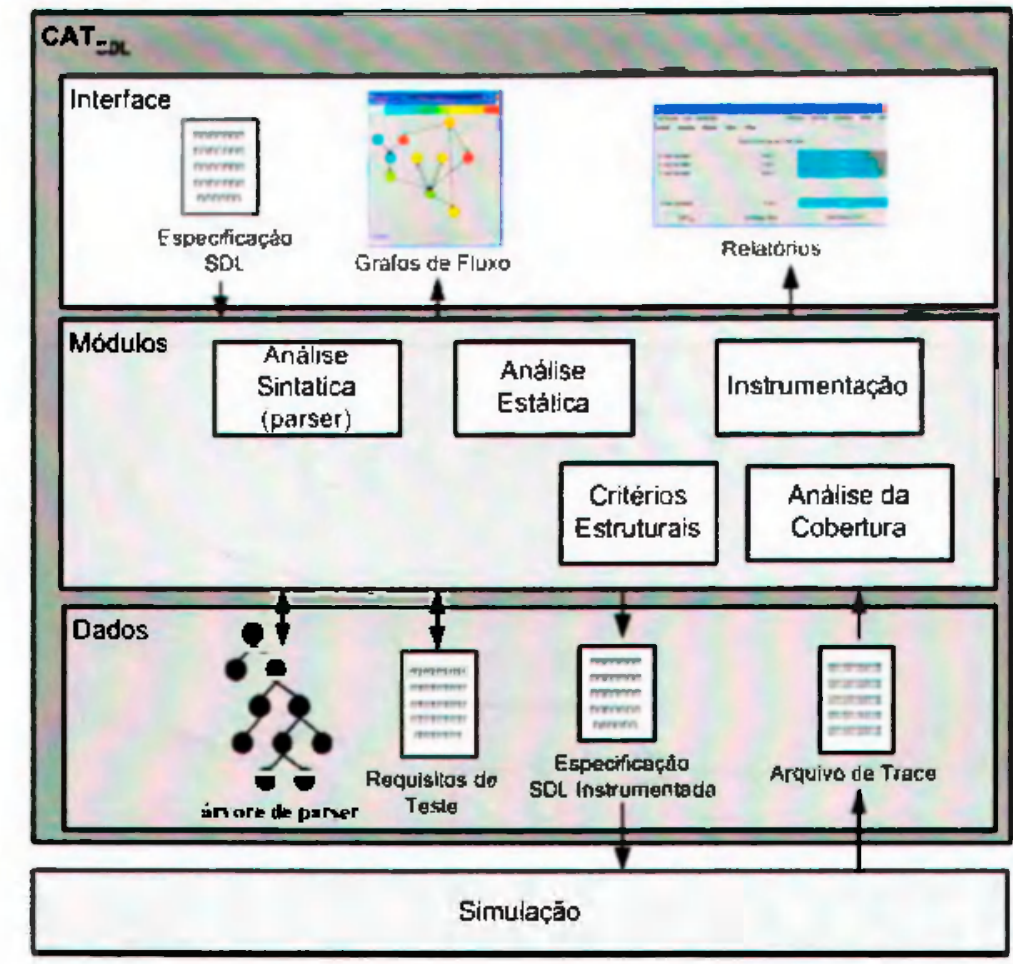

Figura 5.1: Arquitetura da Ferramenta $C A T_{S D L}$

É importante também que a ferramenta gere relatórios com as informaçōes mais relevantes para o usuário, tais como a cobertura obtida em relação a cada critério de teste e a cobertura dos requisitos de cada processo SDL pelos casos de teste.

\subsubsection{Aspectos de Implementação}

Antes de serem testadas na $C A T_{S D L}$, as especificaçōes são analisadas sintaticamente por um parser que foi construído com base na gramática SDL-92 da linguagem SDL (ITU, 1993). Apesar da gramática SDL-2000 ser mais recente, optou-se pela gramática SDL-92 pois essa era a gramática aceita pela versão 4.3 da ferramenta Telelogic: Tau ${ }^{1}$ (Telelogic, 2002b), quando a $C A T_{S D L}$ foi construída. A Telelogic Tau é utilizada em conjunto com a $C A T_{S D L}$ para realizar a simulação da especificação $\mathrm{SDL}$ sendo testada.

Na Figura 5.2 ilustra-se a sequência de atividades realizadas pela $C A T_{S D L}$ e como a ferramenta se comunica com a Telelogic Tau. Dada uma especificação SDL, a $C A T_{S D L}$ realiza um parsing na mesma e gera uma árvore de parser. A partir dessa árvore, determinam-se quais partes da especificação devem ser agrupadas em blocos para compor os grafos de fluxo) de cada processo SDL da especificiçãa. A partir dos GFs, são estabelecidos os requísitos de cada critério de teste. A instrumentação da especificação é realizada em cada um dos processos SDL, adicionando-se uma função pré-definida a cada um de seus blocos.

\footnotetext{
'Atualmente o ICMC-USP/São Carlos possui a licenç̧a acadêmica da versão 4.4 da Telelogic Tau, que aceita a gramática SDL-2000
} 
A especificação instrumentada deve então ser exportada para um simulador, nesse caso o simulador da ferramenta Telelogic Tau. A cada simulação, informações sobre os blocos executados são adicionados em um arquivo de trace. Esse arquivo de trace é importado pela $C A T_{S D L}$ para que a cobertura de teste possa ser analisada. Feito isso, relatórios sobre o andamento da atividade de teste podem ser gerados.

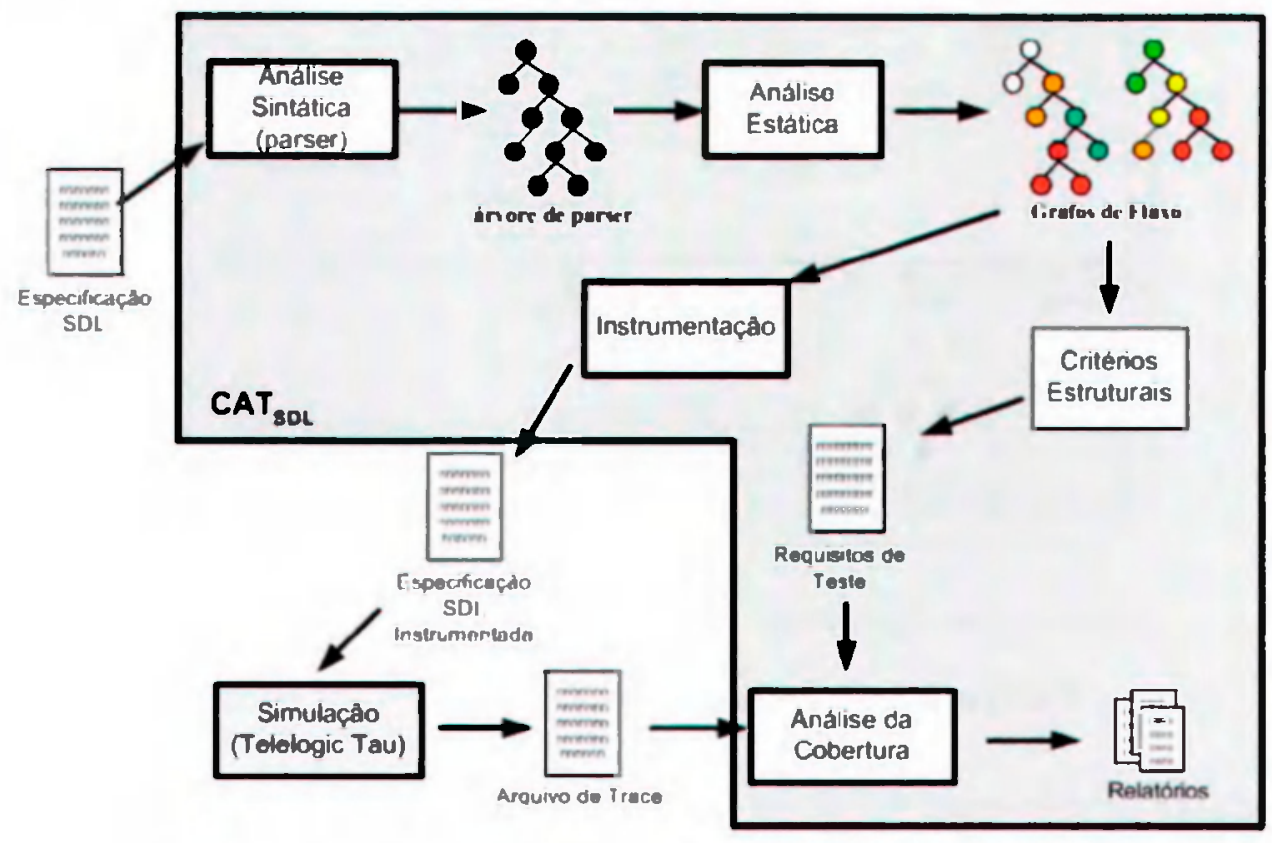

Figura 5.2: Fluxo de Informações na Ferramenta $C A T_{S D L}$

Para auxiliar a geração de casos de teste de modo a aumentar a cobertura de forma mais eficiente a cada execução, ou seja, utilizando um menor número de casos de teste possível, a abordagem implementada pela $C A T_{S D L}$ utiliza informações obtidas pela análise de dominadores, apresentada na Seção 3.2.4 do Capítulo 3. Com esta análise, a cada requisito de teste é atribuído um peso e este determina a prioridade que deve ser dada para a cobertura do respectivo requisito. Para mostrar os pesos associados aos requisitos, utilizam-se diferentes cores na $C A T_{S D L}$. A cor branca indica que o requisito já foi coberto, ou seja, tem peso 0 . Cada requisito ainda não coberto recebe uma cor, de acordo com o número de requisitos que podem ser cobertos caso este requisito seja satisfeito. A cor vermelha sempre indica o requisito de maior peso.

A ferramenta possui 9 pacotes que implementam os módulos responsáveis pela construção da interface gráfica, pela análise sintática e estática da especificação, implementação dos critérios de teste, coleta e armazenamento das informaçōes da simulação e análise de cobertura. Alguns dos pacotes foram adequados dos pacotes pertencentes à ferramenta JaBUTi, desenvolvida em um trabalho de doutorado (Vincenzi, 2004) e que, entre outras coisas, analisa a cobertura de teste de programas Java. Exemplos desses pacotes são: criteria e graph. 
A complexidade dos pacotes em relação ao número de linhas de código (LOC) é apresentada na Tabela $5 \cdot 1^{2}$. Em relação ao pacote parser, a grande maioria do código foi gerado automaticamente pelo gerador de parser JavaCC.

Tabela 5.1: Complexidade dos Pacotes que Compōem a Ferramenta $C A T_{S D L}$

\begin{tabular}{|l|r|}
\hline Pacote & LOC \\
\hline \hline criteria & 5166 \\
\hline graph & 3219 \\
\hline gui & 4882 \\
\hline guf & 1226 \\
\hline parser & 44000 \\
\hline sdlsystem & 813 \\
\hline unparser & 770 \\
\hline util & 210 \\
\hline
\end{tabular}

A $C A T_{S D L}$ foi desenvolvida em Java, linguagem que permite a portabilidade da ferramenta para diferentes plataformas. O parser para SDL foi desenvolvido com o auxilio de um gerador de parser para aplicaçōes em Java denominado JavaCC (Java Compiler Compiler).

\subsubsection{Principais Aspectos Operacionais}

A ferramenta $C A T_{S D L}$ é utilizada por meio de uma interface gráfica. A $C A T_{S D L}$ permite visualizar a especificação em teste de duas maneiras: representação textual e grafos de fluxo. A representação textual mostra a especificação por completo, enquanto que os grafos de fluxo permitem que o fluxo de controle de cada processo seja melhor visualizado, de forma que as duas representaçōes são complementares.

A $C A T_{S D L}$ possibilita a geração de relatórios de cobertura para cada critério, indicando o quão adequado é o conjunto de casos de teste existente e fornecendo informações sobre o progresso da atividade de teste. Pode-se avaliar a cobertura de todo o conjunto ou apenas de alguns casos de teste do conjunto.

Nesta seção, as principais atividades que podem ser realizadas na $C A T_{S D L}$ sâo ilustradas. A especificaçāo do protocolo Bit-Alternante, apresentada no Capítulo 3, é utilizada como exemplo.

\subsubsection{Criação de uma Sessäo de Teste}

O primeiro passo para a condução do teste de uma especificação SDL com o apoio da $C A T_{S D L}$ é íniciar uma sessão de teste. Uma especificaçăo textual SDL (extensão .sdl ou .pr), escrita de acordo com a gramática SDL-92, deve ser fornecida para a ferramenta. Essa especificação é analisada pelo parser e se estiver sintaticamente correta, a ferramenta criará uma versão

\footnotetext{
${ }^{2}$ As linhas de código da ferramenta $S$ mart $D_{S D L}$ estäo embutidas nesses valores uma vez que as ferramentas foram desenvolvidas na mesma base.
} 
instrumentada da mesma e gerará os gralos de fluxo relacionados aos processos SDL da especificação. A Figura 5.3 ilustra as duas possíveis formas de visualização da especificação em teste, a representação textual (Figura 5.3(a)) e um GF de um dos processos (processo Sender) do protocolo Bit-Alternante (Figura 5.3(b)). Nessa etapa. os requisitos de teste de cada critério já foram identificados e os pesos já foram atribuídos a cada urn deles. No caso da Figura 5.3, apresentarn-se os requisitos estabelecidos pelo critério Todos-Blocos. O espectro de cores na parte superior das duas representaçōes indica o valor dos pesos dos requisitos e a cor em que são representados.

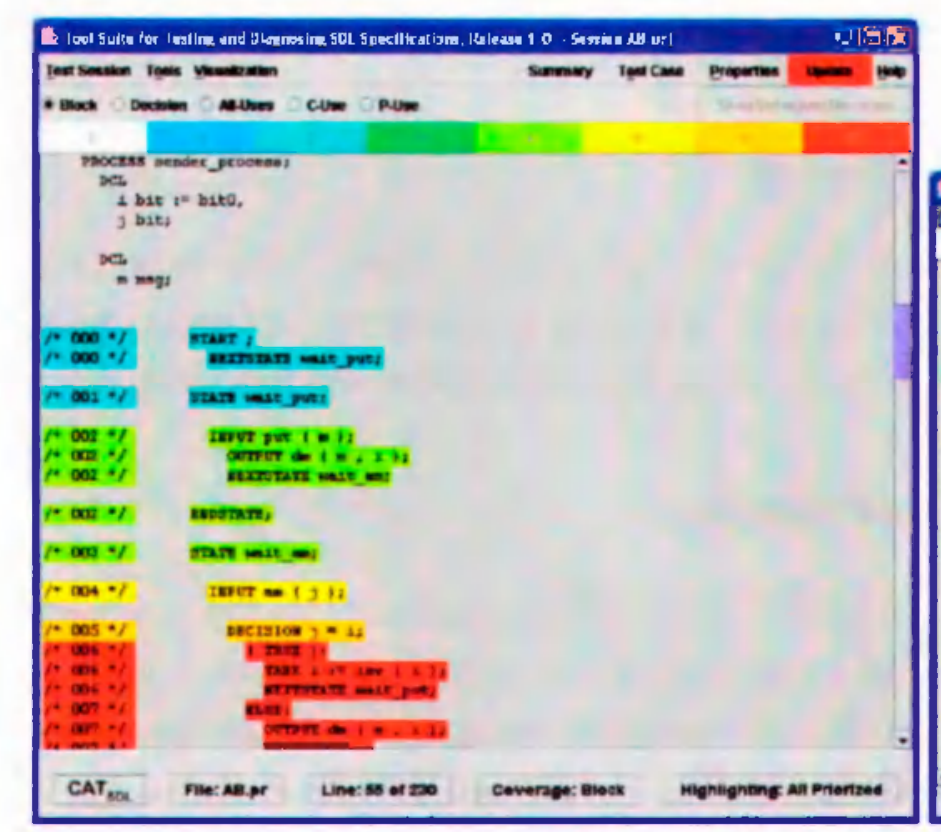

(a) Especificação Textual

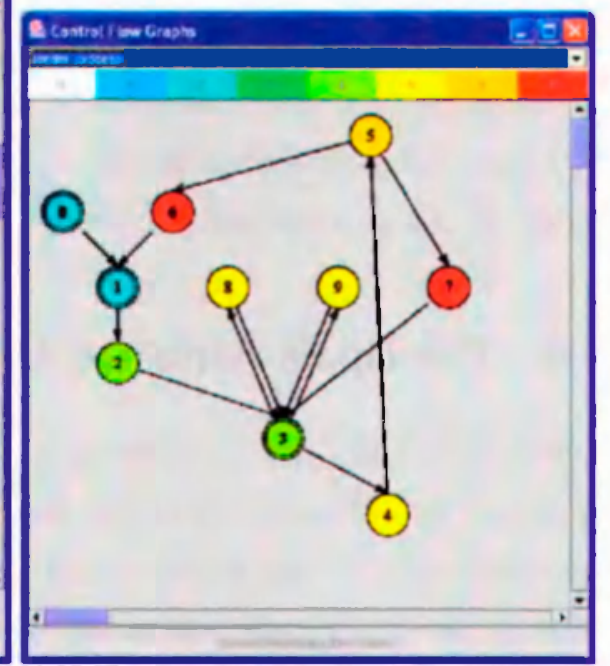

(b) Grafo de Fluxo

Figura 5.3: Telas Iniciais para o processo Sender na $C A T_{S D L}$ com relação ao Critérios Todos-Blocos

\subsubsection{Geração de Casos de Teste}

A partir das informaçōes fornecidas pela $C A T_{S D L}$ é possível iniciar a geração dos casos de teste de forma a obter uma maior cobertura a cada execução da especificação. Ou então pode-se avaliar a cobertura de um conjunto de casos de teste e, no caso da cobertura dos requisitos avaliados não ser de $100 \%$, novos casos de teste podem ser gerados a partir dessas informações.

Como comentado anteriormente, os pesos de cada requisito de teste são apresentados em diversas cores, de acordo com a prioridade que deve ser dada à cobertura do requisito. $O$ peso de um requisito indica quantos outros requisitos serão cobertos no caso deste requisito ser satisfeito. A cor vermelha sempre indica os requisitos de maior peso e a branca indica os requisitos que já foram totalmente cobertos. Por exemplo, na Figura 5.3(a), quando neuhum 
caso de teste foi avaliado, o bloco 4 (em amarelo), em relação ao critério Todos-Blocos, tem peso 5 , ou seja, se esse bloco for coberto, pelo menos outros 5 blocos também serão cobertos. Os blocos de maior peso para o processo Sender, são o 6 e o 7, de forma que a cobertura desses blocos deveria ter prioridade em relação à cobertura dos outros blocos do mesmo processo. Suponha então que um caso de teste seja gerado para cobrir o bloco 6 . A geração de casos de teste deve ser realizada com o auxílio de um simulador. No caso, é utilizado o simulador da Telelogic Tau 4.4, apresentado na Figura 5.4.

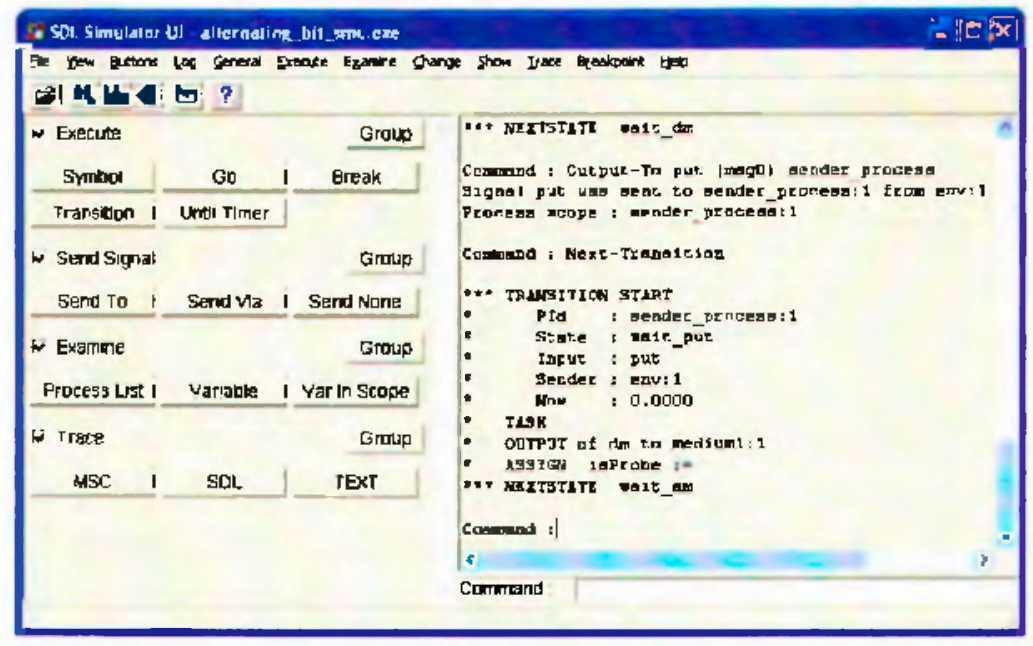

Figura 5.4: Simulação da Especificação na Telelogic Tau

A simulação é realizada na versão instrumentada da especificação, pois durante a simulação com um caso de teste, informações sobre os requisitos executados são coletadas e adicionadas em um arquivo de trace. A cada simulação, a $C A T_{S D L}$ realiza uma análise das informações coletadas, atualizando a cobertura de teste e recalculando os pesos dos requisitos.

\subsubsection{Visualização da Cobertura de Teste}

$\Lambda$ Figura 5.5 ilustra os novos pesos calculados após a execução do caso de teste gerado para cobrir o bloco 6. Após a simulação, os pesos dos requisitos mudaram e, consequentemente, as prioridades dos requisitos de teste também mudaram. O bloco 6 , que anteriormente tinha peso 7, foi totalmente coberto, ou seja, seu peso é 0 e ele é mostrado na cor branca. O bloco 7 continua tendo prioridade maior, mas agora seu peso tem outro valor, 1, e outros blocos (blocos 8 e 9) passaram a ter a mesma prioridade que o bloco 7 , como pode ser observado na Figura 5.5(b). Essas novas informaçôes devem ser consideradas para a geração do próximo caso de teste.

Nas Figuras 5.3 e 5.5 foi ilustrado como a $C A T_{S D L}$ apresenta os requisitos de teste e seus respectivos pesos para o critério Todos-Blocos aplicado à especificação SDL do protocolo Bit-Alternante. Para os demais critérios, os requisitos de teste são apresentados em duas camadas. Para o critério Todas-Decisões, na primeira camada são apresentadas todas as 


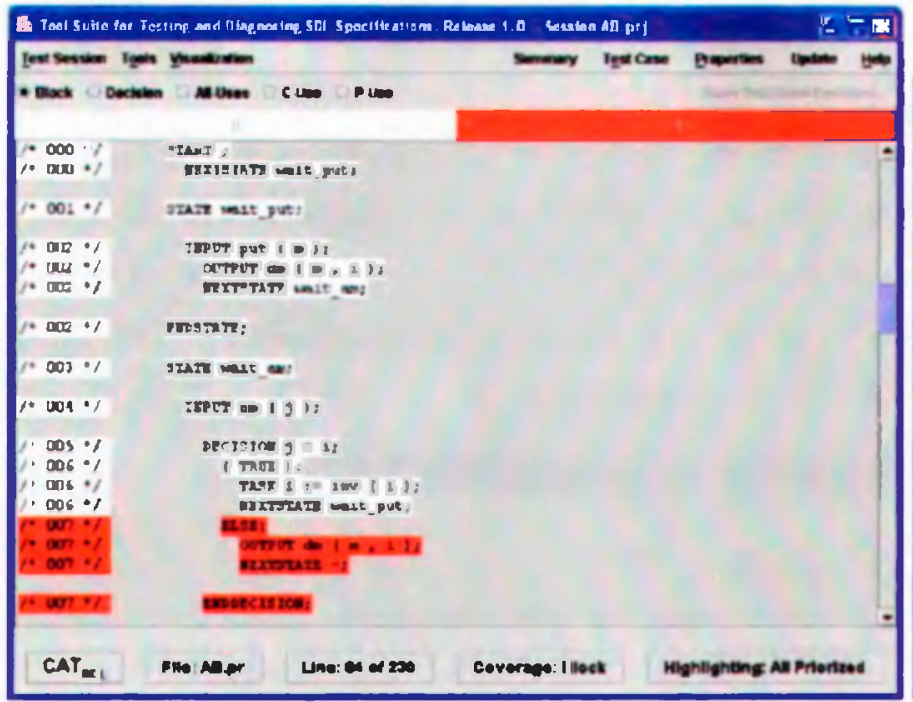

(a) Especificação Textual

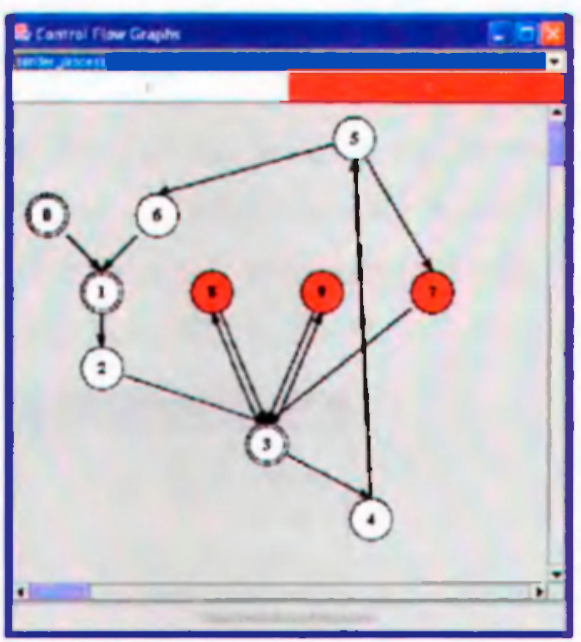

(b) GFC

Figura 5.5: Telas do Processo Sender na $C A T_{S D L}$ com Relação ao Critério Todos-Blocos após a Execução com um Caso de Teste

decisões existentes em cada processo SDL da especificação e seu peso é determinado pelo maior peso de seus arcos, como visto na Seção 3.2.4 do Capítulo 3. Por exemplo, as Figuras 5.6(a) e 5.6(b) apresentam a primeira camada do processo Sender com relação ao critério Todas-Decisões no modo textual e no GF, respectivamente. Nesse caso, o processo Sender possui duas decisões, os blocos 3 e 5, com pesos 1 e 2, respectivamente. Quando uma das decisões é selecionada (por meio de um click duplo no bloco de decisão da representação textual ou do GF), a segunda camada é apresentada, ou seja, seus arcos, com seus respectivos pesos, são apresentados. Selecionando, por exemplo, o bloco 5 , seus arcos são apresentados como ilustrado nas Figuras 5.6(c) e 5.6(d). Ambos arcos têm o mesmo peso, 2. Para obter uma melhor cobertura dos requisitos do critério Todas-Decisões para o processo Sender em uma execução, casos de teste que executem os blocos 6 e 7 devem ser gerados primeiro

Similarmente, os requisitos dos critérios de fluxo de dados também são apresentados em duas camadas, sendo que na primeira camada são apresentados os blocos em que há definições e na segunda camada apresentam-se os usos, sejam p-usos ou c-usos, associados a uma determinada definição. Da mesma forma, o peso associado a um bloco de definição é determinado pelo maior peso associado aos blocos ou arcos com usos associados.

\subsubsection{Geração de Relatórios de Teste}

Após a simulação da especificação com um caso de teste ou um conjunto de casos de teste, é desejável obter algumas informações sobre a situação da atividade de teste, como por exemplo, quantos requisitos de teste derivados para um certo critério de teste para cada processo SDL foram cobertos e qual a cobertura de teste obtida para cada critério. A 

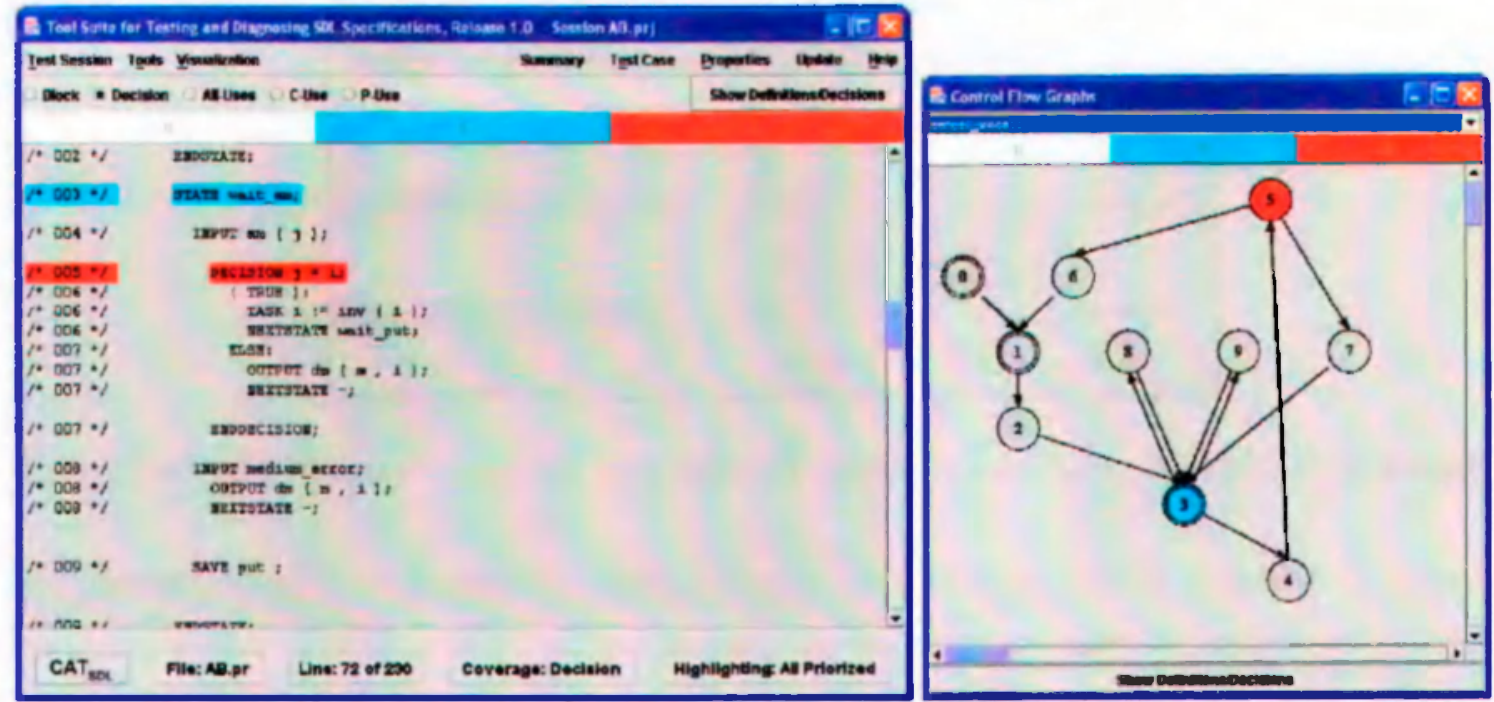

(a) Primeira Camada na Especificação Textual: Todas-Decisōes (b) Primeira Todas-Decisūes
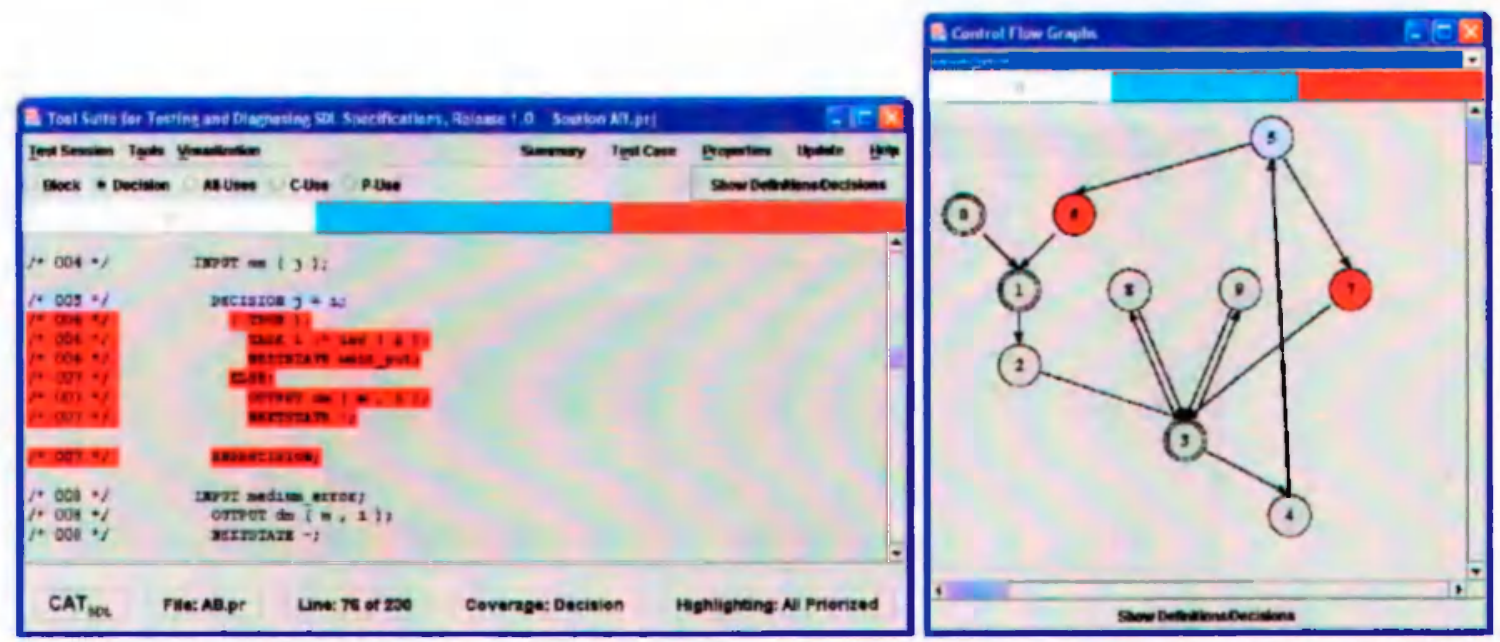

(c) Segunda Camada na Especificação Textual: Todas-Decisões (d) Segunda

Camadn no GF Todas-Decisôes

Figura 5.6: Telas para o Processo Sender na $C A T_{S D L}$ com Relação ao Critério Todas-Decisões

$C A T_{S D L}$ permite a visualização dessas informações e, com base nesses dados, possibilita que o testador analise quais partes da especificação precisam ser ainda testadas c possa decidir por parar ou não a atividade de teste.

Como pode ser observado na. Figura 5.7, o caso de teste que foi gerado inicialmente para cobrir o bloco 6 para o critério Todos-Blocos cobriu $77 \%$ dos requisitos desse critério, ou seja, foram cobertos 24 blocos dos 31 existentes.

A Figura 5.8(a) ilustra um relatório com informações da cobertura de teste por processo SDL, em relação ao critério Todos-Blocos, para o mesmo caso de teste. l'ara csse critério, o caso de teste sendo avaliado cobriu $70 \%$ ( 7 de 10$)$ dos requisitos do processo Sender, $71 \%$ (5 de 7) dos requisitos do processo Receiner e $85 \%$ (6 de 7 ) dos requisitos dos processos Medium1 


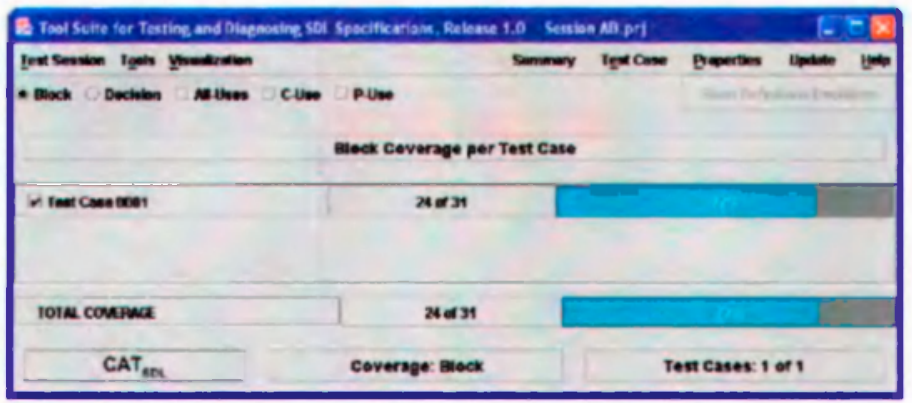

Figura 5.7: Relatório de Casos de Teste Gerado pela $C A T_{S D L}$ para um Caso de Teste

e Medium2. A Figura 5.8(b) apresenta um relatório com a cobertura de teste do mesmo caso de teste, em relação a todos os critérios de teste apoiados pela $C A T_{S D L}$. Para o critério Todos-Blocos foram cobertos $77 \%$ (24 de 31) dos requisitos, para Todas-Decisões foram cobertos $46 \%$ ( 6 de 13) dos requisitos. $37 \%$ ( 6 de 16) dos requisitos do critério Todos-c-Usos, $33 \%$ (4 de 12) dos requisitos do critério Todos-p-Usos e $35 \%$ (10 de 28) dos requisitos do critério Todos-Usos foram cobertos.

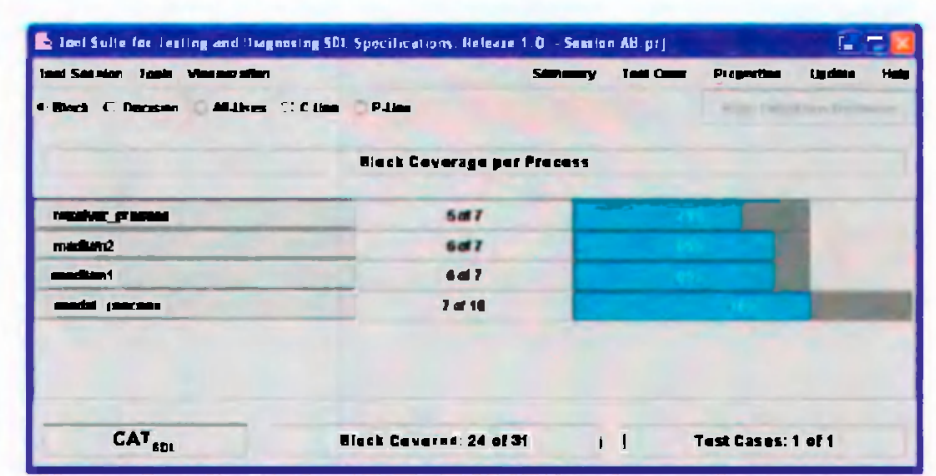

(a) Por processo

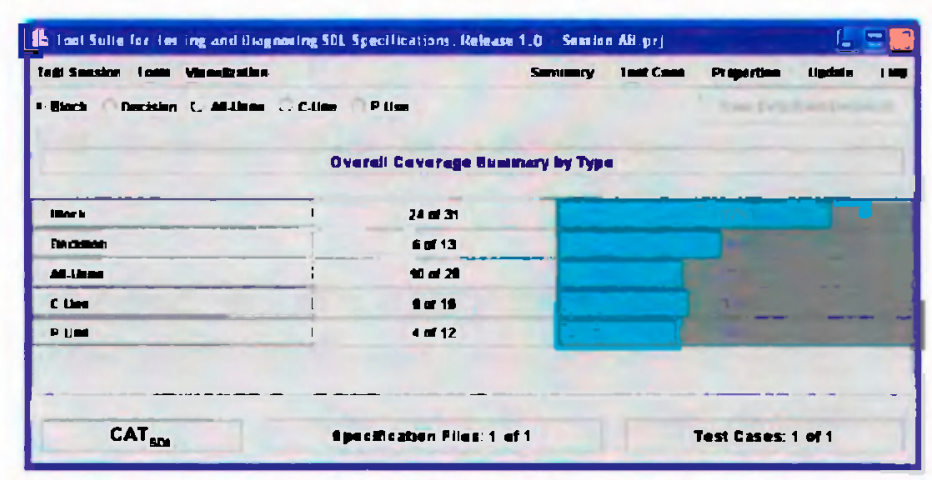

(b) Por critério de teste

Figura 5.8: Relatórios Gerados pela $C A T_{S D L}$

Para aumentar a cobertura de teste, outros casos de teste devem ser adicionados. Com base na informação ilustrada na Figura 5.5 de que os blocos 7, 8 e 9 têm prioridade sob os demais blocos do processo Sender, mais um caso de teste foi adicionado. Nesse caso, a 
informação não foi tão importante visto que só restavam os tres blocos para serem cobertos, e a prioridade é a mesma para os três, mas em uma outra situação, em que os pesos dos blocos ainda nāo cobertos são distintos, essa informação seria mais útil. No relatório apresentado na Figura 5.9, é possível analisar a cobertura obtida com a execução de cada caso de teste, assim como é possível selecionar casos de teste que se desejam analisar simultaneamente.

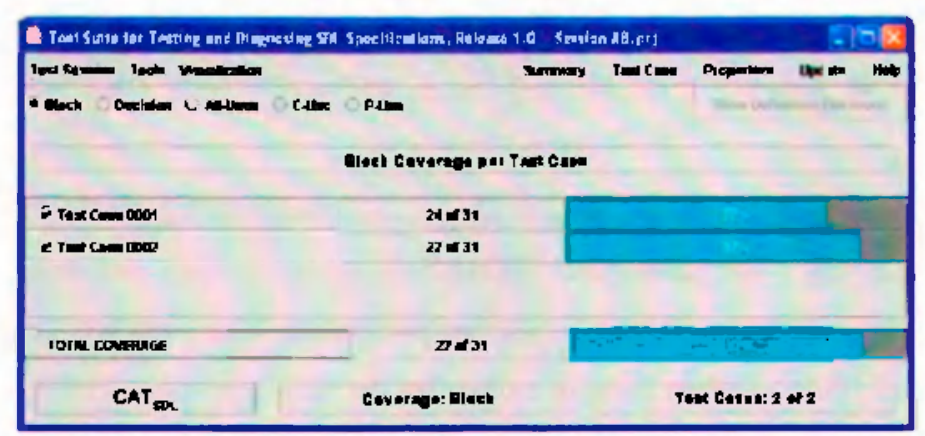

Figura 5.9: Relatório de Casos de Teste Após Inclusão de mais um Caso de Teste

Após a adição do segundo caso de teste, as coberturas obtidas para cada critério de teste são apresentadas na Figura 5.10. Observa-se uma melhora nas coberturas dos requisitos de todos os critérios de teste. A cobertura do critério Todos-Blocos, por exemplo, passou de $77 \%$ para $87 \%$ (27 de 31 ) e do critério Todas-Decisōes, aumentou de $46 \%$ para $69 \%$ (9 de 13).

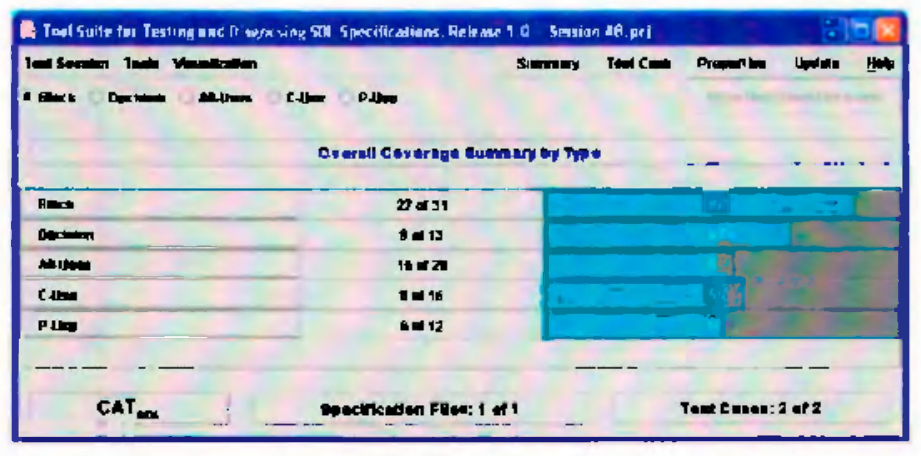

Figura 5.10: Relatório de Cobertura por Critério de Teste para Dois Casos de Testes

Esses passos podem ser repetidos até que todos os requisitos tenham sido cobertos ou até que o testador decida parar a atividade de teste.

No estudo de caso a ser apresentado no Capítulo 6, a $C A T_{S D L}$ foi utilizada para a geração dos casos de teste adequados, por construção, aos critérios de teste estruturais.

\subsection{Apoio à Depuração: A Ferramenta $\operatorname{Smart} D_{S D L}$}

$\mathrm{Na}$ Seção 3.2.5 do Capítulo 3 foram propostas facilidades para a atividade de depuração que utilizam informações de cobertura coletadas durante o teste. Os casos dè teste são selecio- 
nados de forma a permitir que sejam identificados os slices de execuçāo na especificaçāo. A aplicação dessa abordagem pode ser comprometida sem $o$ apoio de ferramentas, pois coletar e analisar os slices de execução são tarefas custosas em termos de tempo e também propensas a erros, se executadas manualmente. Para apoiar essa abordagem foi desenvolvida a ferramenta $S m a r t D_{S D L}$ (Wong et al., 2003, 2004), construída na mesma base da ferramenta $C_{S A} T_{S D L}$. A $C A T_{S D L}$ coleta informações sobre a cobertura obtida pelo conjunto de casos de teste e essas informações são utilizadas pela $S$ mart $D_{S D L}$ para obter os correspondentes slices de execução.

Para ilustrar as funcionalidades da $\operatorname{Smart} D_{S D L}$, a especificaçäo SDL do protocolo INRES é utilizada como exemplo. O protocolo INRES é uma versão do sistema Abracadabra (ISO/TC97/SC21, 1990; Turner, 1993), que implementa um serviço de transferência de dados confiável, assimétrico e orientado à conexão de um initiator para um responder em um meio não confí́vel. Nesse protocolo são caracterizados muitos conceitos básicos OSI e mecanismos como conexão, desconexão, mensagens de reconhecimento (acknowledgments) e retransmissãa por timeout. A Figura 5.11 ilustra uma representação SDL do protocolo INRES em nível de sistema, com três blocos: bloco Ini_Station com dois processos, Initiator e Ini_Coder; bloco Res_Station também com dois processos, Responder e Res_Coder; e o bloco Medium, com os processos MSAP_Manager1 e MSAP_Manager2. A comunicação com o ambiente acontece por meio de dois canais: ISAP1 e ISAPQ.

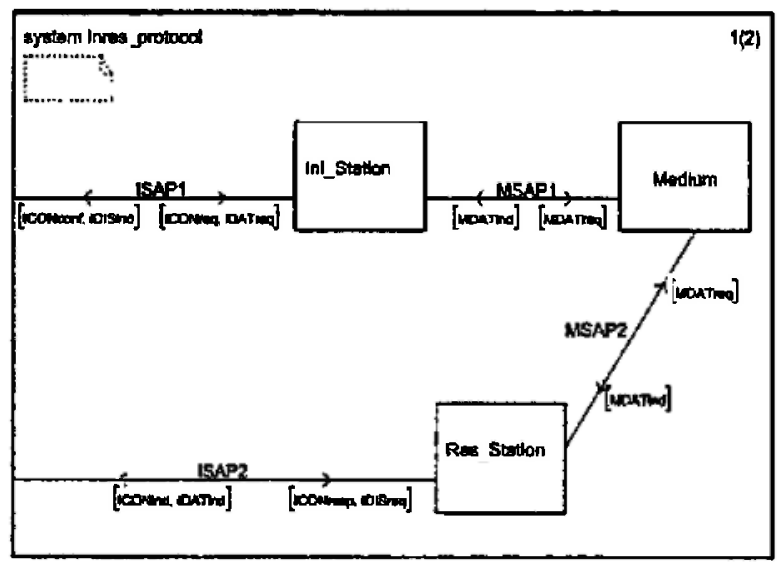

Figura 5.11: Nivel de Sistema do Protocolo INRES em SDL

O initiator (representado pelo bloco Ini'Station) é responsável pelo estabelecimento da conexão e o envio de dados. O responder (representado pelo bloco Res_Station) é responsável por aceitar a conexão, receber os dados e liberar as conexões. Há três fases na comunicação de ambos: estabelecimento da conexăo, transmissão de dados e desconexão. $O$ primeiro passo é estabelecer a conexão entre o initiator e.o, responder por meio de 'quatro primitivas de serviço: ICONreq (INRES connection request), ICONind (INRES connection indication), ICONresp (INRES connection response) e ICONconf.(INRES connection confirmation). Depois que uma conexão é estabelecida, o initiator pode enviar dados pela primitiva de 
serviço IDATreq (INRES data request) que serão recebidos pelo responder como IDATind (INRES data indication). Quando uma transmissão termina, o responder pode finalizar a conexão por meio de IDISreq (INRES disconnection request), enviada ao initiator como IDISind (INRES disconnection indication). Se houver algum problema no estabelecimento da conexão ou durante a transmissão de dados, o initiator recebe como indicação um IDISind. No caso da perda de dados inerentes ao serviço do meio, esses são retransmitidos quando o tempo estipulado pelo timeout acabar.

A Figura 5.12 ilustra a especificação SDL do processo Res_Coder. A especificação textual completa do protocolo INRES é apresentada no Apêndice B.

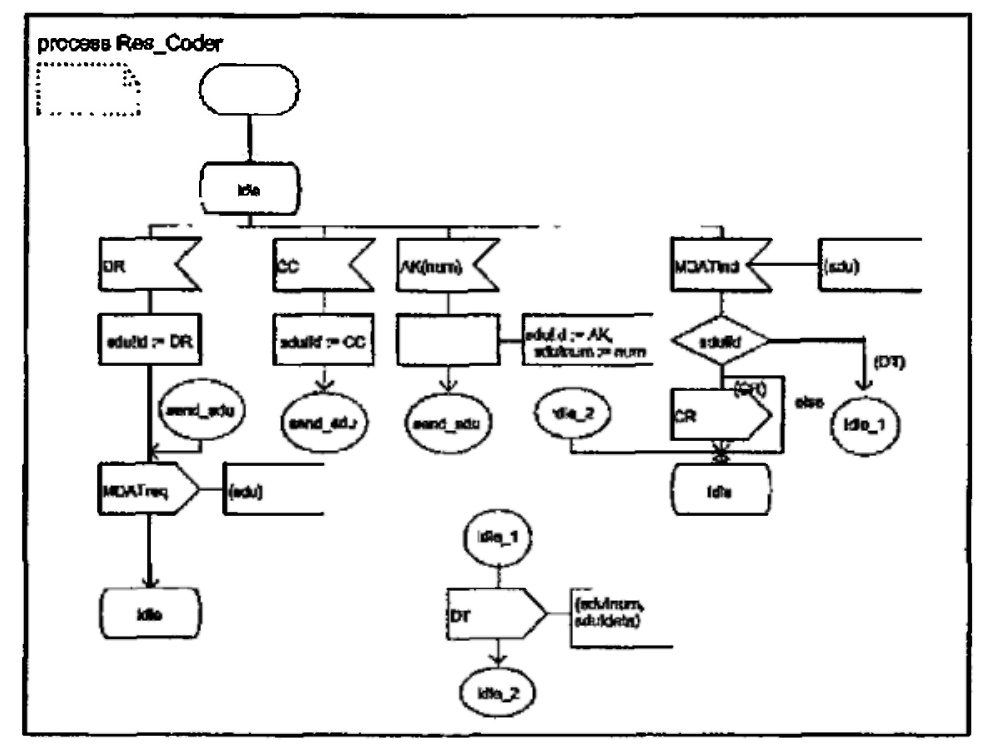

Figura 5.12: Especificação do Processo Res_Coder

Um erro foi inserido na especificação do processo Res_Coder do protocolo INRES, como ilustra a Figura 5.13, para melhor apresentar as funcionalidades da ferramenta $S$ mart $D_{S D L}$. $\mathrm{O}$ erro foi inserido na atribuição de um valor à variável sdu!id. Na especificação correta, essa variável recebe "DR", enquanto que para ilustrar um erro, " $\mathrm{DR}$ " foi trocada por " $\mathrm{CC}$ ".

\subsubsection{Aspectos Funcionais e Arquitetura}

As principais atividades que devem ser apoiadas pela $S \operatorname{mart} D_{S D L}$ são: permitir a seleção de uma das três heurísticas apresentadas na Seção 3.2.5 do Capítulo 3; seleçāo de casos de teste bem e mal sucedidos, e; avaliação das partes da especificação mais prováveis de conter erros. Caso o erro não seja encontrado nas partes da especificação indicadas pela $S$ mart $D_{S D L}$ como mais prováveis de contê-lo (com maior prioridade), pode-se examinar outras partes com menor prioridade ou então utilizar uma outra heurística e/ou diferentes casos de teste.

A arquitetura da $S$ mart $D_{S D L}$ é ilustrada na Figura 5.14. O módulo Heurísticas é responsável por identificar e atribuir pesos às partes da especificaçäo executadas pelos casos 


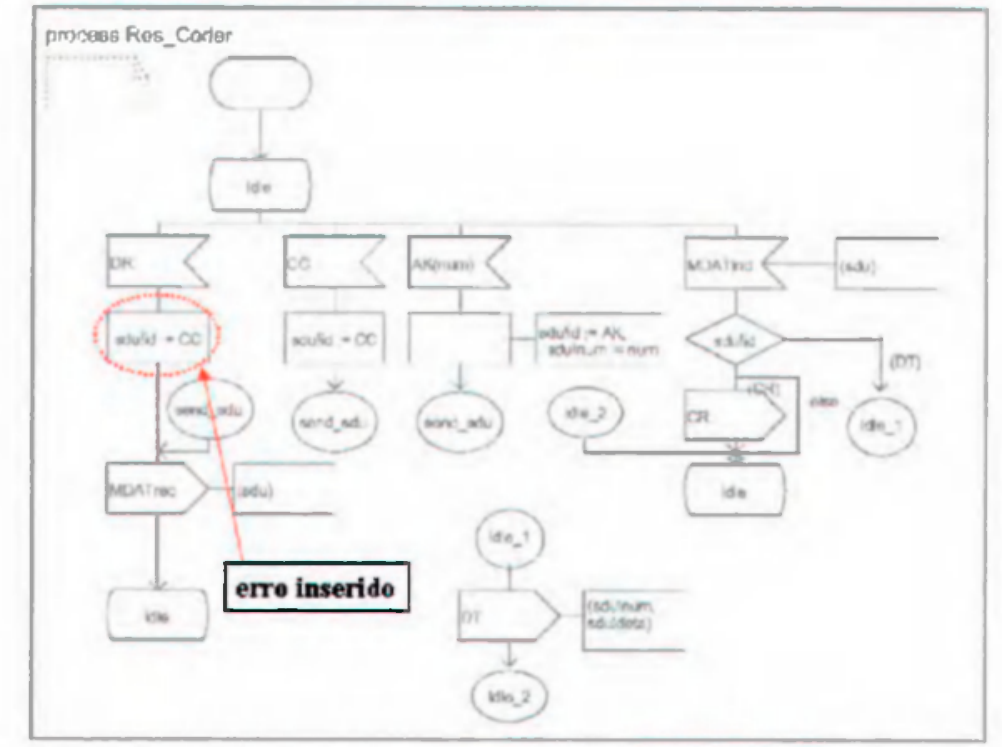

Figura 5.13: Erro inserido na especificação SDI, do Protocolo lNRES

de teste de acordo com suas probabilidades em conter o erro procurado. Como pode ser observado, os módulos responsáveis pela análise de cobertura e pelos critérios de teste da $C A T_{S D L}$ são também utilizados na $S m a r t D_{S D L}$. No caso do módulo análise de cobertura, uma modificação foi necessária para que os slices executados pelos casos de teste fossem identificados.

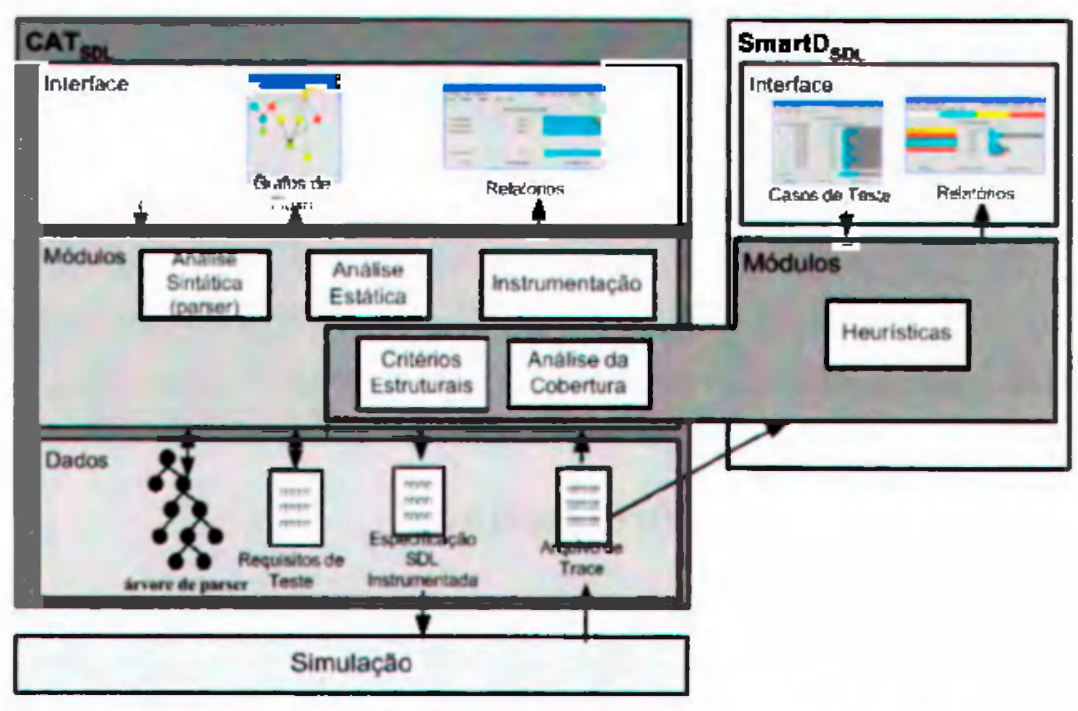

Figura 5.14: Arquitetura da Ferramenta $S \operatorname{mart} D_{S D L}$ 


\subsubsection{Aspectos de Implementação}

A $S m a r t D_{S D L}$ foi desenvolvida na mesma base da ferramenta $C A T_{S D L}$ de forma que esforço foi necessário para a implementação das heurísticas e para a identificação dos slices de execıção dos casos de teste. Além disso, o pacote responsável pela interface gráfica também foi modificado para atender às necessidades da $S$ mart $D_{S D L}$.

As informaçōes obtidas pela $C A T_{S D L}$ sobre a cobertura de cada caso de teste são utilizadas pela $S m a r t D_{S D L}$. Essas informações são relacionadas aos slices de execuçāo de cada caso de teste. De acordo com a heurística selecionada, a ferramenta combina os slices de execução dos casos de teste indicados, e informa ao usuário os possíveis locais do erro, atribuindo prioridades a esses locais. Os slices de execução podem ser representados por blocos, decisões, c-usos ou p-usos, de acordo com o critério de cobertura sendo utilizado.

\subsubsection{Principais Aspectos Operacionais}

Alguns casos de teste foram gerados na $C A T_{S D L}$ para o teste da especificação do protocolo INRES com alteração, de forma que durante a simulação, foram identificados comportamentos inesperados da especificação com alguns casos de teste. Essas informaçōes foram então utilizadas na depuração dessa especificação com o auxílio da $S \operatorname{mart} D_{S D L}$.

Para utilizar a $S m a r t D_{S D L}$ uma das heurísticas disponíveis deve ser selecionada, assim como devem ser atribuídas aos casos de teste a serem utilizados pela heurística, informações. sobre seu sucesso ou não em executar a especificação em depuração. A Figura 5.15 apresenta a janela em que essas tarefas podem ser realizadas. As heurísticas dos Casos I e II podem ser selecionadas pelo botão "use pre-defined heuristics" e o Caso Geral por "choose your oum heuristics". Por exemplo, na Figura 5.15, foi selecionada a heurística do Caso II. Dentre os casos de teste disponiveis (gerados durante a atividade de teste com o auxilio da $C A T_{S D L}$ e da Telelogic Tau, para simulação), três foram selecionados, 0002, $0003 \mathrm{e}$ 0009 , sendo que o primeiro é dito mal sucedido ("failed" test case) e os outros dois são bem sucedidos ("successful" test case). Como pode ser observado nessa figira, os casos de teste bem sucedidos são marcados com um sinal verde, enquanto que os casos de teste mal sucedidos são marcados com um sinal vermelho.

Feita a seleção dos casos de teste, os slices são combinados de acordo com a heurística selecionada e as partes da especificação SDL mais prováveis em conter o(s) erro(s) podem ser visualizadas. Na Figura 5.15, como o critério selecionado é Todos-c-Usos, os slices são apresentados em termos de c-usos. O resultado da heurística selecionada, por processo SDL, é apresentado na Figura 5.16. Cada processo SDL é ilustrado com a cor de seu requisito de maior prioridade. Nesse caso, dois processos têm prioridade 3 (apresentados em vermelho), portanto a maior prioridade encontrada entre os requisitos desses processos é 3. Um processo está em amarelo e dois estão em azul, de forma que suas prioridades são 


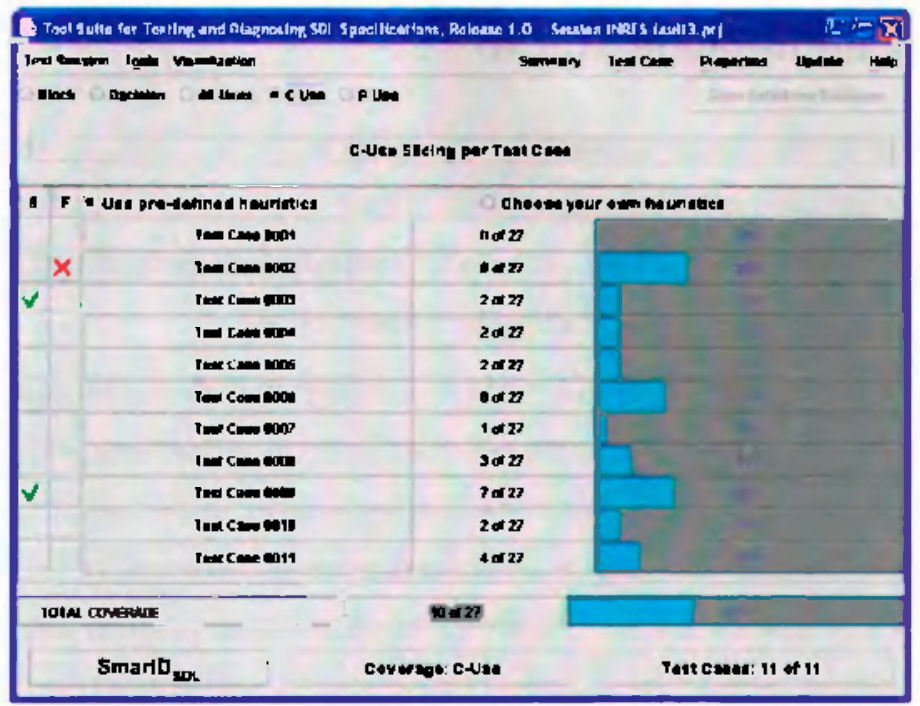

Figura 5.15: Tela de Seleção da Heurística do Caso II e Casos de Teste na Smart $D_{S D L}$

2 e 1 , respectivamente. O processo Responder, em branco, tem prioridade 0 , ou seja, não contém qualquer c-uso no slice de execução dos casos de teste 0002,0003 e 0009.

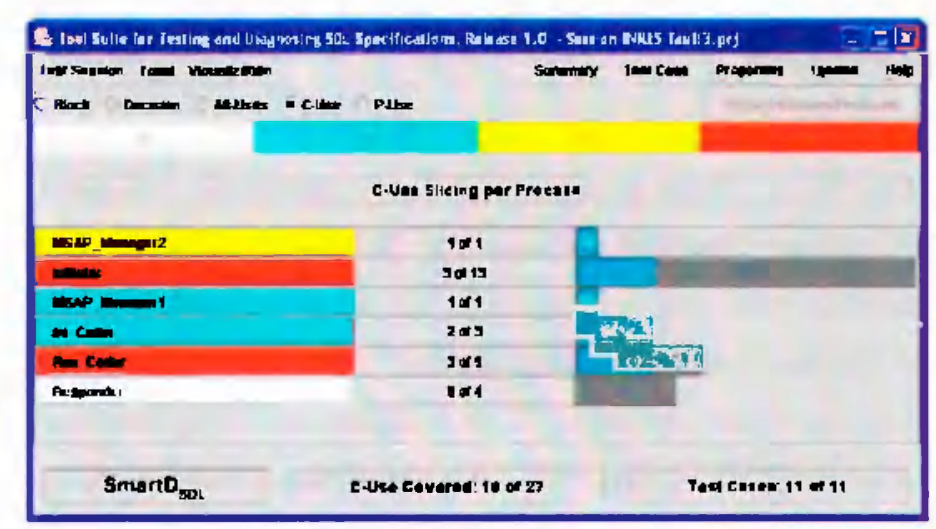

Figura 5.16: Prioridades dos Processos em Relação ao Critério Todos-c-Usos na Smart $D_{S D L} \cdot$ Caso II

Diante dessas informações, os processos corn maior prioridade (3) deveriam ser analisados antes dos processos com prioridade 2. Por exemplo, selecionando o processo "Rer Coder", pode-se visualizar as prioridades atribuídas aos seus requisitos, de acordo com a heurística e os casos de teste selecionados. Na Figura 5.17(a) apresentam-se os requisitos do processo "Res_Coder" e suas respectivas prioridades na forma textual, possibilitando a visualizaçāo de quais requisitos são mais prováveis de conter o(s) erro(s). Também é possível visualizar essas informações no GF do processo, como mostrado na Figura 5.17(b). Fm ambas as figuras, os requisitos em vermelho têm maior prioridade e sāo os mais prováveis de conter o(s) erro(s). Em scguida, os requisitos em amarelo são menos prováveis de conter erro em relaçāo aos requisitos em vermelho, mas mais prováveis do que os requisitos em azul. Os menos prováveis de conter erro(s) sāo os requisitos em branco, que nāo foram sequer executados 
pelos casos de teste mal sucedidos. Nessa situação, observa-se que o bloco em que um erro foi inserido (Figura 5.13) é apresentado em vermelho, ou seja, foi apontado como um dos blocos mais prováveis de conter o(s) erro(s).

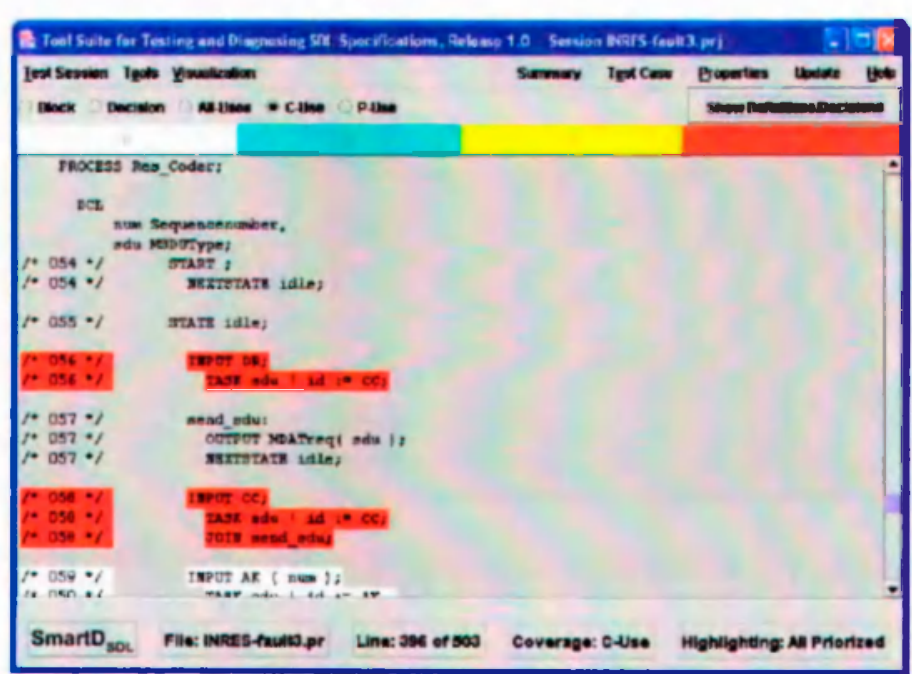

(a) Especificação Textual

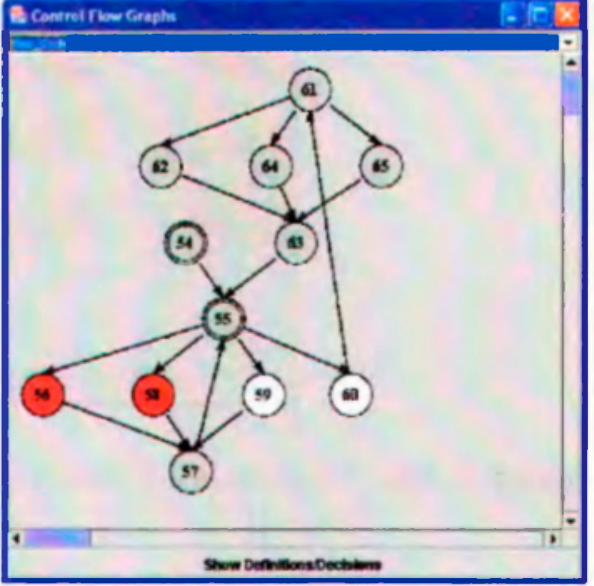

(b) GFC

Figura 5.17: Prioridades dos Requisitos do Processo Rę Coder em relação a Todos-c-Lisos: Caso II

Considerando a mesma situação, isto é, selecionando a mesma heurística e os mesmos casns de teste, mas agora considerando os slices em relação ao critério Todos-Blocos, têm-se as prioridades dos processos como apresentado na Figura 5.18. Quatro processos aparecem com prioridade 3 e dois processos com prioridade 2 . O processo que contém o erro inserido, "Res_Coder", é um dos processos com maior prioridade e, analisando-se as prioridades atribuídas a cada requisito desse processo (Figura 5.19), pode-se observar que o bloco que contém o erro tem prioridade 3 , sendo também apontado como mais provável de conter o(s) erro(s).

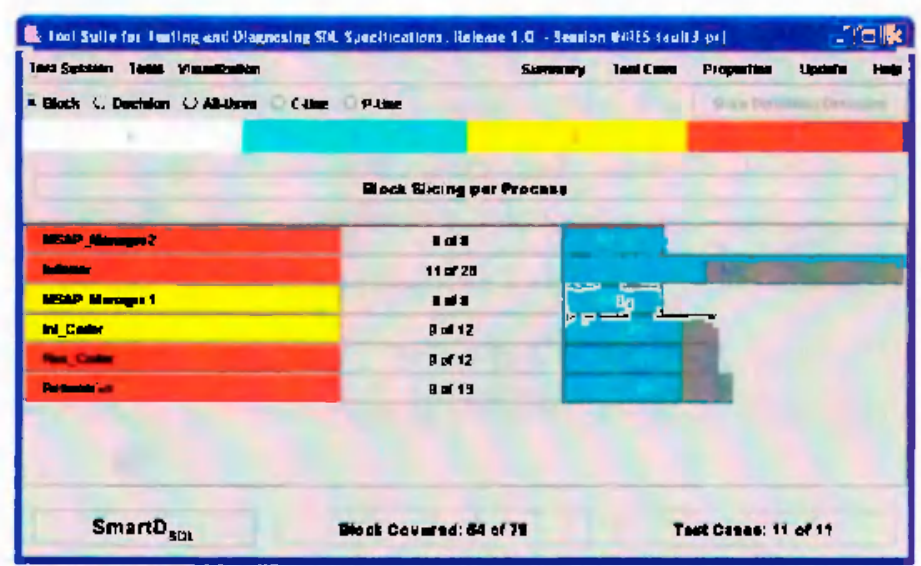

Figura 5.18: Prioridades dos Processos em Relação ao Critério Todos-Blocos na $S_{\text {mart }} D_{S D L}$. Caso II 


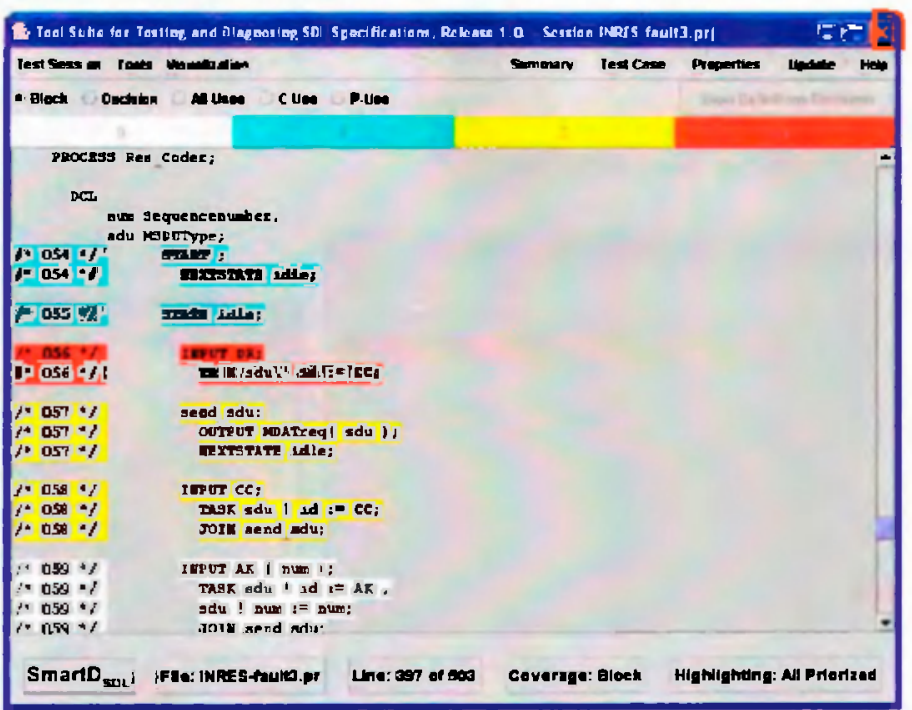

Figura 5.19: Prioridades dos Requisitos do Processo Res_Coder em relação a Todos-Blocos: Caso II

Apesar de ambos os critérios terem apontado adequadamente o provável local do erro na especificação SDL, no caso desse exemplo, o espaço de busca obtido pelo critério Todos-c-Usos foi menor do que o espaço de busca obtido pelo critério Todos-Blocos, pois apontou apenas dois processos com maior prioridade, enquanto que o critério Todos-Blocos apontou quatro processos.

A Figura 5.20 apresenta uma outra situação, em que se deseja examinar somente os requisitos de teste do critério Todos-Blocos executados pelos casos de teste mal sucedidos 0002, 0006 e 0011 e não executados pelos demais casos de teste (bem sucedidos). Nessa situação, é selecionada a heurística do Caso Geral e os casos de teste 0002, 0006 e 0011 são marcados como "executed test cases", enquanto os demais casos de teste são marcados como "non-executed test cases". O resultado dessa análise é apresentado na Figura 5.21, em que os possíveis locais do erro são indicados.

Segundo as prioridades atribuídas a cada processo, dois processos são apontados com maior prioridade, sendo que um deles é o processo "Res_Coder". Selecionando-se esse processo (Figura 5.22), observa-se que apenas um bloco está destacado em vermelho, ou seja, o espaço de busca nos blocos do processo foi reduzido, se comparado aos casos anteriores. De fato, o bloco em destaque é o bloco em que o erro foi introduzido.

Assim, evidencia-se como a $S \operatorname{mart} D_{S D L}$ pode auxiliar a atividade de depuração de especificações SDL, utilizando informações obtidas durante o teste sobre a cobertura de cada caso de teste. 


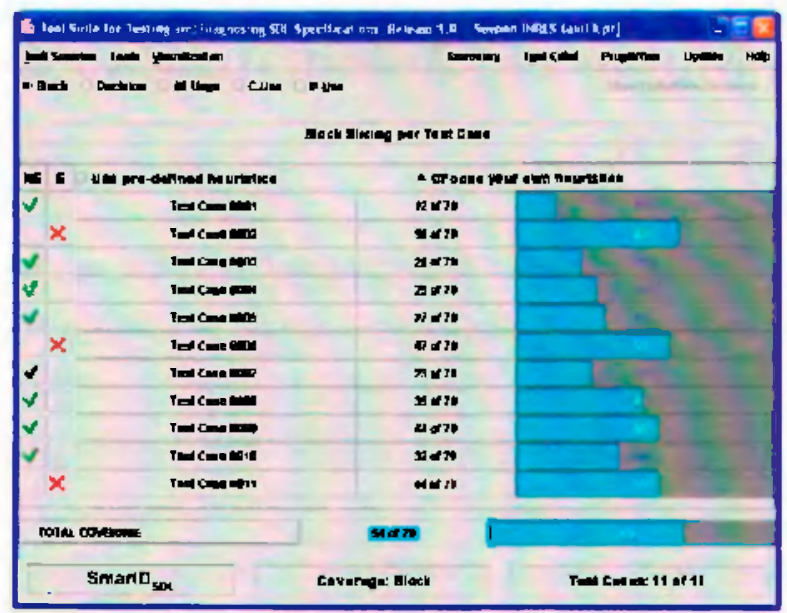

Figura 5.20: Tela de Seleção de Heurística do Caso Geral e Casos de 'Teste na Smart $D_{S D L}$

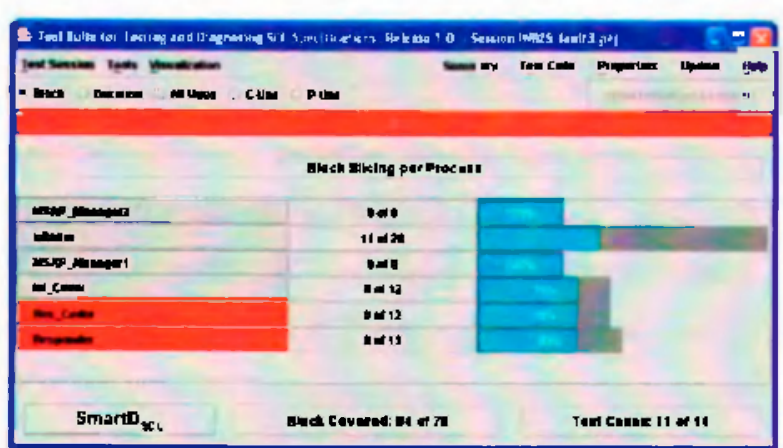

Figura 5.21: 'Tela de Apresentação de Possíveis Locais em que o Erro se Encontra na Smart $D_{S D L}$. Caso Geral

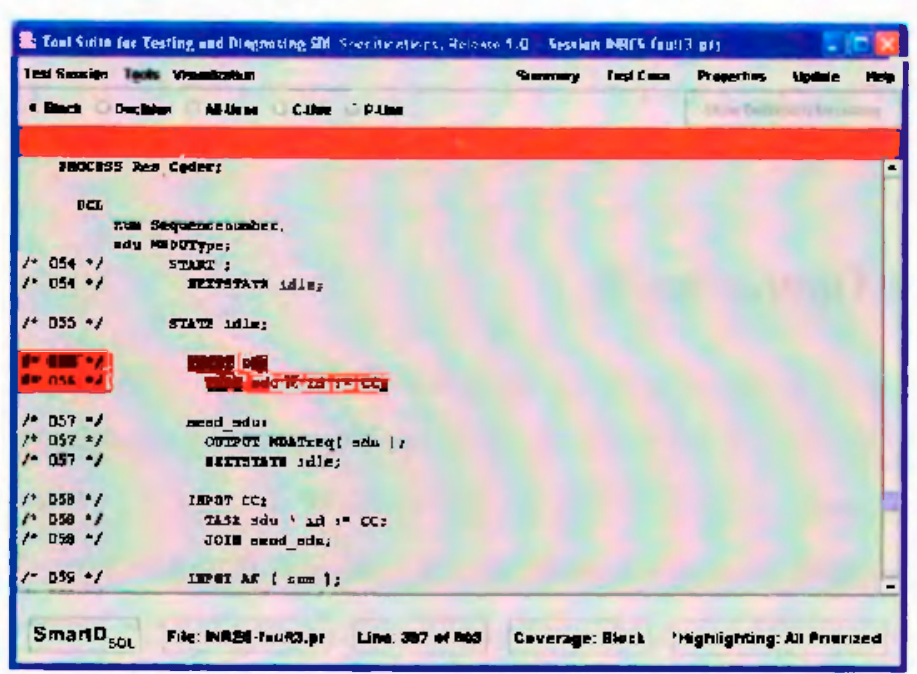

Figura 5.22: Prioridades dos Requisitos do Processo Res_Coder em relação a Todos-Blocos: Caso Geral 


\subsection{Análise de Mutantes: Automatização do Teste de Es- pecificações SDL}

Para a aplicaçāo da Análise de Mutantes é importante o apoio de ferramentas, pois é uma. atividade que pode ser improdutiva e propensa a erros, se realizada manualmente. Assim, a existência de ferramentas torna-se crucial neste contexțo. Nesta seção são abordados os aspectos operacionais e de implementação de uma ferramenta para apoiar a Análise de Mutantes no teste de especificaçöes SDL.

O grupo de Engenharia de Software do ICMC-USP/São Carlos tem desenvolvido uma famllia de ferramentas de apoio a critério Análise de Mutantes para o teste de programas e o teste de especificações (Maldonado et al., 2000b). Essa famflia de ferramentas, denominada Proteum, permite que as principais funções relacionadas ao teste de mutação sejam realizadas: definição de um conjunto de casos de teste, execução do programa (especificação), geração de mutantes, execuçāo do mutantes, análise dos mutantes, cálculo do escore de mutação e geração de relatórios. Essas ferramentas permitem que o testador trabalhe em sessōes de teste e dessa 'maneira, ele/ela pode iniciar uma sessão de teste, parar quando for conveniente e posteriormente retomar a atividade de teste no ponto em que a sessão foi interrompida. As informaçōes sobre os mutantes e os casos de teste são mantidas em uma base de dados. Também é possivel selecionar apenas um subconjunto de operadores de mutação (mutação restrita) (Offutt et al., 1996a) ou especificar uma porcentagem a ser aplicada para gerar os mutantes.

A ferramenta de teste de especificaçōes SDL para apoiar a Análise de Mutantes deve considerar todas as características implementadas nạ família Proteum. Na seção a seguir, as principais funcionalidades que a ferramenta deve ter são descritas com mais detalhe.

\subsubsection{Aspectos Operacionais}

A ferramenta deve permitir que o usuário crie sessōes de teste, informando qual especificação SDL será testada. Depois que uma sessão de teste é criada, o usuário pode parar a sessão de teste em qualquer ponto e mais tarde retomá-la, sem qualquer perda de informação.

Em uma sessão de teste, o usuário pode inserir interativamente casos de teste ou importar um arquivo de casos de teste para ser analisado pela ferramenta. A especificação em teste deve então ser executada com os casos de teste inseridos para determinar seu comportamento, que será posteriormente comparado ao comportamento dos mutantes.

Os mutantes podem ser gerados pela aplicação dos operadores de mutação. Pode-se optar por aplicar todos os operadores de mutação, aplicar apenas alguns operadores ou ainda gerar uma porcentagem do conjunto de mutantes que poderiam ser gerados, escolhidos aleatoriamente. 
Depois de gerados, os mutantes devem ser executados com o conjunto de casos de teste e os que permaneceram vivos devem ser analisados para verificar se são equivalentes ou não à especificação original. Para permitir a análise de mutantes, a ferramenta pode apresentá-los, um de cada vez, lado a lado com a especificação em teste, de forma a facilitar a comparação, e ainda destacar a parte da especificaçāo em que houve a mutação.

O escore de mutação pode ser verificado a qualquer momento na sessão de teste. Relatórios também devem ser gerados para fornecer ao usuário algumas informações, tais como o número de mutantes gerados, vivos, mortos e equivalentes em relação a cada operador de mutação. Com essas informações, o usuário pode decidir em parar a sessão de teste, ou então continuá-la, adicionando mais casos de teste até que se obtenha um escore de mutação de 1.

\subsubsection{Requisitos de Implementação}

Os operadores de mutação propostos para SDL no Capítulo 4 foram informalmente definidos. Uma abordagem promissora, já utilizada em outros trabalhos do grupo de Engenharia de Software do ICMC-USP/São Carlos, é descrever os operadores de mutação na linguagem MEIDL (MUtant DEscription Language) (Simão e Maldonado, 2002). Para o desenvolvimento dessa linguagem foram considerados conceitos de paradigmas de programação transformacional e lógica, além de conceitos da teoria de gramática livre de contexto. $O$ paradigma de programação transformacional tem sua base na descrição abstrata de como transformar um item fonte em um item alvo por meio de uma série sistemática de mudanças sintáticas. No caso da $\mathcal{M}$ CEL $\mathcal{L}$, o programa ou especificação original é o item fonte e os mutantes são os itens alvos.

Segundo Simão e Maldonado (2002), dos conceitos da gramática livre de contexto, a linguagem $\mathcal{M} D E \mathcal{L}$ considera a árvore sintática, de modo a introduzir um conjunto de meta-variáveis, mas estendendo a árvore sintática de forma a permitir que as folhas sejam meta-variáveis ou símbolos terminais. O nó raiz da árvore pode ser qualquer símbolo não-terminal, diferentemente da árvore sintática, que permite apenas o símbolo inicial como raiz. Essa extensão da árvore sintática é denominada de árvore de padrões. A $\mathcal{M}$ CLEL pode ser vista como uma linguagem para descrever como a árvore de padrões do programa ou especificação original é transformada nas árvores de padrões dos mutantes.

Para descrever os operadores de mutação de SDL utilizando a $\mathcal{M}(\mathbb{L E L}$, o primeiro passo é instanciar a $\mathcal{M}$ IDEC com a gramática de SDL, determinando a forma e a sintaxe da árvore de padröes para essa técnica. Após essa instanciação, os operadores de mutação podem ser descritos em MUDEL e para compilar essas descrições pode ser utilizado o sistema mudelgen, que auxilia a geração dos mutantes. O sistema mudelgen possui uma interface gráfica, $\mathcal{M C O C \mathcal { L }}$ Animator, que facilita a visualização da execução de um operador de mutação, permitindo também sua depuração. 
Para o desenvolvimento da ferramenta de apoio à Análise de Mutantes para o teste de especificaçōes SDL têm-se algumas opções de implementaçāo. Pode-se implementá-la na mesma plataforma da ferramenta $C A T_{S D L}$, de forma a ter um ambiente que permita o teste de especificaçōes SDL com base em critérios estruturais e na Análise de Mutantes. Outra abordagem é implementá-la para ser usada via Web, como as ferramentas Proteum/CPN, 'Proteum/SML e Proteum/OO. Para o desenvolvimento dessas ferramentas tem-se identificado funcionalidades comuns a toda ferramenta de apoio ao teste de mutação (chamadas de módulos independentes) e funcionalidades que são intrínsecas à linguạgem alvo, de programação ou especificação (chamadas de módulos dependentes). Desta forma, possibilita-se o reuso do código. Assim, se a ferramenta for desenvolvida utilizando-se essa abordagem, os módulos independentes podem ser reaproveitados das outras ferramentas, bastando implementar os módulos dependentes, de acordo com as características de SDL. Nesse caso, a ferramenta terá a arquitetura ilustrada na Figura '5.23 (extraída de Vincenzi (2004)). O módulo gerenciador de skins é responsável pela formatação das páginas, ,separando os outros módulos de detalhes específicos de exibição, de forma que a aparência dạs páginas que compõem a ferramenta podem ser alteradas sem a necessidade de modificar os códigos relacionados às funcionalidades da ferramenta. Além disso, é possível personalizar.a interface para se adequar às necessidades de uma linguagem/especificação particular.

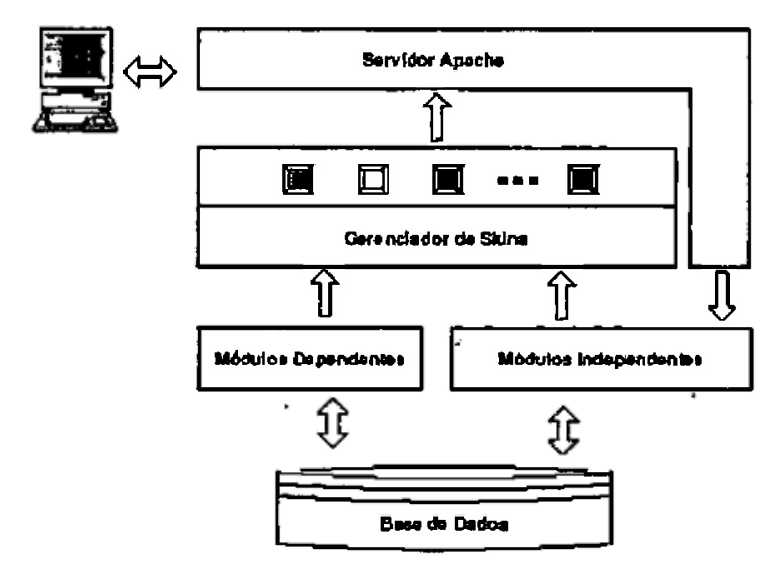

Figura 5.23: Possível Arquitetura da Ferramenta de Apoio à Análise de Mutantes (Vincenzi, 2004)

Caso a ferramenta seja disponibilizada via Web, pode-se fazer o mesmo para a $C A T_{S D L}$, de forma a criar um ambiente de teste de especificaçōes SDL com interface Web.

\subsection{Considerações Finais}

Neste capítulo foram apresentados os aspectos de automatização relacionados à atividade de teste de especificações SDL. A existência de ferramentas de apoio é importante para auxiliar 
a aplicação de critérios de teste no teste de programas e de especificações. Para o teste de programas, há uma diversidade de ferramentas que auxiliam a geração de casos de teste e a análise de cobertura de teste. No contexto de especificações SDL, em geral, as ferramentas apóiam a geração de casos de teste com base na especificação para serem utilizados no teste da implementação correspondente, ou seja, visam ao teste de conformidade. Outras ferramentas possibilitam que técnicas como model checking, sejam aplicadas na verificação de algumas propriedades, como deadlock, mas não fornecem informações sobre a cobertura de teste da especificação.

Neste trabalho foi proposta a utilização de critérios de teste estruturais e de mutação no contexto de teste de especificações SDL. Para apoiar essas abordagens de modo que elas possam ser efetivamente aplicadas, é importante o suporte automatizado. Para auxiliar a aplicação de critérios estruturais no teste de processos SDL, foi desenvolvida a ferramenta $C A T_{S D L}$. Essa ferramenta, como ilustrado neste capítulo, permite a análise de cobertura de teste e também auxilia a geração de casos de teste fornecendo informações de quais requisitos deveriam ser satisfeitos primeiro para que se obtenha uma maior cobertura a cada execução.

A $C A T_{S D L}$ pode ser utilizada apenas por sua interface gráfica. Muitas vezes é desejável rodar uma ferramenta por meio de scripts, principalmente durante a condução de estudos empíricos. Essa alternativa porém, a princípio, não permitiria o uso de cores para informar os pesos dos requisitos, reduzindo as funcionalidades da $C A T_{S D L}$. Ainda assim, a ferramenta seria importante no contexto de especificações SDL para auxiliar a análise de cobertura de teste. Assim, a disponibilidade da $C A T_{S D L}$ para executar via scripts deve ser considerada como uma atividade futura.

Outra ferramenta desenvolvida no contexto deste trabalho foi a $\operatorname{Smart} D_{S D L}$, que auxilia a atividade de depuração de especificações SDL. Essa ferramenta implementa uma abordagem de depuração utilizada para programas e proposta neste trabalho para ser aplicada na depuração de especificações SDL. Essa abordagem visa a auxiliar a atividade de depuração reduzindo o domínio de busca pelo erro, com base em informações da cobertura obtida pelos casos de teste para apontar partes da especificação SDL mais prováveis de conter o(s) erro(s) existente(s), atribuindo prioridades a essas partes.

A $S m a r t D_{S D L}$ implementa três heurísticas, sendo duas pré-definidas e uma terceira que pode ser customizada. A prioridade de cada parte da especificação SDL é mostrada por meio de cores. A efetividade de se encontrar erros na especificação SDL com o apoio da Smart $D_{S D L}$ também foi ilustrada.

Para a aplicação da Análise de Mutantes no teste de especificações SDL, foram apresentados alguns aspectos que devem ser considerados no desenvolvimento de uma ferramenta de teste, tendo como base trabalhos do grupo de Engenharia de Software do ICMC-USP/São Carlos. O desenvolvimento dessa ferramenta é um dos pontos cruciais para permitir a aplicação da Análise de Mutantes no teste de especificações SDL, e viabilizar a condução de estudos empíricos. 
Para a aplicação dos critérios FCCSDL também é importante o apoio ferramental. Esse aspecto nāo foi discutido neste trabalho, mas a viabilidade da aplicação desses critérios de forma produtiva certamente depende da existência de ferramentas de apoio. 


\section{Teste de Especificações SDL: Estudo de}

Neste capítulo é apresentado um exemplo de aplicação dos critérios de teste estruturais e da Análise de Mutantes para a geração de conjuntos de teste adequados ao teste da especificação do protocolo Bit-Alternante. Uma comparação do strength entre os critérios apoiados pela $C A T_{S D L}$ e a Análise de Mutantes também foi realizada e é apresentada neste capítulo.

Com base nessa comparação, é proposta uma estratégia de teste incremental para a aplicação, de forma complementar, dos critérios de teste propostos neste trabalho na atividade de teste de especificações SDL.

\subsection{Requisitos de Teste e Geração de Casos de Teste para os Critérios Estruturais e de Mutação}

Nesta seção apresentam-se os requisitos de teste derivados de cada critério de teste. Os requisitos dos critérios apoiados pela ferramenta $C A T_{S D L}$ são derivados dos grafos de fluxo de cada processo da especificação do protocolo Bit-Alternante. Os critérios estruturais da FCCSDL - Família de Critérios de Cobertura para SDL, por sua vez, derivam seus requisitos a partir da árvore de alcançabilidade que modela o comportamento do protocolo. Para a Análise de Mutantes, os requisitos de teste são os próprios mutantes gerados com a aplicação do conjunto de operadores de mutação. 
Para os critérios apoiados pela $C A T_{S D L}$ e a Análise de Mutantes, além dos requisitos de teste, foram também obtidos conjuntos de teste adequados. Para os critérios FCCSDL: neste trabalho não foram gerados casos de teste adequados, pois sem apoio ferramental, essa atividade é muito custosa. Cada uma dessas atividades é relatada nas seções a seguir.

\subsubsection{Critérios de Teste Estruturais apoiados pela $C A T_{S D L}$}

Os conjuntos de requisitos de teste derivados pelos critérios de teste apoiados pela $C A T_{S D L}$ para a especificaçāo do protocolo Bit-Alternante são apresentados na Tabela 6.1. O conjunto de requisitos do critério Todos-Blocos é composto de 31 requisitos e do critério Todas-Decisões é composto de 13 requisitos de teste. Os conjuntos de requisitos dos critérios de fluxo de dados Todos-p-Usos, Todos-c-Usos e Todos-Usos são compostos por 12, 16 e 28 requisitos. respectivamente.

Tabela 6.1: Conjunto de Requisitos de Teste Derivados dos Critérios Estruturais Apoiados pela $C A T_{S D L}$ para o processo Sender do Protocolo Bit-Alternante

\begin{tabular}{|c|c|c|}
\hline Critério de Teste & \#Requisitos & Requisitos de Teste \\
\hline Todos-Blocos & $\overline{31}$ & $\begin{array}{l}(0,1,2,3,4,5,6,7,8,9,10,11,12,13,14,15,16,17,18,19,20,21,22,23,24,25,26,27, \\
28,29,30\}\end{array}$ \\
\hline Todas-Decisóes & $\overline{13}$ & $\begin{array}{l}\begin{array}{l}\{(3,4),(3,8),(3,9),(5,6),(5,7),(13,14),(13,16),(20,21),(20,23),(25,26),(25,30), \\
(27,28),(27,29)\}\end{array}\end{array}$ \\
\hline Todos-p-Usos & 12 & $\begin{array}{l}\{(0,(5,6), i),\langle 0,(5,7), 2),\langle 4,(5,6), j\rangle,\langle 4,(5,7), J\rangle,\langle 6,(5,6), i\rangle,\langle 6,(5,7), 2\rangle, \\
\langle 24,(27,28), i\rangle,\langle 24,(27,29), i\rangle,(26,(27,28), j\rangle,\langle 26,(27,29), j\rangle,\langle 28,(27,28\rangle, i\rangle) \\
(28,(27,29\rangle, 2)\}\end{array}$ \\
\hline Todos-c-Usos & 16 & $\begin{array}{l}(\langle 0,2, i),\langle 0,7, i\rangle,\langle 0,8,2\rangle,\langle 2,7, m),\langle 2,8, m\rangle,\langle 6,2, i),\langle 6,7, i\rangle,\langle 6,8, i),\langle(12,16, i\rangle, \\
(12,16, m\rangle,\langle 19,23, i\rangle,(24,30, i\rangle,\langle 26,28, j\rangle,(26,28, m),\langle 26,29,3\rangle,\langle 28,30, i\rangle\}\end{array}$ \\
\hline Todos-Usos & 28 & 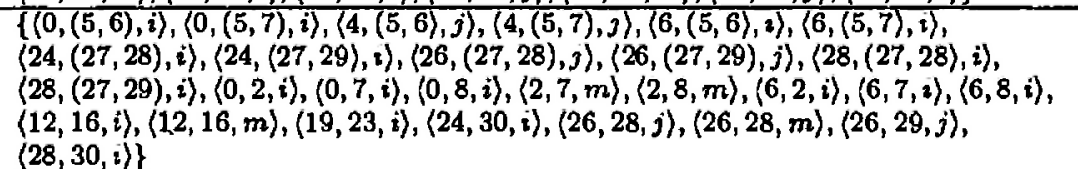 \\
\hline
\end{tabular}

Para a geração de conjuntos de teste que satisfaçam todos os requisitos de teste de cada critério, as informações dos pesos dos requisitos fornecidas pela $C A T_{S D L}$ foram utilizadas, iniciando-se pela cobertura dos requisitos de maior peso.

O primeiro critério selecionado foi Todos-Blocos. Retomando-se a situação apresentada na Figura 5.9 do Capítulo 5, com dois casos de teste gerados, como a cobertura ainda não era de $100 \%$, um terceiro caso de teste foi adicionado e a cobertura desejada foi obtida para o critério, como mostra a Figura 6.1. Como pode ser observado, os casos de teste 0001, 0002 e 0003 cobriram, respectivamente, $77 \%, 87 \%$ e $90 \%$ dos requisitos estabelecidos pelo critério Todos-Blocos para a especificação do protocolo Bit-Alternante.

Para os demais critérios, depois de criada uma nova sessão de teste para cada um deles, os mesmos passos foram realizados, ou seja, os casos de teste foram gerados um a um, com base na informação dos requisitos de maior peso. $O$ conjunto de teste obtido para cada critério é apresentado na Tabela 6.2. O conjunto de teste do critério Todos-Blocos é composto de três casos de teste, assim como o conjunto de teste do critério Todas-Decisões. Já os critérios 


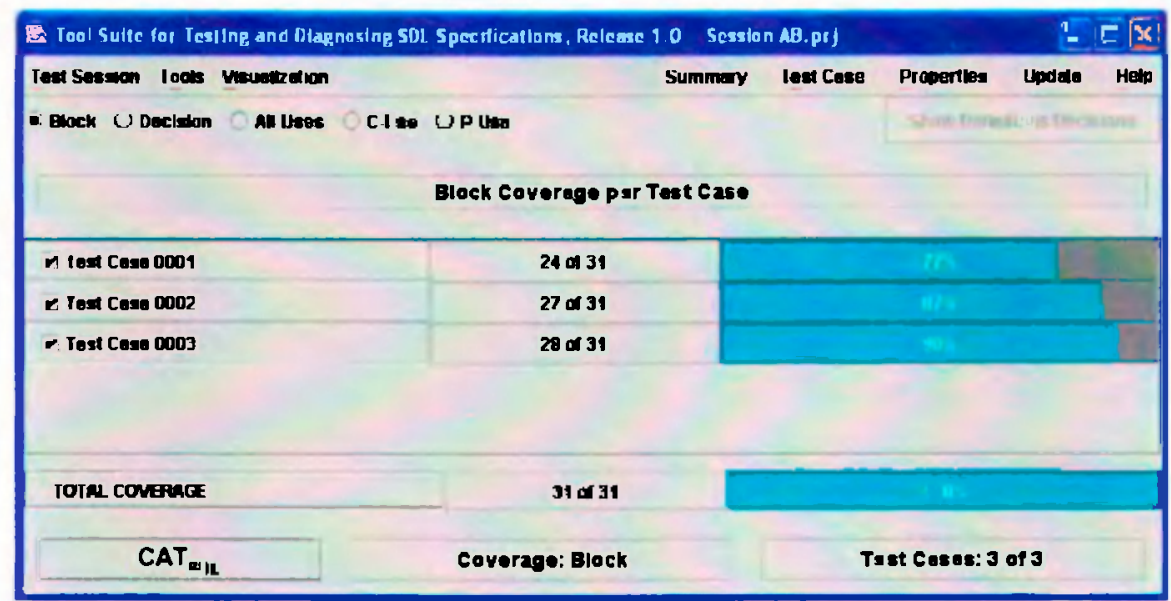

Figura 6.1: Relatório de Cobertura do Conjunto de Casos de Teste Adequado ao Critério Todos-Blocos

baseados em fluxo de dados geraram o mesmo conjunto de teste, composto por cinco casos de teste.

Tabela 6.2: Conjuntos de Teste Adequados ao Critérios Estruturais para o protocolo

\begin{tabular}{|c|c|}
\hline de T & 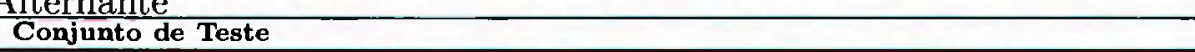 \\
\hline Todos-Blocos & 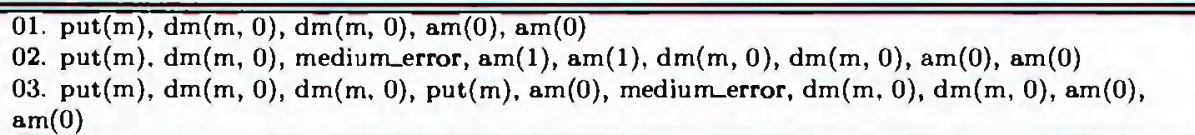 \\
\hline Todas-Decisôes & 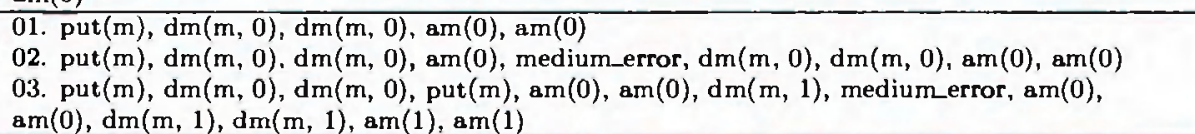 \\
\hline $\begin{array}{l}\text { Todos-c-Usos } \\
\text { Todos-p-Usos } \\
\text { Todos-Usos }\end{array}$ & 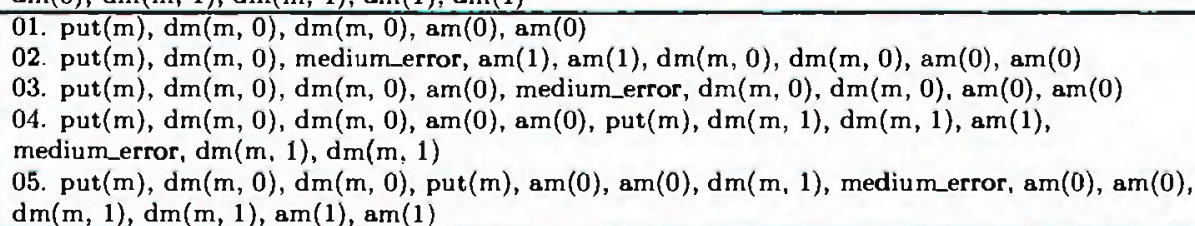 \\
\hline
\end{tabular}

\subsubsection{Análise de Mutantes}

Os passos realizados para a geração do conjunto de teste adequado à Análise de Mutantes foram: obtenção de um conjunto de teste inicial $T$; geração de mutantes; execução dã espècificação com o conjunto de teste $T$; execução dos mutantes; análise de adequação e geração de conjuntos de teste adequados. Para a obtenção dos requisitos de teste estabelecidos pela $\Lambda$ nálise de Mutantes, que corresponde à geração dos mutantes, e a geração do conjunto de teste adequado ao critério para a especificação SDL do protocolo Bit-Alternante, foi aplicada 
a estratégia ITS-SDL, apresentada no Capítulo 4, empregando-a de modo top-down. A seguir, apresentam-se esses passos com mais detalhes.

\section{Passo 1. Obtenção de um Conjunto Inicial de Casos de Teste}

Um conjunto inicial de seqüências de teste ad hoc foi gerado para ser executado com a especificação SDL do protocolo Bit-Alternante. Esse conjunto inicial contém 8 casos de teste, apresentados na Tabela 6.3. A especificação SDL do protocolo foi executada com esse conjunto de casos de teste utilizando-se o simulador da ferramenta Telelogic Tau 4.4 (Telelogic, 2004a).

Tabela 6.3: Conjunto de Teste Inicial "Ad Hoc"

\begin{tabular}{|c|c|}
\hline Caso de Teste & Seqüência de Sinais \\
\hline 01 & put(m) \\
\hline 02 & $\operatorname{put}(m), d m(m, 0)$ \\
\hline 03 & put $(m), d m(m, 0), d m(m, 0), a m(0), a m(0)$ \\
\hline 04 & put $(m), \operatorname{dm}(m, 0), \operatorname{dm}(m, 0)$, am $(0)$, medium_error, $\operatorname{dm}(m, 0)$ \\
\hline 05 & $\operatorname{put}(m), \operatorname{dm}(m, 0), d m(m, 0), \operatorname{am}(0)$, mediumerror $d m(m, 0), d m(m, 0), \operatorname{am}(0), \operatorname{am}(0)$ \\
\hline 06 & put $(m), d m(m, 0)$, medium_error, $a m(1), a m(1), d m(m, 0)$ \\
\hline 07 & $\operatorname{put}(m), \operatorname{dm}(m, 0), \operatorname{dm}(m, 0), \operatorname{put}(m), \operatorname{am}(0), \operatorname{am}(0)$ \\
\hline 08 & put $(m), d m(m, 0)$, medium error, $\operatorname{am}(1), \operatorname{am}(1), \operatorname{dm}(m, 0), d m(m, 0), \operatorname{am}(0), \operatorname{am}(0)$ \\
\hline
\end{tabular}

Como comentado anteriormente, uma seqüência de teste para a técnica SDL é constituída pela sequência de sinais trocados durante a execução da especificação SDL. Por exemplo, uma das sequências de teste que compõem o conjunto inicial para o protocolo Bit-Alternante é $t s=\langle p u t(m), d m(m, 0), d m(m, 0), \operatorname{get}(m) \wedge a m(0), a m(0)\rangle$, já apresentada na Seção 4.2 do Capítulo 4.

Quando a especificação SDL é executada com a seqüência de teste $t s$, os estados finais ativados na especificação original são $f s=([($ wait_put $)],[($ wait_dm $),($ wait_am $)],[($ wait_dm $)])$. No caso da especificação do protocolo Bit-Alternante, o conjunto de estados alcançados em cada processo SDL da especificação é representado pela seguinte sequência: ([(Sender) $)],[($ Medium 1$),($ Medium 2$)],[($ Receiver $)])$, em que os "[ ]" identificam os blocos SDL da especificação e, dentro de cada bloco, há o conjunto de processos separados por "( ,)" e ":". Por exemplo, no primeiro bloco SDL há um processo, Sender; no segundo bloco SDL há dois processos, Medium1 e Medium2; e no terceiro bloco SDL há um processo, Receiver.

\section{Passo 2. Geração dos Mutantes}

A partir deste passo, a estratégia ITS-SDL foi aplicada priorizando, nesta ordem, o comportamento dos processos, a comunicação entre os processos e a estrutura da especificação.

Assim, o primeiro conjunto de mutantes foi gerado pela aplicação dos operadores de mutação de processos. Foram gerados 78 mutantes, mas alguns operadores não geraram mutantes. pois a estrutura sintática em que devem ser aplicados não ocorre na especificação do protocolo sendo utilizada. O número de mutantes gerados individualmente pelos operadores de mutação de processo para o protocolo Bit-Alternante, é apresentado na Tabela 6.4. 
Tabela 6.4: Mutantes Gerados para o Protocolo Bit-Alternante

\begin{tabular}{|c|c|c|c|}
\hline \multicolumn{4}{|c|}{ Operadores de Mutação de Processos } \\
\hline 1. Substituiçäo de Estado Ōrigem & 03 & 15. Cobertura de Código & $\overline{15}$ \\
\hline 2. Troca Definiçăo de Estado & 01 & 16. Negaçāo de Questāo de Decisāo & 04 \\
\hline 3. Substituiçäo de Estado Destino & 10 & 17. Troca de Resposta de Decisäo & 04 \\
\hline 4. Remoģāo de Estado & 02 & 18. Remoção de Resposta de Decisão & 08 \\
\hline 5. Remoçầo de Transição & 08 & 19. Remoçūo de Parada de Processo (Stop) & 0 \\
\hline 6. Remoçāo de Condiçāo & 0 & 20. Remoģāo de Save & 01 \\
\hline 7. Negaçāo de Condiçāo & 0 & 21. Remogāo de Sinal a ser Salvo & 0 \\
\hline 8. Substituiçāo de Atribuiçāo Booleana & $\overline{0}$ & 22. Substituiçâa de Sinal a ser Salvo & 0 \\
\hline 9. Substituição de Variável por Variável & 12 & 23. Remoçāo de Set Timer & $\overline{0}$ \\
\hline 10. Substituiçấo de Variável por Constante & 0 & 24. Remoģão de Reset Timer & $\overline{0}$ \\
\hline 11. Incremento/Decremento de Variáveis/Constantes & $\mathbf{0}$ & 25. Remoçāo de Criaçāo Create de Processo & 0 \\
\hline 12. Inclusāo de Operador Unário nas Variáveis & 0 & 26. Substituiçâa de Operador Aritmético & 0 \\
\hline 13. S̄ubstituiçāo de Tarefa & 0 & 27. Substituição de Join/Label & 0 \\
\hline 14. Remoção de Tarefa & 02 & 28. Substituiçāo de Operador Relacional/Lógico & 08 \\
\hline \multicolumn{3}{|r|}{3} & 78 \\
\hline \multicolumn{4}{|c|}{ Operadores de Mutação de Interface } \\
\hline \multicolumn{2}{|l|}{ Group I: Calling Point } & \multicolumn{2}{|l|}{ Group II: Called Process } \\
\hline 1. Remoçäo de Sajda & 11 & 9. Substituiçāo de Variáveis de Interface & 08 \\
\hline 2. Substituiçāo de Saída & 15 & 10. Substituição de Variável de Não-Interface & 0 \\
\hline 3. Substituiçūo de Destino de Saída & 0 & 11. Incremento/Decremento de Variável & $\overline{0}$ \\
\hline 4. Substituiçäo de Signal Route de Sáda & 06 & 12. Inclusāo de Operadores Unários nas Variáveis & 0 \\
\hline 5. Substituiçäo de Parâmetros & 0 & 13. Substituiçāo de Atribuiçāo Booleana & 0 \\
\hline 6. Incremento/Decremento de Parâmetros & 0 & 14. Remoçāo de Entrada & 07 \\
\hline 7. Troca a Ordem dos Parâmetros & $\mathbf{0}$ & 15. Substituiçẫo de Entrada & 04 \\
\hline 8. Inclusāo de Operadores Unários nos Parâmetros & 0 & & \\
\hline \multicolumn{3}{|c|}{ TOTAL } & 51 \\
\hline \multicolumn{4}{|c|}{ Operadores de Mutação de Estrutura } \\
\hline \multicolumn{3}{|l|}{ 1. Inclusāo de Sinal da Lista de Sinais } & 44 \\
\hline \multicolumn{3}{|l|}{ 2. Remoçāo de Sinal da Lista de Sinais } & 12 \\
\hline \multicolumn{3}{|l|}{ 3. Troca de Sinais da Lista de Slnais } & 35 \\
\hline \multicolumn{3}{|l|}{ 4. Remoção de Signal routes/Channels } & 16 \\
\hline \multicolumn{3}{|l|}{$\begin{array}{l}\text { 5. Remoçāo de Conexāo entre Channels e Signal routes } \\
\text { 6. Substituicao de Channets/Signal routes Conectados }\end{array}$} & 08 \\
\hline \multirow{2}{*}{\multicolumn{3}{|c|}{ 6. Substituiçao de Channels/Signal routes Conectados }} & 18 \\
\hline & & & 133 \\
\hline
\end{tabular}

\section{Passo 3. Execução dos Mutantes}

O próximo passo foi a execução dos mutantes com o conjunto de casos de teste $T$, utilizando o simulador da Telelogic Tau 4.4. Para distinguir o comportamento dos mutantes e da especificação original, os estados finais de todos os processos SDL alcançados após a execução com cada caso de teste foram analisados. Assim, todo mutante que se comportava diferentemente do esperado foi considerado morto. Caso contrário, o mutante permanecia vivo.

Cada caso de teste do conjunto inicial foi executado apenas com os mutantes vivos, ou seja, quando um caso de teste do conjunto matava um mutante, esse mutante não era mais executado com os demais casos de teste. Para ilustrar esse passo, apresenta-se a execução de um mutante gerado pelo operador Substituição de Estado Destino, apresentado a seguir (e já ilustrado na Figura 4.3 do Capítulo 4), da classe de operadores de mutação de processos com um caso de teste de $T$. Quando este mutante é executado com a seqüência de teste $t s=\langle p u t(m), d m(m, 0), d m(m, 0), \operatorname{get}(m) \wedge a m(0), a m(0)\rangle$, os estados finais ativos são $f s=$ $\left(\left[\left(w a i t \_a m\right)\right],\left[\left(w a i t \_d m\right),(\right.\right.$ wait_am $\left.)\right],[($ wait_dm $\left.)]\right)$. O estado wait_am do processo Sender 
é diferente do estado esperado, wait_put. Como resultado, o mutante é distinguido da especificação original e considerado morto.

\begin{tabular}{|l|l|}
\hline Especificaçāo Original & \multicolumn{1}{|c|}{ Especificação Mutante } \\
\hline \hline STATE wait_am; & STATE wait_am; \\
INPUT am $(\mathrm{j}) ;$ & INPUT am $(\mathrm{j}) ;$ \\
DECISION $\mathrm{j}=\mathrm{i} ;$ & DECISION $\mathrm{j}=\mathrm{i} ;$ \\
( TRUE $):$ & (TRUE ): \\
TASK $\mathrm{i}:=\operatorname{inv}(\mathrm{i}) ;$ & TASK $\mathrm{i}:=\operatorname{inv}(\mathrm{i}) ;$ \\
NEXTSTATE wait_put; & $\rightarrow$ NEXTSTATE WAIT_AM; \\
ELSE: & ELSE: \\
$\ldots$ & $\ldots$ \\
\hline
\end{tabular}

Após a execução de todos os mutantes com o conjunto de casos de teste $T, 54$ foram mortos e um dos mutantes tinha um erro semântico ${ }^{1}$, e foi considerado anômalo. Restaram 23 mutantes vivos para serem analisados no próximo passo.

Passo 4. Análise dos Mutantes e Geração de Conjuntos de Teste Adequados

Cada mutante vivo foi analisado e quatro deles foram identificados como equivalentes, ou seja, para qualquer caso de teste, seu comportamento sempre será similar ao comportamento da especificação original. Dessa forma, 19 mutantes permaneceram vivos. O escore de mutação ${ }^{2}$ calculado para o conjunto de teste $T$ em relação aos mutantes de processo foi de 0.80 , ou seja, $\frac{54}{78-1-1}$. Para obter um escore de mutação de 1 , novos casos de teste foram gerados e a especificação original e os 19 mutantes vivos foram executados. Esse passo foi repetido até que todos os mutantes foram mortos. O resultado é um conjunto de 15 casos de teste (casos de teste 1 a 15 da Tabela 6.6), adequados por construção aos mutantes gerados pelos operadores de processo. Como pode ser observado, sete novos casos de teste foram adicionados ao conjunto $\mathrm{T}$ inicial (casos de teste 9 a 15 da Tabela 6.6).

Esse conjunto de 15 casos de teste foi então utilizado como conjunto inicial $T_{1}$. para ser executado com os mutantes gerados pelos operadores que exploram aspectos de comunicação entre os processos, seguindo o próximo passo da estratégia ITS-SDL.

Os Passos 2-4 foram repetidos para os operadores de mutação de interface, sendo que um conjunto de 51 mutantes foi gerado (como pode ser observado na Tabela 6.4) e, novamente, alguns operadores não geraram mutantes pois a estrutura sintática em que agem não ocorre na especificação do protocolo Bit-Alternante.

Os 51 mutantes foram executados com o conjunto de casos de teste $T_{1}$, sendo que 33 foram mortos e 6 foram identificados como anômalos, com erros semânticos. Permaneceram 12 mutantes vivos para serem analisados.

\footnotetext{
${ }^{1}$ No contexto de mutação, este trabalho denomina erro semântico qualquer erro detectado pelo analisador semântico da Telelogic Tau. As especificações mutantes que apresentam esse tipo de erro no entanto, são sintaticamente corretas.

${ }^{2} \mathrm{~A}$ relação entre o número de mutantes mortos e o número total de mutantes não-equivalentes $\mathrm{e}$ não-anômalos gerados.
} 
Para ilustrar um dos mutantes gerados pelos operadores de interface, o mutante ilustrado na Figura 4.14 do Capítulo 4, gerado pelo operador Remoção de Saída, é apresentado novamente a seguir. Fisse operador modela erros de saída, excluindo cada saída definida nas transições dos estados nos processos. Para gerar esse mutante, o operador é aplicado à saída "OUTPUT dm ( m , i );" da transição do estado wait_put, excluindo-a. Quando este mutante é executado com $t s$, os estados finais alcançados são $f s=([($ wait_am $)],[($ wait_dm $),($ wait_am $)],[($ wait_dm $)])$. O estado wait_am do processo Sender não era o esperado e, portanto, esse mutante foi distinguido e morto por esse caso de teste.

\begin{tabular}{|l|l|}
\hline Especificação Original & Especificação Mutante \\
\hline \hline STATE wait_put; & STATE wait_put; \\
INPUT put ( m ); & INPUT put ( m ); \\
OUTPUT dm ( m , i ); & $\rightarrow$ \\
NEXTSTATE wait_am; & NEXTSTATE wait_am; \\
ENDSTATE; & ENDSTATE; \\
\hline
\end{tabular}

Após a análise dos mutantes vivos, 9 foram identificados como equivalentes, restando 3 mutantes vivos. Nesse ponto, o escore de mutação foi calculado para o conjunto de teste $T_{1}$ e seu valor foi 0.91 , ou seja, $\frac{33}{51-9-6}$. Para obter um escore de mutação de 1 , novos casos de teste foram gerados e a especificação original e os 3 mutantes vivos foram executados. Esse passo foi repetido até que todos os mutantes foram mortos.

O conjunto de casos de teste resultante é apresentado na Tabela 6.6, sendo que os casos de teste adicionados foram os de número 16 a 18 . Esse conjunto é utilizado como conjunto inicial $T_{2}$ para os mutantes gerados pelos operadores de mutação de estrutura na última etapa da estratégia ITS-SDL.

Com a aplicação dos operadores de estrutura foram gerados 133 mutantes, como pode ser observado na Tabela 6.4. Todos os mutantes porém, têm erros semânticos e não puderam ser simulados na Telelogic Tau. Dessa forma, esses mutantes foram considerados anômalos. É necessário investigar se o mesmo acontece com outras especificações SDL e, se for o caso, essa classe de operadores deve ser excluída do conjunto de operadores.

A Tabela 6.5 apresenta um resumo das informações sobre os mutantes gerados, que são os requisitos de teste derivados para a Análise de Mutantes para o protocolo Bit-Alternante. Foram gerados 262 mutantes, sendo 13 equivalentes e 140 anômalos.

O conjunto de 18 casos de teste adequados à Análise de Mutantes para o teste da especificação SDL do protocolo Bit-Alternante é apresentado na Tabela 6.6. 
Tabela 6.5: Análise dos Mutantes Gerados para o protocolo Bit-Alternante \begin{tabular}{|l|l|l|l|}
\hline Classe de Mutação & Mutantes Gerados & Equivalentes & Anômalos \\
\hline
\end{tabular}

\begin{tabular}{|c|c|c|c|}
\hline \hline Processo & 78 & 04 & 01 \\
\hline Interface & 51 & 09 & 06 \\
\hline Estrutura & 133 & 00 & 133 \\
\hline \hline TOTAL & 262 & 13 & 140 \\
\hline
\end{tabular}

Tabela 6.6: Conjunto de Teste Adequado à Análise de Mutantes para o protocolo Bit-Alternante

\begin{tabular}{|c|c|}
\hline Caso de Teste & tuência de Sinais \\
\hline 01 & put(m) \\
\hline 02 & put $(m), d m(m, 0)$ \\
\hline 03 & put(m), $\operatorname{dm}(m, 0), d m(m, 0), a m(0), a m(0)$ \\
\hline 04 & put $(m), \operatorname{dm}(m, 0), d m(m, 0), a m(0)$, medium_error, $\operatorname{dm}(m, 0)$ \\
\hline 05 & $\operatorname{put}(m), \operatorname{dm}(m, 0), \operatorname{dm}(m, 0), \operatorname{am}(0)$, medium_error, $\operatorname{dm}(m, 0), \operatorname{dm}(m, 0), \operatorname{am}(0), \operatorname{am}(0)$ \\
\hline 06 & put $(m), \operatorname{dm}(m, 0)$, medium_error, $\operatorname{am}(1), \operatorname{am}(1), \operatorname{dm}(m, 0)$ \\
\hline$\overline{07}$ & put $(m), d m(m, 0), d m(m, 0), p u t(m), \operatorname{am}(0), \operatorname{am}(0)$ \\
\hline 08 & $\operatorname{put}(m), \operatorname{dm}(m, 0), \operatorname{medium} e r r o r, \operatorname{am}(1), \operatorname{am}(1), \operatorname{dm}(m, 0), \operatorname{dm}(m, 0), \operatorname{am}(0), \operatorname{am}(0)$ \\
\hline 09 & put(m), $d m(m, 0), d m(m, 0), \operatorname{put}(m), a m(0), a m(0), d m(m, \overline{0})$ \\
\hline 10 & put $(m), \operatorname{dm}(m, 0), \operatorname{dm}(m, 0), \operatorname{am}(0), \operatorname{am}(0), \operatorname{put}(m), d m(m, 1), d m(m, 1), \operatorname{am}(1), \operatorname{am}(1)$ \\
\hline 11 & put(m), $\operatorname{dm}(m, 0), \operatorname{dm}(m, 0), \operatorname{am}(0), \operatorname{am}(0), \operatorname{put}(m), \operatorname{dm}(m, 1)$, mediumLerror, $\operatorname{am}(0), \operatorname{am}(0)$ \\
\hline$\overline{12}$ & $\begin{array}{l}\text { put(m), } \operatorname{dm}(m, 0), \operatorname{dm}(m, 0), \operatorname{am}(0), \text { mediumeerror, } \operatorname{dm}(m, 0), \operatorname{dm}(m, 0), \operatorname{am}(0), \operatorname{am}(0), \operatorname{put}(m), \\
\operatorname{dm}(m, 1), \text { medium error, } \operatorname{am}(0), \operatorname{am}(0)\end{array}$ \\
\hline$\overline{13}$ & $\begin{array}{l}\text { put(m), } \operatorname{dm}(m, 0), \text { mediumerror, } \operatorname{am}(1), \operatorname{am}(\mathrm{i}), \operatorname{dm}(m, 0), \operatorname{dm}(m, 0), \text { am }(0), \text { mediumerror, } \\
\operatorname{dm}(m, 0), \operatorname{dm}(m, 0), \operatorname{am}(0), \operatorname{am}(0)\end{array}$ \\
\hline 14 & $\begin{array}{l}\text { put(m), } \operatorname{dm}(m, 0), \operatorname{dm}(m, 0), \operatorname{am}(0), \operatorname{am}(0), \operatorname{put}(m), \operatorname{dm}(m, 1), \operatorname{dm}(m, 1), \operatorname{am}(1), \text { medium_error, } \\
\operatorname{dm}(m, 1), \operatorname{dm}(m, 1), \operatorname{am}(1), \operatorname{medium}(\mathrm{m} r a r, \operatorname{dm}(m, 1), \operatorname{mediumerror}, \operatorname{am}(0), \operatorname{am}(0)\end{array}$ \\
\hline$\overline{15}$ & $\begin{array}{l}\text { put }(m), \operatorname{dm}(m, 0), d m(m, 0), \operatorname{am}(0), \text { medium_error }, \operatorname{dm}(m, 0), \operatorname{dm}(m, 0), \operatorname{am}(0), \text { medium_error, } \\
\operatorname{dm}(m, 0), \text { medium error, } \operatorname{am}(1), \operatorname{am}(1)\end{array}$ \\
\hline 16 & $\begin{array}{l}\text { put(m), } \operatorname{dm}(m, 0), \text { mediumerror, am(1), am }(1), \operatorname{dm}(m, 0), \text { mediumerror, am(1), mediumerror, } \\
\operatorname{dm}(m, 0), \operatorname{dm}(m, 0), \operatorname{am}(0), \operatorname{am}(0)\end{array}$ \\
\hline$\frac{17}{18}$ & $\operatorname{put}(m), \operatorname{dm}(m, 0), \operatorname{put}(m), \operatorname{dm}(m, 0), \operatorname{am}(0), m$ \\
\hline
\end{tabular}

\subsubsection{Critérios de Fluxo de Controle FCCSDL}

Para obter os requisitos de teste dos critérios de teste FCCSDL, a árvore de alcançabilidade é percorrida em profundidade até que todos os requisitos sejam derivados, seguindo a definição de cada critério.

Os critérios FCCSDL utilizam dois conjuntos definidos durante a construção da árvore de alcançabilidade: CC, que é o conjunto de configurações da árvore; e CT, que é o conjunto de transições da árvore. Para cada critério de teste, tem-se um conjunto TR de requisitos de teste $r_{i}$, formados por um conjunto de configurações que satisfazem o critério de teste.

A geração dos requisitos de teste a partir dos critérios FCCSDL foi automatizada. A Tabela 6.7 apresenta o número de requisitos de teste gerados pelos critérios FCCSDL para o protocolo Bit-Alternante e exemplos de alguns requisitos de teste gerados. Para esse protocolo, o número de requisitos de teste que poderiam ser gerados pelos critérios Todos-Caminhos e Todos-Caminhos- $k$ - $C_{1}$-Configuração é infinito. No caso do critério Todos-Caminhos- $k$-Configurações, mesmo para $k=2$, o custo de sua aplicação se mostrou alto e esse critério não foi aplicado. 
Tabela 6.7: Número de Requisitos de Teste para o protocolo Bit-Alternante e Alguns Exemplos de Requisitos

\begin{tabular}{|c|c|c|}
\hline Critério & \multicolumn{2}{|r|}{ \# de Requisitos de Teste e Alguns Requisitos } \\
\hline Todas-Configurações & 22 & $\begin{array}{l}T R=\left\{C_{1}, C_{2}, C_{3}, C_{4}, C_{5}, C_{6}, C_{7}, C_{8}, C_{9}, C_{10}, C_{11},\right. \\
C_{12}, C_{13}, C_{14}, C_{15}, C_{16}, C_{17}, C_{18}, C_{19}, C_{20}, C_{21}, C_{22} \\
\}\end{array}$ \\
\hline Todas-Transições & $\overline{44}$ & $\begin{array}{l}T R=\left\{\left(C_{1}, C_{2}\right),\left(C_{2}, C_{3}\right),\left(C_{3}, C_{4}\right),\left(C_{3}, C_{5}\right),\left(C_{3}, C_{9}\right),\right. \\
\left(C_{4}, C_{10}\right),\left(C_{4}, C_{6}\right),\left(C_{5}, C_{6}\right),\left(C_{5}, C_{6}\right),\left(C_{5}, C_{11}\right), \\
\left(C_{9}, C_{10}\right),\left(C_{9}, C_{22}\right),\left(C_{9}, C_{11}\right),\left(C_{10}, C_{21}\right),\left(C_{10}, C_{12}\right), \\
\left(C_{6}, C_{8}\right),\left(C_{6}, C_{7}\right),\left(C_{6}, C_{12}\right),\left(C_{11}, C_{12}\right),\left(C_{11}, C_{20}\right), \\
\left(C_{11}, C_{12}\right),\left(C_{21}, C_{19}\right),\left(C_{8}, C_{3}\right),\left(C_{8}, C_{1}\right), \quad\left(C_{8}, C_{18}\right), \\
\left(C_{7}, C_{15}\right),\left(C_{7}, C_{3}\right),\left(C_{12}, C_{13}\right),\left(C_{12}, C_{16}\right),\left(C_{12}, C_{19}\right), \\
\left(C_{18}, C_{9}\right),\left(C_{18}, C_{2}\right),\left(C_{15}, C_{9}\right),\left(C_{13}, C_{14}\right),\left(C_{16}, C_{17}\right), \\
\left(C_{19}, C_{17}\right),\left(C_{19}, C_{14}\right),\left(C_{14}, C_{22}\right),\left(C_{17}, C_{2}\right),\left(C_{17}, C_{22}\right), \\
\left.\left(C_{22}, C_{21}\right),\left(C_{22}, C_{20}\right),\left(C_{20}, C_{19}\right),\left(C_{20}, C_{19}\right)\right\}\end{array}$ \\
\hline Todos-Caminhos & $\infty$ & \\
\hline $\begin{array}{l}\text { Todos-Caminhos- } k-C_{1^{-}} \\
\text {Configuração }\end{array}$ & $\infty$ & \\
\hline $\begin{array}{l}\text { Todos-Caminhos-com- } \\
\text { um-Laço }\end{array}$ & 1530 & $\begin{array}{l}T R=\left\{\left(C_{1}, C_{2}, C_{3}, C_{9}, C_{11}, C_{12}, C_{16}, C_{17}, C_{22}, C_{20}\right.\right. \\
\left.C_{19}, C_{14}, C_{22}\right),\left(C_{1}, C_{2}, C_{3}, C_{9}, C_{11}, C_{12}, C_{16}, C_{17},\right. \\
\left.C_{22}, C_{20}, C_{19}, C_{14}, C_{22}, C_{21}\right),\left(C_{1}, C_{2}, C_{3}, C_{9}, C_{11},\right. \\
\left.C_{12}, C_{16}, C_{17}, C_{22}, C_{20}, C_{19}, C_{17}\right),\left(C_{1}, C_{2}, C_{3}, C_{9},\right. \\
\left.\left.C_{11}, C_{12}, C_{16}, C_{17}, C_{22}, C_{21}, C_{19}\right), \ldots\right\} \\
\end{array}$ \\
\hline $\begin{array}{l}\text { Todos-Caminhos-Sim- } \\
\text { ples }\end{array}$ & 1030 & $\begin{array}{l}T R=\left\{\left(C_{1}, C_{2}, C_{3}, C_{5}, C_{5}, C_{8}, C_{1}\right),\left(C_{1}, C_{2}, C_{3}, C_{5},\right.\right. \\
\left.C_{6}, C_{12}, C_{13}, C_{14}, C_{22}, C_{20}, C_{19}\right),\left(C_{1}, C_{2}, C_{3}, C_{4}, C_{6},\right. \\
\left.C_{8}, C_{1}\right),\left(C_{1}, C_{2}, C_{3}, C_{5}, C_{6}, C_{12}, C_{13}, C_{14}, C_{22}, C_{20},\right. \\
\left.C_{19}, C_{17}\right),\left(C_{1}, C_{2}, C_{3}, C_{5}, C_{6}, C_{12}, C_{16}\right),\left(C_{1}, C_{2},\right. \\
\left.C_{3}, C_{5}, C_{11}, C_{12}, C_{19}, C_{14}, C_{22}, C_{20}\right),\left(C_{1}, C_{2}, C_{3}, C_{5},\right. \\
\left.\left.C_{11}, C_{12}, C_{19}, C_{14}, C_{22}, C_{21}\right), \ldots\right\}\end{array}$ \\
\hline $\begin{array}{l}\text { Todos-Caminhos-livre } \\
\text { Laço }\end{array}$ & 1028 & $\begin{array}{l}T R=\left\{\left(C_{1}, C_{2}, C_{3}, C_{4}, C_{6}, C_{7}, C_{15}, C_{9}, C_{10}, C_{12},\right.\right. \\
\left.C_{13}, C_{14}, C_{22}, C_{20}, C_{19}, C_{17}\right),\left(C_{1}, C_{2}, C_{3}, C_{4}, C_{6}, C_{7},\right. \\
\left.C_{15}, C_{9}, C_{10}, C_{12}, C_{13}, C_{14}, C_{22}, C_{21}\right),\left(C_{1}, C_{2}, C_{3},\right. \\
\left.C_{4}, C_{6}, C_{7}, C_{15}, C_{9}, C_{11}, C_{12}, C_{16}, C_{17}\right),\left(C_{1}, C_{2}, C_{3},\right. \\
\left.\left.C_{4}, C_{6}, C_{8}, C_{18}, C_{9}, C_{10}, C_{12}, C_{13}, C_{14}\right), \ldots\right\}\end{array}$ \\
\hline
\end{tabular}

Observa-se que o número de requisitos gerados pelos critérios FCCSDL é consideravelmente grande, quando não infinito. Conseqüentemente, o custo de aplicação dos mesmos tende a ser alto, tornando a atividade de geração de sequiências de teste improdutiva. A geração de casos de teste adequados a esses critérios não foi realizada no contexto deste trabalho, mas analisando alguns requisitos de teste de cada critério, pode-se perceber que muitos deles têm partes de seus caminhos coincidentes. Por exemplo, sejam dois requisitos $r_{1}=C_{1}, C_{2}, C_{3}, C_{5}, C_{6}, C_{7}$ e $r_{2}=C_{1}, C_{2}, C_{3}, C_{5}, C_{6}, C_{7}, C_{8}, C_{9}$. A seqüência de teste que satisfaz o requisito $r_{2}$, também satisfaz o requisito $r_{1}$, ou seja, sequiências de teste que satisfazem um requisito, podem satisfazer outro requisito gerado pelo mesmo critério de teste ou não, diminuindo o número de sequiências de teste a serem geradas. Uma solução, visto que existe essa similaridade entre alguns requisitos, é, para cada critério de teste, começar a 
geração de seqüências de teste dando prioridade àquelas que executam os requisitos de maior tamanho em termos de número de configurações e, dessa forma, espera-se que os requisitos de menor tamanho e que sejam parcialmente coincidentes, sejam também cobertos.

A estratégia de teste proposta para a aplicação dos critérios FCCSDL, na Seção 3.3.4 do Capítulo 3, pode ser combinada com essa abordagem de geração de casos de teste. Ou seja, durante a geração de sequências de teste adequadas para cada critério, pode-se começar a geração priorizando-se aquelas sequências que executam os requisitos de maior tamanho e dessa forma, espera-se que os requisitos de menor tamanho e que coincidam com algum requisito de maior tamanho, sejam também cobertos. Com isso, espera-se diminuir o número de sequências de teste a serem geradas.

\subsection{Avaliação dos Critérios de Teste para SDL: Um Estudo de Caso}

Para o teste de programas, destaca-se a relevância de se determinar a interação existente entre os diversos critérios de teste e de se encontrar a melhor maneira de combiná-los em uma estratégia de teste mais efetiva (Harrold, 2000; Maldonado, 1997). Como discutido no Capítulo 2, os critérios de teste podem ser avaliados em relação ao custo de aplicação, eficácia e strength. O strength se refere à relação de inclusão (Rapps e Weyuker, 1982, 1985) estabelecida entre os critérios de teste do ponto de vista teórico.

Considerando-se esses aspectos para o teste de especificaçōes, foi realizado um estudo de caso em que o strength entre os critérios estruturais apoiados pela $C A T_{S D L}$ e a Análise de Mutantes foi avaliado. Nesse estudo de caso avaliou-se o quanto seqüências de teste adequadas aos critérios estruturais cobrem os requisitos estabelecidos pela Análise de Mutantes e vice-e-versa. A geração dos conjuntos de teste adequados aos critérios estruturais e a avaliação da cobertura do conjunto de teste adequado à mutação, em relação aos requisitos dos critérios estruturais, foram realizadas com o auxílio da $C A T_{S D L}$. Já a parte relacionada à mutação, ou seja, a geração do conjunto de teste adequado e a avaliação da cobertura dos conjuntos de teste adequados aos critérios estruturais, foi manualmente conduzida. Os critérios FCCSDL não foram avaliados nesse estudo de caso por seu alto custo computacional que, sem o apoio automatizado, torna essa tarefa improdutiva.

Zhu (1996) demonstrou que em determinados cenários (aqueles em que o testador não tem conhecimento-sobre os requisitos de um critério de teste para gerar os casos de teste), a relação de inclusão pode garantir uma melhor capacidade em detectar erros. Nesse caso, se há uma relação de inclusão estabelecida entre critérios, pode-se garantir que, se um critério $A$ inclui um critério $B$, então $A$ tem maior capacidade em detectar erros do que $B$. Sendo assim, a análise empírica do strength entre critérios de teste pode fornecer informações que 
auxiliam o estabelecimento de estratégias de teste mais efetivas, de forma a melhor explorar cada critério de teste.

Os critérios de teste avaliados nesse estudo de caso foram aplicados na especificação SDL do protocolo Bit-Alternante. Os conjuntos de casos de teste adequados aos critérios estruturais e de mutação utilizados foram os apresentados nas Seções 6.1.1 e 6.1.2, respectivamente.

\subsubsection{Strength dos Critérios de Teste Estruturais e de Mutação}

Primeiramente, avaliou-se a cobertura obtida pelo conjunto de teste adequado à mutação em relação aos critérios estruturais, com o auxílio da $C A T_{S D L}$. A Figura 6.2 mostra a cobertura obtida pelo conjunto de teste em relação aos requisitos do critério Todos-Usos, por processo SDL. Como pode ser observado, foram cobertos todos os requisitos estabelecidos por esse critério.

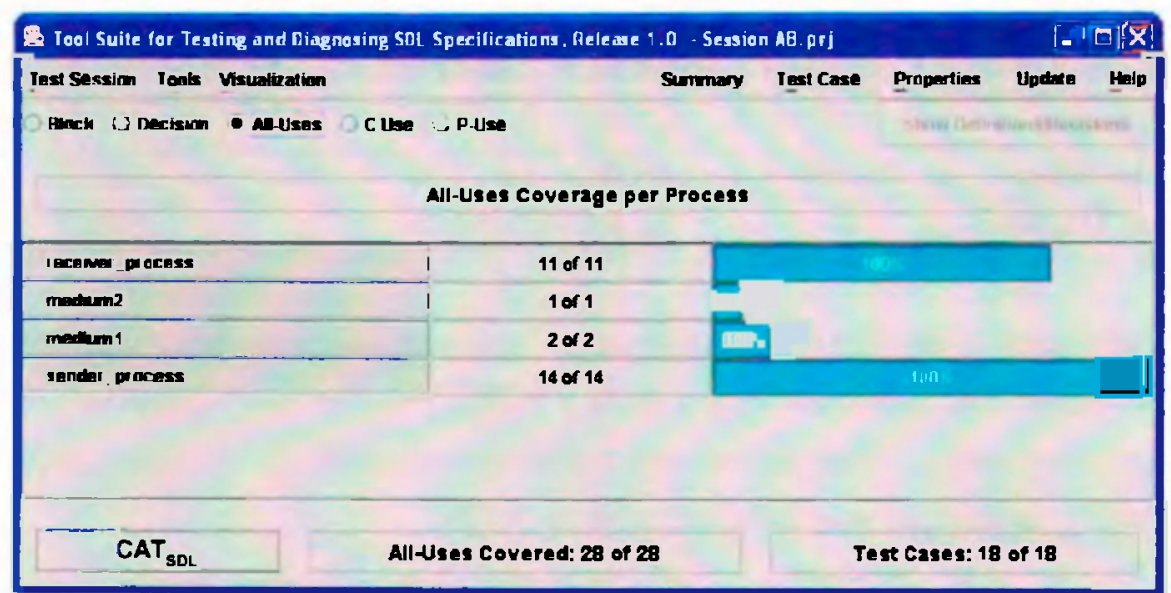

Figura 6.2: Cobertura Obtida Por Processo pelo Conjunto de Teste Adequado à Mutação em Relação a Todos-Usos

As coberturas obtidas para cada critério de teste são apresentadas na Fỉgura 6.3. Conforme pode ser observado, todos os requisitos dos critérios de fluxo de controle e dos critérios de fluxo de dados foram satisfeitos pelo conjunto de teste, indicando que o conjunto de teste adequado à Análise de Mutantes é adequado também aos critérios de fluxo de controle, Todos-Blocos e Todas-Decisões, e de fluxo de dados, Todos-c-Usos, Todos-p-Usos e Todos-Usos. Ou seja, para a especificação utilizada neste estudo de caso, o critério Análise de Mutantes inclui os critérios estruturais apoiados pela $C A T_{S D L}$.

Os conjuntos de teste adequados aos critérios estruturais foram manualmente avaliados em relação à cobertura dos requisitos da Análise de Mutantes. Para cada conjunto de teste foi calculado o escore de mutação e os resultados obtidos são apresentados na Tabela 6.8 .

Como pode ser observado, o escore de mutação foi calculado para cada classe de mutação. Uma vez que todos os mutantes gerados pelos operadores de estrutura são anômalos, o escore 


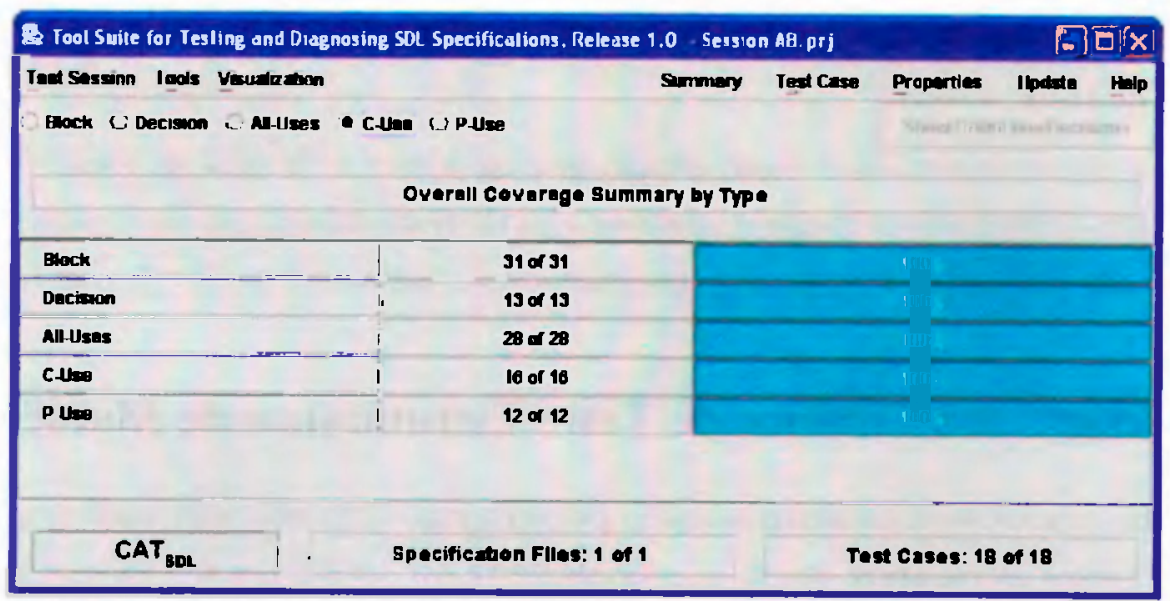

Figura 6.3: Relatório de Cobertura Obtida pelo Conjunto de Casos de Teste Adequado à Mutação em Relação aos Critérios Estruturais

Tabela 6.8: Escore de Mutação Obtido pelos Conjuntos de Teste dos Critérios Estruturais \begin{tabular}{|l|l|l|l|l|}
\hline Critério de Teste & Processo & Interface & Estrutura & Escore de Mutação \\
\hline
\end{tabular}

\begin{tabular}{|l|c|c|c|c|}
\hline \hline Todos-Blocos & 0.75 & 0.837 & 0 & 0.779 \\
\hline Todas-Decisões & 0.736 & 0.59 & 0 & 0.688 \\
\hline Fluxo de Dados & 0.91 & 0.837 & 0 & 0.889 \\
\hline
\end{tabular}

de mutação para essa classe é 0 . Os escores de mutação obtidos pelo conjunto de teste adequado ao critério Todos-Blocos foram 0.75 e 0.837 , para os mutantes de processo e de interface, respectivamente. Considerando-se todos os requisitos da Análise de Mutantes, o escore de mutação obtido por esse conjunto foi de 0.779 .

Já o conjunto de teste adequado a Todas-Decisões obteve escores de mutação de $0.736 \mathrm{e}$ 0.59 para os mutantes de processo e interface, respectivamente. O escore de mutação obtido para o conjunto todo de mutantes foi de 0.688 . O conjunto de teste adequado aos critérios de fluxo de dados obteve escore de 0.889 quando se considerou todo o conjunto de mutantes, sendo que para os mutantes de processo o escore foi de 0.91 e para os mutantes de interface o escore foi de 0.837. Comparando-se os escores obtidos pelos critérios de fluxo de controle e de dados, observa-se que o conjunto de teste adequado aos critérios de fluxo de dados alcançaram um escore de mutação maior. Esses resultados mostram que os conjuntos de teste adequados aos critérios estruturais considerados neste estudo de caso não satisfazem completamente os requisitos de teste do critério Análise de Mutantes.

Sumarizando os resultados obtidos, tem-se que o critério Análise de Mutantes inclui os critérios Todos-Blocos e Todas-Decisões, mas o contrário não é verdadeiro. Ou seja, conjuntos de teste adequados à Análise de Mutantes satisfazem por completo os requisitos gerados por esses critérios, mas conjuntos de teste adequados a esses critérios não satisfazem por completo os requisitos estabelecidos pela Análise de Mutantes. Assim, a Análise de Mutantes inclui estritamente os critérios de fluxo de controle, Todos-Blocos e Todas-Decisões. 
Em relação aos critérios de fluxo de dados, a Análise de Mutantes também satisfaz todos os requisitos estabelecidos pelos critérios Todos-c-Usos, Todos-p-Usos e Todos-Usos. Já os conjuntos adequados aos critérios Todos-c-Usos, Todos-p-Usos e Todos-Usos não satisfazem por completo os requisitos estabelecidos pela Análise de Mutantes.

Nesse estudo de caso, a Análise de Mutantes incluiu estritamente os critérios de fluxo de controle e de dados no contexto de teste de especificações SDL. No entanto, os critérios de fluxo de dados e a Análise de Mutação são incomparáveis, tanto no teste de unidade, quanto no teste de integração (Delamaro, 1997; Frankl e Weyuker, 1993b; Offutt et al., 1996b; Wong et al., 1994c; Zhu et al., 1997). Resultado similar ao do estudo de caso conduzido neste trabalho foi obtido no experimento de Mathur e Wong (1994), em que alguns conjuntos de teste gerados pela Análise de Mutantes se mostraram adequados ao critério Todos-Usos. $\mathrm{O}$ contrário já não foi verdadeiro. Mathur e Wong (1994) concluíram que a cobertura obtida pelos conjuntos de teste gerados pela Análise de Mutantes em relação aos requisitos dos critérios de fluxo de dados é maior do que a cobertura obtida pelos conjuntos de teste gerados pelos critérios de fluxo de dados em relação aos requisitos da Análise de Mutantes. É necessário que outros experimentos sejam realizados, com outras especificações SDL, para obter um resultado conclusivo no contexto de teste de especificações SDL.

A condução deste estudo de caso evidenciou mais uma vẹz a necessidade de uma ferramenta de apoio à aplicação da Análise de Mutantes no teste de especificações SDL. O apoio da $C A T_{\mathrm{SDL}}$ para gerar casos de teste e para avaliar o conjunto de teste adequado à mutação em relação aos critérios estruturais tornou essas atividades mais produtivas e menos propensas a erros.

Esses resultados podem ser utilizados para o estabelecimento de estratégias de teste incremental no contexto de especificações SDL. Uma possível estratégia de teste é discutida na Seção 6.3.

Apesar dos critérios FCCSDL não terem sido comparados aos outros critérios nesse estudo de caso, intui-se que o resultado obtido seria similar ao obtido por Souza (2000), que comparou a Análise de Mutantes e critérios estruturais similares aos FCCSDL, no contexto de Statecharts e Estelle. Souza (2000) concluiu que esses critérios são incomparáveis. Além disso, os conjuntos de teste adequados à mutação obtiveram uma cobertura baixa em relação aos requisitos dos critérios estruturais, pois esses critérios exigem que seqüências de teste percorram caminhos específicos na árvore de alcançabilidade. Muitas vezes também esses caminhos são longos em termos de número de configurações alcançadas e os conjuntos de teste gerados pela Análise de Mutantes contêm seqüências de teste curtas. 


\subsection{Estratégia de Teste para Especificações SDL}

Com os resultados obtidos no estudo de caso apresentado na seção anterior, evidencia-se o aspecto complementar da Análise de Mutantes e dos critérios estruturais, que pode ser explorado durante o estabelecimento de estratégias de teste. Por exemplo, uma possivel estratégia de teste de especificações baseadas em SDL, considerando o custo de aplicação de cada critério em termos de número de requisitos de teste, é: (1) aplicar os critérios de fluxo de controle, que são menos custosos; (2) aplicar os critérios de fluxo de dados, mais rigorosos e com custo mais alto que os anteriores; e por fim, (3) aplicar a Análise de Mutantes, cujo custo de aplicação é o mais alto entre os critérios de teste avaliados no estudo de caso.

Outra possível estratégia poderia também considerar os critérios FCCSDL:

1. Aplicar os critérios de fluxo de controle Todos-Blocos e Todas-Decisões, apoiados pela $C A T_{S D L}$

2. Aplicar os critérios de fluxo de dados, Todos-p-Usos, Todos-c-Usos e Todos-Usos;

3. Aplicar a Análise de Mutantes;

4. Aplicar os critérios FCCSDL.

No Passo 3, a estratégia de teste ITS-SDL pode ser aplicada, assim como a estratégia apresentada na Seção 3.3.4 do Capítulo 3, pode ser aplicada no Passo 4.

Essa estratégia considera o custo de aplicação dos critérios de teste, começando por critérios menos rigorosos e com baixo custo em termos de número de requisitos de teste, e terminando com critérios que têm um custo mais alto.

\subsection{Considerações Finais}

Neste capítulo os critérios de teste propostos neste trabalho foram aplicados no teste de uma especificação SDL do procotolo Bit-Alternante. Foi demonstrada a viabilidade de aplicação tanto dos critérios estruturais quanto da Análise de Mutantes no contexto de teste de especificações SDL, com a obtenção dos respectivos conjuntos de requisitos de teste e a geração dos conjuntos de teste adequados aos critérios.

No caso dos critérios estruturais de fluxo de controle e de dados, a avaliação teve o auxílio da ferramenta $C A T_{S D L}$. Esses critérios têm um custo de aplicação baixo em termos de número de requisitos de teste, mas são menos rigorosos que os demais critérios. Foram derivados 31 e 13 requisitos para os critérios de fluxo de controle Todos-Blocos e Todas-Decisões, respectivamente, e 12, 16 e 28 requisitos para os critérios de fluxo de dados Todos-p-Usos, Todos-c-Usos e Todos-Usos, respectivamente. Os conjuntos de teste que cobrem os requisitos 
dos critérios de fluxo de controle têm 3 casos de teste, cada um. No caso dos critérios de fluxo de dados, os conjuntos de teste são iguais e compostos por 5 casos de teste.

A Análise de Mutantes, por ainda não ter apoio ferramental, foi avaliada manualmente Dado que o custo de aplicação desse critério foi alto em termos de número de mutantes gerados, 262 no total, que foram executados e avaliados, a existência de uma ferramenta de apoio se mostrou essencial para a condução da atividade de teste de forma produtiva. $O$ conjunto de teste adequado à Análise de Mutantes contém 18 casos de teste. Também é importante a condução de estudos de caso com outras especificações SDL para avaliar os mutantes gerados pelos operadores de mutação de estrutura. No estudo conduzido, apenas mutantes anômalos foram gerados.

Para os critérios FCCSDL foram obtidos apenas os requisitos de teste, a geração dos conjuntos de teste não foi realizada. O número de requisitos derivados para esses critérios foi alto e tende a aumentar em especificações mais complexas, demonstrando que o apoio ferramental também é importante para auxiliar a geração de conjuntos de teste adequados. Como sugerido anteriormente, para a geração de conjuntos de teste que satisfaçam esses requisitos, pode-se começar por cobrir os requisitos mais longos em termos de números de configurações, pois muitos dos requisitos gerados são subcaminhos de requisitos mais longos. Outra solução é automatizar o processo de derivação dos requisitos, de forma a descartar requisitos que podem ser cobertos quando outros requisitos mais longos forem satisfeitos.

Os critérios de teste propostos neste trabalho visam a complementar a atividade de teste de especificações SDL, permitindo a análise da cobertura de teste e a avaliação da qualidade do teste sendo realizado. Esses critérios podem complementar as atividades de simulação e model checking, comumente utilizadas no contexto de SDL. Outro ponto importante é que no contexto de teste de especificações, os conjuntos de teste adequados aos critérios são aplicados no teste da própria especificação, como abordado neste trabalho. Porém, esses conjuntos de teste podem também ser utilizados no teste de conformidade de uma implementação relacionada.

O strength entre os critérios estruturais apoiados pela $C A T_{S D L}$ e a Análise de Mutantes foi avaliado. Nesse caso, a Análise de Mutantes incluiu estritamente os critérios estruturais. É necessário que outros estudos sejam realizados para confirmar esse resultado. O estabelecimento dessa relação é importante para auxiliar a determinação de estratégias de teste que explorem da melhor maneira possível os critérios de teste no teste de especificaçōes SDL. A eficácia em revelar erros também é um fator importante quando se avalia um critério de teste. Nesse sentido, Zhu (1996) demonstrou que, em alguns casos, o strength pode garantir também uma melhor capacidade de detecção de erros dos critérios de teste.

Considerando o caráter complementar dos critérios de teste estabelecidos neste trabalho, e fatores como rigor e custo de aplicação, neste capítulo foi proposta uma estratégia de teste incremental, que pode ser aplicada por completo ou parcialmente, de acordo com a disponibilidade de recursos para a atividade de teste de especificações SDL. Destaca-se que 
para a aplicação da Análise de Mutantes e dos critérios FCCSDL, e por conseqüência da estratégia de teste, de forma mais produtiva, é importante a disponibilidade de ferramentas de apoio.

No próximo capítulo as principais contribuições deste trabalho são sumarizadas, algumas limitações são discutidas e as perspectivas de trabalhos futuros são apresentadas. 
Motivado pelo fato de que SDL é uma técnica que tem sido muito empregada na especificação de sistemas reativos, tais como protocolos de comunicação, e mais recentemente, na descrição de arquitetura de software, neste trabalho a atividade de teste de especificações SDL foi investigada.

Foram investigados critérios de teste estruturais e baseado em mutação. Os critérios estruturais foram abordados de duas perspectivas. Em uma delas, os requisitos de teste dos critérios de fluxo de controle e de dados são derivados de um grafo de fluxo de controle e de dados estabelecido para cada processo SDL. Para auxiliar a geração de casos de teste com base nos requisitos estabelecidos por esses critérios, algumas informaçōes são fornecidas para que sejam gerados primeiro casos de teste que obterão maiores coberturas de teste a cada execução. Na outra perspectiva, foi definida uma família de critérios de fluxo de controle, a FCCSDL, que estabelece seus requisitos de teste a partir da árvore de alcançabilidade, que modela o comportamento da especificação SDL. Para essa família, foi estabelecida uma relação de inclusão entre seus critérios e uma estratégia de teste incremental foi proposta, com base nos resultados da relação de inclusão.

Em relação ao critério Análise de Mutantes, foi definido um conjunto de operadores de mutação que exploram erros no comportamento dos processos SDL, na comunicação entre os processos SDL e na estrutura da especificação. Também foi estabelecida uma estratégia de teste incremental, ITS-SDL, para auxiliar a exploração das características abordadas pelas operadores de mutação.

O custo de aplicação da Análise de Mutantes, em geral, é alto devido ao número de mutantes gerados, que devem ser executados e analisados. Uma avaliação da complexidade 
dos operadores de mutação, em relação ao número de mutantes gerados no pior caso, foi realizada. Os resultados apontam que alguns operadores têm complexidade quadrática em relação a algum elemento da especificação SDL, mas a maioria tem complexidade linear.

Tanto os critérios estruturais quanto a Análise de Mutantes auxiliam a geração de casos de teste adequados e a análise de adequação de conjuntos de teste. Apesar de serem propostos para o teste de especificações SDL, como ressaltado anteriormente, os casos de teste gerados com base nesses critérios também podem ser utilizados no teste de conformidade de implementações associadas às especificações SDL.

Também foram propostas facilidades para a ativìdade de depuração com base em informações obtidas durante o teste de especificações SDL com relação aos critérios estruturais. Essa proposta foi baseada em trabalhos desenvolvidos para a depuração de programas, que utilizam os slices de execução dos casos de teste. Durante a atividade de teste são coletadas informações sobre a cobertura de cada caso de teste. Nessa abordagem, essas informações são coletadas de forma a fornecerem dados sobre os slices de execução de cada caso de teste.

$\mathrm{O}$ apoio ferramental é crucial para a condução da atividade de teste. Neste trabalho foi implementada a ferramenta $C A T_{S D L}$ que, além de auxiliar a análise de cobertura de teste em relação aos critérios de teste estruturais, ainda fornece algumas informações que podem ser utilizadas na geração de casos de teste, de forma que maiores coberturas de teste podem ser obtidas a cada execução. A ferramenta $S$ mart $D_{S D L}$ apóia a abordagem proposta para auxiliar a depuração de especificações SDL, aproveitando as informações coletadas pela $C A T_{S D L}$ sobre quais requisitos foram executados pelos casos de teste para informar as possíveis localizações do erro na especificação, de acordo com três heurísticas. Essa abordagem tem se mostrado viável quando utilizada no contexto de depuração de especificações SDL.

Para a aplicação da Análise de Mutantes é fundamental o apoio de ferramentas, pois o número de mutantes que podem ser gerados, e que devem ser executados e analisados, em geral, é alto, tornando essa atividade improdutiva se realizada manualmente. Neste trabalho foram abordados os principais aspectos a serem considerados para o desenvolvimento de uma ferramenta para apoiar a aplicação desse critério no teste de especificaçōes SDL. Esses aspectos têm como base ferramentas de apoio à mutação desenvolvidas em outros trabalhos do grupo de Engenharia de Software do ICMC-USP/São Carlos.

Em geral, os critérios de teste podem ser avaliados segundo o custo, eficácia e strength. Neste trabalho, o strength entre os critérios estruturais que a $C A T_{S D L}$ apóia e a Análise de Mutantes foi avaliado. Os resultados indicam que a Análise de Mutantes inclui estritamente os critérios estruturais baseados em fluxo de controle e de dados, de modo que uma estratégia de teste pode ser estabelecida de forma a explorar esses critérios. Esses resultados devem ser investigados em outros estudos de caso, com outros conjuntos de teste e com outras especificações $\mathrm{SDL}$, pois estudos teóricos e empíricos conduzidos em outras pesquisas indicam que esses critérios são incomparáveis. 
A seguir, as contribuições deste trabalho são sumarizadas. As dificuldades e limitações também são apresentadas, assim como as perspectivas de trabalhos futuros.

\subsection{Contribuições}

As principais contribuições deste trabalho são:

- Adequação de critérios de teste estruturais de fluxo de controle e de dados para o teste de especificações SDL com base em informações do comportamento dos processos SDL; e proposta de utilização do conceito de dominadores para auxiliar a geração de casos de teste que obtenham maior cobertura de teste a cada execução;

- Definição dos critérios FCCSDL de fluxo de controle e avaliação teórica da relação de inclusão entre esses critérios de teste. Com base nos resultados dessa avaliação, uma estratégia de teste incremental foi estabelecida para auxiliar a aplicação dessa família de critérios;

- Proposta de aplicação do critério Análise de Mutantes no teste de especificações SDL. Um conjunto de operadores de mutação foi definido e sua complexidade, em termos do número de mutantes gerados, foi avaliada. A estratégia de teste incremental ITS-SDL para auxiliar a aplicação dos operadores de mutação também foi definida;

- Proposta de facilidades para auxiliar a depuração de especificações SDL. com a utilização de informações da cobertura de teste obtida pelos casos de teste;

- Desenvolvimento da ferramenta $C A T_{S D L}$, que apóia os critérios de teste estruturais e fornece informações ao testador sobre quais casos de teste podem obter uma maior cobertura a cada execução;

- Desenvolvimento da ferramenta $S m a r t D_{S D L}$, que auxilia a atividade de depuração fornecendo informações sobre as possíveis localizações de erros nas especificações SDL;

- Descrição dos principais aspectos a serem considerados no desenvolvimento de uma ferramenta de apoio à Análise de Mutantes no teste de especificações SDL;

- Condução de estudo de caso para comparar o strength entre os critérios estruturais apoiados pela $C A T_{S D L}$ e a Análise de Mutantes;

- Estabelecimento de uma estratégia de teste incremental para auxiliar o teste de especificações SDL, considerando a aplicação de todos os critérios de teste propostos neste trabalho. 


\subsection{Dificuldades e Limitações}

Os critérios estruturais de fluxo de dados são baseados em associações def-uso executáveis. Embora algumas técnicas de análise possam ser aplicadas para identificar alguns pares def-uso não-executáveis (infeasible), na prática é muito difícil identificá-los e eliminá-los. Neste trabalho, o problema da executabilidade de associações def-uso não é tratado. Assim, no caso de haver associações def-uso não-executáveis, a cobertura de teste obtida pode ser um pouco diferente daquela que seria obtida caso essas associaçōes fossem eliminadas. No entanto, como a sintaxe de SDL é mais simples do que a sintaxe de linguagens de programaçāo, tais como $\mathrm{C}$, espera-se que o número de associações def-uso não-executáveis seja pequeno e, consequentemente o impacto dessas associações na cobertura de teste deve ser menor do que no caso de programas $\mathrm{C}$. No estudo de caso realizado neste trabalho com a especificação do protocolo Bit-Alternante, não foram identificados pares def-uso não-executáveis. Estudos com outras especificações SDL devem ser conduzidos para melhor avaliar esse aspecto.

Um ponto importante associado à implementação da ferramenta $C A T_{S D L}$ está relacionado à gramática de SDL. Na versão atual, a $C A T_{S D L}$ aceita especificaçōes descritas na versão SDL-92, escolhida por ser a versão apoiada pela Telelogic Tau 4.3, utilizada para simular as especificações SDL instrumentadas pela $C A T_{S D L}$. Para atualizar a ferramenta para que ela accitc especificações escritas na versão SDL-2000, que é a mais atual, é preciso, além de gerar um novo parser, adequar o código responsável pela geração dos grafos de fluxo, a partir da árvore de parser.

Ainda em relação à implementação da ferramenta $C A T_{S D L}$, as principais dificuldades envolveram aspectos intrínsecos da técnica SDL. Apesar de simples, a gramática da linguagem exigiu certos cuidados, pois alguns aspectos comportamentais ficam implícitos na especificação. Um exemplo é quando ocorre o comando "save" em um estado do processo SDL. Quando esse comando ocorre, não é descrito explicitamente na especificação como a execução continua, como pode ser observado na especificação textual do processo Sender do protocolo Bit-Alternante apresentada no Capítulo 3 e no Apêndice B. Quando há o comando "save" em um estado, não há mudança de estado, ou seja, o fluxo de execução retorna ao estado ao qual o "save" está vinculado.

Apesar da não utilização da gramática mais recente de SDL neste trabalho, os resultados obtidos, que indicam a viabilidade da aplicação de técnicas e critérios de teste no teste de especificações com base nessa linguagem, podem ser estendidos para a versão SDL-2000, pois as diferenças existentes entre essa versão e a versão SDL-92 não têm influência na aplicação dos critérios de teste. Essas diferenças alteram apenas os requisitos de teste que podem ser derivados a partir dos critérios de teste. 


\subsection{Trabalhos Futuros}

Como perspectivas de trabalhos que podem ser desenvolvidos na mesma linha de pesquisa em que esta tese se insere, têm-se:

- Extensão do modelo de árvore de alcançabilidade para a técnica SDL de forma a representar aspectos de fluxo de dados;

- Extensão dos critérios FCCSDL com a inclusão de critérios de fluxo de dados;

- Definição de uma abordagem de utilização do conceito de dominadores para auxiliar a geração de casos de teste com base no teste de mutação;

- Investigação da abordagem proposta por Simão e Maldonado (2000a) para a geração automática de sequências de teste com base na Análise de Mutantes no contexto de SDL;

- Disponibilização da ferramenta $C A T_{S D L}$ para execução via script, de forma a auxiliar a condução de estudos empíricos;

- Desenvolvimento de uma ferramenta para apoiar os critérios FCCSDL, otimizando a obtenção de requisitos de teste e a geração de casos de teste;

- Desenvolvimento de uma ferramenta para apoiar a aplicação da Análise de Mutantes no teste de especificações SDL;

- Condução de estudo comparativo para avaliar o strength entre os critérios estruturais apoiados pela CAT, os critérios FCCSDL e a Análise de Mutantes;

- Avaliação dos mutantes gerados pela classe de operadores de estrutura para verificar se são gerados apenas mutantes anômalos;

- Condução de estudos empíricos para a determinação de um conjunto de operadores de mutação essencial, de forma a diminuir o custo de aplicação do critério;

- Condução de estudo comparativo avaliando a eficácia dos critérios de teste estruturais e de mutação definidos neste trabalho;

- Avaliação das ferramentas $C A T_{S D L}$ e $S \operatorname{mart} D_{S D L}$, utilizando especificações SDL mais complexas. 


\section{Referências Bibliográficas}

Acree, A. T.; Budd, T. A.; Demillo, R. A.; Lipton, R. J.; SAYward, F. G. Mutation analysis. Relatório Técnico GIT-ICS-79/08, Georgia Institute of Technology, Atlanta, GA, 1979.

AgRAWAL, H. Design of mutant operators for the C programming language. Relatório Técnico SERC-TR-41-P, Software Engineering Research Center/Purdue University, 1989.

Agrawal, H. Dominators, super blocks, and program coverage. In: Proceedings of the $21^{\text {st }}$ Symposium on Principles of Programming Languages, Portland, OR, EUA, p. 25-34, 1994.

Agrawal, H.; Alberi, J. L.; Horgan, J. R.; LI, J. J.; London, S.; Wong, W. E.; Grosh, S.; Wilde, N. Mining system tests to aid software maintenance. IEEE Computer, v. 31, n. 7, p. 64-73, 1998.

Agrawal, H.; DeMillo, R. A.; Spafford, E. H. Debugging with dynamic slicing and backtracking. Software - Practice \& Experience, v. 23, n. 6, p. 589-616, 1996.

Agrawal, H.; Horgan, J. R. Dynamic program slicing. In: Proceedings of the ACM SIGPLAN'90 Conference on Programming Language Design and Implementation, 1990.

Agrawal, H.; Horgan, J. R.; London, S.; WONG, W. E. Fault localization using execution slices and dataflow tests. In: Proceedings of the $6^{\text {th }}$ IEEE Internation Symposium on Software Reliability Engineering, Toulouse, França, p. 143-151, 1995.

AllworTH, S. T. Introduction to real-time software design. London: McMillan, 1981.

Ammann, P.; BlaACK, P. A specification-based coverage metric to evaluate test sets. In: Proceedings of Fourth IEEE International High-Assurance Systems Engineering Symposium (HASE 99), IEEE Computer Society, p. 239-248, 1999. 
Ammann, P.; Black, P.; MajURSKI, W. Using model checking to generate tests from specifications. In: Proceedings of $2^{\text {nd }}$ IEEE International Conference on Formal Engineering Methods, Brisbane, Australia: IEEE Computer Society, p. 46-54, 1998.

BARbosa, E. F. Uma contribuição ao processo de desenvolvimento e modelagem de módulos educacionais. Tese de Doutoramento, ICMC/USP, São Carlos, SP, 2004.

Barbosa, E. F.; Maldonado, J. C.; Vincenzi, A. M. R. Toward the determination of sufficient mutant operators for C. Software Testing, Verification and Reliability Journal, v. 11, n. 2, p. 113-136, John Wiley \& Sons, 2001.

BARnARD, J. COMX: A design methodology using Communicating X-Machines. Information and Software Technology, v. 40, n. 5-6, p. 271-280, 1998.

BeIzER, B. Software testing techniques. 2 ed. New York: Van Nostrand Eeinhold, 1990.

BELINA, F.; Hogrefe, D.; SARMA, A. SDL with applications from protocol specification. Prentice Hall, 1991.

BLACK, P. E.; OKUn, V.; Yesha, Y. Mutation of model checker specifications for test generation and evaluation. In: Mutation 2000 - A Symposium on Mutation Testing for the New Century, San José, California, p. 24-30, 2000a.

Black, P. E.; OKun, V.; YeSha, Y. Mutation operators for specifications. In: Proceedings of $15^{\text {th }}$ IEEE International Conference on Automated Software Engineering (ASE2000), p. 81-89, 2000b.

Disponível em citeseer.nj.nec.com/black00mutation.html (Acessadoem22/06/2004)

Boaventura, I. A. G. Propriedades dinâmicas de Statecharts. Dissertação de Mestrado, ICMC/USP, São Carlos, SP, 1992.

Bochmann, G.; Petrenko, A. Protocol testing: Review of methods and relevance for software testing. In: ISSTA'94 - International Symposium on Software Testing and Analysis, p. 109-124, 1994.

Bogdanov, K.; Holcombe, M. Statechart testing method for aircraft control systems. Software Testing, Verification and Reliability, v. 11, n. 1, p. 39-54, 2001.

Botrhfir, C.; Aboulhamid, E.; KHendek, F.; Dssouli, R. Test cases selection from SDL specifications. Computer Networks, v. 35, n. 6, p. 693-708, 2001a.

Bolrhfir, C.; Aboulhamid, E. M.; Dssouli, R.; Rico, N. A test case generation approach for conformance testing of SDL systems. Computer Communications, v. 24, n. $3-4$, p. 319-333, 2001b. 
Bourhfir, C.; Dssouli, R.; ABoulhamid, E. M. Automatic test generation for EFSM-based systems. 1996.

Disponível em citeseer.nj.nec.com/114451.html (Acessado em 22/06/2004)

Bousquet, L. D.; Ramangalahy, S.; Simon, S.; Viho, C.; Belinfante, A.; VRies, R. G. Formal test automation: The conference protocol with TGV/TORX. In: URAL, H.; Probert, R. L.; v. BochmanN, G., eds. IFIP $19^{\text {th }}$ Intermational Conference on Testing of Communicating Systems(TestCom 2000), Kluwer Academic Publishers, 2000.

Boussinot, F.; Simone, R. The Esterel language. Proceedings of the IEEE, v. 79, n. 9, p. 1293--1304, 1991.

Bromstrup, L.; Hogrefe, D. TESDL: Experience with generating test cases from SDL specifications. In: Proceedings of Fourth SDL Forum, p. 267-279, 1989.

BroY, M. Formal description techniques - how formal and descriptive are they? In: Gotzhein, R.; Bredereke, J., eds. In Formal Description Techniques IX: Theory, Application and Tools (FORTE/PSTV 96), Chapman and Hall, p. 95-110, 1996.

Disponível em http://citeseer.ist.psu.edu/315661.html (Acessado em 22/06/2004)

BroY, M. Software technology - formal methods and scientific foundations. Information and Software Technology, v. 41, n. 14, p. 947-950, 1999.

Budd, T. A. Mutation analysis: Ideas, examples, problems and prospects. In: Chandrasekaran, B.; Radicchi, S., eds. Computer Program Testing, Amsterdam: North-Holland Publishing Company, p. 129-148, 1981.

Budd, T. A.; Demillo, R. A.; Lipton, R. J.; Sayward, F. G. Theoretical and empirical studies on using program mutation to test the functional correctness of programs. In: Proceedings of th ACM Symposium on Principles of Programming Languages, $p$. 220-233, 1980.

Candolo, M. A. P.; Simão, A. S.; Maldonado, J. C. MGASet - uma ferramenta para apoiar o teste e validação de especificaçōes baseadas em Máquinas de Estado Finito. In: Anais do XV Simpsio Brasileiro de Engenharia de Software, Rio de Janeiro, RJ, p. 386-391, 2001.

Cavalli, A. R.; Chin, B.; Chon, K. Testing methods for SDL systems. Computer Network and ISDN Systems, v. 28, n. 12, p. 1669-1683, 1996.

CHA, S. D.; HoNG, H. S. Specification and analysis of real-time systems in Statecharts. In: Proceedings of the $2^{\text {nd }}$ International Workshop on Object-Oriented Real-Time Dependable Systems'96, Laguna Beach, CA, USA, p. 137-143, 1996. 
ChAIM, M. L. Poke-Tool - uma ferramenta para suporte ao teste estrutural de programas baseados em análise de fluxo de dados. Dissertação de Mestrado, DCA/FEEC/UNICAMP, Campinas, SP, 1991.

Chaim, M. L.; Jino, M.; Maldonado, J. C.; Nakagawa, E. Y. Poke-Tool: Estado atual de uma ferramenta para teste estrutural de software baseado em análise de fluxo de dados. In: Caderno de Ferramentas do XII. SBES - Simpósio Brasileiro de Engenharia de Software, Maringá, PR, p. 37-45, 1998.

Chaim, M. L.; Maldonado, J. C.; Jino, M. A debugging strategy based on requirements of testing. In: Proceedings of the $7^{\text {th }}$ European Conference on Software Maintenance and Reengineering - CSMR'03, Benevento, Italia, p. 160-170, 2003.

CHow, T. S. Testing software design modeled by Finite-State Machines. IEEE Transactions on Software Engineering, v. 4, n. 3, p. 178-187, 1978.

Chu, P. M.; LiU, M. T. Global state graph reduction techniques for protocol validation in the EFSM model. In: Proceedings of the IEEE Phoenix Conference on Computers and Communications, p. 371-377, 1989.

Chung, C.-M.; Shih, T. K.; Wang, Y.-H.; Lin, W.-C.; Kou, Y.-F. Task decomposition testing and metrics for concurrent programs. In: Fifth Internationalk Symposium on software Reliability Engineering - ISSR'E'96, p. 122-130, 1996.

Chusho, T. Test data selection and quality estimation based on the concept of essential branches for path testing. IEEE Transactions on Software Engineering, v. 13, n. 5, p. $509-517,1987$.

Clarke, E.; Wing, J. Formal methods: State of the art and future directions. ACM Computing Surveys, v. 28, n. 4, p. 626-643, 1996.

Clarke, L. A.; Podgurski, A.; Richardson, D. J. A formal evaluation of data flow path selection criteria. IEEE Transactions on Software Engineering, v. 15, n. 11, p. 1318-1332, 1989.

DAvis, A. M. A comparison of techniques for the specification of external system behavior. Communications of the ACM, v. 31, n. 9, 1988.

Delamaro, M. E. Proteum - um ambiente de teste baseado na análise de mutantes. Dissertação de Mestrado, ICMC/USP, São Carlos, SP, 1993.

Delamaro, M. E. Mutação de interface: Um critério de adequação interprocedimental para o teste de integração. Tese de Doutoramento, IFSC/USP, São Carlos, SP, 1997. 
Delamaro, M. E.; Maldonado, J. C. Proteum: A tool for the assessment of test adequacy for C programs. In: Conference on Performability in Computing Systems (PCS'96), Brunswick, NJ, p. 79-95, 1996.

Delamaro, M. E.; Maldonado, J. C. Interface mutation: Assessing testing quality at interprocedural level. In: Proceedings of XIX SCCC - International Conference of the Chilean Computer Science Society, Talca, Chile, p. 78-86, 1999.

Delamaro, M. E.; Maldonado, J. C.; Mathur, A. P. Interface mutation: An approach for integration testing. IEEE Transactions on Software Engineering, v. 27, n. 3, p. $228-247,2001$.

Delamaro, M. E.; Maldonado, J. C.; Pasquini, J. C.; Mathur, A. P. Interface mutation test adequacy criterion: An empirical evaluation. Empirical Software Engineering, v. 6, n. 2, p. 111-142, 2001b.

Delamaro, M. E.; Maldonado, J. C.; Vincenzi, A. M. R. Proteum/IM 2.0: An integrated mutation testing environment. In: Mutation 2000 Symposium, San Jose, CA, EUA: Kluwer Academic Publishers, p. 91-101, 2000.

DeMillo, R. A. Mutation analysis as a tool for software quality assurance. In: Proceedings of COMPSAC80, Chicago, IL, 1980.

DeMillo, R. A.; Guindi, D. S.; McCracken, W. M.; Offutt, A. J.; King, K. N. An extended overview of the Mothra software testing environment. In: Second Workshop on Software Testing, Verification and Analysis, Banff, Canadá, p. 142-151, 1988.

DeMillo, R. A.; Lipton, R. J.; Sayward, F. G. Hints on test data selection: Help for the practicing programmer. IEEE Computer, v. 11, n. 4, p. 34-41, 1978.

DeMillo, R. A.; Offutt, A. J. Constraint-based automatic test data generation. IEEE Transactions on Software Engineering, v. 17, n. 9, p. 900-910, 1991.

DeMillo, R. A.; Offutt, A. J. Experimental results on automatic test case generation. ACM Transaction on Software Engineering and Methodology, v. 2, n. 2, p. 109-127, 1993.

DeMillo, R. A.; Pan, H.; Spafford, E. H. Failure and fault analysis for software debugging. In: Proceedings of $21^{\text {st }}$ International Computer Software and Applications Conference, COMPSAC'g7, Washington, D.C., EUA, p. 515-521, 1997.

FABBri, S. C. P. F. $A$ análise de mutantes no contexto de sistemas reativos: Uma contribuição para o estabelecimento de estratégias de teste e validação. Tese de Doutoramento, IFSC/USP, São Carlos, SP, 1996. 
Fabbri, S. C. P. F.; Maldonado, J. C.; Masiero, P. C. Aplicação do critério análise de mutantes na validaçāo de especificações baseadas em Statecharts. In: XI SBES - Simpósio Brasileiro de Engenharia de Software, Fortaleza, CE, p. 429-444, 1997a.

Fabbri, S. C. P. F.; Maldonado, J. C.; Masiero, P. C. Mutation analysis in the context of reactive system specification and validation. In: $5^{\text {th }}$ Annual International Conference on Software Quality Management, Bath, UK, p. 247-258, 1997b.

Fabbri, S. C. P. F.; Maldonado, J. C.; Masiero, P. C.; Delamaro, M. E. Análise de mutantes na validação de especificações baseadas em redes de Petri. In: 8 Workshop de Qualidade de Software, Curitiba, PR, p. 423-438, 1994a.

Fabbri, S. C. P. F.; Maldonado, J. C.; Masiero, P. C.; Delamaro, M. E. Mutation analysis testing for Finite State Machines. In: Proceedings of ISSRE'94 - Fifth International Symposium on Software Reliability Engineering, Monterey, California, USA, p. 220-229, 1994b.

Fabbri, S. C. P. F.; Maldonado, J. C.; Masiero, P. C.; Delamaro, M. E.; WONG, E. Mutation testing applied to validate specifications based on Petri nets. In: Proceedings of FORTE'95 - 8 $^{\text {th }}$ International IFIP Conference on Formal Description Techniques for Distributed Systems and Communications Protocol, Montreal, Canada, p. 329-337, 1995.

Fabbri, S. C. P. F.; Maldonado, J. C.; Sugeta, T.; Masiero, P. C. Mutation testing applied to validate specifications based on Statecharts. In: ISSRE - International Symposium on Software Reliability Systems, Boca Raton, Flórida, EUA, p. 210-219, 1999.

FONSECA, R. P. Suporte ao teste estrutural de programas Fortran no ambiente Poke-Tool. Dissertação de Mestrado, DCA/FEEC/UNICAMP, Campinas, SP, 1993.

Frankl, P. G.; Hamlet, R. G.; Litrtewood, B.; Strigini, L. Evaluating testing methods by delivered reliability. IEEE Transactions on Software Engineering, v. 24, n. 8, p. $586-601,1998$.

FrankL, P. G.; Weyuker, E. J. A data fow testing tool. In: IEEE Softfair. II, p. $46-53,1985$.

FrankL, P. G.; WeYUKer, E. J. An applicable family of data flow testing criteria. IEEE Transactions on Software Engineering, v. 14, n. 10, p. 1483-1498, 1988.

FrankL, P. G.; Weyuker, E. J. A formal analysis of the fault-detecting ability of testing methods. IEEE Transactions on Software Engineering, v. 19, n. 3, p. 202-213, 1993a. 
FrankL, P. G.; WeyUker, E. J. Provable improvements on branch testing. IEEE Transactions on Software Engineering, v. 19, n. 10, p. 962-975, 1993b.

Fujiwara, S.; Bochmann, G.; Khendek, F.; Amalou, M.; Ghedamsi, A. Test selection based on Finite State models. IEEE Transactions on Software Engineering, v. 17, n. 6, p. 591-603, 1991.

FURBACH, U. Formal specification methods for reactive systems. The Journal of Systems and Software, v. 21, n. 2, p. 129-139, 1993.

Geurts, W.; WiJbrans, K.; Tretmans, J. Testing and formal methods - BOS project case study. In: EuroSTAR'98: $6^{\text {th }}$ European International Conference on Software Testing, Analysis \& Review, Munich, Germany: Aimware, Mervue, Galway, Ireland, p. 215-229, 1998.

Ghosh, S.; Mathur, A. P. Interface mutation. Software Testing, Verification and Reliability Journal, v. 11, n. 3, p. 227-247, John Wiley \& Sons, 2001.

GiLL, A. Introduction to the theory of Finite-State Machines. New York: McGraw-Hill, 1962.

Gonenc, G. A method for the design of fault detection experiments. IEEE Transactions on Computers, v. 19, n. 6, p. 551-558, 1970.

Goodenough, J. B.; Gerhart, S. L. Toward a theory of test data selection. IEEE Transactions on Software Engineering, v. 1, n. 2, p. 156-173, 1975.

GRABOWSKI, J. SDL and MSC based teste case generation: an overall view of the SaMsTaG method. Relatório Técnico IAM-94-005, Institute for Informatìcs, University of Bern, Suíça, 1994.

Grabowski, J.; Scheurer, R.; Toggweiler, D.; Hogrefe, D. Dealing with the complexity of state space exploration algorithms for SDL sustems. In: Proceedings of the $6^{\text {th }}$ GI/ITG Technical Meeting on Formal Description Techniques for Distributed Systems, University of Erlangen, p. 1-10, 1996.

HAMlet, D.; TAylor, R. Partition testing does not inspire confidence. IEEE Transactions on Software Engineering, v. 16, n. 12, p. 1402-1411, 1990.

HAREL, D. Statecharts: A visual formalism for complex systems. Science of Computen Programming, v. 8, p. 231-274, 1987.

HAREL, D. Bitting the silver bullet - toward a brighter future for systems development. IEEE Computer, v. 25, n. 1, p. 8-20, 1992. 
Harel, D.; NaAmad, A. The STATEMATE semantics of Statecharts. ACM Transaction on Software Engineering and Methodology, v. 5, n. 4, p. 293-333, 1996.

HAREL, D.; PNueli, A. On the development of reactive systems. In: APT, K. R., ed. Logics and Models of Concurrent Systems, Springer-Verlag, p. 477-498, 1985.

Harel, D.; Pnueli, A.; Schmidt, J.; Sherman, R. Statecharts: On the formal semantics of Statecharts. In: Proceedings of the $2^{\text {nd }}$ IEEE Symposium on Logic in Computer Science, Ithaca, New York, p. 54-64, 1987.

Harrold, M. J. Testing: A roadmap. In: Finkelstein, A., ed. The Future of Software Engineering, Special Volume published in conjunction with 22nd International Conference on Software Engineering, p. 61-72, 2000.

Disponível em citeseer.nj.nec.com/harrold0otesting.html (Acessado em 22/06/2004)

Harrold, M. J.; Soffa, M. L. Selecting and using data for integration testing. IEEE Software, v. 8, n. 2, p. 58-65, 1991.

HoAre, C. A. R. Communicating sequential processes. New Jersey: Prentice-Hall, Englewood-Cliffs, 1984.

HogRefe, D. Validation of SDL systems. Computer Network and ISDN Systems, v. 28, n. 12 , p. $1659-1667,1996$.

Hogrefe, D.; Koch, B.; NeukIRChen, H. Validation and testing. Telektronikk, v. 96, n. 4 , p. $130-136,2000$.

Disponível em citeseer.nj.nec.com/hogrefe99validation.html (Acessado em $22 / 06 / 2004)$

HolzmanN, G. J. The model checker spin. IEEE Transactions on Software Engineering, v. 23, n. 5 , p. $279-295,1997$.

Hong, H. S.; Kim, Y. G.; ChA, S. D.; BAE, D. H.; Ural, H. A test sequence selection method for Statecharts. Software Testing, Verification and Reliability, v. 10, n. 4 , p. 203-227, 2000 .

Horgan, J. R.; Mathur, A. P. Assessing testing tools in research and education. IEEE Software, v. 9, n. 3, p. 61-69, 1992.

HOWDEN, W. E. Methodology for the generation of program test data. IEEE Computer, v. C-24, n. 5, p. 554-559, 1975 .

HowDEN, W. E. Software engineering and technology: Functional program testing and analysis. New York: McGrall-Hill Book Co, 1987. 
HOwDEN, W. E. Reliability of the path analysis testing strategy. IEEE Transactions on Software Engineering, v. 2, n. 3, p. 208-215, 1996.

HUANG, C. M.; Hsu, J. M. An incremental protocol verification method. The Computer Journal, v. 37, n. 8, p. 698-710, 1994.

HUANG, C.-M.; LIN, Y.-C.; JANG, M.-Y. An executable protocol test sequence generation method for EFSM-specified protocols. In: Proceedings of $8^{\text {th }}$ IFIP Intermational Workshop on Protocol Test Systems (IWPTS), Evry, França, p. 20-35, 1995.

IEEE IEEE Standard Glossary of Software Engineering Terminology. Standard 610.12, IEEE Press, 1990.

ISO/IEC Information processing systems - open systems interconnection - Lotos - a formal description technique based on the temporal ordring of observational behaviour. 1989.

ISO/TC97/SC21 Guidelines for the application of estelle, lotos and sdl. 1990.

ISO/TC97/SC21/WG1/DIS9074 Estelle: A formal description technique based on an extended state transition model. 1987.

ITU CCITT Specification and Description Language - recommendation z.100 (03/93). 1993.

ITU Revised itu-t recommendation z.100 - Specification and Description Language. 2002.

JACKSON, M. Formal methods and traditional engineering. Journal of Systems and Software, v. 40, n. 3, p. 191-194, 1998.

Jensen, K. Coloured Petri net. In: Application and Theory of Petri Nets, Berlin: Springer, p. 248-299, 1986 (Lecture Notes on Computer Science, v.254).

JERON, T.; JARD, C. Testing for unboundedness of FIFO channels. Theoretical Computer Science, v. 113, n. 1, p. 93-117, 1993.

JíRACHIEFPATTANA, A.; LAI, R. EVEN: A software environment for Estelle specification verification. Journal of Systems Software, v. 39, p. 119-143, 1997.

JONES, C. B. Systematic software development using VDM. Prentice-Hall, 1986.

JoNEs, C. B. Formal methods light. ACM Computing Surveys, v. 28, n. 4, 1996.

Jones, J. A.; HARRold, M. J.; StASKo, J. Visualization of test information to assist fault localization. In: Proceedings of the $24^{\text {th }}$ Internation Conference on Software Engineering, Florida, FL, EUA, p. 467-477, 2002. 
Kerbrat, A.; JÉRON, T.; Groz, R. Automated test generation from SDL specifications. In: Dssouli, R.; Bochmann, G.; Lahav, Y., eds. Proceedings of the Ninth SDL Forum - SDL'99: The Next Millennium, Montreal, Quebec, Canada: Elsevier Science, p. 135-151, 1999.

KOREL, B. Automated software test data generation. IEEE Transactions on Software Engineering, v. 16, n. 8, p. 870-879, 1990.

KOREL, B.; LASKI, J. Dynamic program slicing. Information Processing Letters, v. 29, n. 3 , p. $155-163,1988$.

KOREL, B.; LASKI, J. W. A tool for data flow oriented program testing. In: Proceedings of Softfair II, San Francisco, CA, p. 34-38, 1985.

Kovács, G.; Pap, Z.; Viet, D. L.; Wu-Hen-Chang, A.; CsopaKi, G. Applying mutation analysis to sdl specifications. In: REED, R.; REED, J., eds. SDL 2003: System Design - $11^{\text {th }}$ SDL Forum, Stuttgart, Germany: Springer-Verlag Heidelberg, p. 269-284, 2003 (Lecture Notes on Computer Science, v.2708).

LAI, R. Towards more industrially relevant academic researches into testing of communicating systems. Journal of Systems and Software, v. 47, n. 2-3, 1999.

V. Lamsweerde, A. Formal specification: a roadmap. In: Finkelstein, A., ed. Proceedings of the Conference on The Future of Software Engineering, ACM Press, p. 147-159, 2000.

Disponível em citeseer.nj.nec.com/vanlamsweerde00formal.html (Acessado em $22 / 06 / 2004)$

LEITÃo JR., P. S. Suporte ao teste estrutural de programas Cobol no ambiente Poke-Tool. Dissertação de Mestrado, DCA/FEEC/UNICAMP, Campinas, SP, 1992.

LI, J. J.; Horgan, J. R. A tool suite for diagnosis and testing of software design specications. In: Proceedings of International Conference on Dependable Systems and Networks, New York, EUA, p. 181-185, 2000.

LI, J. J.; WONG, W. E. Automatic test generation from communicating extended finite state machine (CEFSM)-based models. In: Proceedings of International Symposium on Object-Oriented Real-Time Distributed Computing, Washington, EUA, p. 181-185, 2002.

Lin, F. J.; CHU, P. M.; LIU, M. T. Protocol verification using reachability analysis: The state space explosion problem and relief strategies. In: Proceedings of the ACM Workshop on Frontiers in Computer Communications Technology, ACM Press, p. 126-135, 1987. 
Luckham, D. C.; Kenney, J. J.; Augustin, L. M.; Ver., J.; Bryan, D.; Mana, W. Specification and analysis of system architecture using rapide. IEEE Transactions on Software Engineering, v. 21, n. 4, p. 336-354, 1995.

LuTs, M. Testing tools. IEEE Software, v. 7, n. 3, 1990.

LYLE, J. R.; WEISER, M. Automatic pogram bug location by program slicing. In: Proceedings of the $2^{\text {nd }}$ International Conference on Computer and Applications, Beijing, China, p. 877-883, 1987.

Maldonado, J. C. Critérios Potenciais Usos: Uma contribuição ao teste estrutural de software. Tese de Doutoramento, DCA/FEEC/UNICAMP, Campinas, SP, 1991.

Maldonado, J. C. Critérios de teste de software: Aspectos teóricos, empíricos e de automação. (Trabalho de Livre Docência), ICMC/USP, São Carlos, SP, 1997.

Maldonado, J. C.; Barbosa, E. F.; Vincenzi, A. M. R.; Delamaro, M. E. Evaluating $\mathrm{N}$-selective mutation for $\mathrm{C}$ programs: Unit and integration testing. In: Mutation 2000 Symposium, San Jose, CA: Kluwer Academic Publishers, p. 22-33, 2000a.

Maldonado, J. C.; Delamaro, M. E.; Fabbri, S. C. P. F.; Simão, A. S.; Sugeta, T.; Vincenzi, A. M. R.; Masiero, P. C. Proteum: A family of tools to support specification and program testing based on mutation. In: Mutation 2000 - A Symposium on Mutation Testing for the New Century, San José, California, p. 146-149, 2000b.

Maldonado, J. C.; Fabbri, S. C. P. F.; Delamaro, M. E.; Masiero, P. C. Análise de mutantes no teste de software e na validação de sistemas reativos. In: Jornada da Computação - Sessão Regular da Academia Brasileira de Ciências, São Paulo, SP, 1994.

Maldonado, J. C.; Fabbri, S. C. P. F.; Masiero, P. C. Validação de especificações formais com a aplicação do critério análise de mutantes. In: Anais do I WMF - Workshop Brasileiro de Métodos Formais, Porto Alegre, RS, p. 129-134, 1998a.

Maldonado, J. C.; Vincenzi, A. M. R.; Barbosa, E. F.; Souza, S. R. S.; Delamaro, M. E. Aspectos teóricos e empíricos de teste de cobertura de software. Relatório Técnico 31, ICMC/USP, São Carlos, SP, notas DidÁticas do ICMC, Série Computação, 1998b.

Martins, E.; Sabiño, S. B.; Ambrosio, A. M. Condata: a tool for automating specification-based test case generation for communication systems. In: Proceedings of the $33^{\text {d }}$ Hawaii International Conference on System Sciences, Maui, Hawaii, p. 1-20, 2000.

Mastero, P. C.; Maldonado, J. C.; Boaventura, I. G. A reachability tree for Statecharts and analysis of some properties. Information and Software Technology, v. 36, n. 10, p. $615-624,1994$. 
Mathur, A. P. Performance, effectiveness, and reliability issues in software testing. In: Anais da XV Annual International Computer Software and Applications Conference, Tokio, Japão, p. 604-605, 1991.

MathUR, A. P.; WONG, W. E. Evaluation of the cost of alternative mutation strategies. In: VII Simpósio Brasileiro de Engenharia de Software (SBES 93), Rio de Janeiro, RJ, p. 320-335, 1993.

MathuR, A. P.; Wong, W. E. An empirical comparison of data flow and mutation-based test adequacy criteria. The Journal of Software Testing, Verification, and Reliability, v. 4, n. 1, p. 9-31, 1994.

McMillan, W. W. Where do formal methods fit in software evaluation? In: Proceedings of the $19^{\text {th }}$ Annual Conference on Computer Science, San Antonio, TX, USA, p. 676, 1991.

Milner, A. J. R. G. A calculus of communicating systems. In: Lecture Notes in Computer Science, New York: Springer-verlag, 1980.

Murata, T. Modeling and analysis of concurrent systems. In: Handbook of Software Em nineering, New York: Van Nostrand Reinhold Electrical, 1984.

RATA, T. Petri nets: Properties, analysis and applications. Proceedings of the IEEE, 7, n. 4, p. 541-580, 1989.

ERS, G. The art of software testing. New York: Wiley, 1979.

ITO, S.; Tsunoyama, M. Fault detection for sequential machines by transition tours. Proceedings of the $11^{\text {th }}$ IEEE Fault Tolerant Computing Symposium, p. 238-243, 1981.

KazATo, K. K. Módulos de geração de sequências de teste baseadas em Máquinas de ado Finito. Dissertação de Mestrado, ICMC/USP, São Carlos, SP, 1995.

UMANN, P. G. Using formal methods to reduce risks. Communications of the $A C M$, 9, n. 7, p. 114,1996

AFOS, S. C. A comparison of some structural testing strategies. IEEE Transactions Software Engineering, v. 14, n. 6, p. 868-873, 1988.

futT, A. J.; Lee, A.; Rothermel, G.; Untch, R. H.; ZAPF, C. An experimental ermination of sufficient mutant operators. ACM. Transactions on Software Engineering thodology, v. 5, n. 2, p. 99-118, 1996a.

FUTT, A. J.; PAN, J. Automatically detecting equivalent mutants and infeasible paths. 3ournal of Software Testing, Verification, and Reliability, v. 7, n. 3, p. 165-192, 1997. 
Offutt, A. J.; PAN, J.; TeWARY, K.; Zhang, T. An experimental evaluation of data fow and mutation testing. Software Practice and Experience, v. 26, n. 2, p. 165-176, $1996 \mathrm{~b}$.

Offutt, A. J.; Rothermel, G.; ZAPF, C. An experimental evaluation of selective mutation. In: Proceedings of XV International Conference on Software Engineering, Baltimore, MD, p. 100-107, 1993.

Parnas, D. L. Formal methods technology transfer will fail. The Journal of Systems and Software, v. 40, n. 3, p. 195-198, 1998.

PENG, W. Deadlock detection in communicating finite state machines by even reachability analysis. Mobile Networks and Applications, v. 2, n. 3, p. 251-257, 1997.

Peterson, J. L. Petri nets. ACM Computing Surveys, v. 9, n. 3, p. 223-252, 1977.

Peterson, J. L. Petri net theory and the modeling of systems. New Jersey: Prentice-Hall, Englewood Cliffs, 1981.

Petrenko, A.; Bochmann, G. On fault coverage of tests for Finite State specifications. Relatório Técnico, Département d'Informatique et de Recherche Opérationnelle, Université de Montreal, 1996.

Pettersson, P.; Larsen, K. G. UPPAAL2k. Bulletin of the European Association for Theoretical Computer Science, v. 70, p. 40-44, 2000.

PresSMan, R. S. Software engineering - a practitioner's approach. 5 ed. McGraw-Hill, 2001.

Probert, R. L.; Guo, F. Mutation testing of protocols: Principles and preliminary experimental results. In: Proceedings of the IFIP TC6 Third International Workshop on Protocol Teste Systems, North-Holland, p. 57-76, 1991.

RAISE The RAISE language group. The RAISE specification language. The BCS practioner series. Prentice Hall, 1992.

RAISE The RAISE method group. The RAISE development method. The BCS practitioner series. Prentice Hall, 1995.

RAPPS, S.; WEYUKeR, E. J. Data flow analysis techniques for test data selection. In: Proceedings of the Intermational Conference on Software 'Engineering, Toquio, Japão, p. 272-278, 1982.

RAPPS, S.; WEYUKER, E. J. Selecting software test data using data flow information. IEEE Transactions on Software Engineering, v. 11, n. 4, p. 367-375, 1985. 
REED, R. Methodology for real time systems. Computer Networks and ISDN Systems, v. 28, n. 12 , p. $1685-1701,1996$.

Sabnani, K.; Dahbura, A. A new technique for generating protocol tests. $A C M$ Computer Communication Review, v. 15, n. 4, p. 36-43, 1985.

Sabnani, K.; Dahbura, A. A protocol test generation procedure. Computer Networks and ISDN Systems, v. 15, n. 4, p. 285-297, 1988.

SARIKAYA, B.; BochmanN, G. Obtaining normal form specifications for protocols. Computer Network Usage: Recent Experiences, 1986.

Sarikaya, B.; Bochmann, G.; Cerny, E. A test design methodology for protocol testing. IEEE Transactions on Software Engineering, v. 13, n. 5, 1987.

SDL-FORUM 2004.

Disponível em http://www.sdl-forum.org/sdl88tutorial/index.html (Acessado em $22 / 06 / 2004$ )

SidHU, D.; LEUNG, T.-K. Formal methods for protocol testing: A detailed study. IEEE Transactions on Software Engineering, v. 15, p. 413-426, 1989.

SimÃo, A. S. Proteum-RS/PN: Uma ferramenta para a validação de redes de Petri baseada na análise de mutantes. Dissertação de Mestrado, ICMC/USP, São Carlos, SP, 2000 .

SimÃo, A. S. Teste e validação de redes de petri coloridas usando análise de mutantes. Tese de Doutoramento, Instituto de Ciências Matemáticas e de Computação - ICMC-USP, São Carlos, SP, (Qualificação de Doutorado), 2002.

Simão, A. S.; Maldonado, J. C. Mutation based test sequence generation for Petri nets. In: Proceedings of III Workshop of Formal Methods, João Pessoa, PB, p. 68-79, 2000a.

SimÃo, A. S.; Maldonado, J. C. Proteum-RS/PN: Uma ferramenta para apoiar a edição, simulação e validação de redes de Petri baseada no teste de mutação. In: Caderno de Ferramentas do XIV Simpósio Brasileiro de Engenharia de Software, João Pessoa, PB, p. 376-379, 2000b.

Simão, A. S.; Maldonado, J. C. Mudel: A language and a system for describing and generating mutants. Journal of the Brazilian Computer Society, v. 8, n. 1, p. 73-86, 2002.

Simão, A. S.; Maldonado, J. C.; Fabbri, S. C. P. F. Proteum-RS/PN: A tool to support edition, simulation and validation of Petri nets based on mutation testing. In: 
Anais do XIV Simpósio Brasileiro de Engenharia de Software, João Pessoa, PB, p. 227-242, 2000.

SimÃo, A. S.; Souza, S. R. L.; Maldonado, J. C. A family of coverage testing criteria for coloured petri nets. In: Anais do XVII Simpósio Brasileiro de Engenharia de Software, Manaus, AM, p. 209-224, 2003.

Sommerville, I. Software engineering. 5 ed. Addison-Wesley, 1995.

Souza, S. R. S. Avaliação do custo e eficácia do critério análise de mutantes na atividade de teste de software. Dissertação de Mestrado, ICMC/USP, São Carlos, SP, 1996.

Souza, S. R. S. Validação de especificações de sistemas reativos: Definiçâao e análise de critérios de teste. Tese de Doutoramento, Instituto de Física de São Carlos/USP, São Carlos, SP, 2000.

Souza, S. R. S.; Maldonado, J. C.; Fabbri, S. C. P. F. FCCE: Uma família de critérios de teste para validação de sistemas especificados em Estelle. In: Anais do XV Simpósio Brasileiro de Engenharia de Software, Rio de Janeiro, RJ, Brasil, p. 256-271, 2001.

Souza, S. R. S.; Maldonado, J. C.; Fabbri, S. C. P. F.; Lopes de Souza, W. Mutation testing applied to Estelle specifications. Quality Software Journal, v. 8, n. 4, p. $285-301$, (Also published in the $33^{\text {rd }}$ Hawaii Internacional Conference on System Sciences - 2000), 2000a.

Souza, S. R. S.; Maldonado, J. C.; Fabbri, S. C. P. F.; Lopes de Souza, W. Mutation testing applied to Estelle specifications. In: Proceedings of the $33^{\text {rd }}$ Hawaii Internacional Conference on System Sciences, Mini-Tracks: Distributed Systems Testing, Maui, Havaii, 2000b.

Souza, S. R. S.; Maldonado, J. C.; Fabbri, S. C. P. F.; Masiero, P. C. Statecharts specifications: A family of coverage testing criteria. In: CLEI2000 Conferência Latino Americana de Informática, Cidade do Mexico, Mexico, $2000 \mathrm{c}$.

SPIVEY, J. M. Introducing $z$ : A specification language and its formal semantics. Cambrigde University Press, 1988.

SUGETA, T. Proteum-RS/ST: Uma Ferramenta para Apoiar a Validação de Especificações Statecharts Baseada na Análise de Mutantes. Dissertação de Mestrado, ICMC/USP, São Carlos, SP, 1999.

Sugeta, T.; Maldonado, J. C.; Fabbri, S. C. P. F. Proteum-RS/ST - Uma Ferramenta para Apoiar a Validação de Especificações Statecharts baseada no Critério 
Análise de Mutantes. In: Caderno de Ferramentas do XIII SBES - Simpósio Brasileiro de Engenharia de Software, Florianópolis, SC, p. 41-44, 1999.

Sugeta, T.; Maldonado, J. C.; Masiero, P. C.; Fabbri, S. C. P. F. Proteum-RS/ST - A Tool to Support Statecharts Validation Based on Mutation Testing. In: $4^{\text {th }}$ Workshop Iberoamericano de Engenharia de Requisitos e Ambientes de Software IDEAS'2001, Santo Domingo, Costa Rica, p. 370-384, 2001.

Sugeta, T.; Maldonado, J. C.; Wong, W. E. Mutation testing applied to validate SDL specifications. In: Groz, R.; Hierons, R. M., eds. Testing of Communicating Systems: 16th IFIP International Conference, TestCom 2004, Oxford, UK, p. 193-208, 2004 (Lecture Notes on Computen Science, v.2978).

Tanenbaum, A. S. Computer networks. 3 ed. Prentice Hall, 1996.

TAYlor, R. N.; Levine, D. L.; Kelly, C. D. Structural testing of concurrent programs. IEEE Transactions on Software Engineering, v. 18, n. 3, 1992.

Telelogic 2002a.

Disponível em www.telelogic.com/about/customers/casestudies.cfm (Acessado em $04 / 02 / 2002$ )

Telelogic Telelogic tau 4.3, telelogic ab. Malmo, Sweden, $2002 \mathrm{~b}$.

TELELOGIC 2004a.

Disponível em www.telelogic.com/products/tau/sdl (Acessado em 30/05/04)

TELELOGIC 2004b.

Disponível em http://www. telelogic. com/products/additional/objectgeode/index. cfm (Acessado em 22/06/2004)

TOUAG, A.; Rouger, A. Methods and methodology for an incremental test generation from SDL specifications. In: Proceedings of the Ninth SDL Forum - SDL'99: The Next Millennium, Montreal, Quebec, Canada, 1999.

Tretmans, J.; Belinfante, A. Automatic testing with formal methods. In: EuroSTAR'99: th European International Conference on Software Testing, Analysis \& Review, Barcelona,Spain, 1999.

TURNER, K. J. Using formal description techniques - an introduction to Estelle, Lotos and SDL. John Wiley \& Sons, 1993.

Ural, H.; SAleh, K.; Williams, A. Test generation based on control and data dependencies within system specifications in SDL. Computer Communications, v. 23, n. 7, p. $609-627,2000$. 
Ural, H.; YANG, B. A test sequence selection method for protocol testing. IEEE Transactions on Communications, v. 39, n. 4, p. 514-523, 1991.

Vergílio, S. R.; Maldonado, J. C.; Jino, M. Caminhos não-executáveis na automação das atividades de teste. In: Anais do VI Simpósio Brasileiro de Engenharia de Software, Gramado, RS, p. 343-356, 1992.

Vilela, P. R. S.; Maldonado, J. C.; Jino, M. Data flow based integration testing. In: XII Simpósio Brasileiro de Engenharia de Software, Maringá, PR, p. 393-409, 1998.

Vincenzi, A. M. R. Orientação a objeto: Definição e análise de recursos de teste $e$ validação. Tese de Doutoramento, ICMC/USP, São Carlos, SP, 2004.

Vincenzi, A. M. R.; Maldonado, J. C.; Barbosa, E. F.; Delamaro, M. E. Operadores essenciais de interface: Um estudo de caso. In: XIII Simpósio Brasileiro de Engenharia de Software (SBES 99), Florianópolis, SC, p. 373-391, 1999.

Vincenzi, A. M. R.; Maldonado, J. C.; Barbosa, E. F.; Delamaro, M. E. Unit and integration testing strategies for $\mathrm{C}$ programs using mutation-based criteria. Software Testing, Verification and Reliability, v. 11, n. 4, 2001.

Vincenzi, A. M. R.; Wong, W. E.; Delamaro, M. E.; Maldonado, J. C. JaBUTi: A coverage analysis tool for java programs. In: XVII Simpósio Brasileiro de Engenharia de Software (SBES 2003), Manaus, AM, 2003.

Wang, C. J.; LIU, M. T. Generation test cases for EFSM with given fault model. IEEE INFOCOM'93 - $12^{\text {in }}$ Annual Joint Conference of the IEEE Computer and Communications Societies, p. 774-781, 1993.

Weiser, M. Programmers use slices when debugging. Communications of the ACM, v. 25, n. 7 , p. $446-452,1982$.

Weiser, M. Program slicing. ieeese, v. 10, n. 4, p. 352-357, 1984

WEYUKER, E. J. The applicability of program schema results to programs. International Journal of Computer and Information Sciences, v. 8, n. 5, p. 387-403, 1979a.

WEYUKER, E. J. Translatability and decidability questions for restricted classes of program schemas. SIAM Journal on Computing, v. 8, n. 4, p. 587-598, $1979 \mathrm{~b}$.

WEYUKER, E. J. The cost of data flow testing: an empirical study. IEEE Transactions on Software Engineering, v. SE-16, n. 2, p. 121-128, 1990.

Weyuker, E. J.; Goradia, T.; Singh, A. Automatically generating test data from a boolean specification. IEEE Transactions on Software Engineering, v. 20, n. 5, p. 353-363, 1994. 
WEYUKER, E. J.; JENG, B. Analyzing partition testing strategies. IEEE Transactions on Software Engineering, v. 17, n. 7, p. 703-711, 1991.

WeYUKer, E. J.; Ostrand, T. J. Theories of program testing and the application of revealing subdomains. IEEE Transactions on Software Engineering, v. 6, n. 3, p. 236-246, 1980.

Widmaier, J. C. Producing more reliable software: mature software engineering process vs. state-of-the-art technology? In: Proceedings of the 22nd International Conference on Software Engineering, Limerick,Ireland, p. 88-93, 2000.

Wong, E.; Maldonado, J. C.; Delamaro, M. E.; Mathur, A. P. Constrained mutation for C programs. In: Anais do VII Simpósio Brasileiro de Engenharia de Software, Curitiba, PR, p. 439-452, 1994a.

Wong, W. E.; Horgan, J. R.; London, S.; Mathur, A. P. Effect of test set size and block coverage on fault detection effectiveness. In: Fifth IEEE International Symposium on Software Reliability Engineering, Monterey, CA, p. 230-238, 1994b.

Wong, W. E.; Horgan, J. R.; London, S.; Mathur, A. P. Effect of test set minimization on fault detection effectiveness. Software-Practice and Experience, v. 28, n. 4 , p. $347-369,1998$.

Wong, W. E.; Maldonado, J. C.; Mathur, A. P. Mutation versus all-uses: An empirical evaluation of cost, strength and effectiveness. In: First IFIP/SQI International Conference on Software Quality and Productivity - Theory, Practice, Education and Training, Hong Kong, 1994c.

Wong, W. E.; Maldonado, J. C.; Souza, M. E.; Souza, S. R. S. A comparison of selective mutation in $\mathrm{C}$ and Fortran. In: Anais do Workshop do Projeto Validação $e$ Teste de Sistemas de Operação, Águas de Lindóia, SP, p. 71-84, 1997.

Wong, W. E.; Sugeta, T.; QI, Y.; Maldonado, J. C. Smart debugging software architectural design in SDL. In: Proceedings of the 27th IEEE International Computer Software and Applications Conference (COMPSAC'03), (Artigo selecionado para publicaçāo no Journal of Systems and Software), p. 41-47, 2003.

Wong, W. E.; Sugeta, T.; QI, Y.; Maldonado, J. C. Smart debugging software architectural design in SDL. Journal of Systems and Software, (Artigo selecionado no COMPSAC'2003. A ser publicado.), 2004.

Wood, W. G. Application of formal methods to system and software specification. In: Proceedings of the ACM SIGSOFT International Workshop on Formal Methods in Software Development, p. 144-146, 1990. 
YANG, C.-S.; Souter, A. L.; Pollock, L. L. All-du-path coverage for parallel programs. In: ISSTA'98 - International Symposium on Software Testing and Analysis, $\mathrm{p}$. 153-162, 1998.

Yano, T.; aO, A. S. S.; Maldonado, J. C. Proteum/SML: Uma ferramenta de apoio ao teste de mutaçào para a linguagem Standard ML. In: Sessão de Ferramentas do XVII Simpósio Brasileiro de 'Engeharia de Software, Manaus, AM, Brasil, p. 67-72, 2003.

Young, W. D. Formal methods versus software engineering: Is there a conflict? In: Proceedings of the Fourth Symposium on Testing, Analysis and Verification, Victoria, BC, Canada, p. 188-189, 1991.

Özdemir, K; UraL, H. Protocol validation by simultaneous reachability analysis. Computer Communications, v. 20, n. 9, p. 772-788, 1997.

$\mathrm{ZHU}, \mathrm{H}$. A formal analysis of the subsume relation between software test adequacy criteria. IEEE Transactions on Software Engineering, v. 22, n. 4, p. 248-255, 1996.

ZhU, H.; HALL, P. A. V.; MAY, J. H. R. Software unit test coverage and adequacy. ACM Computing Surveys, v. 29, n. 4, p. 366 427, 1997. 


\section{Lista de Abreviações}

CCS Calculus of Communicating Systems

CPN Coloured Petri Nets ou Redes de Petri Coloridas

CSP Communicating Sequential Processes

DS Distinguishing Sequence

DTE Diagrama de transição de estado

FCCE Família de Critérios de Cobertura para Estelle

FCCS Família de Critérios de Cobertura para Statecharts

FCCSDL Família de Critérios de Cobertura para SDL

FIFO First In First Out

GF Grafo de Fluxo de Controle e de Dados

MEF Máquina de Estados Finitos

MEFC Máquina de Estados Finitos Comunicante

MEFE Máquina de Estados Finitos Estendidas

MEFEC Máquina de Estados Finitos Estendidas Comunicante 
MSC Message Sequence Charts

MTE Matriz de transição de estado

OOHDM Object-Oriented Hypermedia Design Method

PROMELA Process Meta Language

RAISE Rigorous Approach to Industrial Software Engineering

RSL RAISE Specification Language

SDL Specification and Description Language

SML Standard Meta Language

TT Transition Tour

TTCN Tree and Tabular Combined Notation

UIO Unique Input/Output Sequence

UML Unified Modeling Language

VDM Vienna Development Method

W Characterizing Set

Wp Partial W-Method 


\section{Gramática de SDL}

Neste apêndice é apresentada uma versão simplificada da gramática textual de SDL, de acordo com a versão SDL-92 da linguagem, que foi a versão utilizada neste trabalho. Também são apresentadas as especificações SDL de dois protocolos, Bit-Alternante e INRES, utilizadas para ilustrar conceitos definidos neste trabalho. As palavras-chave da linguagem estão representadas em maiúsculo.

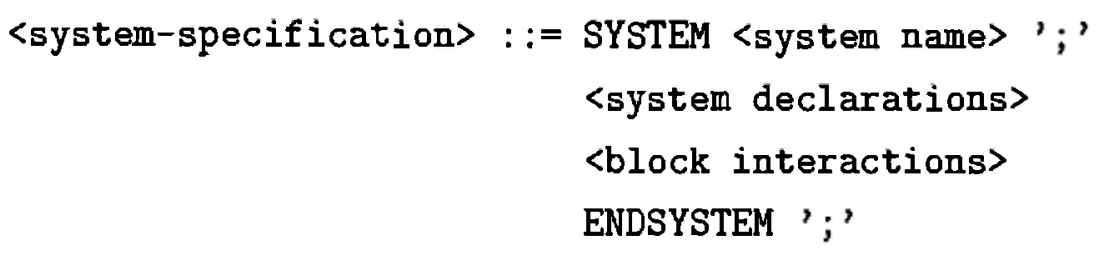

< system declarations> contém as declarações de novos tipos de dados, sinais e listas de sinais.

$\langle$ signal specification $>::=$

SIGNAL <signal name> [(<sort name $>\{,<$ sort nam $\theta\} *)]$

$\{,<$ signal name $>[(<$ sort name $>\{,<$ sort name $>\})]\} *$;

<newtype specification> : :=

NEWTYPE <newtype name> 
$\cdots$

ENDNEWTYPE <newtype name>;

<block interactions> define a arquitetura da especificação do sistema. Descrevem os blocos SDL (blocks) contidos no sistema e as interações entre blocos e entre blocos e o ambiente via channels. Todos os channels devem ser descritos nesse nível.

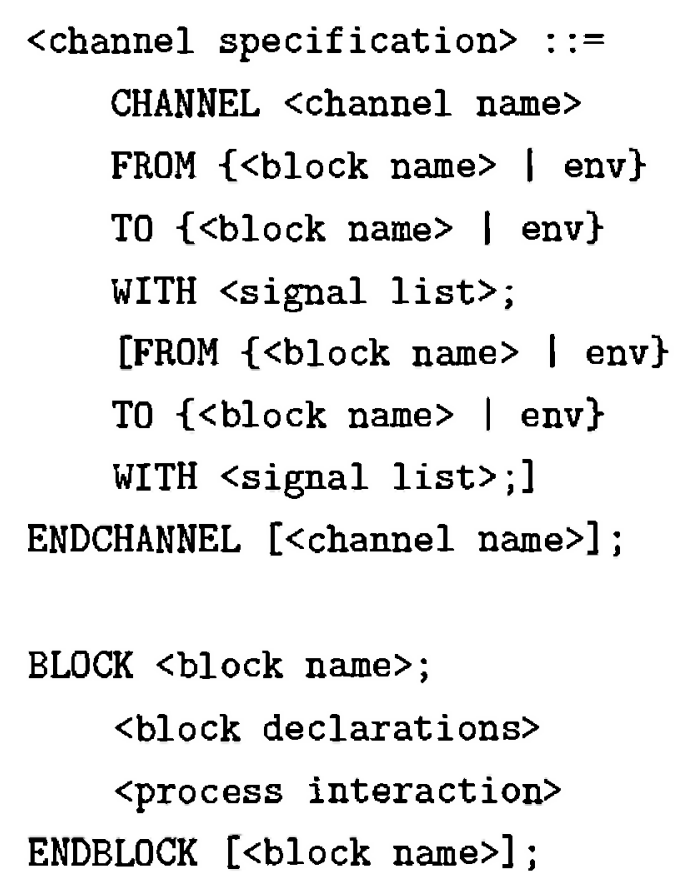

<block declarations> contém as declarações de novos tipos de dados, sinais, listas de sinais.

<process interactions > define a arquitetura da especificaçăo do bloco. Descrevem os processos e suas interações via signal routes, que podem conectar os processos ou processos com um channel que é conectado a um bloco.

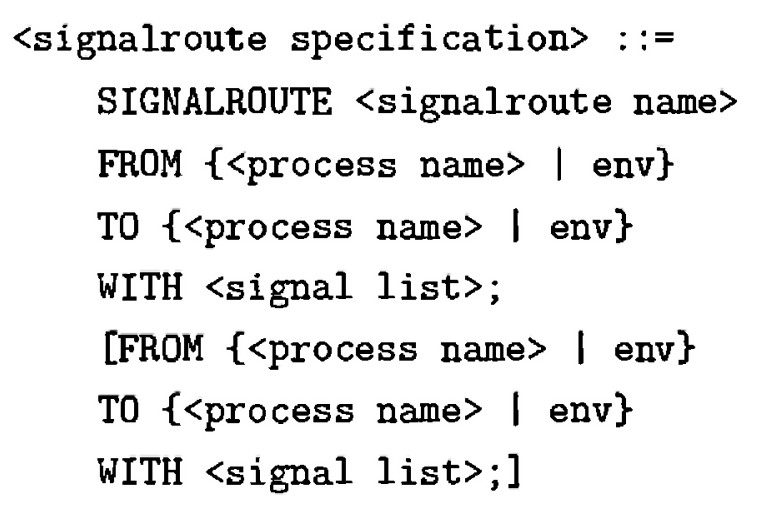

A conexão dos channels aos signal routes é realizada pela declaração connect. 
CONNECT <channel name> AND <signalroute name>

$(,<$ signalroute name $>) *$;

PROCESS <process name>

<process declaration>

$<$ process body>

ENDPROCESS [<process name $>$;

<process declaration > contém as declarações de variáveis, novos tipos de dados, sinais e lista de sinais.

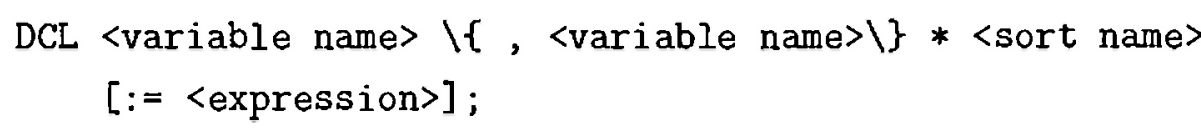

Um processo pode ter sinais internos, que não chegam pelos signal routes. Esses sinais devem ser declarados internamente ao processo:

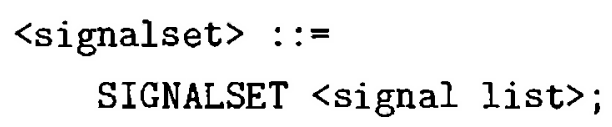

<process body> especifica o comportamento do processo e é baseado no conceito de máquina de transição de estados.

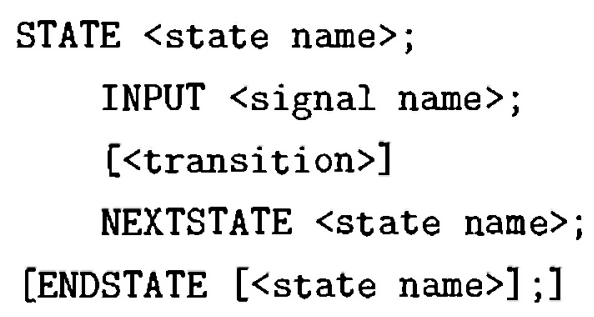

As variáveis em um processo podem receber novos valores em uma tarefa (task) realizada quando o processo está em um determinado estado:

STATE <state name>;

INPUT <signal name>;

.... 
TASK <task body>;

$\cdots$

NEXTSTATE <state name>;

[ENDSTATE [<state name $>;]$

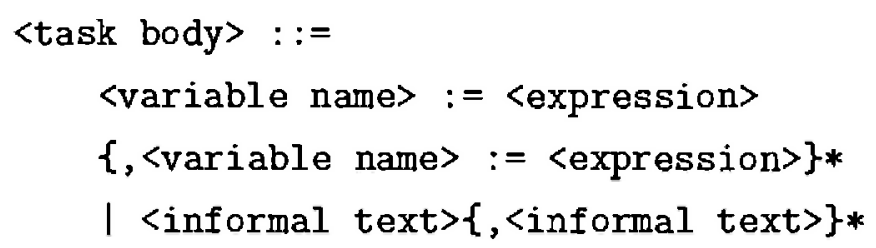

Uma transição pode, dependendo de alguma condição, seguir por diferentes caminhos Isso é representado pela declaração decision.

STATE <state name>;

INPUT <signal name>;

.....

DECISION <question>

<answer>: <transition branch>

NEXTSTATE <state name>;

<answer > : <transition branch>

NEXTSTATE <state name>

. . .

ENDDECISION;

…

[ENDDECISION [<state name>];]

〈answer> : :=

(<range $>\mid<$ informal text $>)$ | ELSE

Saídas (outputs) são usadas para enviar sinais e possivelmente valores como parâmetros para outros processos, permitindo a comunicação entre os processos.

STATE <state name>;

INPUT <signal name>;

....

OUTPUT <signal name>

[<actual parameters $>$ ] $\langle$ to or via $>$; 
- .

NEXTSTATE <state name>;

[ENDSTATE [<state name>];]

<to or via> := TO <address> [VIA <signalroute name>]

<actual parameters> ::=([<expression $\rangle]\{,[\langle\operatorname{expression>}\}\})$

O início de um processo é representado pela declaração start.

START;

[<transition $>]$

NEXTSTATE <state name>;

Um processo também pode ter sua execução finalizada, com a declaração stop. Após essa declaração, o processo e todas suas expressões e variáveis associadas deixam de existir.

STATE <state name>;

INPUT <signal name>;

[<transition $>]$

STOP;

[ENDSTATE [<state name>];]

\section{Protocolo Bit-Alternante}

O protocolo Bit-Alternante é composto por três blocos SDL: sender_block, medium e receiver_block. O bloco sender_block é composto pelo processo Sender,o bloco receiver_block é composto pelo processo Receiver e o bloco medium contém dois processos, Medium1 e Medium2. A especificação SDL para o Bit-Alternante é apresentada a seguir:

SYSTEM alternating_bit;

NEWTYPE msg

LITERALS msg0;

ENDNEWTYPE ; 


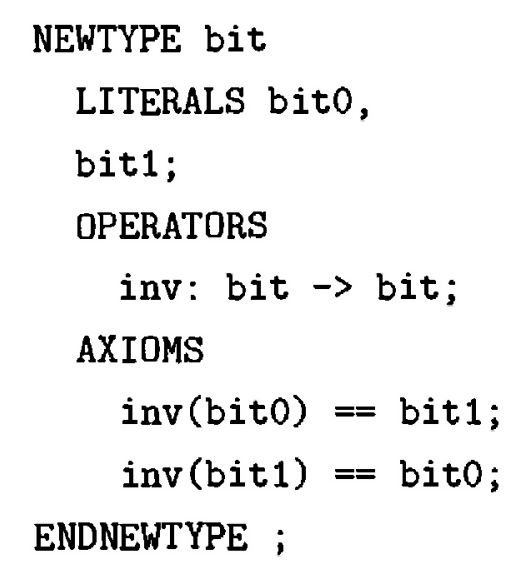

\section{SIGNAL}

put (msg),

get (msg),

$\mathrm{dm}$ (msg, bit),

am(bit),

medium_error;

CHANNEL receiver_higher_interface

FROM receiver_block TO ENV WITH get;

ENDCHANNEL;

CHANNEL sender_higher_interface

FROM ENV TO sender_block WITH put ; ENDCHANNEL;

CHANNEL receiver_lower_interface

FROM medium TO receiver_block WITH dm, medium_error;

FROM receiver_block TO medium WITH am;

ENDCHANNEL;

CHANNEL sender_lower_interface

FROM sender_block TO medium WITH dm;

FROM medium TO sender_block WITH am, medium_error;

ENDCHANNEL;

BLOCK sender_block;

SIGNALROUTE sender_lower_interface

FROM ENV TO sender_process WITH am, medium_error; 
FROM sender_process TO ENV WITH dm;

SIGNALROUTE sender_higher_interface

FROM ENV TO sender_process WITH put;

CONNECT sender_lower_interface AND sender_lower_interface;

CONNECT sender_higher_interface AND sender_higher_interface;

PROCESS sender_process;

DCL

i bit $:=$ bito,

j bit;

DCL

m msg;

START ;

NEXTSTATE wait_put;

STATE wait_put;

INPUT put ( m );

OUTPUT $d m(m, i)$;

NEXTSTATE wait_am;

ENDSTATE;

STATE wait_am;

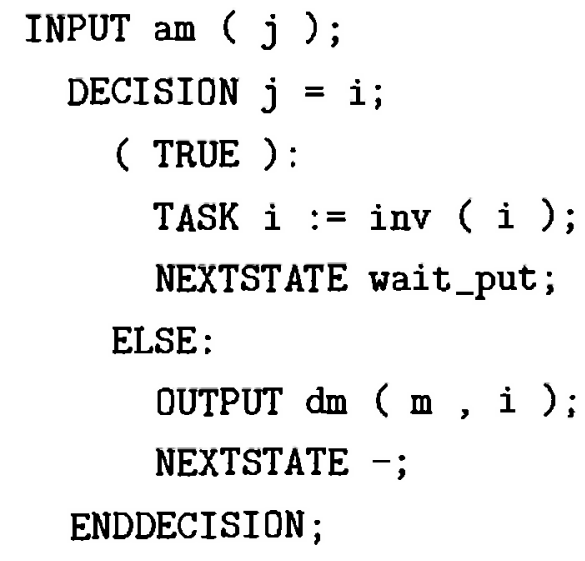


INPUT medium_error;

OUTPUT dm ( $\mathrm{m}, \mathrm{i})$;

NEXTSTATE -;

SAVE put ;

ENDSTATE;

ENDPROCESS;

ENDBLOCK ;

BLOCK medium;

SIGNALROUTE medium_to_sender

FROM medium2 TO ENV WITH am, medium_error;

SIGNALROUTE receiver_to_medium

FROM ENV TO medium2 WITH am;

SIGNALROUTE medium_to_receiver

FROM medium1 TO ENV WITH dm, medium_error;

SIGNALROUTE sender_to_medium

FROM ENV TO medium1 WITH dm;

CONNECT sender_lower_interface AND medium_to_sender, sender_to_medium;

CONNECT receiver_Iower_interface AND receiver_to_medium, medium_to_receiver;

PROCESS medium1;

DCL

i bit;

DCL

m msg;

START ;

NEXTSTATE wait_dm; 


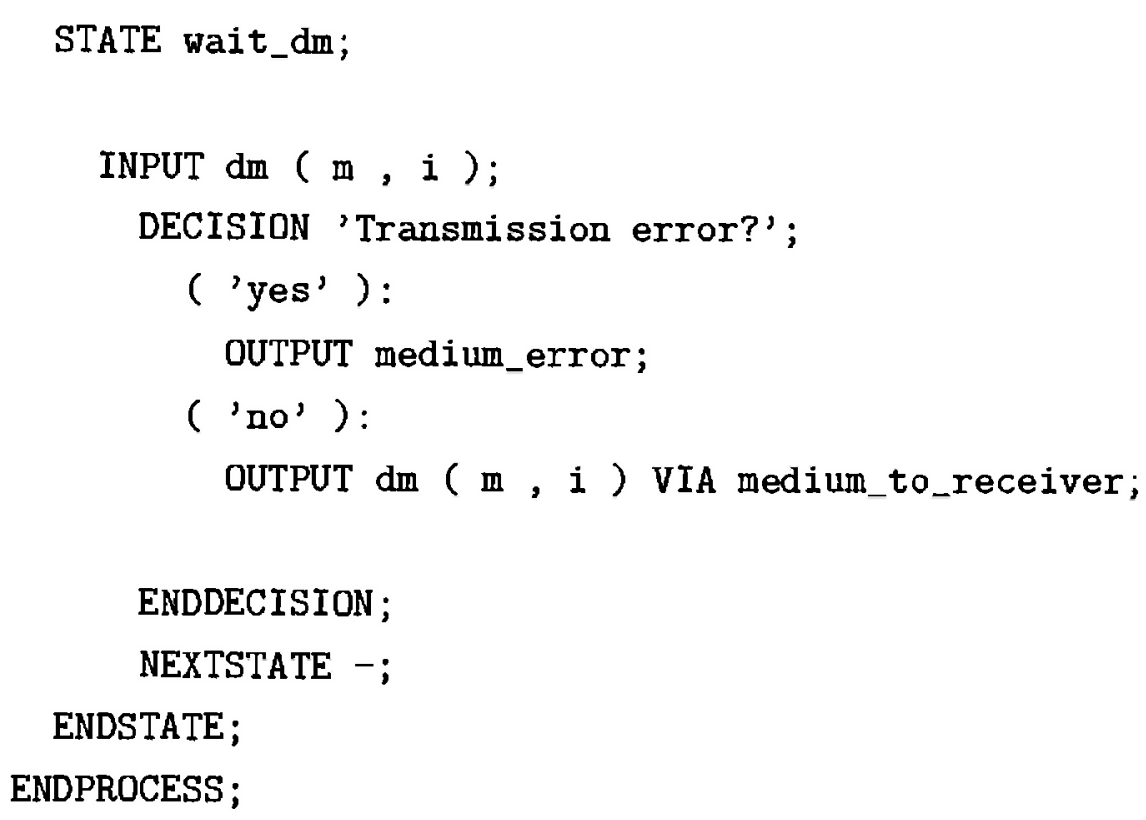


FROM receiver_process TO ENV WITH get;

SIGNALROUTE receiver_lower_interface

FROM ENV TO receiver_process WITH dm, medium_error;

FROM receiver_process TO ENV WITH am;

CONNECT receiver_higher_interface AND receiver_higher_interface;

CONNECT receiver_lower_interface AND receiver_lower_interface;

PROCESS receiver_process;

DCL

i bit $:=$ bito,

j bit;

DCL

m msg;

START ;

NEXTSTATE wait_dm;

STATE wait_dm;

INPUT dm $(m, j)$;

DECISION $j=i$;

( TRUE ):

OUTPUT am $(j)$;

OUTPUT get (m);

$\operatorname{TASK} i:=\operatorname{inv}(i)$;

NEXTSTATE -;

ELSE:

OUTPUT am $(j)$;

NEXTSTATE -;

ENDDECISION;

INPUT medium_error;

OUTPUT am ( inv ( $i)$ );

NEXTSTATE -; 
ENDSTATE;

ENDPROCESS;

ENDBLOCK;

ENDSYSTEM;

\section{Protocolo INRES}

O protocolo INRES possui três blocos: bloco Ini Station com dois processos, Initiator e Ini Coder; bloco Res_Station também com dois processos, Responder e Res_Coder; e o bloco Medium, com os processos MSAP_Manager1 e MSAP_Manager2. A comunicação com o ambiente acontece por meio de dois canais: ISAP.1 e ISAP2. A seguir apresenta-se a especificação SDL para esse protocolo.

SYSTEM Inres_protocol;

NEWTYPE Sequencenumber

LITERALS zero,

un;

OPERATORS

succ: Sequencenumber $\rightarrow$ Sequencenumber;

AXIOMS

$\operatorname{succ}($ zero $)==$ un;

$\operatorname{succ}($ un) $==$ zero;

ENDNEWTYPE Sequencenumber;

NEWTYPE ISDUTyPe

LITERALS data1;

ENDNEWTYPE ISDUTyPe;

NEWTYPE IPDUTyPe

LITERALS CR,

CC,

DT,

$A K$,

$\mathrm{DR}$; 
ENDNEWTYPE IPDUTyPe;

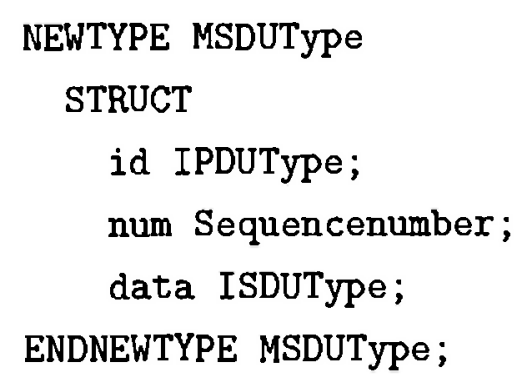

SIGNAL

ICONreq,

IDATreq (ISDUType),

ICONConf,

ICONind,

ICONresp,

IDISreq,

IDISind,

IDATind (ISDUType),

MDATreq (MSDUType),

MDATind(MSDUType);

CHANNEL ISAP1

FROM ENV TO Ini_Station WITH ICONreq, IDATreq;

FROM Ini_Station TO ENV WITH ICONconf, IDISind;

ENDCHANNEL;

\section{CHANNEL MSAP1}

FROM Ini_Station TO Medium WITH MDATreq;

FROM Medium TO Ini_Station WITH MDATind;

ENDCHANNEL;

CHANNEL MSAP2

FROM Medium TO Res_Station WITH MDATind;

FROM Res_Station TO Medium WITH MDATreq;

ENDCHANNEL;

CHANNEL ISAP2 
FROM ENV TO Res_Station WITH ICONresp , IDISreq;

FROM Res_Station TO ENV WITH ICONind, IDATind; ENDCHANNEL;

BLOCK Ini_Station;

SIGNAL

$\mathrm{CR}$,

$\mathrm{CC}$,

DT(Sequencenumber, ISDUType),

AK (Sequencenumber),

$\mathrm{DR}$;

SIGNALROUTE ISAP

FROM ENV TO Initiator WITH ICONreq, IDATreq;

FROM Initiator TO ENV WITH ICONconf, IDISind;

SIGNALROUTE IPDU

FROM Initiator TO Ini_Coder WITH CR, DT;

FROM Ini_Coder TO Initiator WITH CC , AK , DR;

SIGNALROUTE MSAP

FROM Ini_Coder TO ENV WITH MDATreq;

FROM ENV TO Ini_Coder WITH MDATind;

CONNECT MSAP1 AND MSAP;

CONNECT ISAP1 AND ISAP;

PROCESS Initiator;

DCL

counter INTEGER,

d ISDUType, 
num, number Sequencenumber;

TIMER

$\mathrm{T}$;

SYNONYM

P DURATION $=5$;

START ;

NEXTSTATE disconnected;

STATE disconnected;

INPUT ICONreq;

TASK counter $:=1$

OUTPUT $\mathrm{CR}$;

SET (NOW + P, T );

NEXTSTATE wait;

INPUT DR;

OUTPUT IDISind;

NEXTSTATE disconnected;

ENDSTATE;

STATE wait;

INPUT CC;

RESET ( $T$ );

TASK number $:=$ un;

OUTPUT ICONconf;

NEXTSTATE connected;

INPUT T;

DECISION counter $<4$;

( TRUE ): 
OUTPUT $\mathrm{CR}$;

TASK counter $:=$ counter +1 ;

SET ( NOW $+p, T)$;

NEXTSTATE wait;

( FALSE):

OUTPUT IDISind;

NEXTSTATE disconnected;

ENDDECISION;

INPUT DR:

RESET ( $T$ );

OUTPUT IDISind;

NEXTSTATE disconnected;

ENDSTATE;

STATE connected;

INPUT IDATreq ( $d$ );

OUTPUT DT ( number , d );

TASK counter $:=1$;

SET ( NOW $+p, T$ );

NEXTSTATE sending;

INPUT DR;

OUTPUT IDISind;

NEXTSTATE disconnected;

ENDSTATE;

STATE sending;

INPUT AK ( num );

$\operatorname{RESET}(\mathrm{T}$ );

DECISION num = number;

( FALSE ):

JOIN resend; 
( TRUE ):

TASK number := succ ( number);

NEXTSTATE connected;

ENDDECISION;

INPUT T;

resend:

DECISION counter < 4;

( TRUE ):

OUTPUT DT ( number , d );

TASK counter $:=$ counter +1 ;

SET $($ NOW $+\mathrm{p}, \mathrm{T})$;

NEXTSTATE sending;

( FALSE ):

OUTPUT IDISind;

NEXTSTATE disconnected;

ENDDECISION;

INPUT DR;

RESET ( T );

OUTPUT IDISind;

NEXTSTATE disconnected;

SAVE IDATreq;

ENDSTATE;

ENDPROCESS;

PROCESS Ini_Coder;

DCL

d ISDUType,

num Sequencenumber,

sdu MSDUType;

START ; 
NEXTSTATE idle;

STATE idle;

INPUT $\mathrm{CR}$;

TASK sdu ! id $:=\mathrm{CR}$

send_sdu:

OUTPUT MDATreq( sdu );

NEXTSTATE idle;

INPUT DT ( num, d );

TASK sdu ! id := DT, sdu ! num $:=$ num, sdu ! data $:=d$;

JOIN send_sdu;

\section{INPUT MDATind}

( sdu );

DECISION sdu ! id;

( CC ):

OUTPUT CC;

( $\mathrm{AK}$ ):

OUTPUT AK ( sdu ! num );

( DR ):

OUTPUT DR;

ELSE :

ENDDECISION;

NEXTSTATE idle;

ENDSTATE;

ENDPRDCESS;

ENDBLOCK;

BLOCK Medium;

SIGNAL 
IDAT (MSDUTYPO);

SIGNALROUTE MSAPr1

FROM ENV TO MSAP_Manager1 WITH MDATreq;

FROM MSAP_Manager1 TO ENV WITH MDATind;

SIGNALROUTE Internal

FROM MSAP_Manager1 TO MSAP_Manager2 WITH IDAT;

FROM MSAP_Manager2 TO MSAP_Manager1 WITH IDAT;

SIGNALROUTE MSAPr2

FROM MSAP_Manager2 TO ENV WITH MDATind;

FROM ENV TO MSAP_Manager2 WITH MDATreq;

CONNECT MSAP2 AND MSAPr2;

CONNECT MSAP1 AND MSAPr1;

PROCESS MSAP_Manager1;

DCL

d MSDUType;

START ;

NEXTSTATE idle;

STATE idle;

INPUT MDATreq ( d );

DECISION 'loss?'

( 'no')

OUTPUT IDAT ( d ) VIA Internal;

('yes') :

ENDDECISION;

NEXTSTATE idle;

INPUT IDAT ( $d$ );

QUTPUT MDATind ( $d$ );

NEXTSTATE idle; 
ENDSTATE;

ENDPROCESS;

PROCESS MSAP_Manager2;

DCL

d MSDUType;

START ;

NEXTSTATE idle;

STATE idle;

INPUT MDATreq ( $\mathrm{d}$ );

DECISION 'loss?';

('no'):

OUTPUT IDAT ( d ) VIA Internal;

('yes'):

ENDDECISION;

NEXTSTATE idle;

INPUT IDAT ( $d$ );

OUTPUT MDATind ( d );

NEXTSTATE idle;

ENDSTATE ;

ENDPROCESS ;

ENDBLOCK;

BLOCK Res_Station;

SIGNAL

$\mathrm{CR}$,

$\mathrm{CC}$,

DT (Sequencenumber, ISDUType) ,

AK (Sequencenumber), 
$\mathrm{DR}$;

SIGNALROUTE MSAP

FROM ENV TO Res_Coder WITH MDATind;

FROM Res_Coder TO ENV WITH MDATreq;

SIGNALROUTE IPDU

FROM Res_Coder TO Responder WITH CR , DT;

FROM Responder TO Res_Coder WITH CC , AK , DR;

\section{SIGNALROUTE ISAP}

FROM Responder TO ENV WITH ICONind, IDATind;

FROM ENV TO Responder WITH ICON'resp , IDISreq;

CONNECT ISAP2 AND ISAP;

CONNECT MSAP2 AND MSAP;

PROCESS Res_Coder;

DCL

num Sequencenumber,

sdu MSDUType;

START ;

NEXTSTATE idle:

STATE idle;

INPUT DR;

TASK sdu ! id := DR

send_sdu:

DUTPUT MDATreq ( $\mathbf{s} d \mathbf{u}$ );

NEXTSTATE idle;

INPUT CC;

TASK sdu ! id $:=\mathrm{CC}$

JOIN send_sdu;

INPUT AK ( num ); 


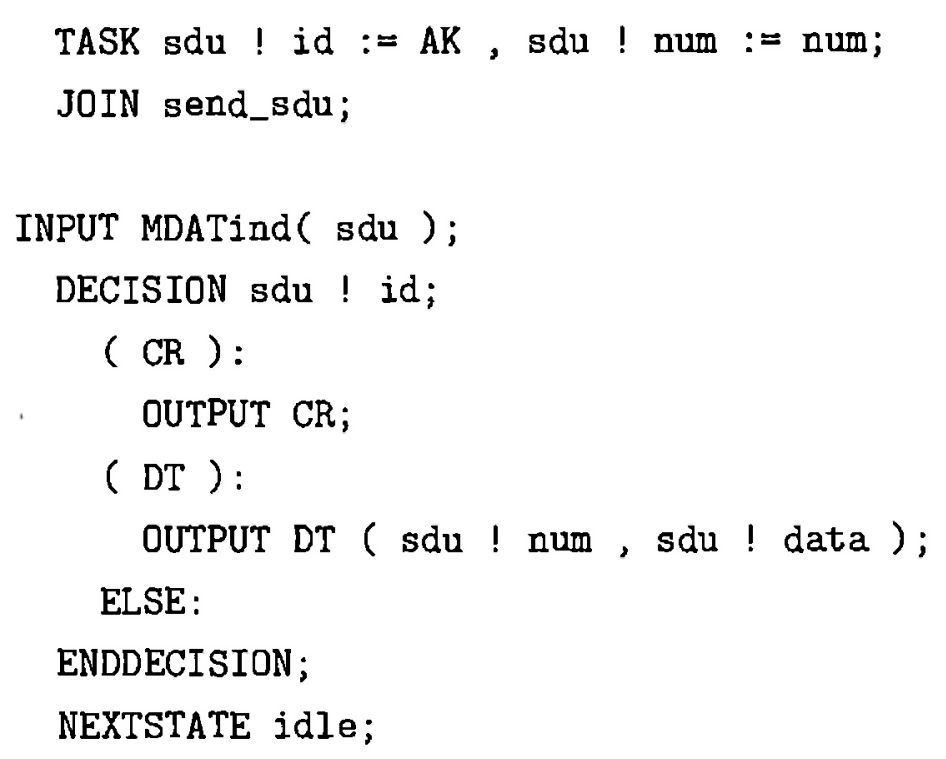

STATE disconnected;

INPUT $\mathrm{CR}$;

OUTPUT ICONind;

NEXTSTATE wait;

ENDSTATE;

STATE wait;

INPUT ICONresP;

TASK number := zero;

OUTPUT CC;

NEXTSTATE connected; 
ENDSTATE;

STATE connected;

INPUT DT ( num , d );

DECISION num $=\operatorname{succ}($ number $)$;

( FALSE ):

OUTPUT AK ( number);

NEXTSTATE connected;

( TRUE ) :

OUTPUT IDATind ( $d$ );

OUTPUT AK ( num );

TASK number $:=\operatorname{succ}$ ( number);

NEXTSTATE connected;

ENDDECISION;

INPUT $\mathrm{CR}$;

OUTPUT ICONind;

NEXTSTATE wait;

ENDSTATE;

STATE *

(disconnected);

INPUT IDISreq;

OUTPUT DR;

NEXTSTATE disconnected;

ENDSTATE;

ENDPROCESS;

ENDBLOCK;

ENDSYSTEM; 